UNIVERSIDADE DE BRASÍLIA

FACULDADE DE TECNOLOGIA

DEPARTAMENTO DE ENGENHARIA CIVIL E AMBIENTAL

AVALIAÇÃO DA RESISTÊNCIA MECÂNICA DE MATERIAL LEVE UTILIZANDO MISTURAS DE PEDAÇOS DE PNEUS COM SOLO DO DISTRITO FEDERAL

JAIME ALBERTO SUÁREZ MORENO

ORIENTADOR: GREGÓRIO LUÍS SILVA ARAÚJO, DSc.

DISSERTAÇÃO MESTRADO EM GEOTECNIA PUBLICAÇÃO: G.MD-267/16

BRASÍLIA / DF: MARÇO / 2016 


\author{
UNIVERSIDADE DE BRASÍLIA \\ FACULDADE DE TECNOLOGIA \\ DEPARTAMENTO DE ENGENHARIA CIVIL E AMBIENTAL
}

\title{
AVALIAÇÃO DA RESISTÊNCIA MECÂNICA DE MATERIAL LEVE UTILIZANDO MISTURAS DE PEDAÇOS DE PNEUS COM SOLO DO DISTRITO FEDERAL
}

\section{JAIME ALBERTO SUÁREZ MORENO}

DISSERTAÇÃO DE MESTRADO SUBMETIDA AO DEPARTAMENTO DE ENGENHARIA CIVIL DA UNIVERSIDADE DE BRASÍLIA COMO PARTE DOS REQUISITOS NECESSÁRIOS PARA A OBTENÇÃO DO GRAU DE MESTRE.

APROVADA POR:

Gregório Luís Silva Araújo, DSc (UnB)

(ORIENTADOR)

Juan Félix Rodríguez Rebolledo, PhD (UnB)

(EXAMINADOR INTERNO)

Yuri Daniel Jatobá Costa, D.Sc (UFRN)

(EXAMINADOR EXTERNO)

DATA: BRASÍLIA/DF, 23 de março de 2016. 


\section{FICHACATALOGRÁFICA}

\section{SUÁREZ, MORENO JAIME}

Avaliação da Resistência Mecânica de Material Leve Utilizando Misturas de Pedaços de Pneus com Solo do Distrito Federal [Distrito Federal] 2016 xviii, 119 p., 210 x 297 mm (ENC/FT/UnB, Mestre, Geotecnia, 2016)

Dissertação de Mestrado - Universidade de Brasília. Faculdade de Tecnologia. Departamento de Engenharia Civil
1. Pedaço de borracha de pneu
2. Resistência ao cisalhamento
3. Solo tropical
4. Melhoria de solos
I. ENC/FT/UnB
II. Título (série)

\section{REFERÊNCIA BIBLIOGRÁFICA}

SUÁREZ, M. J. (2016). Avaliação da Resistência Mecânica de Material Leve Utilizando Misturas de Pedaços de Pneus com Solo do Distrito Federal. Dissertação de Mestrado, Publicação G.DM-267/16, Departamento de Engenharia Civil, Universidade de Brasília, Brasília, DF, 119 p.

\section{CESSÃO DE DIREITOS}

NOME DO AUTOR: Jaime Alberto Suárez Moreno

TÍTULO DA DISSERTAÇÃO DE MESTRADO: Avaliação da Resistência Mecânica de Material Leve Utilizando Misturas de Pedaços de Pneus com Solo do Distrito Federal GRAU / ANO: Mestre /2016

É concedida à Universidade de Brasília a permissão para reproduzir cópias desta dissertação de mestrado e para emprestar ou vender tais cópias somente para propósitos acadêmicos e científicos. O autor reserva outros direitos de publicação e nenhuma parte desta dissertação de mestrado pode ser reproduzida sem a autorização por escrito do autor.

Jaime Alberto Suárez Moreno

Calle 16 \# 12-23 Barrio Sta. Barbara -

Tunja- Boyacá - Colômbia

jaime.suarez01@gmail.com 
Agradeço a Deus que me tem dado a oportunidade de obter tudo o que eu sonhei. A minha família, meu pai Mario J. C. Suarez e minha mãe Rosalba Moreno obrigado por todos os ensinamentos da vida, sabedoria, amor e apoio incondicional em cada uma das minhas decisões. A minha irmã Jully Fernanda, obrigado por me dar tanto apoio e estar ciente da minha formação à distância. Meus avós, Zacarias Suarez, Cleotilde Castelblanco, Pablo Moreno e Rosalbina Rodriguez, eu sei que do céu vocês me acompanham. 


\section{AGRADECIMENTOS}

Oportunidades deste tipo só ocorre uma vez na vida, faz você ver que os limites não existem. Além de ser um processo de formação acadêmica que requer paciência, dedicação, trabalho duro e tempo; é também uma experiência de vida que ajuda você a se tornar uma pessoa melhor, para apreciar o que você tem, as pessoas ao seu redor, as que foram embora e que chegaram; a experiência ensina que os seus sucessos são o resultado de trabalho. Agradeço a Deus por me dar um lar, uma família de pessoas maravilhosas, amigos incondicionais e por me dar a oportunidade de continuar meus estudos.

Agradeço ao Professor Gregório Luis Silva Araújo, orientador, pelo excelente tema de pesquisa, ajuda, paciência e orientação durante o desenvolvimento deste.

Meus pais Mario J. Suarez C. e Rosalba Moreno R., gratidão pelo amor, sabedoria, conselhos e apoio incondicional á distancia, uma vida inteira não será suficiente para pagar-lhes, amo vocês com todo o meu coração.

A Minha irmã Fernanda Jully Suarez, obrigado pelo apoio à distância, eu adoro irmã e esperou que Deus dai-nos inúmeras alegrias para comemorar. Aqui eu agradeço ao seu companheiro de vida Ricardo Diaz Valbuena, obrigado por cuidar de minha irmã durante este tempo e obrigado pelo apoio que sempre recebi de você, eu espero que as suas vidas estejam cheias de sucessos e bênçãos.

Amigos são a família que você escolher, então eu quero agradecer à irmandade entre Alejandro Adame, Gustavo Barrera, Javier Amarillo, muito obrigado pelo apoio que recebi de vocês, é gratificante saber que, assim os anos passam a vida nos mantém juntos. À família Adame, Amarillo e Barrera, que também são a minha família. Aqui agradeço de maneira especial ao Javier Amarillo já que nós compartilhamos desta vez no Brasil como uma família.

Diana Cárdenas, você é mais do que uma amiga, é outra irmã para mim, gratidão pelos conselhos, amizade e apoio incondicional que me deu. A vida terá para você um caminho cheio de sucessos e bênçãos por ser uma excelente pessoa. 
Sandra Buitrago, amiga incondicional, mãe de Samuelito, obrigado por me ouvir quando eu precisava, que Deus encha vocês de bênçãos.

Amigos da Colômbia, Christian Marin, Diego Cárdenas, Luis Felipe Buitrago, Andrés Castillo, Edna Barajas, Patricia Jaime, obrigado por chamadas e mensagens de apoio durante o processo de desenvolvimento do mestrado, amigos como vocês são poucos.

Amigos de Brasília, Evonne Lopez, Damaris Muñoz, Christian Gonzalez, obrigado por sua companhia e por seu apoio durante este tempo. Aqui agradeço de maneira especial a Damaris Muñoz, obrigado por tudo, das melhores pessoas que eu conheci aqui no DF.

A família que foi formada em Brasília, Javier Amarillo, Nairo Tarazona e Diana Cárdenas, a vida nos fez viver uma experiência única e que melhor para isso que compartilhar com pessoas como vocês.

Amigos do mestrado, Javier Amarillo, Nairo Tarazona, Jader Ruiz, Cristina Martinez, Heydy Trejos, John Burgos, Mariela Ocampo, Michael Barrantes, Renato Paulanelli, Juan Joya, Henry Castillo, Juan Bastidas e Carlos Moreno. Aqui agradeço especialmente á Heydy Trejos, o Javier Amarillo e o Nairo Tarazona, gratidão por tudo.

Ao Jaime e a Ivonne, obrigado pela ajuda durante o mestrado, e especialmente durante o desenvolvimento da pesquisa. 


\section{RESUMO}

A excessiva produção de pneus e as dificuldades para sua disposição em aterros sanitários ao fim de sua vida útil são casos comuns de geração de problemas ambientais nos últimos anos no mundo inteiro. Por sua vez, há dificuldade na obtenção de material que atendam às exigências que as obras de engenharia geotécnica requerem. No caso especifico da região do Distrito Federal, a predominância de solo laterítico altamente intemperizado algumas vezes requer melhoramento com outros materiais, o que pode levar ao aumento do custo. Nesse contexto, este trabalho propõe o estudo de material alternativo de baixo custo (resíduos provenientes de processos de trituração de pneus com diâmetro médio de $20 \mathrm{~mm}$ ), misturado ao solo do Distrito Federal.

Para o desenvolvimento do projeto de pesquisa, foi necessário realizar ensaios de compactação (energia de compactação modificada) e empregar um equipamento de cisalhamento direto em escala média (amostras de $300 \mathrm{~mm}$ x $300 \mathrm{~mm}$ x $175 \mathrm{~mm}$ ) para estudar e avaliar o comportamento mecânico das misturas solo - borracha, em teores de 0\% (solo puro), 2,5\%, 3,75\%, 5\%, 7,5\%, 10\% e 100\% (borracha pura) com relação ao peso do solo seco, submetidas a tensões confinantes de $25 \mathrm{kPa}, 50 \mathrm{kPa}, 80 \mathrm{kPa}$ e $100 \mathrm{kPa}$.

Os resultados das compactações mostraram que houve redução do peso especifico aparente seco das misturas com o aumento do teor de borracha, sem afetar sua umidade de compactação ótima, mantendo-se um corpo de prova bem estruturado se este se encontra confinado. Já no exame visual das amostras desconfinadas, estabeleceu-se que até uma mistura de $5 \%$ de teor de borracha não foi encontrado grande número de fissuras, trincas e possíveis planos de fraqueza, avaliando este como teor de borracha ótimo. No caso dos ensaios de cisalhamento direto em escala média foi observado que, com o aumento do teor de borracha, há redução na coesão da estrutura, apesar do acréscimo na tensão ao cisalhamento máxima e no ângulo de atrito. 


\begin{abstract}
The excessive production of rubber tires and the difficulties of their disposal in waste landfills are common causes of generation of environmental problems in recent years worldwide. On the other hand, it is difficult to obtain materials that satisfy the requirements that the geotechnical engineering works require. In the specific case of the Federal District region, the lateritic soil predominantly highly weathered sometimes requires improvement with other materials, which can lead to the increasing in the cost of the construction. In this context, this research proposes the study of low-cost alternative materials (waste from tire shredding process with an average diameter of $20 \mathrm{~mm}$ ) mixed with the soil of the Federal District.
\end{abstract}

For the development of the research project, it was necessary to perform Proctor compaction test (modified compaction test) and carrying out direct shear tests with a medium scale (samples of $300 \mathrm{~mm} \times 300 \mathrm{~mm} \times 175 \mathrm{~mm}$ ) to study and evaluate the mechanical behavior of soil - rubber mixtures, at $0 \%$ content (pure soil), 2.5\%, 3.75\%, 5\%, 7.5\%, 10\% and 100\% (pure rubber) with respect to the weight of dry soil, with confining pressures of $25 \mathrm{kPa}, 50$ $\mathrm{kPa}, 80 \mathrm{kPa}$, and $100 \mathrm{kPa}$.

The results of the compaction study showed that there was a decrease in the apparent dry unity weight of mixtures with increasing rubber content, without affecting its optimal moisture content. . According to the visual inspection of unconfined samples, it was observed that for a mixture of 5\% rubber content it wasn't noticed many cracks or possible weakness planes. Thus, this was considered the optimal rubber content. For the direct shear medium scale testing it was found that increasing rubber content the cohesion of the structure was reduced and maximum shear stress and the friction angle were increased. 


\section{SUMÁRIO}

1 INTRODUÇÃ

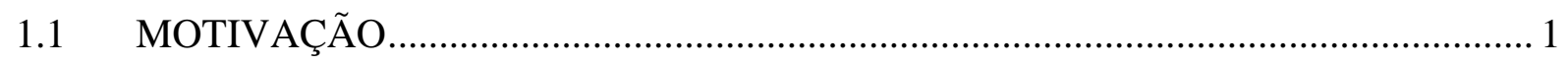

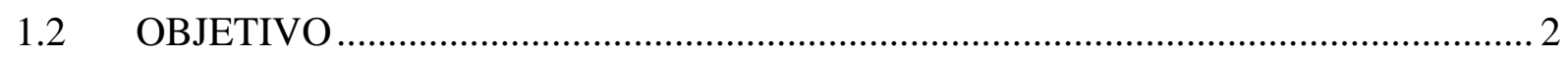

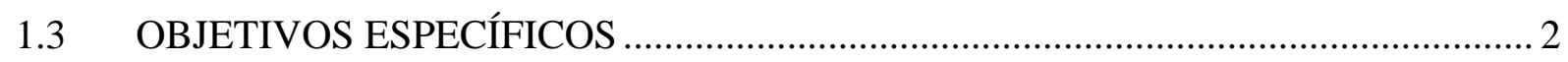

2 REVISÃO BIBLIOGRAFICA................................................................................. 3

2.1 HISTÓRICO: PRODUÇÃO, RECICLAGEM E REUTILIZAÇÃO DE PNEUS .......... 3

2.2 TECNICAS DE MELHORIA DE SOLOS UTILIZANDO FRAGMENTOS DE

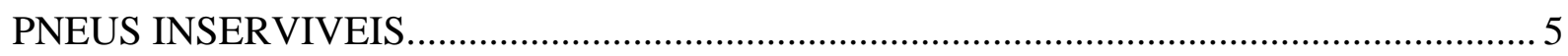

2.3 MELHORIA DE SOLOS UTILIZANDO FRAGMENTOS DE BORRACHA............. 6

2.3.1 MELHORIA DE SOLOS USANDO MIGALHAS DE PNEUS .............. 11

2.3.2 MELHORIA DE SOLOS USANDO DESBASTES DE PNEUS ............. 15

2.3.3 MELHORIA DE SOLOS USANDO LASCAS DE PNEUS ................... 21

2.3.4 MELHORIA DE SOLOS USANDO PEDAÇOS DE PNEUS ................. 30

3 EQUIPAMENTOS E MATERIAIS UTILIZADOS NA PESQUISA ..........................44

3.1 EQUIPAMENTO DE CISALHAMENTO DIRETO EM ESCALA MÉDIA ...............44

3.2 MATERIAIS UTILIZADOS ………………………………………………. 46

3.2.1 SOLO LATERÍTICO ARGILOSO DO DISTRITO FEDERAL ………....46

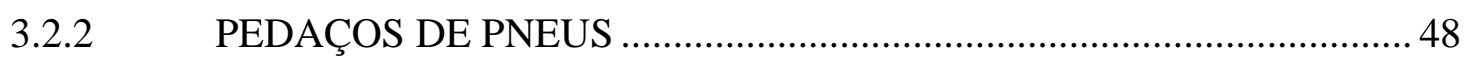

4 METODOLOGIA DA PESQUISA .........................................................................52

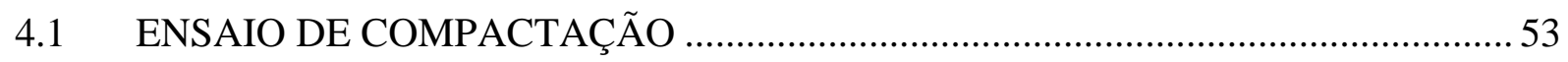

4.2 ENSAIO DE CISALHAMENTO DIRETO EM MÉDIA ESCALA ……………........57

5 APRESENTAÇÃO E DISCUSSÃO DE RESULTADOS ............................................. 63

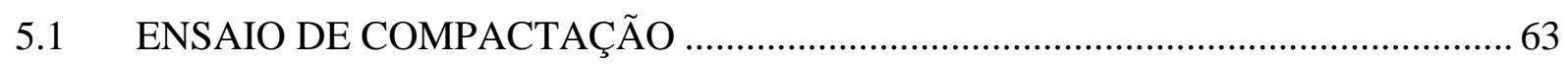

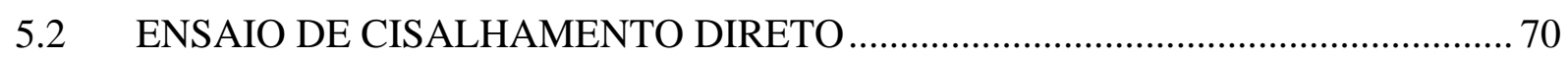


5.3 ANALISE DOS RESULTADOS APRESENTADOS

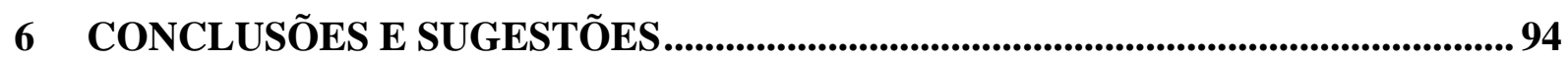

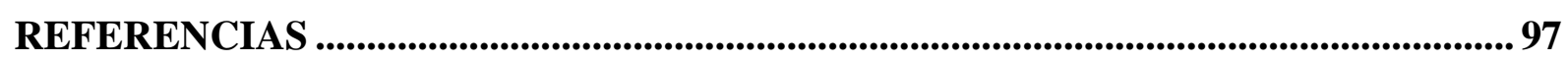

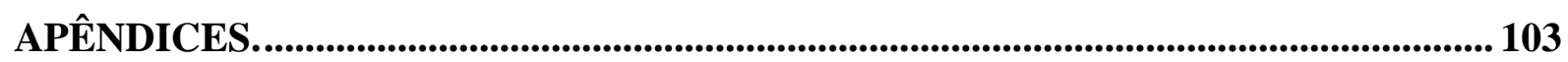

APÊNDICE A. ENSAIOS DE COMPACTAÇÃO ……………………………………....... 103

APÊNDICE B. ENSAIOS DE CISALHAMENTO DIRETO EM MÉDIA ESCALA .......... 106 


\section{LISTA DE FIGURAS}

Figura 2.1. Uso de pedaços de pneus como enchimentos de peso leve em uma estrutura de contenção para rodovias (Benson, 1995).

Figura 2.2. Resistência ao cisalhamento de misturas de solos e pneus triturados (Benson, 1995).

Figura 2.3. Tipos de diferentes processamentos de pneus inservíveis, fora de escala (Edinçliler et al., 2010).

Figura 2.4.Variação da resistência ao cisalhamento vs deslocamento horizontal para misturas fofas sob uma tensão normal de $23.3 \mathrm{kN} / \mathrm{m} 2$ (Ghazavi, 2004).

Figura 2.5. Tensão cisalhante - deslocamentos horizontais para areia, migalhas de pneus e misturas de areia com migalhas de pneus (80 kPa) (Edinçliler et al., 2010).

Figura 2.6. Curvas tensão-desvio vs deformação axial das amostras S100 e S80/B20 em ensaios triaxiais de compressão axial (Szeliga et al., 2014).

Figura 2.7. Curvas deformação volumétrica VS deformação axial das amostras S100 e S80/B20 em ensaios triaxiais de compressão axial (Szeliga et al., 2014).

Figura 2.8. Comportamento tensão - deformação para misturas solo argiloso vs desbaste de pneu (Al-Tabbaa \& Aravinthan, 1998).

Figura 2.9. Envoltórias de resistência ao cisalhamento para diferentes porcentagens de resíduo de pneu (Franco, 2012).

Figura 2.10. Relação teor de resíduo de pneu versus ângulo de atrito interno (Franco, 2012)18

Figura 2.11. Relação teor resíduo de pneu vs coesão (Franco, 2012). 19

Figura 2.12. Efeito dos desbastes de pneus na coesão e no ângulo de atrito do solo sedimentário (Sellaf et al., 2014).

Figura 2.13. Efeito dos desbastes de pneus na coesão e no ângulo de atrito do solo vulcânico (Sellaf et al., 2014).

Figura 2.14. Envoltórias de ruptura das lascas de pneus (Humphrey \& Sandford, 1993)....... 22

Figura 2.15. Envoltórias de ruptura para as lascas de pneu misturadas com areia (Foose et al., 1996). 
Figura 2.16. Envoltórias de ruptura para as lascas de pneus misturadas com silte (Tatlisoz et al., 1998).

Figura 2.17. Curvas tensão cisalhamento $v s$ deslocamento horizontal para tensão normal de 90 $\mathrm{kPa}$ (Ghazavi et al., 2011).

Figura 2.18. Curvas de deslocamento vertical $v s$ deslocamento horizontal para tensão normal de $90 \mathrm{kPa}$ (Ghazavi et al., 2011).

Figura 2.19. Variação da máxima tensão de cisalhamento vs teor de lascas de pneus (Ghazavi et al., 2011). 26

Figura 2.20. Variação do ângulo de atrito vs teor de lascas de pneus (Ghazavi et al., 2011).26 Figura 2.21. Curvas de compactação da argila e das misturas com lascas de pneus de granulometria (a) fina, e (b) grossa (Cetin et al., 2006). 28

Figura 2.22. Relação entre teor de borracha e as tensões de ruptura para as misturas de lascas de pneu e solo argiloso (Cetin et al., 2006).

Figura 2.23. Relação entre teor de borracha e a coesão das misturas de lascas de pneu e solo argiloso (Cetin et al., 2006).

Figura 2.24. Relação entre teor de borracha e do ângulo de atrito para as misturas de lascas de pneu e solo argiloso (Cetin et al., 2006)..... 30

Figura 2.25. Resultados do ensaio de cisalhamento direto para uma mistura 25:75 de pedaços de pneu e de areia ,sob diferentes tensões normais (Bosscher et al., 1994).

Figura 2.26. Envoltórias de ruptura dos ensaios de cisalhamento direto para uma mistura 25:75 de pedaços de pneu e areia (Bosscher et al., 1994). 32

Figura 2.27. Esquema de orientação dos fragmentos de pneus ao longo da superfície de ruptura (Bosscher et al., 1994).

Figura 2.28. Diagrama de tensão cisalhante para fragmentos de pneus orientados verticalmente (Bosscher et al., 1994). 33

Figura 2.29. Pedaços de pneus com as diferentes relações: (a) $n=1$, (b) $n=2$, (c) $n=3$, (d) $n=8$ (Zornberg et al., 2004). . 34

Figura 2.30. Amostras preparadas para o ensaio de compressão triaxial na pesquisa (a) Pedaços de pneu orientados, e (b) Mistura de pedaços de pneus e lascas de pneus não orientados. (Bałachowski \& Gotteland, 2007). 36 
Figura 2.31. Influência da orientação nos ensaios com pedaços de pneus: HD - Pedaços orientados horizontalmente, NO - pedaços não orientados (distribuição aleatória) (Bałachowski \& Gotteland, 2007).

Figura 2.32. Comportamento tensão - deformação das misturas areia com pedaços de pneus (não orientados) para diferentes teores (Bałachowski \& Gotteland, 2007).

Figura 2.33. Comportamento deformação volumétrica - deformação axial das misturas areia pedaços de pneus (não orientados) para diferentes teores (Bałachowski \& Gotteland, 2007).

Figura 2.34. Curvas de compactação para todos os teores (Chrusciak, 2013)

Figura 2.35. Tensão de cisalhamento versus deslocamento horizontal para tensão confinante de $80 \mathrm{kPa}$ (Chrusciak, 2013).

Figura 2.36. Deslocamento vertical versus deslocamento horizontal para tensão confinante de $80 \mathrm{kPa}$ (Chrusciak, 2013).

Figura 2.37. Relação entre coesão e o teor de resíduo de pneu (Chrusciak, 2013)......

Figura 2.38. Relação entre o ângulo de atrito e o teor de resíduo de pneu (Chrusciak, 2013). 43

Figura 3.1. Equipamento de cisalhamento direto em escala média - laboratório do programa de pós-graduação em geotecnia da Universidade de Brasília.

Figura 3.2. Visão geral dos sistemas mecânicos e de instrumentação (a) e (b) horizontal e (c) vertical. .45

Figura 3.3. Área de coleta do material (Google Earth, 2015). 46

Figura 3.4. Campus experimental da Pós-Graduação em Geotecnia da UnB: (a) Zona de coleta, e; (b) Condição atual da zona de coleta. 46

Figura 3.5. Curva granulométrica do solo laterítico utilizado na pesquisa. 47

Figura 3.6. Curva granulométrica do solo laterítico utilizado na pesquisa comparado com o solo utilizado por Chrusciak (2013). .48

Figura 3.7. Pedaços de pneus utilizados na pesquisa.

Figura 3.8. Peneiramento e separação de material com tamanho nominal inferior a 9,5 mm. 49

Figura 3.9. Processo de saturação dos pedaços de pneus durante 48 horas. .50

Figura 3.10. Curva granulométrica dos pedaços de pneus utilizados na pesquisa. 51 
Figura 3.11. Curva granulométrica dos pedaços de pneus utilizados na pesquisa comparados com a curva granulométrica da borracha utilizada por (Chrusciak, 2013).

Figura 4.1. Preparação das misturas para os ensaios de compactação.

Figura 4.2. Realização dos ensaios de compactação:(a) Colocação da mistura no cilindro de compactação, (b) Nivelação dos cilindros e, (c) Estado final da amostra compactada e nivelada.

Figura 4.3. Preparação das amostras para o ensaio de cisalhamento direto de média escala: (a) divisão da caixa e definição das alturas de cada camada; (b) deposição e compactação estática do material; (c) camada compactada; (d) escarificarão entre camadas, e; (d) corpo de prova compactado. 59

Figura 4.4. Amostras compostas por pedaços de pneu puro (M100) instaladas no equipamento de cisalhamento direto de média escala. 60

Figura 4.5. Atrito na parede lateral no ensaio de cisalhamento (Palmeira, 2009). 60

Figura 4.6. Analogia utilizada por Palmeira (2009). Figura apresentada no relatório realizado por (Chrusciak, 2013). 61

Figura 5.1.Resumo curvas de compactação para todos os teores de borracha. 64

Figura 5.2. Geração de trincas e planos de fraqueza nos corpos de prova pela presença de fragmentos de borracha. 65

Figura 5.3.Corpos de prova dos ensaios de compactação para todos os teores de borracha: (a) M0 -0\% de teor de borracha; (b) M2,5 - 2,5\% de teor de borracha; (c) M3,75-3,75\% de teor de borracha; (d) M5- 5\% de teor de borracha; (e) M7,5 - 7,5\% de teor de borracha, e; (f) M10 $-10 \%$ de teor de borracha. 66

Figura 5.4. Resumo curvas índice de vazios para todos os teores de borracha. .68

Figura 5.5. Decréscimo do peso específico aparente seco máximo $\left(\gamma_{\mathrm{dmáx}}\right)$ vs teor de borracha.

Figura 5.6. Acréscimo da umidade ótima (Wót) vs teor de borracha. 69

Figura 5.7. Curvas de compactação de misturas solo-borracha submetidas energias de compactação normal e modificada. .70

Figura 5.8. Tensão cisalhante versus Deslocamento horizontal para todos os teores de borracha sob uma tensão confinante de $25 \mathrm{kPa}$. .75 
Figura 5.9. Deformação volumétrica versus Deslocamento horizontal para todos os teores de borracha sob uma tensão confinante de $25 \mathrm{kPa}$. .75

Figura 5.10. Curvas de adensamento para todos os teores de borracha sob uma tensão confinante de $25 \mathrm{kPa}$. .76

Figura 5.11. Tensão cisalhante versus Deslocamento horizontal para todos os teores de borracha sob uma tensão confinante de $50 \mathrm{kPa}$. .76

Figura 5.12. Deformação volumétrica versus Deslocamento horizontal para todos os teores de borracha sob uma tensão confinante de $50 \mathrm{kPa}$ .77

Figura 5.13. Curvas de adensamento para todos os teores de borracha sob uma tensão confinante de $50 \mathrm{kPa}$. 77

Figura 5.14. Tensão cisalhante versus Deslocamento horizontal para todos os teores de borracha sob uma tensão confinante de $80 \mathrm{kPa}$ .78

Figura 5.15. Deformação volumétrica versus Deslocamento horizontal para todos os teores de borracha sob uma tensão confinante de $80 \mathrm{kPa}$ .78

Figura 5.16. Curvas de adensamento para todos os teores de borracha sob uma tensão confinante de $80 \mathrm{kPa}$. .79

Figura 5.17. Tensão cisalhante versus Deslocamento horizontal para todos os teores de borracha sob uma tensão confinante de $100 \mathrm{kPa}$.

Figura 5.18. Deformação volumétrica versus Deslocamento horizontal para todos os teores de borracha sob uma tensão confinante de $100 \mathrm{kPa}$. 80

Figura 5.19. Curvas de adensamento para todos os teores de borracha sob uma tensão confinante de $100 \mathrm{kPa}$.

Figura 5.20. Variação tensão cisalhante máxima com o aumento do teor de borracha submetidas a tensões confinantes de 25, 50, 80 e $100 \mathrm{kPa}$.

Figura 5.21. Variação tensão cisalhante máxima com o aumento do teor de borracha submetidas a tensões confinantes de 25, 50, 80 e $100 \mathrm{kPa}$ (pequenas deformações - $2 \%$ da do deslocamento máximo).

Figura 5.22. Variação tensão cisalhante máxima com o aumento do teor de borracha submetidas a tensões confinantes de 25, 50, 80 e $100 \mathrm{kPa}$ comparados com os resultados de Chrusciak (2013). 84 
Figura 5.23. Variação da coesão com o aumento do teor de borracha.

Figura 5.24. Decréscimo da coesão com o aumento do teor de borracha. 85

Figura 5.25. Variação do ângulo de atrito com o aumento do teor de borracha. 86

Figura 5.26. Acréscimo do ângulo de atrito com o aumento do teor de borracha. .86

Figura 5.27. Envoltórias de ruptura para todos os teores de borracha utilizados na pesquisa. 87

Figura A.1. Curva de compactação solo estudado, solo puro (M0). 103

Figura A.2. Curva de compactação solo estudado, teor de borracha de 2,5\% (M2,5)..... 103

Figura A.3. Curva de compactação solo estudado, teor de borracha de 3,75\% (M3,75)....... 104

Figura A.4. Curva de compactação solo estudado, teor de borracha de 5,0\% (M5). 104

Figura A.5. Curva de compactação solo estudado, teor de borracha de 7,5\% (M7,5). 105

Figura A.6. Curva de compactação solo estudado, teor de borracha de 10\% (M10). 105

Figura B.1. Curva de adensamento do solo puro (M0). 106

Figura B.2. Tensão cisalhante versus deslocamento horizontal, solo puro (M0). 106

Figura B.3. Deformação volumétrica versus deslocamento horizontal, solo puro (M0). 107

Figura B.4. Envoltória de Mohr-Coulomb, solo puro (M0). 107

Figura B.5. Curva de adensamento da mistura M2,5. 108

Figura B.6. Tensão cisalhante versus Deslocamento horizontal da mistura M2,5. 108

Figura B.7. Deformação volumétrica versus Deslocamento horizontal da mistura M2,5.... 109

Figura B.8. Envoltória de Mohr-Coulomb da mistura M2,5. 109

Figura B.9. Curva de adensamento da mistura M3,75. 110

Figura B.10. Tensão cisalhante versus Deslocamento horizontal da mistura M3,75.

Figura B.11. Deformação volumétrica versus Deslocamento horizontal da mistura M3,75. 111

Figura B.12. Envoltória de Mohr-Coulomb da mistura M3,75.

Figura B.13. Curva de adensamento da mistura M5.

Figura B.14. Tensão cisalhante versus Deslocamento horizontal da mistura M5.

Figura B.15. Deformação volumétrica versus Deslocamento horizontal da mistura M5. 
Figura B.16. Envoltória de Mohr-Coulomb da mistura M5.

Figura B.17. Curva de adensamento da mistura M7,5 ................................................... 114

Figura B.18. Tensão cisalhante versus Deslocamento horizontal da mistura M7,5.............. 114

Figura B.19. Deformação volumétrica versus Deslocamento horizontal da mistura M7,5... 115

Figura B.20. Envoltória de Mohr-Coulomb da mistura M7,5........................................... 115

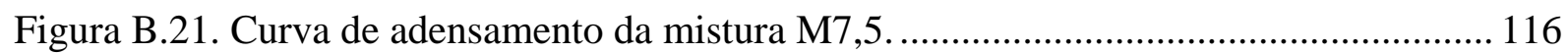

Figura B.22. Deformação volumétrica versus Deslocamento horizontal da mistura M10 ... 116

Figura B.23. Deformação volumétrica versus Deslocamento horizontal da mistura M10 ... 117

Figura B.24. Envoltória de Mohr-Coulomb da mistura M10............................................. 117

Figura B.25. Deslocamento vertical versus Deslocamento horizontal da mistura M100. ..... 118

Figura B.26. Deformação volumétrica versus Deslocamento horizontal da mistura M100. . 118

Figura B.27. Envoltória de Mohr-Coulomb da mistura M100........................................... 119 


\section{LISTA DE TABELAS}

Tabela 2.1. Possibilidades da disposição final de pneus usados (Castro, 2007).

Tabela 2.2. Aplicação de fragmento de pneus (Ghazavi, 2004).

Tabela 2.3. Diferentes classes de resíduos de pneus relatados na literatura (Franco, 2012) baseado nos tamanhos estabelecidos na normativa D6270 (ASTM, 1998).

Tabela 2.4. Resumo dos materiais e seus tamanhos (tomado de CEN Workshop Agreement (CWA) 14243-2002 (CWA, 2002).

Tabela 2.5. Parâmetros de resistência de misturas de solo com fragmentos de pneus usados (Edinçliler et al., 2010).

Tabela 2.6. Resultados do ensaio de cisalhamento direto para areia, migalhas de pneus e misturas de areia com migalhas de pneus (Edinçliler et al., 2010).

Tabela 2.7. Pesos específicos secos máximos (Szeliga et al., 2014)

Tabela 2.8. Pesos específicos secos máximos (Sellaf et al., 2014) .

Tabela 2.9. Valores do ângulo de atrito e da coesão nos ensaios de cisalhamento direto (Humphrey \& Sandford, 1993).

Tabela 2.10. Parâmetros de resistência das misturas de areia e de lascas de pneus das interfaces com geogrelha (Ghazavi et al., 2011).

Tabela 2.11. Parâmetros dos espécimes para ensaio de cisalhamento direto(Bosscher et al., 1994).

Tabela 2.12. Parâmetros de resistência das misturas de areia e pedaços de pneus (Zornberg et al., 2004). 35

Tabela 2.13. Programa de ensaios de compressão triaxial (Bałachowski \& Gotteland, 2007).37

Tabela 2.14. Valores de tensão máxima de cisalhamento, coesão e ângulo de atrito para os ensaios realizados na caixa de medias dimensões (Chrusciak, 2013).

Tabela 4.1. Misturas utilizadas na pesquisa.

Tabela 4.2. Porcentagens calculadas para realização dos ensaios de compactação.

Tabela 4.3. Quantidades calculadas de material para realização dos ensaios de cisalhamento direto de média escala. .58 
Tabela 5.1. Valores de $\gamma_{\text {dmáx }}$ e Wót nos ensaios de compactação para todos os teores de borracha.

Tabela 5.2. Resumo dos resultados dos ensaios de compactação para todos os teores de borracha.

Tabela 5.3. Resultados dos ensaios de cisalhamento direto para todos os teores de borracha. 73

Tabela 5.4. Parâmetros de resistência de misturas de solo com fragmentos de pneus usados (Modificado de Edinçliler et al., 2010). 91 


\section{LISTA DE SÍMBOLOS, NOMENCLATURA E ABREVIAÇÕES}
A
Área de atuação da força normal
$\mathrm{A}_{\mathrm{L}}$
Área lateral de atuação da carga
ABNT
Associação Brasileira de Normas técnicas
ANIP
Associação nacional da indústria de pneumáticos
ASTM
American Society for Testing and Materials
$c$
$c^{\prime}$
CD
CID
Coesão
Coesão efetiva
Ensaios triaxiais adensados e drenados
CL
Ensaios triaxiais isotopicamente adensados e drenados
$\mathrm{cm}$
Argila de baixa compressibilidade
Centímetro

Conama

CWA

Conselho Nacional do Meio Ambiente

$\mathrm{CU}$

CEN Workshop Agreement

$\mathrm{D}_{50}$

Ensaios triaxiais adensados e não drenados

$\mathrm{e}$

Diâmetro médio

$\mathrm{g}$

Índice de vazios

GSsolo

Gramas

Gsbor

Massa especifica dos sólidos do solo

Gseq

Massa específica dos sólidos dos pedaços de pneus

$\mathrm{H}$

Massa específica dos sólidos da mistura

$\mathrm{k}_{0}$

Orientação horizontal

Coeficiente de empuxo no repouso

$\mathrm{kg}$

Kilogramas

$\mathrm{kN}$

Kilonewton

$\mathrm{kPa}$

Kilopascal

m

Metro

$\min$

Minuto

ML

Silte arenoso

$\mathrm{mm}$

Milímetro

M0

Mistura com teor $0 \%$ de pedaços de pneu e $100 \%$ de solo 
M2,5

M3,75

M5

M7,5

M10

M100

$\mathrm{M}_{\mathrm{s}}$

n

NA

NBR

NO

$\mathrm{Pa}$

Q

$\mathrm{R}^{2}$

S

SP

SUCS

$\mathrm{t}$

$\mathrm{t}$

$X_{\text {bor }}$

$\mathrm{X}_{\text {solo }}$

W

$\mathrm{W}_{\mathrm{D}}$

$\mathrm{W}_{\mathrm{h}}$

Wót

Ws

$\mathrm{W}_{\text {bor }} / \mathrm{W}_{\text {solo }}$

$\mathrm{V}_{\text {bor }} / \mathrm{V}_{\text {solo }}$

$\mathrm{V}_{\mathrm{w}}$

○

$\circ$,

,
Mistura com teor 2,5\% de pedaços de pneu e 97,5\% de solo

Mistura com teor 3,75\% de pedaços de pneu e $96,25 \%$ de solo Mistura com teor 5\% de pedaços de pneu e $95 \%$ de solo Mistura com teor 7,5\% de pedaços de pneu e $92,5 \%$ de solo Mistura com teor $10 \%$ de pedaços de pneu e $90 \%$ de solo Mistura com teor $100 \%$ de pedaços de pneu e $0 \%$ de solo Massa do solo em gramas

Relação entre as laterais das lascas de pneu

Não aplicável

Norma Brasileira

Não orientados

Pascal

Máxima forca de cisalhamento

Coeficiente de determinação

Saturação

Areia mal graduada

Sistema Unificado de Classificação de solos

Tempo

Toneladas

Teor de borracha da mistura

Teor de solo da mistura

Umidade

Umidade de agua desejada

Umidade higroscópica

Umidade ótima de compactação

Força peso da parte superior ao plano de ruptura

Relação mistura por peso

Relação mistura por volume

Volume de água a adicionar

Graus

Graus minutos e segundos

Polegadas 


$\begin{array}{cl}{ }^{\circledR} & \text { Registrado } \\ \phi & \text { Ângulo de atrito } \\ \phi_{\mathrm{eq}} & \text { Ângulo de atrito equivalente } \\ \varphi_{\mathrm{sw}} & \text { Ângulo de atrito entre o solo e a parede da caixa } \\ \delta_{\mathrm{eq}} & \text { Ângulo de atrito na interface } \\ \rho & \text { Massa especifica úmida da mistura }\left(\mathrm{kg} / \mathrm{cm}^{3}\right) \\ \gamma & \text { Peso especifico }\left(\mathrm{kN} / \mathrm{m}^{3}\right) \\ \gamma_{\mathrm{d}} & \text { Peso especifico seco }\left(\mathrm{kN} / \mathrm{m}^{3}\right) \\ \gamma_{\mathrm{dmáx}} & \text { Peso especifico seco máximo }\left(\mathrm{kN} / \mathrm{m}^{3}\right) \\ \gamma_{\mathrm{mistura}} & \text { Peso especifico da mistura sem compactar }\left(\mathrm{kN} / \mathrm{m}^{3}\right) \\ \gamma_{\mathrm{w}} & \text { Peso especifico da agua }\left(\mathrm{kN} / \mathrm{m}^{3}\right) \\ \sigma & \text { Tensão } \\ \sigma_{\mathrm{N}} & \text { Tensão normal } \\ \sigma_{\mathrm{np}} & \text { Tensão normal no plano de ruptura } \\ \tau & \text { Tensão de cisalhamento } \\ \tau_{\mathrm{máx}} & \text { Tensão de cisalhamento máxima } \\ \% & \text { Porcentagem } \\ > & \text { Sinal de maior } \\ < & \text { Sinal de menor }\end{array}$




\section{INTRODUÇÃO}

\subsection{MOTIVAÇÃO}

A grande produção de pneus e as dificuldades para disposição dos mesmos em aterros ao fim da vida útil são casos comuns de geração de problemas ambientais, ao longo das últimas décadas. Para ter-se uma ideia dos quantitativos gerados, os Estados Unidos geram mais de 250 milhões de unidades anualmente. Grande porcentagem destes pneus são processados e reutilizados como: aditivos para mesclas de asfalto quente; materiais para geração de energia; fabricação de novos pneus; aditivos para pavimentos, e; material de enchimento em base e sub-base granular (Lund, 1933).

De acordo com os dados divulgados pela Associação Nacional da Indústria de Pneumáticos (ANIP, 2015), a indústria brasileira produziu 68,8 milhões de pneus no ano 2013, um aumento de 9,8\% ante 2012, sendo este um recorde para a indústria brasileira. Por esse motivo, é importante a que sejam feitos estudos relativos à disposição dos resíduos de pneus ao final da vida útil, abordando os seguintes aspectos: tratamento e/ou seu armazenamento e definição dos danos causados ao meio ambiente resultantes do manejo inadequado dos mesmos.

No mundo, existe um grande número de pesquisas e metodologias que orientam a reciclagem de produtos utilizados pelo homem. Na América Latina, no entanto, ainda são poucas as implementações destas por falta de políticas que apóiem indústrias dedicadas à coleta, recuperação de material e/ou eliminação dos mesmos de forma limpa. Por exemplo, a incineração destes resíduos resulta em problemas ambientais através da emissão de gases que contém partículas prejudiciais.

No caso dos pneus, na literatura são propostos métodos de recuperação dos materiais por meio da eliminação dos compostos perigosos e reutilizando borracha produto de processos de trituração mecânica. Uma proposta de reutilização desses resíduos de forma limpa é a utilização do material triturado no enchimento de diferentes obras geotécnicas. 
Nesta pesquisa é dada continuidade aos trabalhos relativos à mistura de solos com fragmentos de pneus em ensaios de pequena escala (Franco, 2012) e mistura de solos com fragmentos de borracha em ensaios de média escala (Chrusciak, 2013). Foi empregado um equipamento de cisalhamento direto com dimensões maiores que as convencionais visando o estudo da utilização de fragmentos de lascas de borracha em obras geotécnicas. O uso de equipamento com tais dimensões se deve à necessidade de redução do efeito de escala relativo ao tamanho dos fragmentos de borracha. Os ensaios foram realizados para diferentes teores de mistura de borracha e de solos representativos do Distrito Federal.

\subsection{OBJETIVO}

Estudar os parâmetros de resistência de misturas de solo argiloso do Distrito Federal com pedaços de borracha recicláveis provenientes de processos de trituração de pneus, os quais são usados como material de enchimento leve.

\subsection{OBJETIVOS ESPECÍFICOS}

- Determinar a influência dos fragmentos de pneus misturados com solo argiloso do Distrito Federal em relação aos parâmetros do ensaio de compactação: peso específico máximo e teor de umidade ótimo;

- Executar o ensaio de cisalhamento direto de dimensões médias para amostras compactadas de misturas entre solo e borracha, avaliando-se a influência do tamanho dos grãos e dos fragmentos de borracha nos parâmetros de resistência;

- Comparar os resultados obtidos com os resultados de pesquisas prévias, determinando a influência do tamanho do resíduo de borracha nos parâmetros medidos. 


\section{REVISÃO BIBLIOGRAFICA}

Neste capítulo é apresentado o resumo da situação atual da produção, os métodos de reciclagem e os possíveis usos de pneus após sua vida útil, onde tal uso é focado a aplicações em engenharia geotécnica. Além disso, são apresentadas pesquisas prévias realizadas por diferentes autores que utilizam diferentes tamanhos de resíduos de pneus baseados na classificação exposta pela normativa D6270 (ASTM, 1998).

\subsection{HISTÓRICO: PRODUÇÃO, RECICLAGEM E REUTILIZAÇÃO DE PNEUS}

A produção de pneus nos Estados Unidos gera mais de 250 milhões de unidades anualmente (Bader, 2012). Grande porcentagem destes pneus são processados e reutilizados como: aditivo para mesclas de asfalto quente; material gerador de energia; gerador de novos pneus; aditivo em pavimentos e material de enchimento em base e sub-base granular (Lund, 1933).

No Brasil, enquanto nos doze meses de 2013 foram produzidos 68,8 milhões de pneus, o acumulado mensal de 2014 chegou a 68,7 milhões de unidades, uma queda de 0,2\%. Em 2014 foram importados 27,2 milhões de pneus, dos quais sete milhões foram trazidos por fábricas associadas e 20,2 milhões por marcas que não contam com fábrica no país(ANIP, 2015).Apesar da produção de pneus no mercado brasileiro ter registrado retração no ano de 2014, a quantidade produzida ainda é relevante. Frente a estes números, o país tem políticas ambientais como a resolução CONAMA No. 258 (1999) que determina que as empresas fabricantes e as importadoras de pneumáticos ficam obrigadas a coletar e dar destinação final ambientalmente adequada aos pneus inservíveis; as mesmas também devem aplicar novas metodologias para reciclagem e reutilização deste tipo de material, devido à geração de problemas como descarte indevido do material, lenta degradação de resíduos, criação e abrigos de vetores de doenças e problemas na compactação em aterros sanitários.

Operações como recuperação de pneus e destruição de componentes perigosos, aplicando métodos de reutilização, recauchutagem e reciclagem dos pneus usados, representam uma oportunidade significativa para criar indústria e desenvolvimento de novas tecnologias, bem como uma importante fonte de novos empregos. 
Castro (2007), no relatório "Reutilización, reciclado y disposición final de neumáticos", apresenta situação atual da América Latina, citando a falta de tecnologias e políticas ambientais que apóiem aplicação de métodos para coleta, reciclagem, reutilização e disposição final deste tipo de material. O autor também cita os atuais processos que acontecem com este tipo de material, seus possíveis usos e disposições finais. Na Tabela 2.1 está apresentado um resumo das diferentes finalidades que os pneus usados podem ser submetidos.

Tabela 2.1. Possibilidades da disposição final de pneus usados (Castro, 2007).

\begin{tabular}{|c|c|c|c|c|}
\hline \multicolumn{3}{|c|}{ Finalidade } & Técnica ou processo & Exemplos \\
\hline Prevenção & \multicolumn{2}{|c|}{ Prevenção / minimização } & \multicolumn{2}{|c|}{$\begin{array}{l}\text { Fabricação de pneus duráveis } \\
\text { Uso de materiais reciclados } \\
\text { Produzir pneus facilmente }\end{array}$} \\
\hline \multirow{4}{*}{ Valorização } & \multirow[t]{3}{*}{$\begin{array}{l}\text { Valorização } \\
\text { material }\end{array}$} & Reutilização & Aplicações diretas & $\begin{array}{l}\text { Proteção: corridas de } \\
\text { circuito com veículos, } \\
\text { postos de segurança. } \\
\text { Construção de muros } \\
\text { de contenção } \\
\text { Barreiras em zonas } \\
\text { costeiras } \\
\text { Barreiras acústicas } \\
\text { Obras de drenagem }\end{array}$ \\
\hline & & \multirow[t]{2}{*}{ Reciclagem } & Regeneração & $\begin{array}{l}\text { Elaboração de novos } \\
\text { pneus }\end{array}$ \\
\hline & & & Trituração e separação & $\begin{array}{l}\text { Pavimentos } \\
\text { Zonas esportivas }\end{array}$ \\
\hline & $\begin{array}{l}\text { Valorização } \\
\text { energética }\end{array}$ & $\begin{array}{l}\text { Incineração, } \\
\text { combustão, } \\
\text { pirolise }\end{array}$ & $\begin{array}{l}\text { Os pneus são u } \\
\text { hidrocarbonetos, metais } \\
\text { aditivos, e assim po } \\
\text { fabricação de mais de } \\
\text { emissóes produzidas } \\
\text { incineração de pneus } \\
\text { seguintes substâncias: } \\
\text { Dióxido de Carbono, Di } \\
\text { de azoto, Óxidos de } \\
\text { Fenóis, Óxidos de ch } \\
\text { Naftaleno, Furanos, Ben }\end{array}$ & $\begin{array}{l}\text { a mistura complexa de } \\
\text { enxofre, plastificantes e } \\
\text { em ser utilizados na } \\
200 \text { componentes. As } \\
\text { na combustão ou } \\
\text { são, entre outras, as } \\
\text { Monóxido de Carbono, } \\
\text { xido de Enxofre, Óxidos } \\
\text { inco, Xileno, Benzeno, } \\
\text { mbo, Pireno, Tolueno, } \\
\text { opireno. }\end{array}$ \\
\hline Eliminação & Depositc & $\mathrm{m}$ aterros & $\begin{array}{l}\text { Trituração ou depósito } \\
\text { em aterro. }\end{array}$ & $\begin{array}{l}\text { Alguns países proíbem } \\
\text { depósito em Aterros } \\
\text { sanitários }\end{array}$ \\
\hline
\end{tabular}




\subsection{TECNICAS DE MELHORIA DE SOLOS UTILIZANDO FRAGMENTOS DE PNEUS INSERVIVEIS.}

Existem inúmeras formas de reciclagem e reutilização da borracha dos pneus, entretanto neste trabalho é dada maior relevância a destinações dentro da Engenharia Civil. Na Tabela 2.2, apresentada no relatório "Ground tire rubber as a stabilizer for subgrade soils" (Consentino et al., 2014), podem-se ver a compilação feita por Ghazavi (2004) das aplicações deste tipo de material e seus principais pesquisadores.

A utilização de fragmentos de pneus em aplicações de engenharia civil é vantajosa em virtude de sua baixa densidade, alta durabilidade, elevado isolamento térmico e, em muitos casos, menor custo em comparação com outras alternativas (Humphrey et al., 1999).

Tabela 2.2. Aplicação de fragmento de pneus (Ghazavi, 2004).

\begin{tabular}{|c|c|}
\hline Aplicação da borracha & Referência \\
\hline Construção de estradas & $\begin{array}{c}\text { (Bosscher et al., 1997) } \\
\text { (Heimdahl \& Drescher, 1999) } \\
\text { (Nightingale \& Green, 1997) }\end{array}$ \\
\hline Controle da erosão & (Poh \& Broms, 1995) \\
\hline Estabilização de encostas & (Poh \& Broms, 1995) \\
(Garga \& O'Shaughnessy, 2011)
\end{tabular}




\subsection{MELHORIA DE SOLOS UTILIZANDO FRAGMENTOS DE BORRACHA}

Os pneus inservíveis podem ser divididos em duas categorias gerais: total ou processado, onde o processado dependerá da classe de resíduo gerado. Os usos para pneus inteiros incluem recifes artificiais, combustível e recauchutagem, enquanto usos para pneus processados incluem produtos de borracha e material de combustível (Benson, 1995).

Benson (1995), devido ao crescimento desmedido dos resíduos gerados no mundo e a dificuldade na sua disposição final, apresenta a possibilidade de aproveitamento deste material em projetos de rodovias e terraplanagem, uma vez que grande quantidade deste material pode ser utilizado em um único projeto. Pneus triturados como adição a solos a fim de criar material de enchimento leve com melhores propriedades mecânicas, criação de material de drenagem, construção de barreiras acústicas e formulação de aditivos para asfaltos, são alternativas de uso deste tipo de material.

$\mathrm{O}$ uso de pneus triturados como enchimento de peso leve, ou aditivo para melhorar as propriedades mecânicas do solo, é particularmente vantajoso. Por exemplo, pneus ou misturas de pneus triturados com solo podem ser usados como material de enchimento de estruturas de contenção de rodovias (Figura 2.1). Pneus e misturas de pedaços de pneus com solo são mais leves do que o solo puro e, assim, pressões mais baixas são exercidas sobre a estrutura de contenção. Como resultado, os requisitos estruturais para a parede são reduzidos, e isso pode traduzir-se na diminuição dos custos da estrutura.

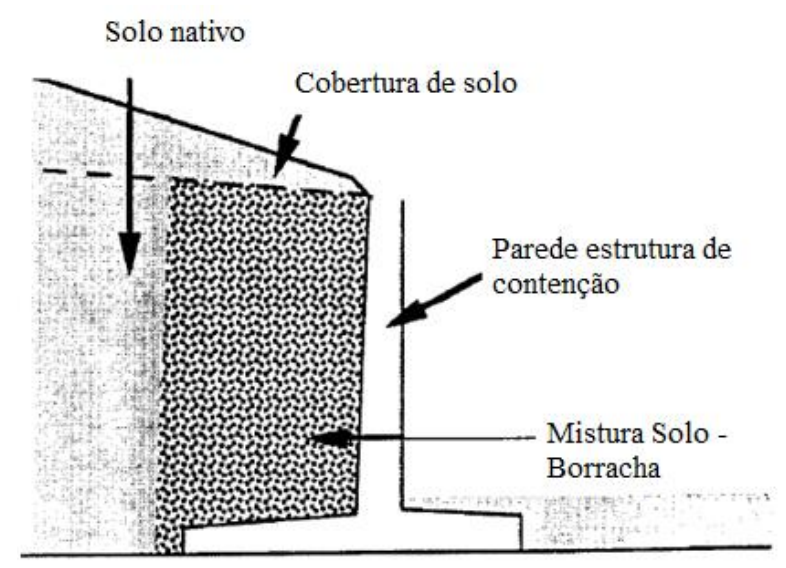

Figura 2.1. Uso de pedaços de pneus como enchimentos de peso leve em uma estrutura de contenção para rodovias (Benson, 1995). 
Além disso, em alguns casos, quando os pneus triturados são misturados com o solo, a resistência da mistura é superior à resistência do solo ou dos fragmentos de pneus sozinho (Figura 2.2). Na verdade, em alguns casos a resistência pode até dobrar. Uma vez que a mistura está submetida a uma tensão cisalhante mais elevada para uma mesma tensão normal, há uma maior capacidade de suportar a si mesma, exercendo menos pressão sobre as paredes de estruturas e resultando em uma estrutura mais econômica. De fato, algumas misturas de pneus triturados como solo podem ser autos sustentáveis até alturas de 6 metros e, em tais casos, o muro de contenção simplesmente se destina a proteger a mistura de solo e pedaços pneus da erosão e a proporcionar uma superfície mais agradável esteticamente.

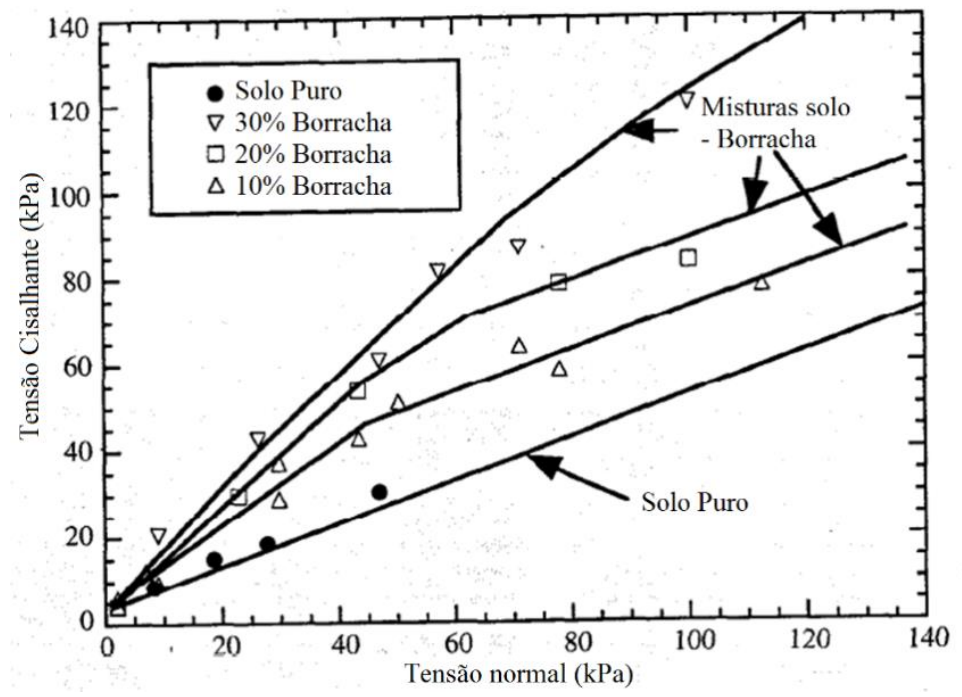

Figura 2.2. Resistência ao cisalhamento de misturas de solos e pneus triturados (Benson, 1995).

Embora o descarte de pneus seja proibido para economizar espaço nos aterros, os fragmentos de pneus triturados podem ter valiosas funções em um geotécnico. Pneus triturados podem ser utilizados como material de drenagem, meio de tratamento de lixiviados, cobertura diária ou isolamento térmico.

Segundo Benson (1995), pneus inservíveis podem ser mais permeáveis do que areias ou cascalhos normalmente utilizados em sistemas de coleta de chorume. Além disso, podem absorver tóxicos e produtos químicos normalmente encontrados em chorume. Assim, o uso de pneus inservíveis na coleta de chorume resulta em sistema mais eficiente, pois o chorume é facilmente removido. Além disso, os fragmentos de pneu podem substituir recursos valiosos e até caros como areia e cascalho, dependendo das condições do projeto. 
Dependendo do tamanho do material processado do pneu, podem ocorrer alterações nas propriedades mecânicas das misturas solo-borracha.

Edinçliler et al. (2010) propuseram a classificação do material processado baseando-se na normativa D6270 (ASTM, 1998) em: pedaços de pneus (do inglês tire sherds), migalhas de pneus (do inglês tire crumb), lascas de pneus (do inglês tire chips) e desbastes de pneus (do inglês tire buffings), como apresentado na Figura 2.3. Franco (2012) apresentou a Tabela 2.3 com os diferentes tamanhos de grãos de resíduo de pneu e seus principais pesquisadores. Este tipo de material é normalmente empregado na engenharia civil como material de enchimento leve. Outros autores como Oikonomou \& Mavridou (2009) aplicaram em suas pesquisas a classificação feita pelo CEN Workshop Agreement (CWA, 2002), apresentado na Tabela 2.4. $\mathrm{Na}$ atual pesquisa, foi utilizada a classificação utilizada pela norma ASTM D6270 (ASTM, 1998).

Tabela 2.3. Diferentes classes de resíduos de pneus relatados na literatura (Franco, 2012) baseado nos tamanhos estabelecidos na normativa D6270 (ASTM, 1998).

\begin{tabular}{|c|c|c|}
\hline Classificação & $\begin{array}{c}\text { Tamanho dos resíduos de pneus } \\
\text { utilizados }\end{array}$ & Referência \\
\hline Pedaços de pneus & $50 \mathrm{~mm}, 50-100 \mathrm{~mm}, 100-150 \mathrm{~mm}$ & Foose et al., (1996) \\
Pedaços de pneus & $50,8 \mathrm{~mm}-152 \mathrm{~mm}$ & $\begin{array}{c}\text { Zornberg et al., (2004) } \\
\text { (Shalaby \& Khan, 2005) }\end{array}$ \\
Pedaços de pneus & $50 \mathrm{~mm}-300 \mathrm{~mm}$ & (Yoon et al., 2006) \\
Pedaços de pneus e lascas de pneus & $\begin{array}{c}50-100 \mathrm{~mm}, 100-200 \mathrm{~mm} \text { (pedaços de } \\
\text { pneus); } 9,5 \mathrm{~mm} \text { (lascas de pneus) }\end{array}$ & $\begin{array}{c}\text { (Lee et al., 1999) } \\
\text { Lascas de pneus }\end{array}$ \\
Desbastes de pneus & $2-4 \mathrm{~mm}$ & (Edinçliler et al., 2004) \\
Migalhas de pneus & $<0,6 \mathrm{~mm}$ & (Ghazavi, 2004) \\
\hline
\end{tabular}

Tabela 2.4. Resumo dos materiais e seus tamanhos (tomado de CEN Workshop Agreement (CWA) 14243-2002 (CWA, 2002).

\begin{tabular}{|c|c|}
\hline Classificação & Tamanho dos resíduos de pneus utilizados \\
\hline Cortes de pneus & $>300 \mathrm{~mm}$ \\
Pedaços de pneus & $50-300 \mathrm{~mm}$ \\
Lascas de pneus & $10-50 \mathrm{~mm}$ \\
Desbastes de pneus & $1-40 \mathrm{~mm}$ \\
Migalhas de pneu & $1-10 \mathrm{~mm}$ \\
Pó de pneu & $<1 \mathrm{~mm}$ \\
Pó fino de pneu & $<500 \mu \mathrm{m}$ \\
\hline
\end{tabular}



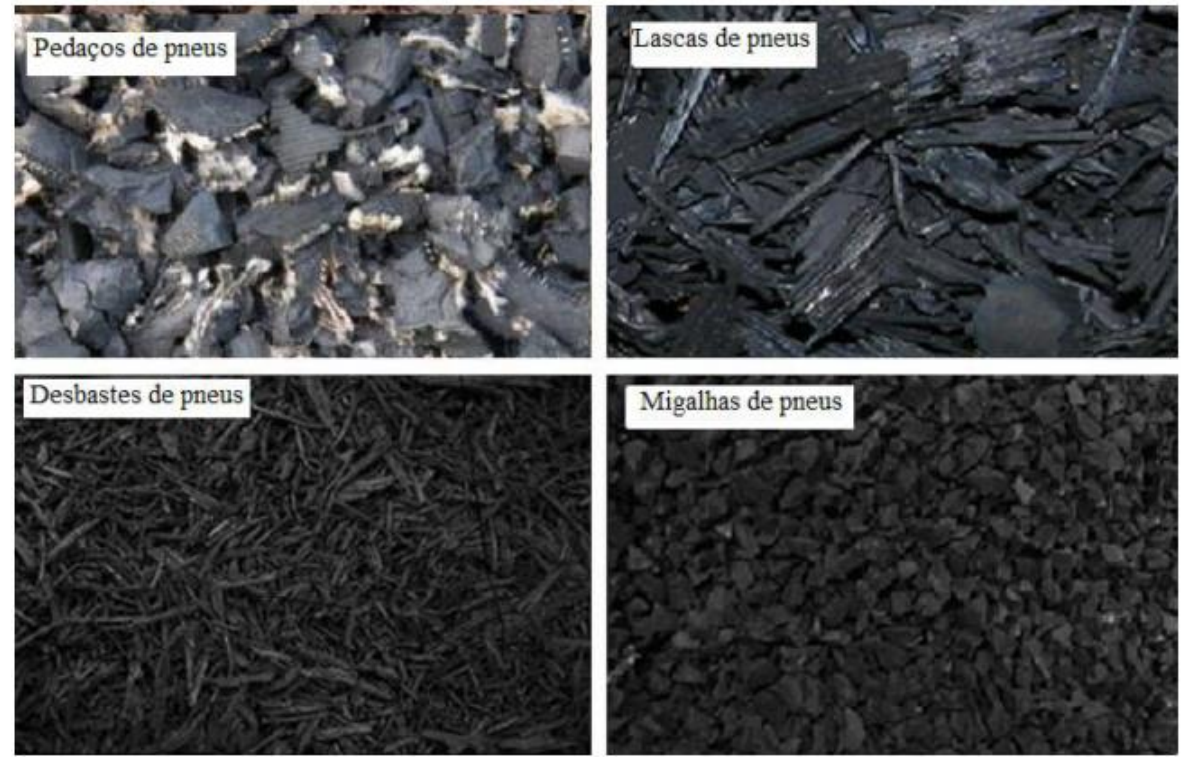

Figura 2.3. Tipos de diferentes processamentos de pneus inservíveis, fora de escala (Edinçliler et al., 2010).

Edinçliler et al. (2010) apresentaram um resumo de estudos de melhoramento dos parâmetros de resistência de misturas solo-borracha, previamente realizados por diferentes pesquisadores com diferentes tamanhos de fragmentos de pneu (Tabela 2.5). Esses estudos concentraram-se principalmente na determinação das propriedades de resistência das misturas de borracha com areia, como material de enchimento em estruturas de contenção. A maioria dos pesquisadores concluiu que a mistura de fragmentos de pneus com areia pode ser usada como material de enchimento, em estruturas de contenção, em taludes de estradas e em solos de alta compressibilidade, devido à sua alta resistência e permeabilidade. Entretanto, mais estudos são necessários para investigar o uso com diferentes tipos de borrachas, granulometrias e com diferentes tipos de solos. 
Tabela 2.5. Parâmetros de resistência de misturas de solo com fragmentos de pneus usados (Edinçliler et al., 2010).

\begin{tabular}{|c|c|c|c|}
\hline Referência & Material & $\begin{array}{c}\gamma \\
(k N / m 3)\end{array}$ & $\begin{array}{c}\text { Parâmetros de } \\
\text { resistência }\end{array}$ \\
\hline $\begin{array}{l}\text { (Humphrey } \\
\text { et al., 1999) }\end{array}$ & $\begin{array}{l}\text { Produto } 1(<76 \mathrm{~mm} \text { pedaços }-1) \\
\text { Produto } 2(<76 \mathrm{~mm} \text { pedaços }-1) \\
\text { Produto } 3(<76 \mathrm{~mm} \text { pedaços }-1) \\
\text { Produto } 3(<76 \mathrm{~mm} \text { pedaços }-2)\end{array}$ & $\begin{array}{c}7,01 \\
6,82 \\
7,24 \\
-\end{array}$ & $\begin{aligned} \mathrm{c}^{\prime} & =8,6 \mathrm{kPa} \phi=25^{\circ} \\
\mathrm{c}^{\prime} & =11,5 \mathrm{kPa} \phi=19^{\circ} \\
\mathrm{c}^{\prime} & =7,7 \mathrm{kPa} \phi=21^{\circ} \\
\mathrm{c}^{\prime} & =4,3 \mathrm{kPa} \phi=26^{\circ}\end{aligned}$ \\
\hline $\begin{array}{l}\text { (Ahmed \& } \\
\text { Lovell, } \\
\text { 1993) }\end{array}$ & $\begin{array}{l}\text { Pedaços de pneus (tamanho: } 1,3 \mathrm{~cm} \text { ) } \\
\text { Pedaços de pneus (tamanho: } 2,5 \mathrm{~cm} \text { ) } \\
\text { Pedaços de pneus (tamanho: } 2,5 \mathrm{~cm} \text { ) } \\
\text { Pedaços de pneus (tamanho: } 2,5 \mathrm{~cm} \text { ) }\end{array}$ & $\begin{array}{l}4,67 \\
6,71 \\
6,29 \\
6,45 \\
\end{array}$ & $\begin{array}{l}\mathrm{c}^{\prime}=35,8 \mathrm{kPa} \phi=20,5^{\circ} \\
\mathrm{c}^{\prime}=39,2 \mathrm{kPa} \phi=24,6^{\circ} \\
\mathrm{c}^{\prime}=33,2 \mathrm{kPa} \phi=25,3^{\circ} \\
\mathrm{c}^{\prime}=37,3 \mathrm{kPa} \phi=22,6^{\circ}\end{array}$ \\
\hline $\begin{array}{l}\text { (Wu et al., } \\
\text { 1997b) }\end{array}$ & $\begin{array}{l}\text { Lascas de Pneus - Produto } 1 \text { (máx, } 38 \mathrm{~mm} \text { ) } \\
\text { Lascas de Pneus - Produto } 2 \text { (máx, } 19 \mathrm{~mm} \text { ) } \\
\text { Lascas de Pneus - Produto } 3 \text { (máx, 9,5 mm) } \\
\text { Lascas de Pneus - Produto } 4 \text { (máx, 9,5 mm) } \\
\text { Migalhas - Produto } 5 \text { (máx, 2 mm) }\end{array}$ & $\begin{array}{l}5,89 \\
5,69 \\
4,95 \\
5,89 \\
5,69\end{array}$ & $\begin{array}{l}\mathrm{c}^{\prime}=0 \mathrm{kPa} \phi=57^{\circ} \\
\mathrm{c}^{\prime}=0 \mathrm{kPa} \phi=54^{\circ} \\
\mathrm{c}^{\prime}=0 \mathrm{kPa} \phi=54^{\circ} \\
\mathrm{c}^{\prime}=0 \mathrm{kPa} \phi=47^{\circ} \\
\mathrm{c}^{\prime}=0 \mathrm{kPa} \phi=45^{\circ}\end{array}$ \\
\hline $\begin{array}{l}\text { (Tatlisoz et } \\
\text { al., 1998) } \\
\text { (Tatlisoz et } \\
\text { al., 1998) }\end{array}$ & $\begin{array}{c}100 \% \text { lascas de pneus } \\
100 \% \text { Areia } \\
90 \% \text { de areia }+10 \% \text { lascas de pneus } \\
80 \% \text { de areia }+20 \% \text { lascas de pneus } \\
70 \% \text { de areia }+30 \% \text { lascas de pneus } \\
100 \% \text { Silte arenoso } \\
90 \% \text { Silte arenoso+10\% lascas de pneus } \\
80 \% \text { Silte arenoso }+20 \% \text { lascas de pneus } \\
70 \% \text { Silte arenoso+30\% lascas de pneus }\end{array}$ & $\begin{array}{c}5,9 \\
16,8 \\
15,6 \\
14,5 \\
13,3 \\
18,3 \\
17,6 \\
17,0 \\
18,9\end{array}$ & $\begin{aligned} \mathrm{c}^{\prime} & =0 \mathrm{kPa} \phi=30^{\circ} \\
\mathrm{c}^{\prime} & =2 \mathrm{kPa} \phi=34^{\circ} \\
\mathrm{c}^{\prime} & =2 \mathrm{kPa} \phi=46^{\circ} \\
\mathrm{c}^{\prime} & =2 \mathrm{kPa} \phi=50^{\circ} \\
\mathrm{c}^{\prime} & =2 \mathrm{kPa} \phi=52^{\circ} \\
\mathrm{c}^{\prime} & =21 \mathrm{kPa} \phi=30^{\circ} \\
\mathrm{c}^{\prime} & =8 \mathrm{kPa} \phi=53^{\circ} \\
\mathrm{c}^{\prime} & =38 \mathrm{kPa} \phi=54^{\circ} \\
\mathrm{c}^{\prime} & =39 \mathrm{kPa} \phi=53^{\circ}\end{aligned}$ \\
\hline $\begin{array}{c}\text { (Foose et al., } \\
1996)\end{array}$ & 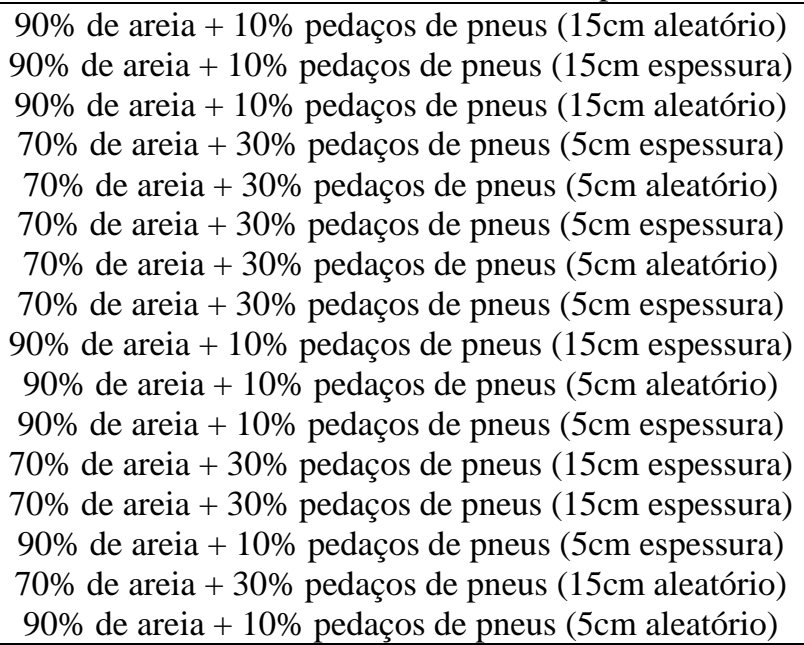 & $\begin{array}{l}16,8 \\
16,8 \\
14,7 \\
14,7 \\
14,7 \\
16,8 \\
16,8 \\
14,7 \\
14,7 \\
16,8 \\
14,7 \\
16,8 \\
16,8 \\
16,8 \\
14,7 \\
14,7\end{array}$ & $\begin{aligned} \tau & =37,9 \mathrm{kPa}(\sigma=25,5 \mathrm{kPa}) \\
\tau & =18,6 \mathrm{kPa}(\sigma=25,5 \mathrm{kPa}) \\
\tau & =8,3 \mathrm{kPa}(\sigma=25,5 \mathrm{kPa}) \\
\tau & =37,2 \mathrm{kPa}(\sigma=25,5 \mathrm{kPa}) \\
\tau & =11,0 \mathrm{kPa}(\sigma=25,5 \mathrm{kPa}) \\
\tau & =20,7 \mathrm{kPa}(\sigma=25,5 \mathrm{kPa}) \\
\tau & =55,2 \mathrm{kPa}(\sigma=25,5 \mathrm{kPa}) \\
\tau & =32,4 \mathrm{kPa}(\sigma=25,5 \mathrm{kPa}) \\
\tau & =32,4 \mathrm{kPa}(\sigma=25,5 \mathrm{kPa}) \\
\tau & =32,4 \mathrm{kPa}(\sigma=25,5 \mathrm{kPa}) \\
\tau & =13,8 \mathrm{kPa}(\sigma=25,5 \mathrm{kPa}) \\
\tau & =78,6 \mathrm{kPa}(\sigma=25,5 \mathrm{kPa}) \\
\tau & =22,8 \mathrm{kPa}(\sigma=25,5 \mathrm{kPa}) \\
\tau & =29,0 \mathrm{kPa}(\sigma=25,5 \mathrm{kPa}) \\
\tau & =42,1 \mathrm{kPa}(\sigma=25,5 \mathrm{kPa}) \\
\tau & =19,3 \mathrm{kPa}(\sigma=25,5 \mathrm{kPa})\end{aligned}$ \\
\hline $\begin{array}{l}\text { (Attom, } \\
2006)\end{array}$ & $\begin{array}{l}100 \% \text { areia } \mathrm{A} \\
10 \% \text { pedaços de pneu }+90 \% \text { areia } \mathrm{A} \\
20 \% \text { pedaços de pneu }+80 \% \text { areia } \mathrm{A} \\
30 \% \text { pedaços de pneu }+70 \% \text { areia } \mathrm{A} \\
40 \% \text { pedaços de pneu }+60 \% \text { areia } \mathrm{A} \\
100 \% \text { areia } \mathrm{B} \\
10 \% \text { pedaços de pneu }+90 \% \text { areia } \mathrm{B} \\
20 \% \text { pedaços de pneu }+80 \% \text { areia } \mathrm{B} \\
30 \% \text { pedaços de pneu }+70 \% \text { areia } \mathrm{B} \\
40 \% \text { pedaços de pneu }+60 \% \text { areia } \mathrm{B} \\
100 \% \text { areia } \mathrm{C} \\
10 \% \text { pedaços de pneu }+90 \% \text { areia } \mathrm{C} \\
20 \% \text { pedaços de pneu }+80 \% \text { areia } \mathrm{C} \\
30 \% \text { pedaços de pneu }+70 \% \text { areia } \mathrm{C} \\
40 \% \text { pedaços de pneu }+60 \% \text { areia } \mathrm{C}\end{array}$ & $\begin{array}{c}15,5 \\
14 \\
15 \\
15,5 \\
16 \\
15,9 \\
14 \\
15 \\
15,9 \\
16 \\
16,6 \\
15 \\
16 \\
16,5 \\
16,6\end{array}$ & $\begin{array}{l}\phi=25^{\circ} \\
\phi=30^{\circ} \\
\phi=37^{\circ} \\
\phi=41^{\circ} \\
\phi=45^{\circ} \\
\phi=28^{\circ} \\
\phi=35^{\circ} \\
\phi=42^{\circ} \\
\phi=47^{\circ} \\
\phi=49^{\circ} \\
\phi=36^{\circ} \\
\phi=42^{\circ} \\
\phi=45^{\circ} \\
\phi=48^{\circ} \\
\phi=50^{\circ}\end{array}$ \\
\hline
\end{tabular}


Tabela 2.5. Parâmetros de resistência de misturas de solo com fragmentos de pneus usados (Edinçliler et al., 2010). (continuação)

\begin{tabular}{|c|c|c|c|}
\hline Referência & Material & $\begin{array}{c}\gamma \\
(\mathrm{kN} / \mathrm{m} 3)\end{array}$ & $\begin{array}{l}\text { Parâmetros de } \\
\text { resistência }\end{array}$ \\
\hline $\begin{array}{c}\text { (Edinçliler et } \\
\text { al., 2004) }\end{array}$ & $\begin{array}{c}100 \% \text { Desbastes de pneus } \\
100 \% \text { Areia } \\
90 \% \text { Areia+10\% Desbastes de pneus }\end{array}$ & $\begin{array}{c}5,1 \\
15,3 \\
13,0\end{array}$ & $\begin{array}{l}\mathrm{c}^{\prime}=3,1 \mathrm{kPa} \phi=22^{\circ} \\
\mathrm{c}^{\prime}=6,9 \mathrm{kPa} \phi=33^{\circ} \\
\mathrm{c}^{\prime}=8,7 \mathrm{kPa} \phi=29^{\circ}\end{array}$ \\
\hline $\begin{array}{c}\text { (Edinçliler, } \\
\text { al., 2007) }\end{array}$ & $\begin{array}{c}100 \% \text { Desbastes de pneus } \\
100 \% \text { Areia } \\
\text { 95\% Areia+5\% Desbastes de pneus } \\
90 \% \text { Areia+10\% Desbastes de pneus } \\
80 \% \text { Areia+20\% Desbastes de pneus } \\
70 \% \text { Areia+30\% Desbastes de pneus }\end{array}$ & $\begin{array}{c}5,1 \\
15,3 \\
15,2 \\
14,9 \\
14,2 \\
13,5\end{array}$ & $\begin{array}{c}\mathrm{c}^{\prime}=3,1 \mathrm{kPa} \phi=22^{\circ} \\
\mathrm{c}^{\prime}=6,9 \mathrm{kPa} \phi=33^{\circ} \\
\mathrm{c}^{\prime}=10,4 \mathrm{kPa} \phi=28,2^{\circ} \\
\mathrm{c}^{\prime}=8,7 \mathrm{kPa} \phi=29^{\circ} \\
\mathrm{c}^{\prime}=15,5 \mathrm{kPa} \phi=8,3^{\circ} \\
\mathrm{c}^{\prime}=10,7 \mathrm{kPa} \phi=8,3^{\circ}\end{array}$ \\
\hline $\begin{array}{c}\text { (Ghazavi, } \\
\text { 2004) }\end{array}$ & $\begin{array}{l}100 \% \text { Areia } \\
\text { 90\% Areia+10\% migalhas de pneus } \\
85 \% \text { Areia }+15 \% \text { migalhas de pneus } \\
80 \% \text { Areia }+20 \% \text { migalhas de pneus } \\
50 \% \text { Areia }+50 \% \text { migalhas de pneus } \\
30 \% \text { Areia }+70 \% \text { migalhas de pneus } \\
\text { 100\% migalhas de pneus }\end{array}$ & $\begin{array}{c}14-14,5 \\
13-13,5 \\
12,3-13 \\
11-12,4 \\
7,7-8 \\
6,4-6,7 \\
4,7-5,1\end{array}$ & $\begin{array}{c}\phi=31,2^{\circ}-37^{\circ} \\
\phi=31^{\circ}-37^{\circ} \\
\phi=35,3^{\circ}-37,6^{\circ} \\
\phi=34,5^{\circ}-33,5^{\circ} \\
\phi=33^{\circ}-35^{\circ} \\
\phi=33^{\circ} \\
\phi=31^{\circ}\end{array}$ \\
\hline
\end{tabular}

\subsubsection{MELHORIA DE SOLOS USANDO MIGALHAS DE PNEUS}

As migalhas são produto da trituração secundária dos pneus, com um tamanho de 0,6 mm ou menos, não apresentam malha de aço e normalmente são utilizadas como aditivo para modificar a resistência e a deformabilidade do solo (Benson, 1995).

Ghazavi (2004) realizou ensaios de cisalhamento para misturas de areia com migalhas com porcentagens de $0 \%$ (solo puro), 10\%, 15\%, 20\%, 50\%, 70\% e 100\% (migalhas puras), em peso. Os resultados indicaram que os parâmetros que influenciam sobre as características de resistência ao cisalhamento das misturas são a tensão normal, o peso especifico seco e o teor de borracha. Como resultado, sugeriu-se que uma adição de $10 \%$ a $20 \%$, em peso, como teor ótimo de misturas de areia-migalhas, para gerar materiais mais leves com melhores propriedades mecânicas. 


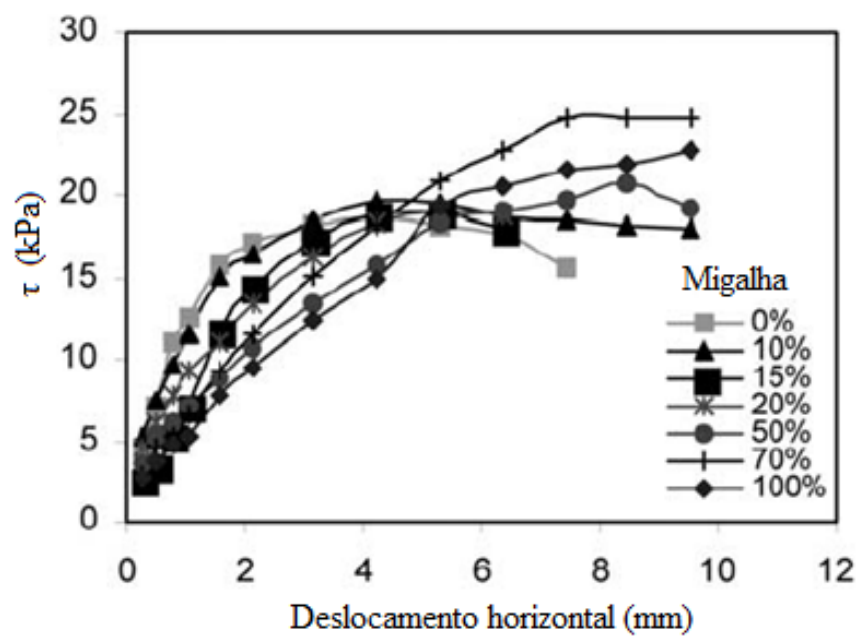

Figura 2.4.Variação da resistência ao cisalhamento vs deslocamento horizontal para misturas fofas sob uma tensão normal de $23.3 \mathrm{kN} / \mathrm{m} 2$ (Ghazavi, 2004).

Edinçliler et al. (2010) avaliaram as propriedades mecânicas de misturas de areia com migalhas de pneus em um equipamento de média escala com dimensões iguais a $300 \mathrm{~mm} \mathrm{x}$ $300 \mathrm{~mm}$. No estudo, foram empregadas misturas com 0\% (areia pura), 5\%, 10\%, 20\%, 30\% e $100 \%$ (migalhas de pneus puro) de migalhas de pneus em peso, sob tensões normais de 20, 40, e $80 \mathrm{kPa}$. Os comportamentos das misturas a tensões cisalhantes sob tensão normal de 80 kPa estão apresentados na Figura 2.5, e os resultados da pesquisa estão apresentados na Tabela 2.6. Nesta pesquisa foram avaliados diferentes parâmetros que influenciaram na resistência ao cisalhamento máxima: a tensão normal, o peso seco aparente da matriz da mistura, o teor de pneu usado, a forma e a orientação das partículas.

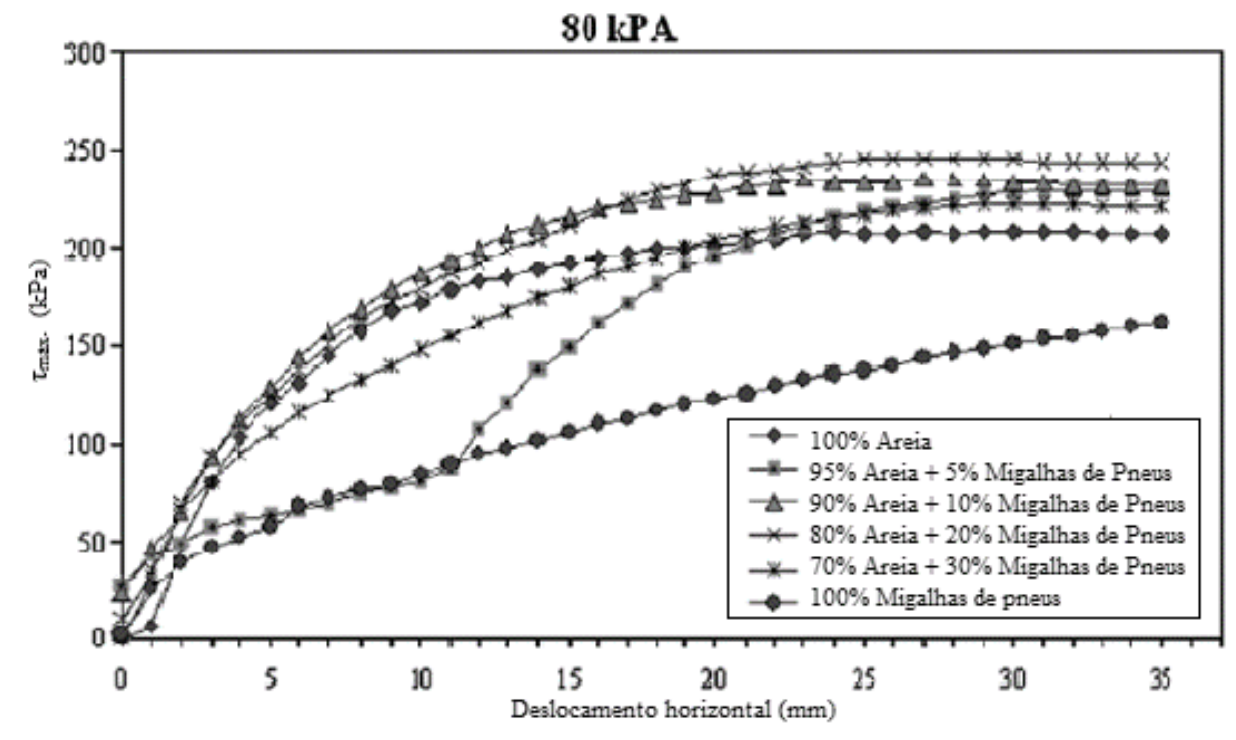

Figura 2.5. Tensão cisalhante - deslocamentos horizontais para areia, migalhas de pneus e misturas de areia com migalhas de pneus (80 kPa) (Edinçliler et al., 2010). 
Tabela 2.6. Resultados do ensaio de cisalhamento direto para areia, migalhas de pneus e misturas de areia com migalhas de pneus (Edinçliler et al., 2010).

\begin{tabular}{|c|c|c|c|}
\hline Material & $\gamma_{\text {dmáx }}(\mathbf{k N} / \mathbf{m 3})$ & $\mathbf{c}^{\mathbf{9}}(\mathbf{k P a})$ & $\left.\boldsymbol{\phi} \mathbf{(}^{\mathbf{9}}\right)$ \\
\hline 100\% Migalhas de pneus & 5,4 & 4,6 & 31 \\
\hline 100\% Areia & 13,78 & 0 & 38,7 \\
\hline 95\% Areia + 5\% Migalhas de Pneus & 13,38 & 1,3 & 41,2 \\
\hline 90\% Areia + 10\% Migalhas de Pneus & 13,02 & 0,2 & 41,4 \\
\hline 80\% Areia + 20\% Migalhas de Pneus & 12,38 & 1,1 & 42,6 \\
\hline 70\% Areia + 30\% Migalhas de Pneus & 11,85 & 1,2 & 40 \\
\hline
\end{tabular}

A partir do estudo realizado por Edinçliler et al. (2010) concluiu-se que, devido ao aumento da tensão cisalhante máxima da mistura de pneu e areia, as inclusões empregadas podem ser usadas como elementos de reforço. A partir dos testes laboratoriais empregados na pesquisa, observou-se que a adição de migalhas de pneus à areia aumentou a resistência ao cisalhamento máxima para todas as porcentagens.

Szeliga et al. (2014) apresentaram um estudo experimental do comportamento de um solo argiloso puro e misturado com migalhas de pneus inservíveis, por meio da realização de ensaios de caracterização, de compactação e triaxiais isotopicamente adensados e drenados (CID). A borracha moída foi obtida do processamento de pneus inservíveis, sendo classificada como "pó de borracha malha 20", com um diâmetro médio ( $\mathrm{D}_{50}$ ) de 1,0 mm, variando de 0,2 $\mathrm{mm}$ a 2,0 $\mathrm{mm}$. O solo tropical de origem coluvionar, por sua vez, foi retirado do campo experimental da PUC-Rio. Os ensaios foram realizados em amostras compactadas no peso especifico aparente seco máximo e na umidade ótima, com teores de migalha de pneus de 5\%, $10 \%$ e $20 \%$, em relação ao peso seco do solo. Os pesos específicos secos máximos estão apresentados na Tabela 2.7 .

Tabela 2.7. Pesos específicos secos máximos (Szeliga et al., 2014).

\begin{tabular}{|c|c|c|}
\hline Material / Mistura & $W_{\text {ot }}(\%)$ & $\gamma_{\text {dmáx }}(\boldsymbol{k N} / \mathbf{m 3})$ \\
\hline S100 & 26,3 & 15,6 \\
S95/B5 & 23,5 & 15,1 \\
S90/B10 & 23,1 & 14,7 \\
S80/B20 & 22,5 & 14,2 \\
\hline
\end{tabular}

Terminados os ensaios de compactação, foram realizados ensaios triaxiais no solo argiloso e nas misturas estabelecidas, cujos teores de migalha de pneu foram determinados em peso. 
Para cada tipo de material foram executados quatro ensaios triaxiais, sendo que os níveis de tensão confinante foram $50 \mathrm{kPa}, 100 \mathrm{kPa}, 200 \mathrm{kPa}$ e $400 \mathrm{kPa}$. Alguns resultados estão apresentados nas Figura 2.6 e na Figura 2.7.

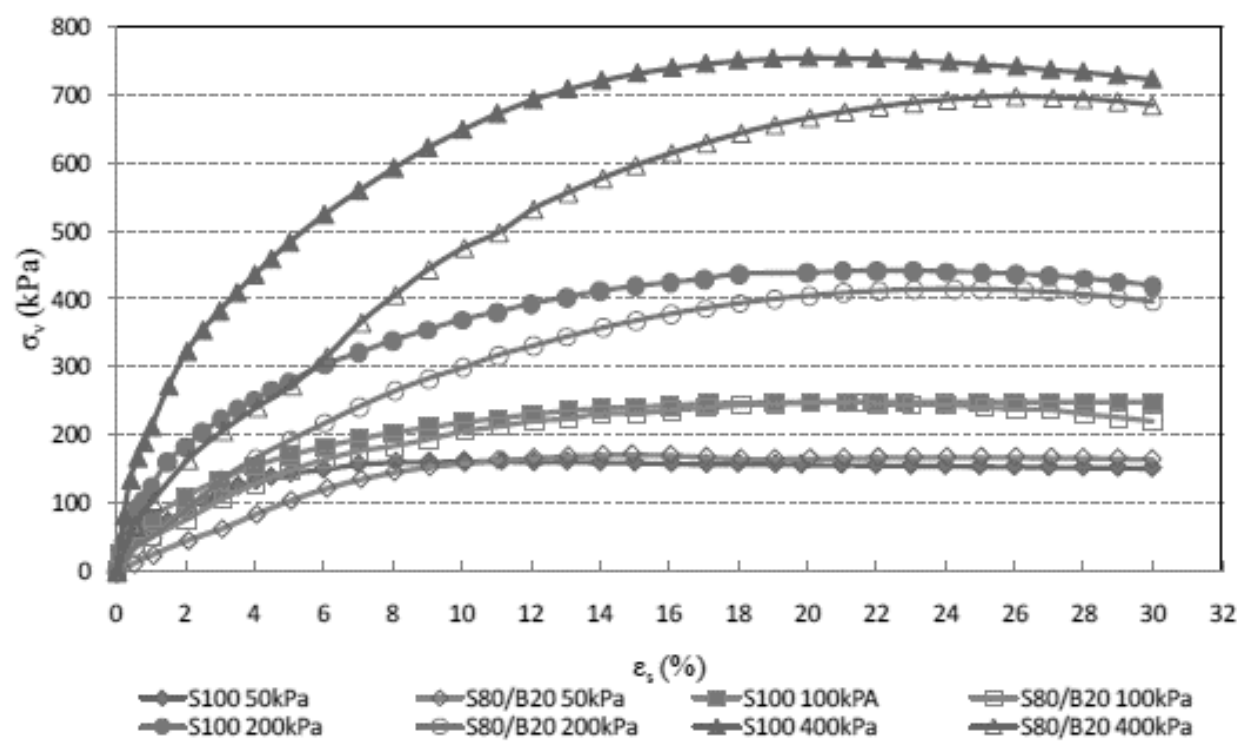

Figura 2.6. Curvas tensão-desvio vs deformação axial das amostras S100 e S80/B20 em ensaios triaxiais de compressão axial (Szeliga et al., 2014).

Os autores concluíram que os parâmetros de compactação das misturas solo argiloso-migalha são influenciados pelo teor de borracha, sendo que o peso específico aparente seco e a umidade decrescem para maiores teores de borracha. Foi observado também que o comportamento mecânico dos compósitos depende do teor de borracha inserido no solo e existe uma tendência de melhoria da resistência ao cisalhamento com o aumento do teor de borracha empregado. No entanto, a partir de certo teor a inserção de borracha, há prejuízo das propriedades do solo puro. Observou-se ainda que a tensão confinante sob a qual é cisalhado o composto influi de maneira relevante no comportamento mecânico deste e que, para tensões de confinamento excessivamente altas (>200 kPa), a resistência ao cisalhamento diminui significativamente. Segundo os autores, este fenômeno pode ser explicado pelo fato que tensões de confinamento muito altas podem restringir a dilatação do composto, a qual é necessária para mobilizar a resistência a tração da borracha. 


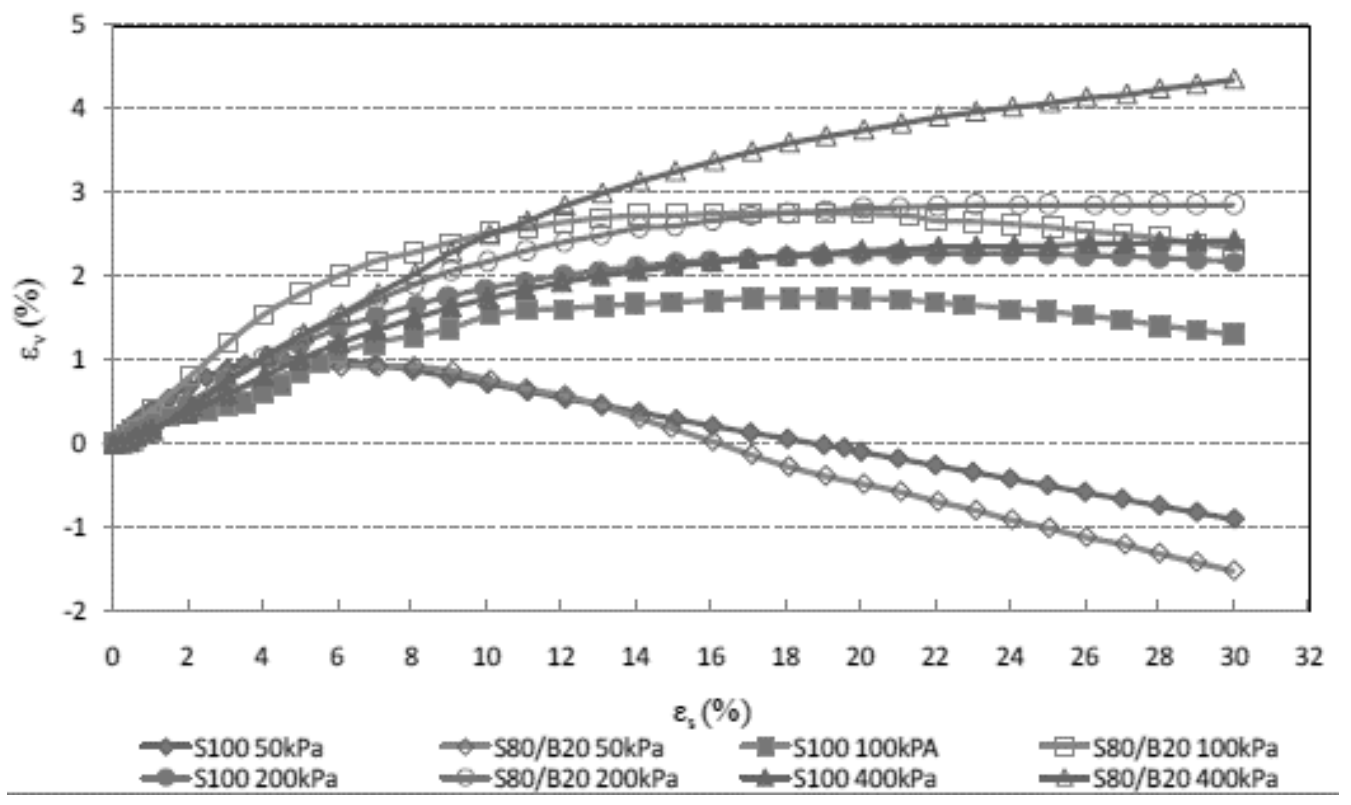

Figura 2.7. Curvas deformação volumétrica VS deformação axial das amostras S100 e S80/B20 em ensaios triaxiais de compressão axial (Szeliga et al., 2014).

\subsubsection{MELHORIA DE SOLOS USANDO DESBASTES DE PNEUS}

Os desbastes de pneus são subprodutos da indústria de recauchutagem dos pneus, sendo que seus tamanhos e formas são função do método de retirada da camada de borracha superficial do pneu. Os mesmos não apresentam malha de aço e possuem baixa resistência ao cisalhamento. Podem ser usados para modificação dos parâmetros de resistência do solo, não sendo recomendável na construção de aterros (Benson, 1995). Desbastes de pneus têm sido usados como substituto de agregado miúdo em pavimentos asfálticos. Neste processo, as partículas de borracha são adicionadas à mistura quente como um agregado fino. $\mathrm{O}$ tamanho deste tipo de material varia de aproximadamente $6,4 \mathrm{~mm}(1 / 4$ polegadas $)$ até $0,85 \mathrm{~mm}$ (peneira $\left.\mathrm{n}^{\circ} .20\right)$ (Heitzman, 1992).

Al-Tabbaa \& Aravinthan (1998) estudaram misturas de desbastes de pneus inservíveis de 1-4 $\mathrm{mm}$ e 4-8 $\mathrm{mm}$ com argila sobre-adensada, em porcentagem em peso variando entre $6 \%$ e $15 \%$, examinadas para avaliar sua utilização como componente de revestimento de aterro, em termos de compactação e resistência ao cisalhamento. 
Nos ensaios de compactação do solo puro e com teores de desbastes de pneus entre 8 e $15 \%$ de tamanho de 1-4 mm e 4-8 mm respectivamente, foi analisada a variação do peso específico seco com a variação do teor de umidade apresentado. Observou-se a diminuição do peso específico seco máximo e quase nenhuma variação no teor de umidade ótimo com a inclusão dos desbastes. Uma diminuição do peso específico aparente seco máximo era esperada, uma vez que o pneu possui menor densidade em relação ao solo. Observou-se ainda que a presença do pneu não tem efeito prejudicial na compactação da argila.

Após sua compactação, as amostras foram testadas em ensaios de compressão simples e foi concluído que a inclusão de desbastes de pneu no solo argiloso ocasionou uma diminuição considerável na resistência à compressão simples. Este comportamento também pode ser observado na Figura 2.8, onde se apresenta o comportamento da tensão desviadora vs deformação durante os testes de compressão simples. Os autores concluíram que o efeito dos fragmentos de pneus em misturas com solo depende do tamanho e da forma das partículas e que lascas de pneus podem aumentar a resistência das misturas, enquanto tamanhos menores como desbastes podem chegar a reduzi-la consideravelmente.

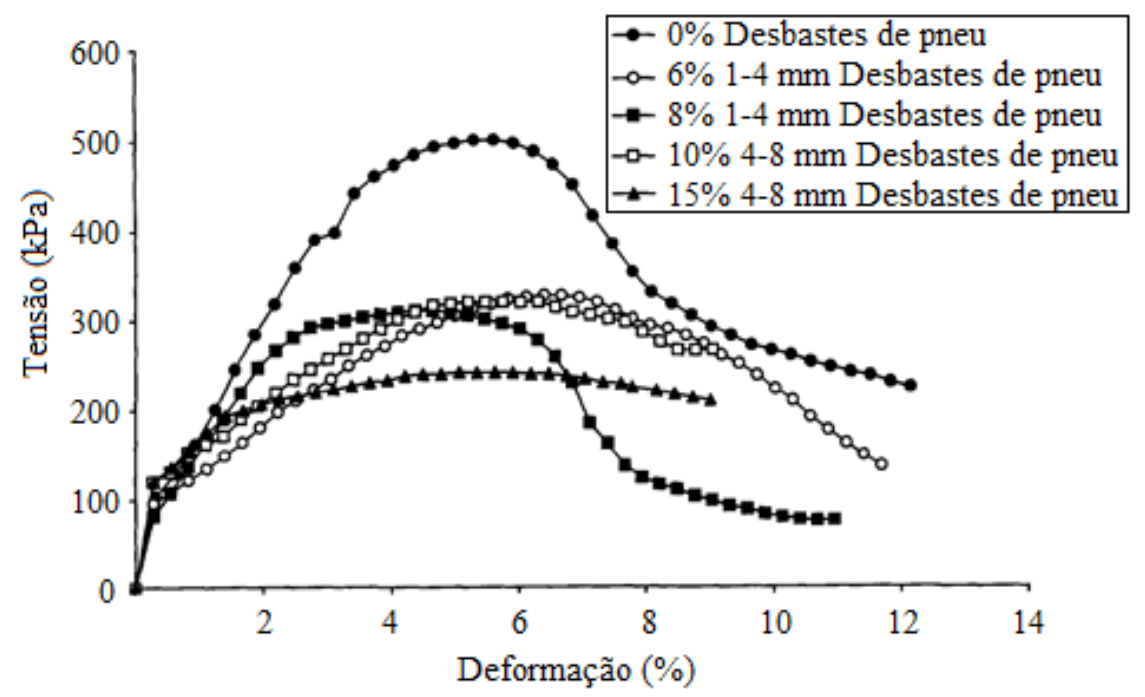

Figura 2.8. Comportamento tensão - deformação para misturas solo argiloso vs desbaste de pneu (Al-Tabbaa \& Aravinthan, 1998).

O trabalho de Edinçliler et al. (2004) foi complementado pela pesquisa de Edinçliler et al. (2007), onde foram realizados ensaios de cisalhamento direto em média escala (300 mm x 300 mm x $300 \mathrm{~mm}$ ), para comparação de parâmetros de resistência ao cisalhamento de agregados como desbastes de pneus, areia e a mistura destes dois materiais com teores de 5\%, 10\%, 20\% 
e 30\% de desbastes de pneus em peso. A areia empregada na pesquisa era uniformemente graduada, densidade média, com um peso especifico seco de $15,3 \mathrm{kN} / \mathrm{m}^{3}$. Os desbastes tinham comprimentos máximos de $40 \mathrm{~mm}$, com peso específico de $5,13 \mathrm{kN} / \mathrm{m}^{3}$. Os ensaios de cisalhamento foram realizados com tensões normais de 20, 40 e $80 \mathrm{kPa}$.

Os resultados dos testes mostraram que a adição de desbastes melhorou as propriedades mecânicas do material. O alongamento dos desbastes de pneus melhorou o grau de compatibilidade da interface de solo-pneu. Os resultados mostraram que a adição de desbastes de pneus aumentou o ângulo de atrito de $22^{\circ}$ para $29^{\circ}$ e que a coesão variou de $5,1 \mathrm{kPa}$ a 13,5 $\mathrm{kPa}$. Assim, concluiu-se que com o aumento observado da resistência ao cisalhamento das misturas de desbastes de pneus e areia, é possível sua utilização como elemento de reforço.

Ensaios deste tipo são a base para novas investigações. Franco (2012) avaliou o comportamento mecânico e hidráulico de misturas de desbastes de pneu com solo laterítico, onde os desbastes utilizados têm tamanho médio de 1,4 mm. Foram utilizadas proporções de $0 \%$ (solo puro), 10\%, 20\%, 30\%, 40\%, 50\% e 100\% (resíduo puro). Os ensaios de cisalhamento direto foram feitos em caixas de dimensões de $50 \mathrm{~mm}$ de diâmetro e $20 \mathrm{~mm}$ de altura e foram aplicadas tensões normais de $50 \mathrm{kPa}, 100 \mathrm{kPa}$, e $200 \mathrm{kPa}$ a uma velocidade de $0,05 \mathrm{~mm} / \mathrm{min}$. As envoltórias de resistência ao cisalhamento para as diferentes porcentagens são apresentados na Figura 2.9.

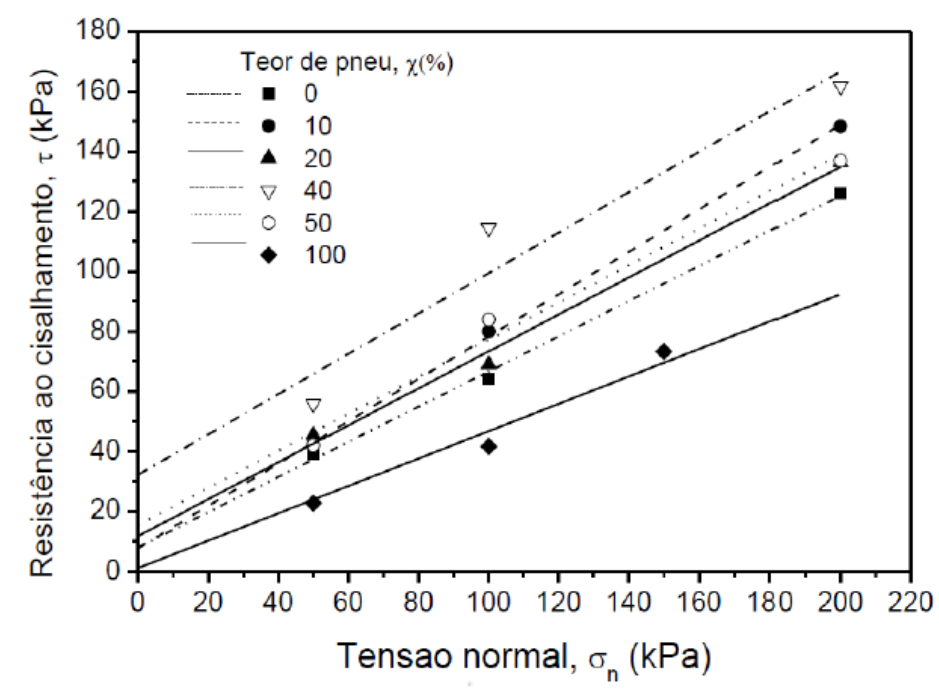

Figura 2.9. Envoltórias de resistência ao cisalhamento para diferentes porcentagens de resíduo de pneu (Franco, 2012). 
A pesquisa de Franco (2012) concluiu que a máxima resistência ao cisalhamento foi obtida para um teor de resíduo de $40 \%$ em peso, valor próximo ao teor ótimo em torno de $35 \%$ obtido por Zornberg et al. (2004). Observou-se também que o teor de pneus exerce uma influência significativa na curva de compactação do material onde, quanto o maior é o teor de pneu, menor é o peso especifico máximo atingido. Uma tendência clara não foi observada para a variação do ângulo de atrito interno com o teor de resíduo e o ângulo de atrito das misturas de 10\%, 20\%, 40\%, 50\%, porém observou-se que esse valor foi maior do que o solo puro $(0 \%)$ e do que o desbaste puro (100\%) (Figura 2.10). Finalmente, a pesquisa mostrou que, para o solo aplicado, a coesão aumenta com o aumento dos teores de desbastes utilizados, atingindo um pico para um teor ótimo de $40 \%$ e depois diminui para teores além deste valor (Figura 2.11).

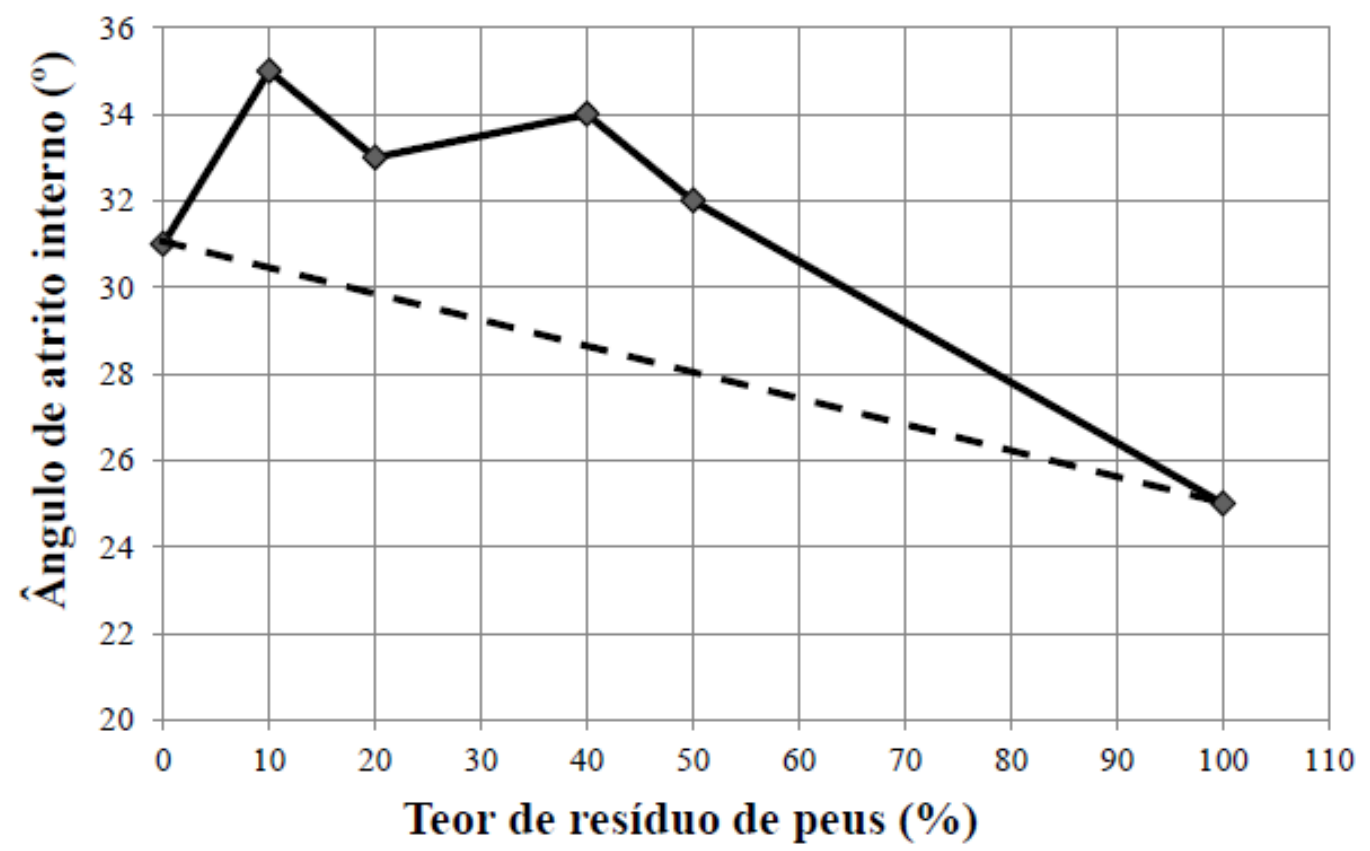

Figura 2.10. Relação teor de resíduo de pneu versus ângulo de atrito interno (Franco, 2012) 


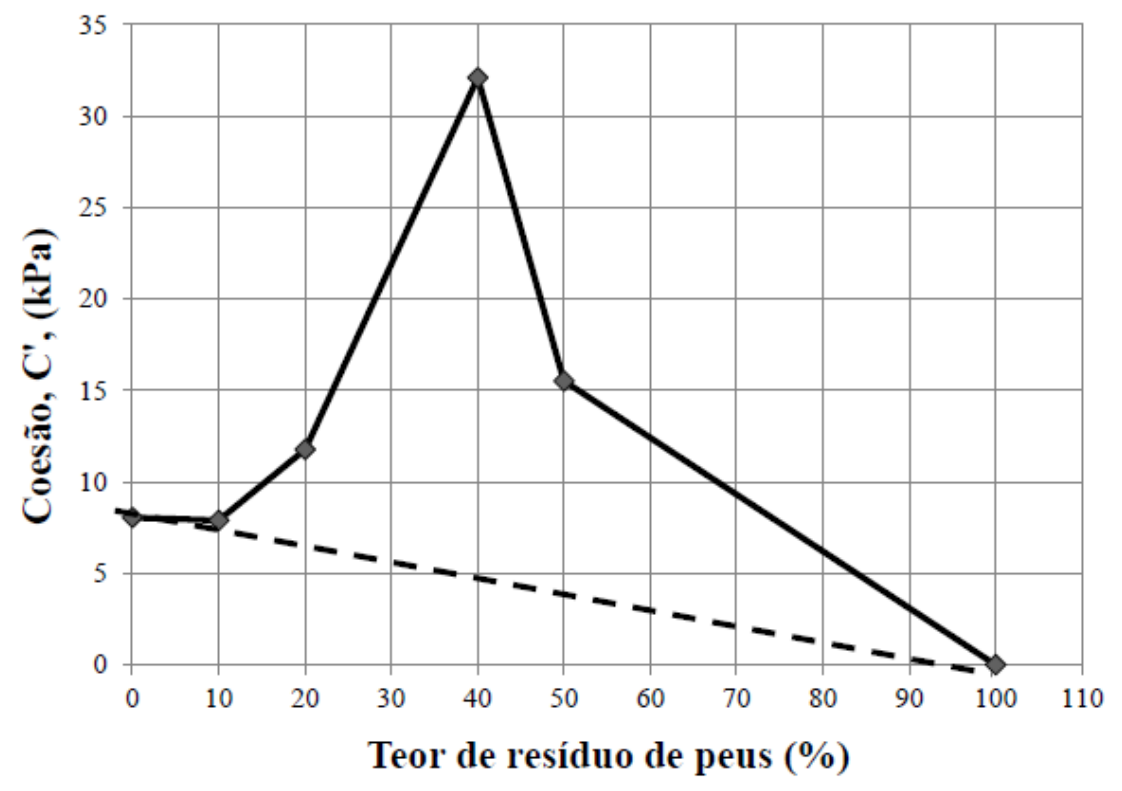

Figura 2.11. Relação teor resíduo de pneu vs coesão (Franco, 2012).

Sellaf et al. (2014) realizaram um programa experimental para estudar o efeito de desbastes de pneus sobre as propriedades geotécnicas de sedimentos dragados. Para efeitos de comparação, dois tipos de solo foram estudados: sedimentos dragados das barragens Fergoug e solo vulcânico de Tizi, no noroeste da Argélia. Tendo em conta a elevada compressibilidade e da baixa absorção de água dos fragmentos de borracha, foram feitos ensaios de análise granulométrica, limites de Atterberg, ensaios de compactação e ensaios de cisalhamento direto para os solos puros e suas misturas com lascas de pneus em teores de desbastes de pneus de 10, 20, 25 e 50\% em peso. Os resultados dos ensaios de compactação estão apresentados na Tabela 2.8.

Tabela 2.8. Pesos específicos secos máximos (Sellaf et al., 2014) .

\begin{tabular}{|l|c|c|c|c|c|c|}
\hline Teor de desbastes de pneus & $\mathbf{0 \%}$ & $\mathbf{1 0 \%}$ & $\mathbf{2 0 \%}$ & $\mathbf{2 5 \%}$ & $\mathbf{5 0 \%}$ & $\mathbf{1 0 0 \%}$ \\
\hline \multicolumn{7}{|c|}{ Peso especifico seco máximo $\gamma_{\mathbf{d} \text { máx. }}\left(\mathbf{k N} / \mathbf{m}^{3}\right)$} \\
\hline Solo sedimentário & 24,6 & 23,0 & 21,3 & 20,5 & 16,4 & \\
\hline Solo vulcânico & 25,9 & 24,1 & 22,4 & 21,5 & 17,1 & 8,3 \\
\hline
\end{tabular}

Os ensaios de cisalhamento direto foram realizados utilizando uma caixa de 60 x $60 \mathrm{~mm}$ de lado e uma altura de 50,8 mm, sob tensões normais de 100, 200, $300 \mathrm{kPa}$. Os resultados estão apresentados na Figura 2.12e na Figura 2.13. Nota-se que há um decréscimo na coesão com o 
aumento do teor de desbastes de pneus e, por outro lado, a variação do ângulo de atrito aumenta até um teor ótimo de desbastes de pneu de $10 \%$ em peso.

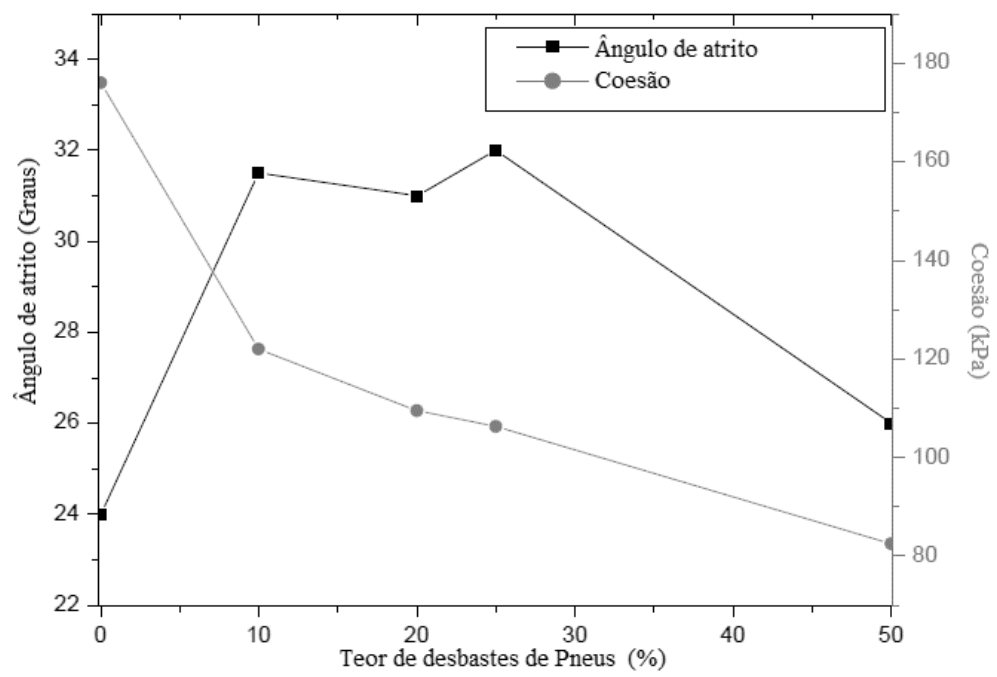

Figura 2.12. Efeito dos desbastes de pneus na coesão e no ângulo de atrito do solo sedimentário (Sellaf et al., 2014).

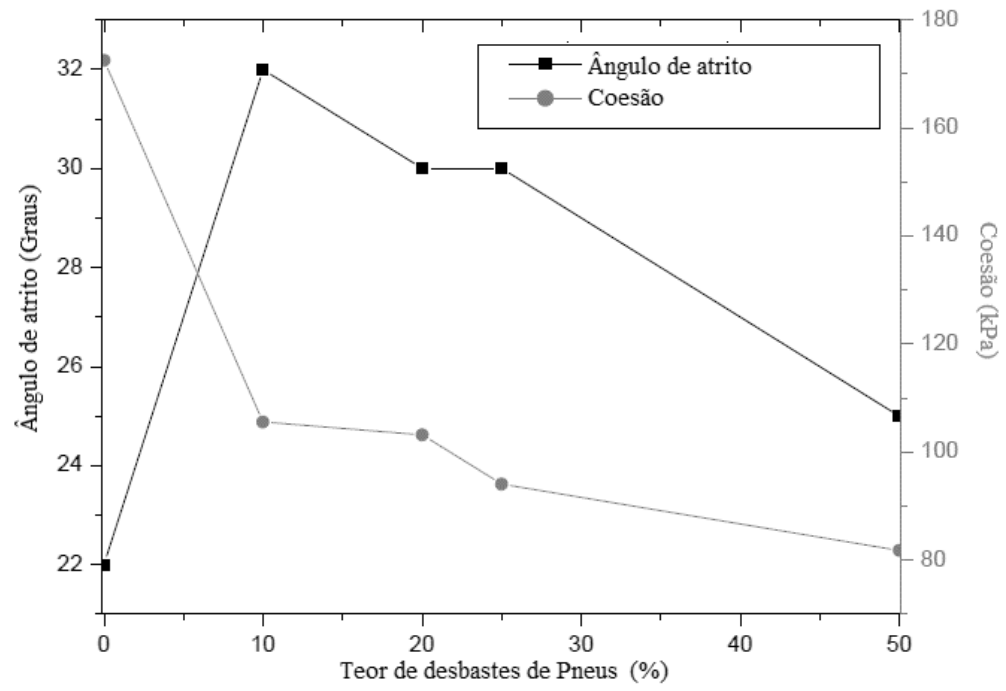

Figura 2.13. Efeito dos desbastes de pneus na coesão e no ângulo de atrito do solo vulcânico (Sellaf et al., 2014). 


\subsubsection{MELHORIA DE SOLOS USANDO LASCAS DE PNEUS}

As lascas de pneus são produto da trituração primária e secundária de pneus, com tamanho entre $4 \mathrm{~mm}$ a $20 \mathrm{~mm}$, geralmente possuindo forma cúbica e trapezoidal. Muitos estudos afirmam que ao misturar lascas de pneus ao solo pode aumentar a ductilidade do mesmo, porém reduzindo a resistência à tração. Esses materiais têm sido utilizados como material de enchimento de peso leve para construção de aterros. No entanto, os mesmos têm alta probabilidade de ocorrência de problemas de combustão (Forsyth \& Egan, 1976).

Ahmed \& Lovell (1993) investigam a viabilidade da utilização de lascas de pneus pura e misturada com solo (areia de Ottawa), como material de peso leve em aterros de rodovias. Verificou-se que as misturas de areia e lascas de pneus, até um teor de $38 \%$ de borracha, resultam em excelentes propriedades de engenharia: fácil compactação, baixa densidade seca, baixa compressibilidade, resistência ao cisalhamento elevada e excelentes características de drenagem.

Humphrey \& Sandford (1993) estudaram parâmetros de resistência mecânica por meio de ensaios de cisalhamento direto com lascas de pneus de quatro diferentes fornecedores $(\mathrm{F} \& \mathrm{~B}$ Enterprise, Palmer Shredding, Pine State Recycling e Sawyer Enviroment Rec.), onde os menores comprimentos foram de $72 \mathrm{~mm}$. Os resultados encontram-se apresentados na Figura 2.14 e na Tabela 2.9 .

Os ensaios de compressão indicaram que as lascas de pneus são altamente compressíveis durante a porção inicial do primeiro ciclo de carregamento, mas a compressibilidade mostrouse significativamente menor durante os ciclos subsequentes. A quantidade de malha de aço exposta aparentou ter algum efeito sobre as propriedades das lascas dos pneus. Grandes quantidades de malhas de aço expostas tendem a causar maior compressibilidade, durante o primeiro ciclo de carga, e menor resistência ao cisalhamento. 
Tabela 2.9. Valores do ângulo de atrito e da coesão nos ensaios de cisalhamento direto (Humphrey \& Sandford, 1993).

\begin{tabular}{|c|c|c|}
\hline Empresa & $\mathbf{c}^{\mathbf{(}} \mathbf{( k P a )}$ & $\left.\boldsymbol{\phi} \mathbf{(}^{\mathbf{0}}\right)$ \\
\hline F\&B Enterprises & 8,6 & 25 \\
\hline Palmer Shredding & 11,5 & 19 \\
\hline Pine State $(305-\mathrm{mm})$ & 7,7 & 21 \\
\hline Pine State $(406-\mathrm{mm})$ & 4,3 & 26 \\
\hline
\end{tabular}

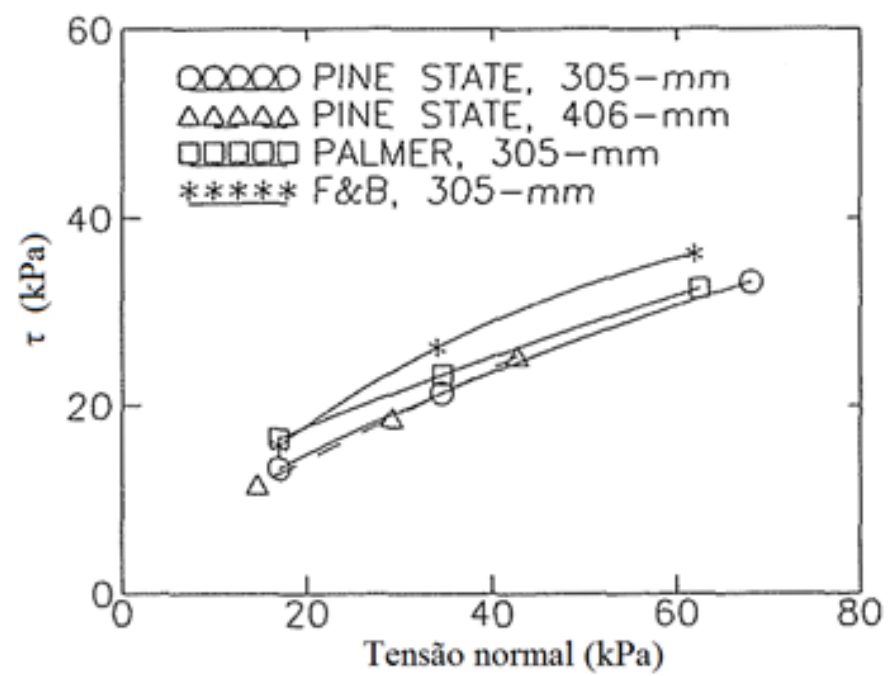

Figura 2.14. Envoltórias de ruptura das lascas de pneus (Humphrey \& Sandford, 1993).

$\mathrm{Wu}$ et al. (1997) realizaram ensaios triaxiais em lascas de pneus ( $<40 \mathrm{~mm}$ de comprimento) para determinar a resistência ao cisalhamento de cinco produtos do pneu inservíveis com diferentes gradações e formas de partículas. Os resultados experimentais mostraram que todos os produtos de pneus tinham ângulo de atrito de $45^{\circ}$ a mais de $60^{\circ}$. Estes resultados foram corroborados pela observação em campo de aterros de lascas de pneus, nos quais foi medido um ângulo de repouso variado entre $37^{\circ}$ a $43^{\circ}$ (material empilhado), podendo atingir até $85^{\circ}$ (material compactado). Sendo assim, este tipo de material pode ser útil em aplicações de engenharia de solos.

Ahmed \& Lovell (1993), Foose et al. (1996) e Tatlisoz et al. (1998) relataram que a areia e o silte podem ser reforçados usando lascas de pneus (Figura 2.15 e Figura 2.16 respectivamente). Estes estudos demonstraram que a adição de lascas de pneus aumentou a resistência ao cisalhamento da areia e o ângulo de atrito para até $65^{\circ}$, sendo os valores obtidos para misturas até uma porcentagem de $30 \%$ em peso do solo seco. 


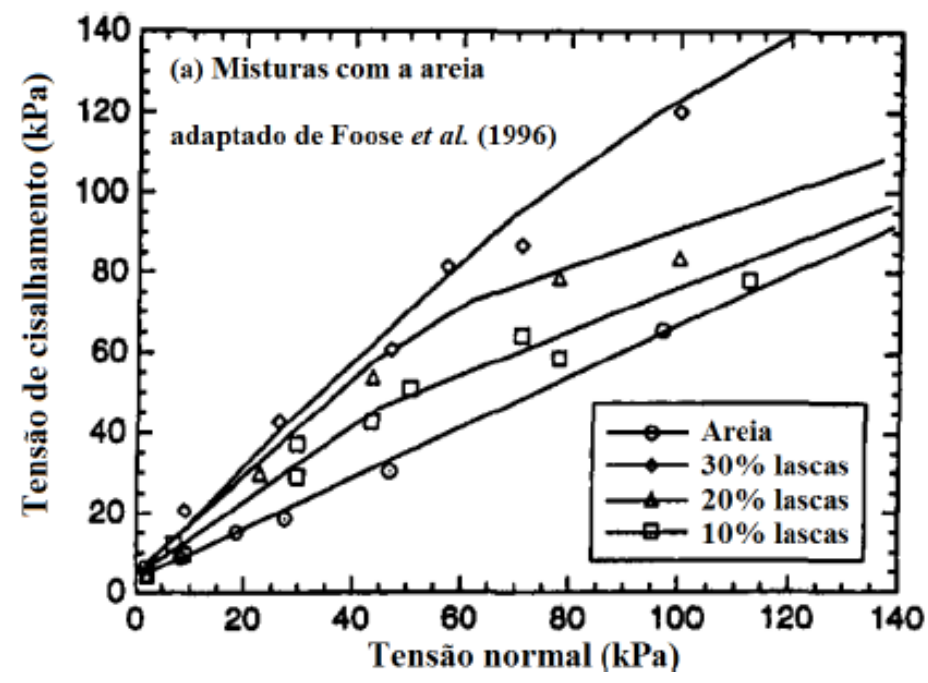

Figura 2.15. Envoltórias de ruptura para as lascas de pneu misturadas com areia (Foose et al., 1996).

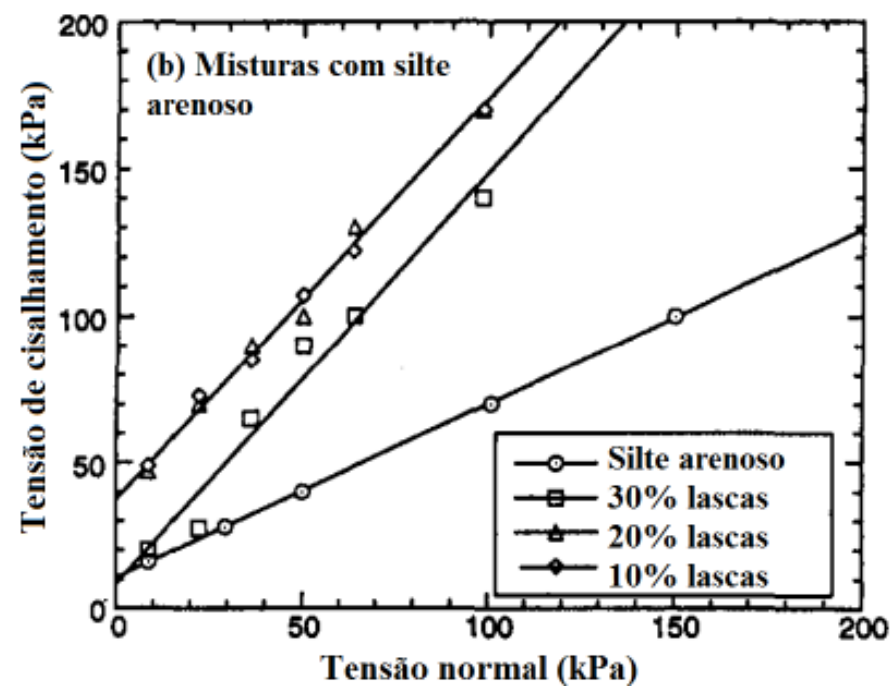

Figura 2.16. Envoltórias de ruptura para as lascas de pneus misturadas com silte (Tatlisoz et al., 1998).

Dando continuidade na pesquisa realizada por Ghazavi (2004), Ghazavi et al. (2011) avaliam as propriedades de lascas de pneus e de misturas de areia e lascas com geossintéticos por meio de ensaios de arrancamento e de cisalhamento. Foram estudados os parâmetros de resistência ao cisalhamento na interface de lascas de pneus, areia e geogrelha, utilizando um equipamento de cisalhamento direto de dimensões de $300 \mathrm{~mm}$ x $300 \mathrm{~mm}$. As porcentagens utilizadas na pesquisa foram de $0 \%$ (solo puro), 15\%, 25\%, 30\%, 35\% e 100\% (lasca pura), em relação ao peso. Este equipamento tem uma capacidade máxima de carga de $50 \mathrm{kN}$, e está ligado a uma célula de carga de $50 \mathrm{kN}$ de capacidade, sendo as deformações controladas por meio de transdutores de deslocamento. 
O solo testado foi areia, com um coeficiente de uniformidade de 1,62, um coeficiente de curvatura de 1,38 e uma densidade específica de 2,67. Utilizando esses valores, o solo foi classificado pela USC como SP. O ângulo de atrito da areia para uma densidade de 14 $\mathrm{kN} / \mathrm{m}^{3}$ foi $30,2^{\circ}$. As lascas utilizadas no estudo são produto da trituração de pneus inservíveis, sendo sua gravidade específica sem malha de aço igual a 1,20. Além disso, foi utilizada uma geogrelha de $12 \mathrm{~mm}$ de abertura, $3 \mathrm{~mm}$ de espessura, $340 \mathrm{~g} / \mathrm{m}^{2}$ massa por unidade de área e $4,68 \mathrm{kN} / \mathrm{m}$ de resistência a tração.

Para os testes, baseados nas experiências de Foose et al. (1996) e de Ghazavi (2004), houve cuidado de distribuir as lascas aleatoriamente nas misturas, tanto quanto fosse possível. A mistura foi controlada por meio de observação visual. Todos os testes foram realizados até um deslocamento de corte de $25 \mathrm{~mm}$, aplicando-se tensões normais de $20 \mathrm{kPa}, 30 \mathrm{kPa}, 60 \mathrm{kPa}$ e $90 \mathrm{kPa}$.A velocidade de corte selecionada para todos os testes foi de $1 \mathrm{~mm} / \mathrm{min}$, sendo todas as amostras testadas sob condições de deformação controlada.

Os ensaios de cisalhamento direto foram realizados em misturas de areia com lascas de pneus para avaliar os parâmetros de resistência, como coesão (c'), ângulo de atrito $(\phi)$ e os parâmetros de resistência da interface entre geogrelha e misturas de areia com lascas de pneus (aderência "ca" e ângulo de atrito na interface " $\delta ")$.

Nas Figura 2.17 e Figura 2.18 estão apresentadas as curvas de tensão cisalhante vs o deslocamento e a variação do deslocamento vertical vs deslocamento horizontal, para misturas de areia com lascas de pneus, sob tensão normal de $90 \mathrm{kPa}$. Com o aumento da porcentagem do teor de lascas de pneus ocorreu o aumento da tensão de cisalhamento.

Na Figura 2.19 está apresentada a variação da tensão máxima de cisalhamento com o aumento do teor de lascas de pneus. Observa-se que a resistência ao cisalhamento aumenta com o aumento do teor de lasca de pneus, até um volume ótimo de $30 \%$ e que, após deste valor, a resistência ao cisalhamento diminui, especialmente sob altas tensões normais.

O comportamento do ângulo de atrito do pneu com o aumento do teor de lascas de pneus pode ser observado na Figura 2.20 O ângulo de atrito cresce com o aumento do teor de lascas de pneus até atingir um valor máximo para um teor em torno de $30 \%$ e, em seguida, o atrito diminui para teores maiores. 


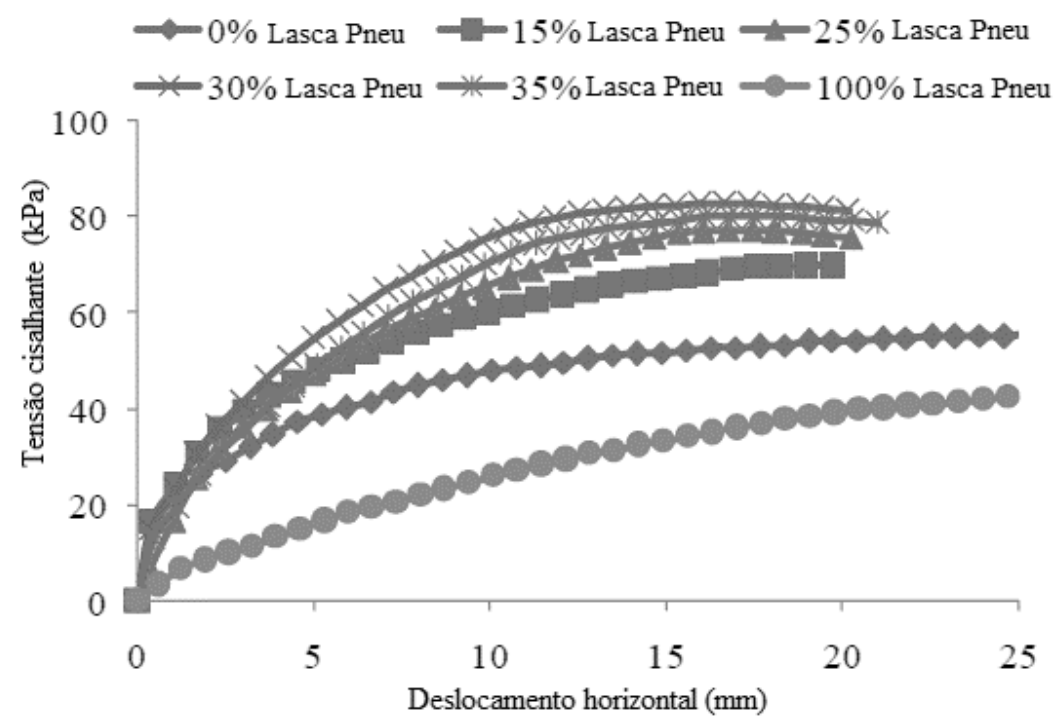

Figura 2.17. Curvas tensão cisalhamento $v s$ deslocamento horizontal para tensão normal de 90 $\mathrm{kPa}$ (Ghazavi et al., 2011).

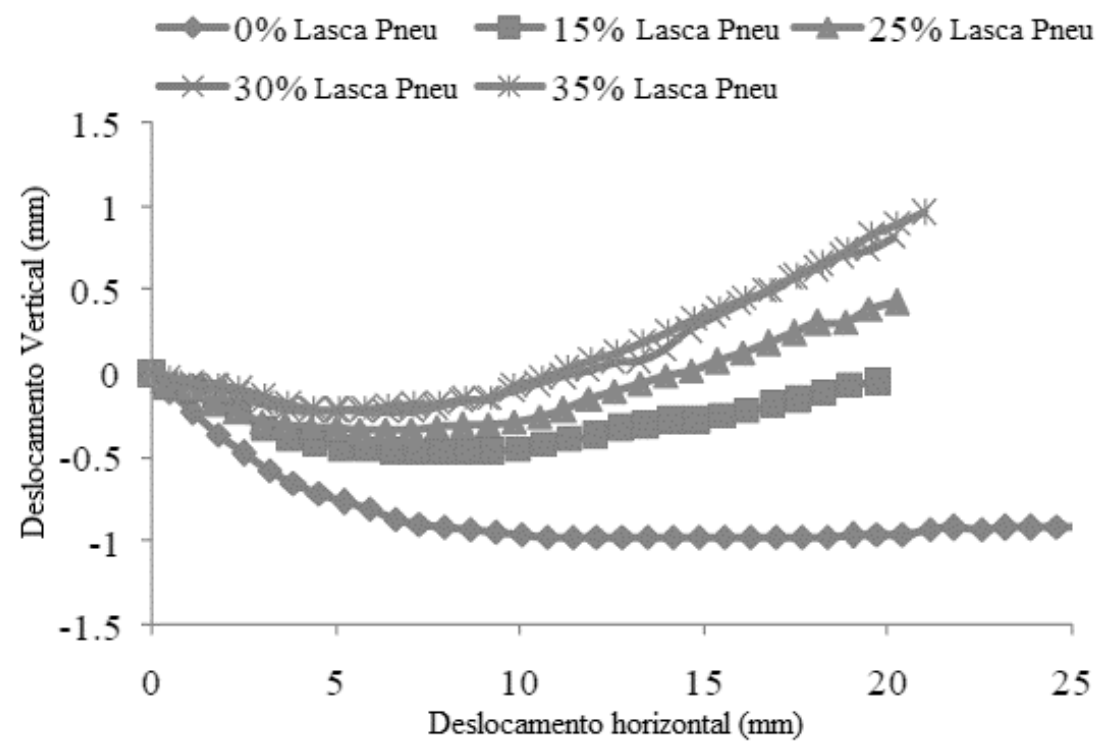

Figura 2.18. Curvas de deslocamento vertical vs deslocamento horizontal para tensão normal de $90 \mathrm{kPa}$ (Ghazavi et al., 2011).

A variação do ângulo de atrito $(\phi)$ e da coesão (C') foram calculadas traçando envoltórias de ruptura de Morh-Coulomb. Também foi calculado um ângulo de atrito equivalente $\left(\phi_{\mathrm{eq}}, \delta_{\mathrm{eq}}\right)$, considerando-se a coesão como zero. Na Tabela 2.10 está apresentado o ângulo de atrito das misturas de areia com lascas de pneus e o ângulo de atrito das misturas na interface com a geogrelha. 


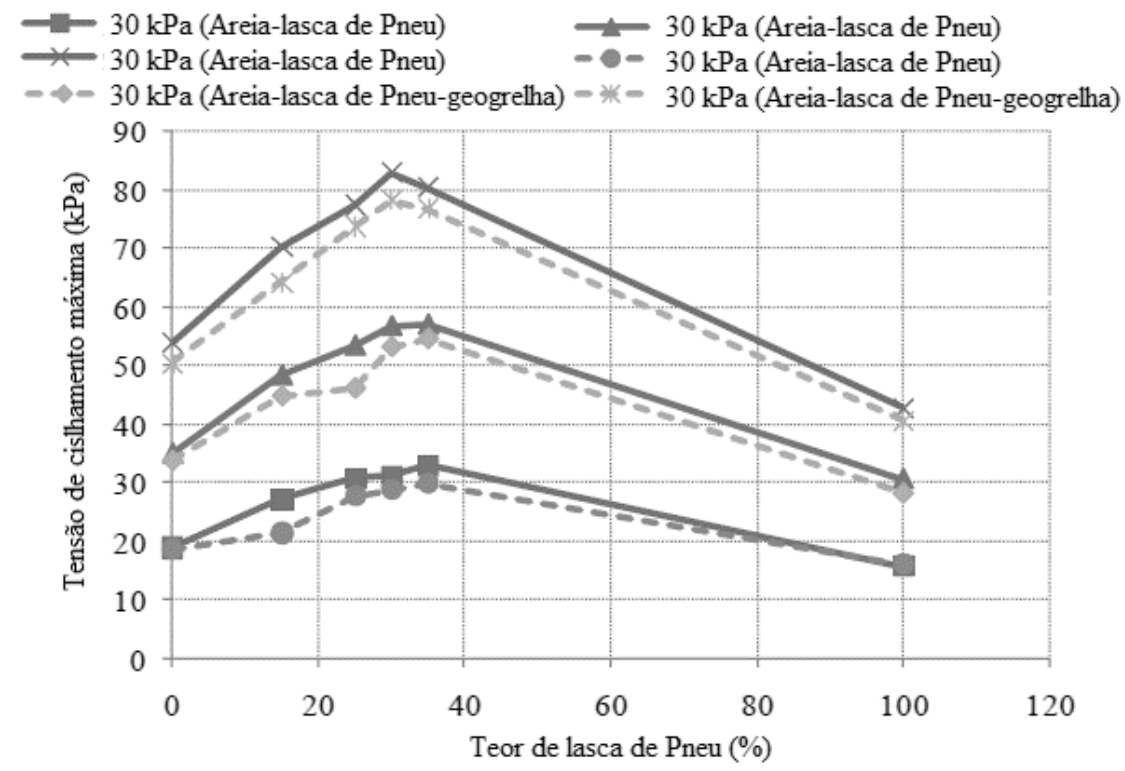

Figura 2.19. Variação da máxima tensão de cisalhamento vs teor de lascas de pneus (Ghazavi et al., 2011).

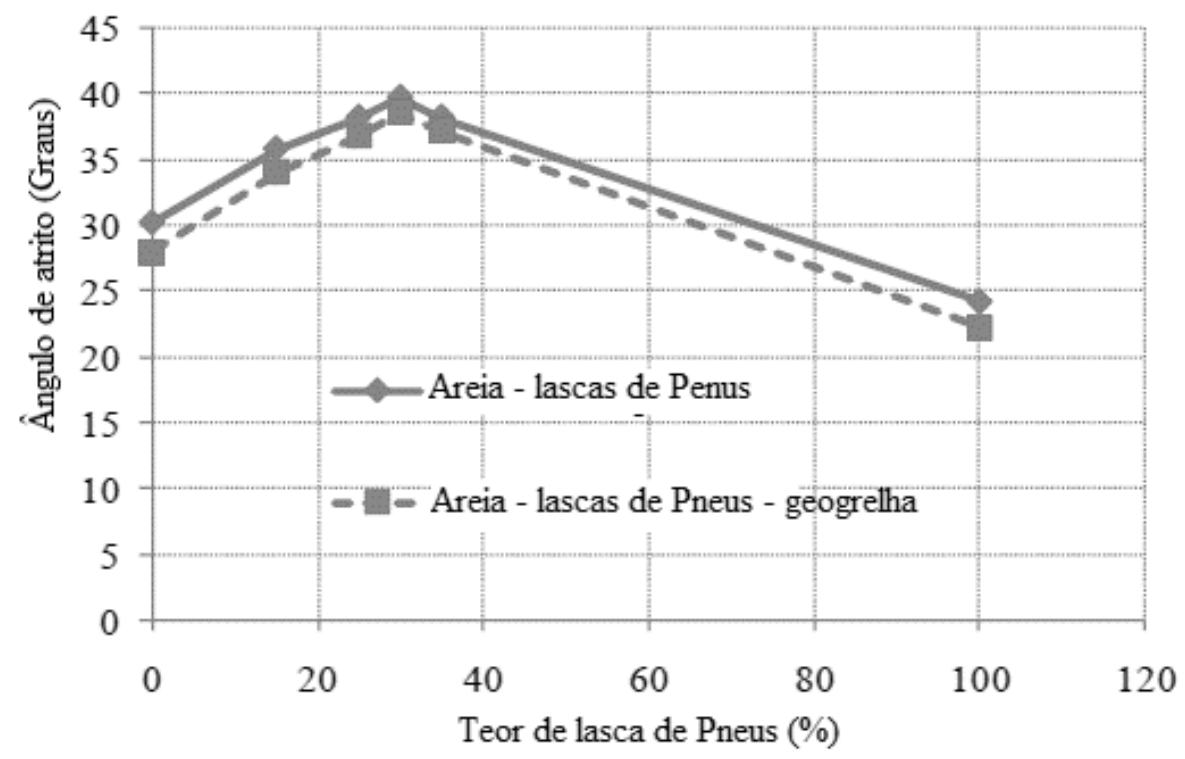

Figura 2.20. Variação do ângulo de atrito vs teor de lascas de pneus (Ghazavi et al., 2011).

Baseando-se nos resultados sob a mesma tensão normal, Ghazavi et al. (2011) concluíram que a resistência ao cisalhamento das lascas de pneus misturados com areia é maior que a resistência ao cisalhamento da areia pura. Além disso, a resistência ao cisalhamento aumenta com o aumento do teor até um valor de $30 \%$. Após este valor a resistência da mistura diminui, especialmente sob tensões normais altas. Esta tendência é similar aos resultados apresentados por Humphrey \& Sandford (1993) e Foose et al. (1996). Também foram observados comportamentos dilatantes em misturas de lascas de pneus e areia e em misturas de lascas de pneus e areia com interface de geogrelha. A dilatação apresentou diminuição, especialmente 
em amostras com maior teor de lascas de pneus. Notou-se ainda que a relação do ângulo de atrito de interface com o ângulo de atrito interno das misturas de areia e lascas de pneu (Tan $\delta$ / Tan $\phi$ ) aumentou com a elevação do teor das lascas de pneus.

Tabela 2.10. Parâmetros de resistência das misturas de areia e de lascas de pneus das interfaces com geogrelha (Ghazavi et al., 2011).

\begin{tabular}{|c|c|c|c|c|c|c|c|}
\hline \multirow[t]{2}{*}{ Material } & \multirow[t]{2}{*}{ Parâmetro } & \multicolumn{6}{|c|}{$\begin{array}{c}\text { Porcentagem de lascas de pneus (\% pelo } \\
\text { volume) }\end{array}$} \\
\hline & & $\mathbf{0}$ & 15 & 25 & 30 & 35 & 100 \\
\hline Areia - lascas de pneu & $\begin{array}{c}\mathrm{C}^{\prime}(\mathrm{kPa}) \\
\phi \text { (graus) } \\
\phi_{\mathrm{eq}} \text { (graus) }\end{array}$ & $\begin{array}{c}0,8 \\
30,2 \\
30,7\end{array}$ & $\begin{array}{c}5,1 \\
35,8 \\
38,4\end{array}$ & $\begin{array}{c}6,8 \\
38,2 \\
41,3\end{array}$ & $\begin{array}{c}7,3 \\
39,7 \\
43\end{array}$ & $\begin{array}{c}9,4 \\
38,2 \\
42,6\end{array}$ & $\begin{array}{c}2,5 \\
24,2 \\
25,9\end{array}$ \\
\hline $\begin{array}{c}\text { Areia - lascas de pneu interface } \\
\text { com geogrelhia }\end{array}$ & $\begin{array}{c}\mathrm{C}^{\prime}(\mathrm{kPa}) \\
\phi \text { (graus) } \\
\phi_{\mathrm{eq}} \text { (graus) } \\
\text { Tan } \delta_{\mathrm{eq}} / \text { Tan } \phi_{\mathrm{eq}}\end{array}$ & $\begin{array}{c}2,3 \\
27,9 \\
29,2 \\
0,94\end{array}$ & $\begin{array}{c}3,3 \\
34 \\
35,9 \\
0,9\end{array}$ & $\begin{array}{c}4,5 \\
36,7 \\
39 \\
0,92\end{array}$ & $\begin{array}{c}5,8 \\
38,5 \\
41,4 \\
0,94\end{array}$ & $\begin{array}{r}8,3 \\
37,2 \\
41,4 \\
0,96\end{array}$ & $\begin{array}{c}3,7 \\
22,2 \\
24,7 \\
0,94\end{array}$ \\
\hline
\end{tabular}

Cetin et al. (2006) estudaram as propriedades geotécnicas de lascas de pneus de granulometria fina e grossa e suas misturas $(10,20,30,40$ e 50\% em relação ao peso) com um solo argiloso coesivo (tipo CL). As misturas formam analisadas através de ensaios mecânicos, a fim de avaliar possibilidade de uso como material de enchimento de peso leve.

Foram determinados, por meio de ensaios de compactação, a porcentagem de umidade ótima (Wót) e os pesos específicos secos máximos $\left(\gamma_{\text {smáx }}\right)$ para o solo argiloso puro e para todas suas misturas, tanto para lascas com granulometria grossa como fina. Os resultados estão apresentados na Figura 2.21. Para o solo argiloso sozinho, o peso específico seco máximo de $15,79 \mathrm{kN} / \mathrm{m}^{3}$ foi obtido na umidade ótima de $19 \%$. Os pesos específicos secos para ambas misturas de lascas de pneus, de granulometria fina e grossa, diminui à medida que o teor de lascas aumenta. Os resultados indicam que os pesos específicos secos das misturas de solo argiloso com lascas são menores que os pesos específicos secos típicos de solos argilosos, incluindo o solo argiloso estudado nesta pesquisa. Esses valores mostram um bom potencial para utilização deste tipo de misturas como material de enchimento leve. 


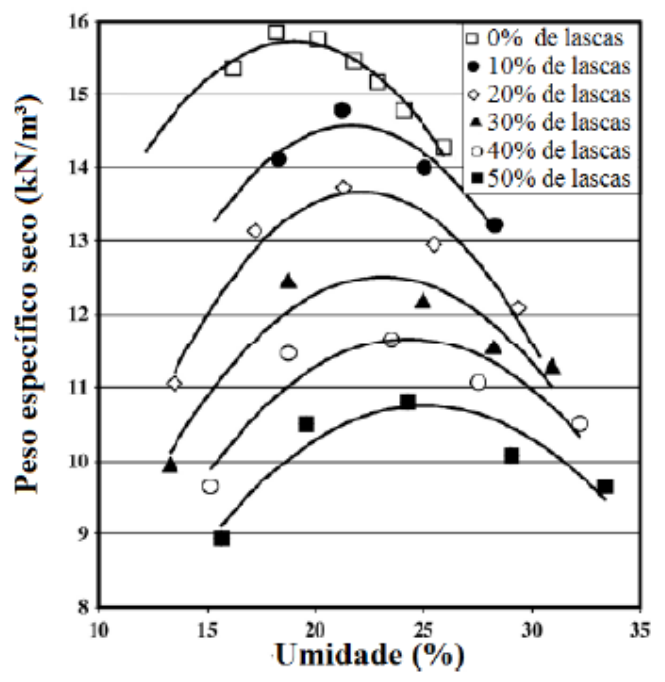

(a)

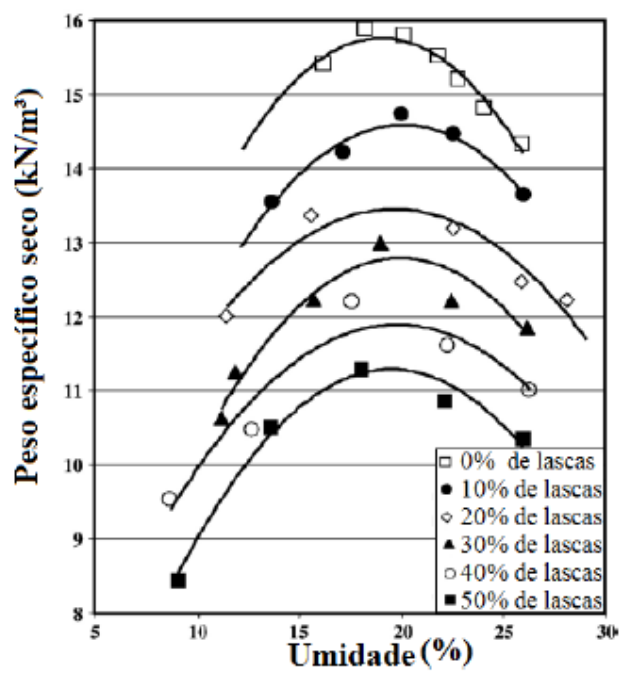

(b)

Figura 2.21. Curvas de compactação da argila e das misturas com lascas de pneus de granulometria (a) fina, e (b) grossa (Cetin et al., 2006).

Foram feitos ensaios de cisalhamento direto em condições consolidadas e não drenadas (CU), com a finalidade de determinar a resistência ao cisalhamento e as deformações volumétricas do solo argiloso puro e também para cada uma das misturas de solo com lascas de pneus (tanto finas e grossas), sob diferentes pressões de confinamento. Na pesquisa feita por Cetin et al. (2006) observou-se que quase todas as amostras apresentam um comportamento de endurecimento, ou seja, as mesmas não apresentaram picos pronunciados (pontos de falha) sobre as curvas de tensão cisalhante em relação ao deslocamento horizontal. Nestes casos, sugere-se 10-20\% de deformação de cisalhamento, deve no ser tomado como ponto de tensão cisalhante máxima (ASTM D 3080/98). Assim, a tensão de cisalhamento máxima foi encontrada tomando a deformação de $15 \%$ (este caso $9 \mathrm{~mm}$ ).

As tensões de ruptura em relação ao teor de lascas de pneus (grossos e finos) estão mostradas na Figura 2.22, onde existe um claro aumento nas tensões ruptura até 30\% para misturas de solo argiloso com lascas de pneus, de granulometria fina, e de $20 \%$ para as misturas de solo argiloso com lascas de pneus de granulometria grossa. Além disso, as forças de cisalhamento aumentaram à medida que foram elevadas as tensões normais. Na Figura 2.23 apresenta-se a variação da coesão com o aumento do teor de lascas de pneus, mostrando-se um aumento deste parâmetro até um valor de $40 \%$ de teor, para ambas as misturas, finas e grossas, enquanto existe uma redução do ângulo de atrito (Figura 2.24). Em outras palavras, caso o 
teor aumente, as misturas vão ter aumento na coesão e diminuição do ângulo de atrito, até um teor de $40 \%$. A partir de $40 \%$ adiante, enquanto a coesão diminui, o ângulo de atrito aumenta.

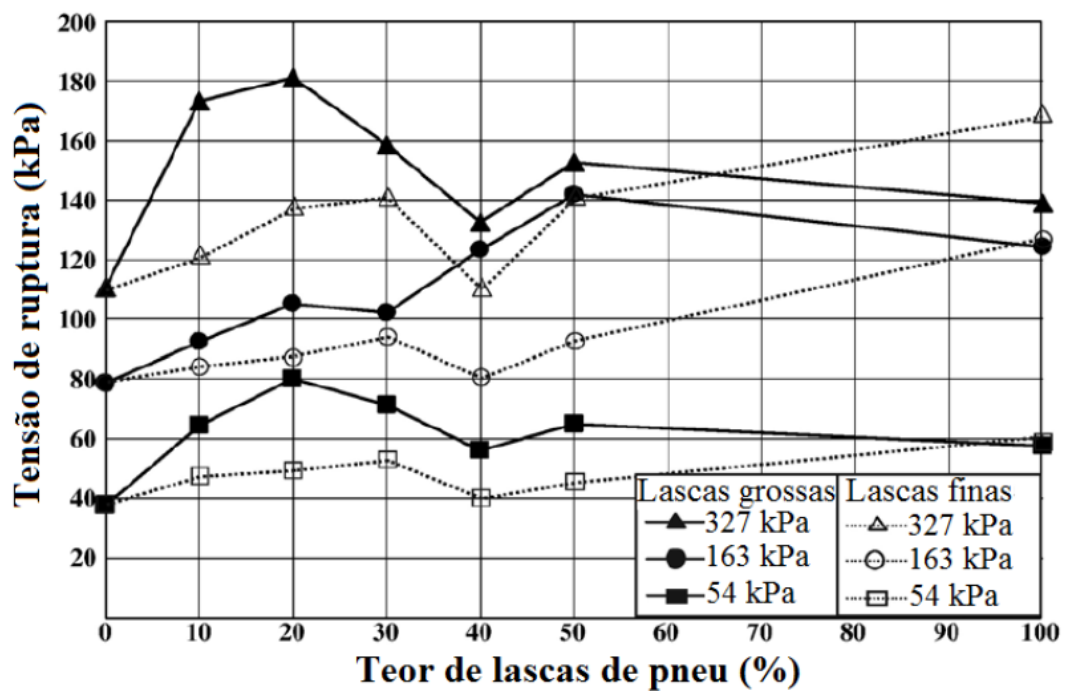

Figura 2.22. Relação entre teor de borracha e as tensões de ruptura para as misturas de lascas de pneu e solo argiloso (Cetin et al., 2006).

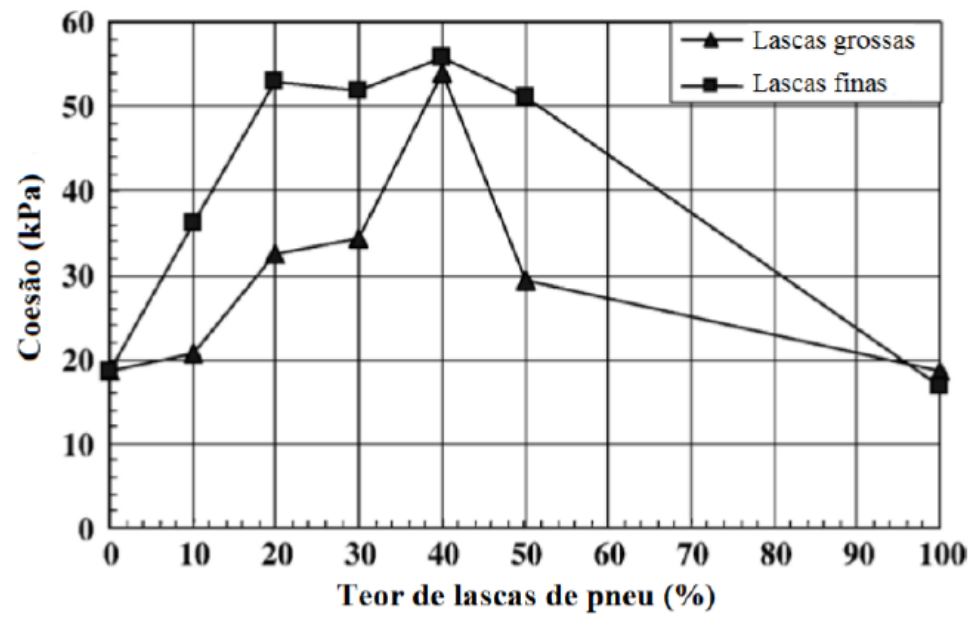

Figura 2.23. Relação entre teor de borracha e a coesão das misturas de lascas de pneu e solo argiloso (Cetin et al., 2006).

Finalmente, os resultados indicam que as misturas, até um teor de $20 \%$ para granulometrias grossas e de $30 \%$ para granulometrias finas, podem ser usadas acima de águas subterrâneas onde o baixo peso, baixa permeabilidade e alta resistência são requisitos necessários, em obras tais como aterros de rodovias, juntas de pontes, e aterros atrás de estruturas de contenção, especialmente quando estes vão ser construídos sobre solos moles com baixa capacidade de suporte. 


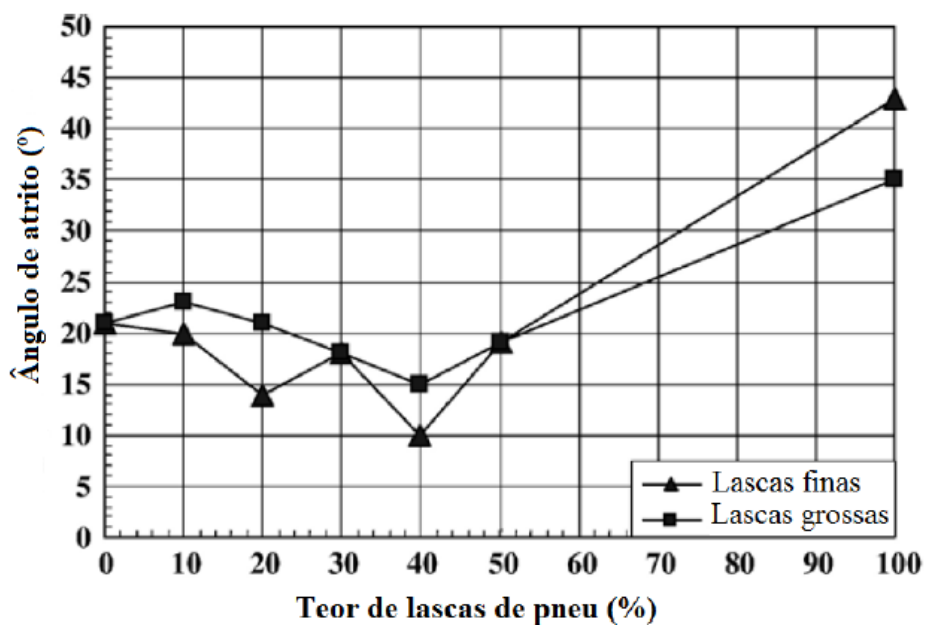

Figura 2.24. Relação entre teor de borracha e do ângulo de atrito para as misturas de lascas de pneu e solo argiloso (Cetin et al., 2006).

\subsubsection{MELHORIA DE SOLOS USANDO PEDAÇOS DE PNEUS}

Os pedaços de pneus são produtos da trituração primária e secundária de pneus, sendo que o tamanho dos mesmos varia entre $20 \mathrm{~mm}$ e $100 \mathrm{~mm}$. Além disso, os mesmos apresentam baixo peso especifico $\left(2,4\right.$ e $\left.7,0 \mathrm{kN} / \mathrm{m}^{3}\right)$, alta permeabilidade $(0,75$ a $2,0 \mathrm{~cm} / \mathrm{s})$ e são normalmente utilizados na construção de aterros leves e de sistemas de drenagem. No entanto, os mesmos possuem alta probabilidade de ocorrência de problemas de combustão (Forsyth \& Egan, 1976).

Bosscher et al. (1992) é complementado por Bosscher et al. (1994), os quais avaliaram as propriedades em engenharia de misturas de pedaços de pneus com solo, a fim de eliminar a necessidade de descarte de pneus em aterros, mitigando assim eventuais problemas de instabilidade decorrentes do peso mais leve de pneus e também reduzindo o uso de agregados naturais valiosos. Foram realizados trabalhos de coleta de material com tamanho médio de 50 a $75 \mathrm{~mm}$, com densidade específica média de 1,25. Cinco solos diferentes foram usados em misturas com os pedaços de pneus, sendo constituídos basicamente por areias bem gradadas e limpas, sendo realizados os correspondentes ensaios de compactação de cada um dos materiais. 
Devido ao tamanho do pedaço da borracha, Bosscher et al. (1994) construíram um equipamento de cisalhamento direto de grande escala, sendo o mesmo constituído por dois anéis de cisalhamento de $305 \mathrm{~mm}$ de diâmetro. Assim foram ensaiadas amostras com as proporções apresentadas na Tabela 2.11 .

Tabela 2.11. Parâmetros dos espécimes para ensaio de cisalhamento direto(Bosscher et al., 1994).

\begin{tabular}{|c|c|c|}
\hline $\begin{array}{c}\text { Relação mistura por peso } \\
\mathbf{W}_{\text {bor: }}: \mathbf{W}_{\text {solo }}\end{array}$ & $\begin{array}{c}\text { Relação mistura por Volume } \\
\mathbf{V}_{\text {bor }}: \mathbf{V}_{\text {solo }}\end{array}$ & Peso específico $\left(\mathbf{k N} / \mathbf{m}^{\mathbf{3}}\right)$ \\
\hline $0: 100$ & $0: 100$ & 17,0 \\
$4: 96$ & $6: 94$ & 17,1 \\
$8,8: 91,2$ & $13: 87$ & 16,8 \\
$15: 85$ & $21: 79$ & 16,6 \\
$25: 75$ & $35: 65$ & 16,0 \\
\hline
\end{tabular}

Na Figura 2.25 estão apresentadas as curvas de tensão cisalhante $v s$ deslocamento horizontal para uma mistura de 25:75 ( $\mathrm{W}_{\text {bor: }} \mathrm{W}_{\text {solo) }}$. As curvas têm um comportamento típico e o valor da tensão máxima de cisalhamento aumenta com o aumento da tensão normal. Na Figura 2.26 estão apresentadas as envoltórias de ruptura do material puro denso, do material puro fofo e da mistura do material numa proporção de 25:75. Como resultado se observa que a adição de mais de $10 \%$ de pedaços de pneus no solo aumenta a resistência ao cisalhamento do material e que a resistência obtida na mistura 25:75 chega a ser maior que a resistência ao cisalhamento da areia densa em tensões normais baixas ou moderadas. No entanto, no nível de tensão normal mais elevado $(76 \mathrm{kPa})$ o efeito dos pedaços de pneus na força de cisalhamento não foi tão relevante, independentemente do teor.

A influência do reforço no solo depende da presença e da orientação dos pedaços de pneus no plano de ruptura, uma vez que existe aleatoriedade na localização dos fragmentos. Assim, Bosscher et al (1994), realizaram testes da influência do número e da orientação dos fragmentos em relação ao plano de ruptura. Na Figura 2.27 está apresentado um esquema do ensaio realizado, comparando resistências ao cisalhamento em planos de ruptura que sofrem interferência dos fragmentos de pneus orientados verticalmente (5 fragmentos e 10 fragmentos). Os resultados destes testes estão apresentados na Figura 2.28, onde se observa que os solos reforçados têm maior resistência que o solo arenoso denso. $\mathrm{Na}$ intrusão de 5 fragmentos orientados verticalmente, o efeito do reforço é evidente, mas não tão significativo, a força de cisalhamento resultante é comparável ao da areia densa, embora a unidade o peso 
específico é um pouco menor $\left(17,3 \mathrm{kN} / \mathrm{m}^{3}\right.$ contra $\left.17,6 \mathrm{kN} / \mathrm{m}^{3}\right)$. Resultados mais significativos foram observados na intrusão de 10 fragmentos de borracha orientados verticalmente no plano de ruptura, causando um aumento na resistência ao cisalhamento de até $40 \%$, comparando-se os valores de resistência da areia densa.

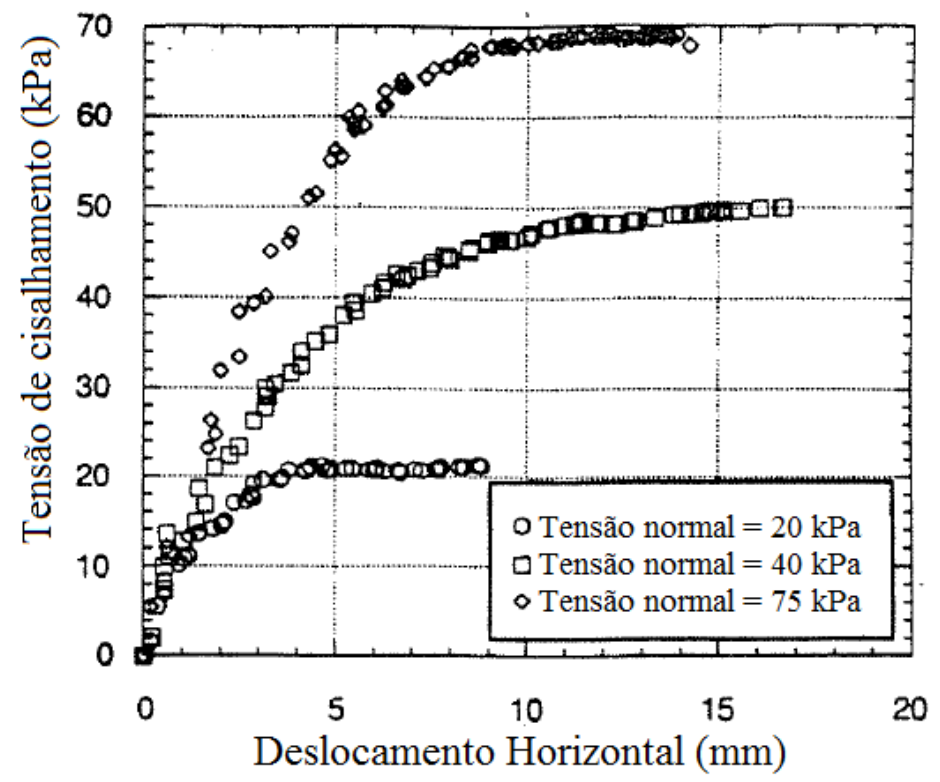

Figura 2.25. Resultados do ensaio de cisalhamento direto para uma mistura 25:75 de pedaços de pneu e de areia ,sob diferentes tensões normais (Bosscher et al., 1994).

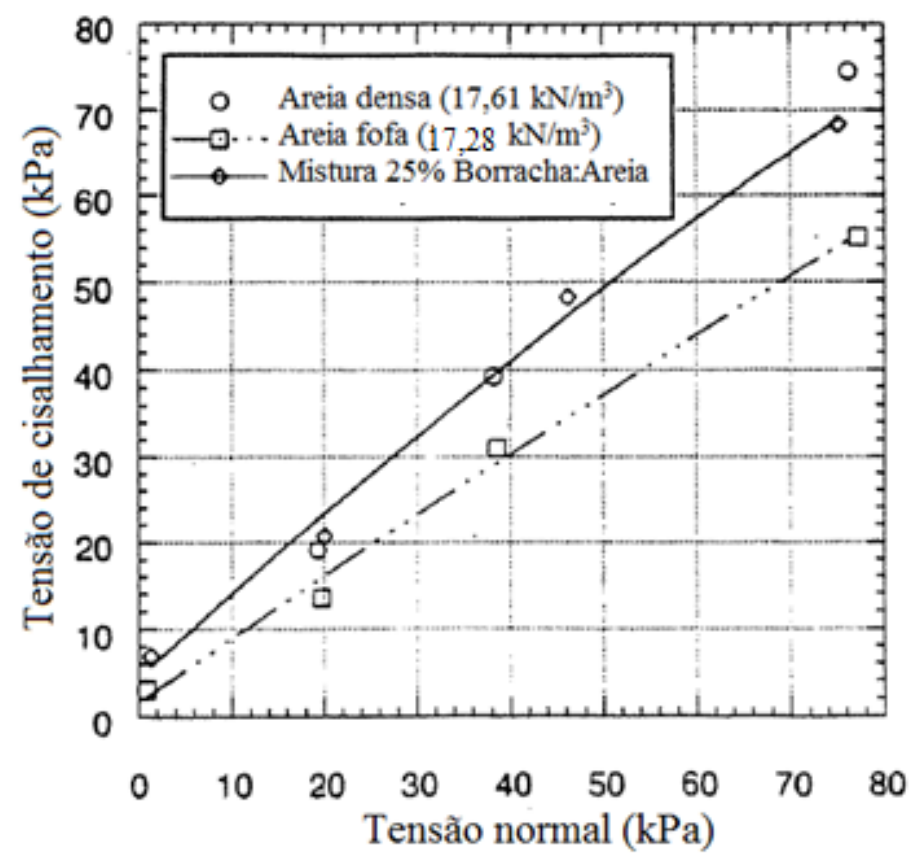

Figura 2.26. Envoltórias de ruptura dos ensaios de cisalhamento direto para uma mistura 25:75 de pedaços de pneu e areia (Bosscher et al., 1994). 


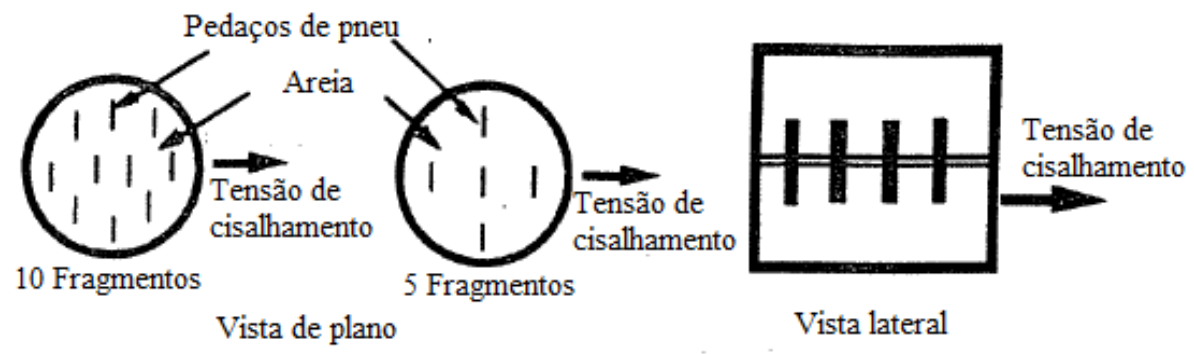

Figura 2.27. Esquema de orientação dos fragmentos de pneus ao longo da superfície de ruptura (Bosscher et al., 1994).

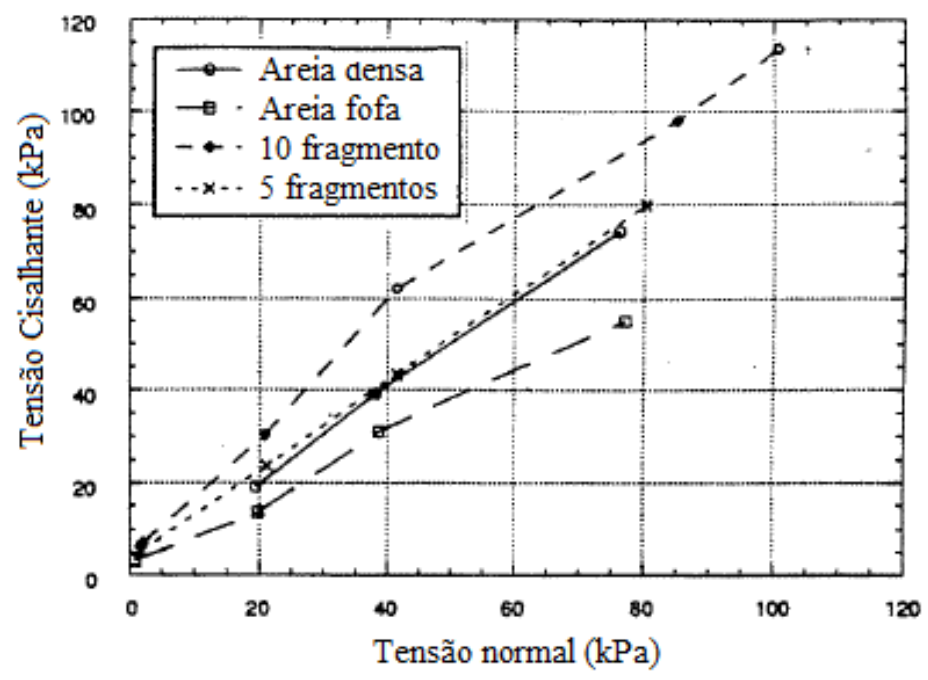

Figura 2.28. Diagrama de tensão cisalhante para fragmentos de pneus orientados verticalmente (Bosscher et al., 1994).

Zornberg et al. (2004) realizaram um programa de testes experimentais utilizando um aparelho triaxial de grande escala, com o objetivo de avaliar a melhor dosagem para preenchimentos granulares. Também foram avaliados os efeitos sobre a resistência ao cisalhamento de diferentes misturas, sendo aplicadas tensões de confinamento. Os pedaços de pneus utilizados na pesquisa variaram de forma e tamanho, ambos misturados com areia seca No. 30 (0,4 mm), classificada como SP pelo SUCS, com coeficiente de uniformidade de 1,3, coeficiente de curvatura de 1,1 e a densidade específica de 2,66. Para definir a melhor dosagem foram utilizadas amostras de areia pura $(x=0 \%)$ e pedaços de pneus puros $(x=100 \%)$, além de misturas destes dois materiais $(x=5,10,15,30,38$ e $60 \%)$.

Os pedaços de pneus foram cortados em tamanhos retangulares controlados para conseguir larguras (dimensão na direção menor) de 12,7 e 25,4 mm. As proporções dos fragmentos usados no programa de testes foram 1, 2, 3, 4 e 8 (Figura 2.29). A utilização de pedaços de pneus sem malha de aço foi considerada no programa de testes para evitar perfurar as membranas dos espécimes triaxiais durante o teste e também para facilitar o corte dos pedaços 
em tamanhos e proporções controladas. Foram realizadas um total de 15 séries de testes em condições consolidadas e drenadas (CD), sendo que cada série incluiu três testes realizados sobre pressões confinantes de 48,3 kPa, 103,5 kPa e $207 \mathrm{kPa}$. A Tabela 2.12 apresenta um resumo das principais características da série de testes realizados na pesquisa.
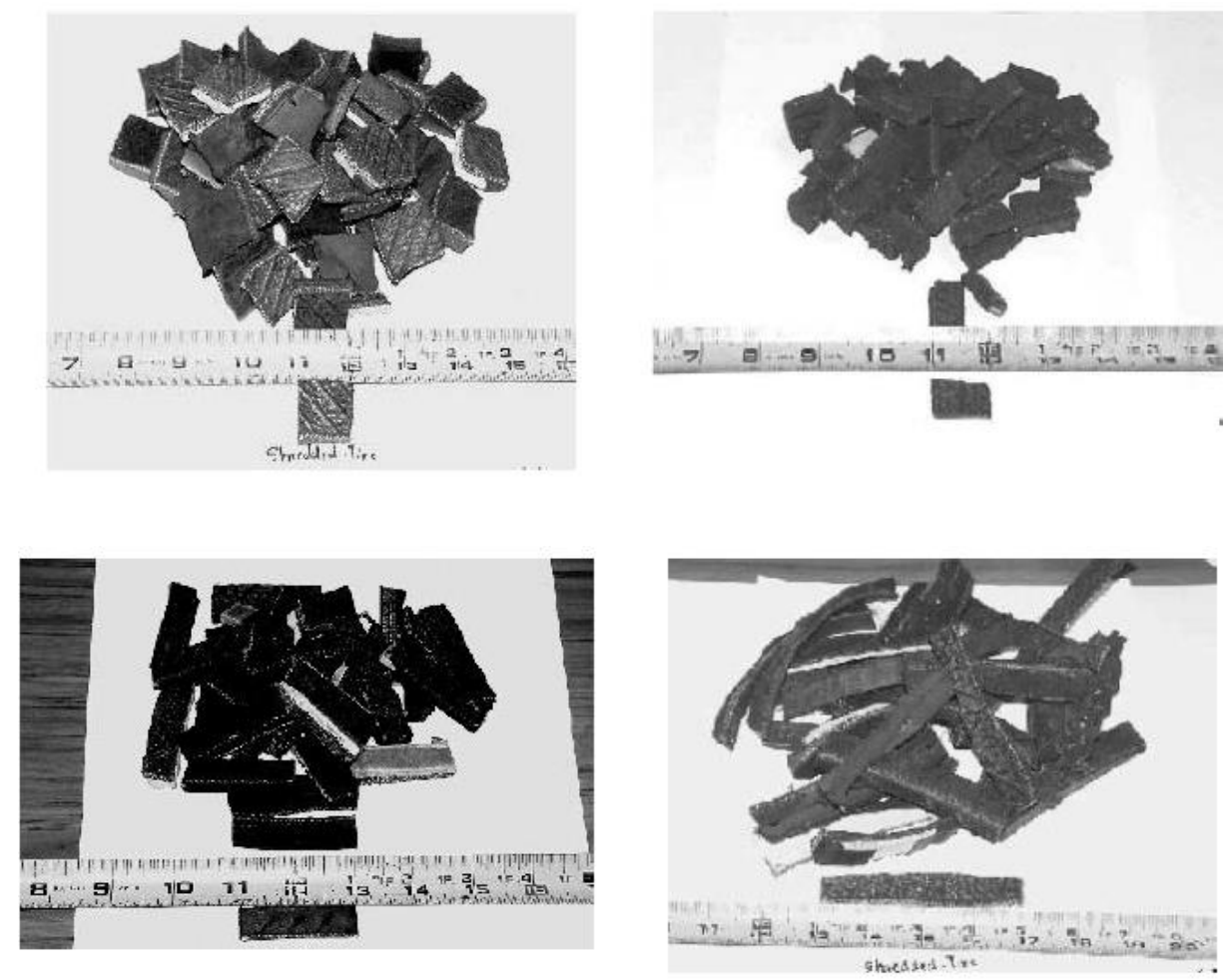

Figura 2.29. Pedaços de pneus com as diferentes relações: (a) $n=1$, (b) $n=2$, (c) $n=3$, (d) $n=8$ (Zornberg et al., 2004).

Os resultados encontrados por Zornberg et al. (2004) indicaram que nos ensaios triaxiais para amostras com pedaços de pneus o comportamento tensão desviadora vs deformação apresentou-se aproximadamente linear, enquanto que o comportamento de deformação resultou em contração volumétrica. A influência do teor de pedaços de pneus nos espécimes foi significativa, observando-se um comportamento dilatante das misturas até se atingir um teor de pedaços de pneus de $35 \%$, sendo que após deste valor o comportamento é de contração. Por fim, a principal conclusão de Zornberg et al. (2004) foi que a contribuição nos mecanismos de reforço para a tensão de cisalhamento das misturas é mais significativa a baixas pressões confinantes. 
Tabela 2.12. Parâmetros de resistência das misturas de areia e pedaços de pneus (Zornberg et al., 2004).

\begin{tabular}{|c|c|c|c|c|c|}
\hline \multirow{2}{*}{$\begin{array}{c}\text { Densidade } \\
\text { relativa da areia } \\
(\%)\end{array}$} & $\begin{array}{c}\text { Teor de } \\
\text { pedaços de } \\
\text { pneus (\%) }\end{array}$ & $\begin{array}{c}\text { Relação da largura e } \\
\text { comprimento dos } \\
\text { pedaços de pneus }\end{array}$ & \multicolumn{3}{|c|}{$\begin{array}{c}\text { Parâmetros de resistência ao } \\
\text { cisalhamento }\end{array}$} \\
\cline { 4 - 6 } & 0 & na & 36,8 & 7,8 & 37,9 \\
75 & 0 & na & 41,0 & 3,8 & 41,4 \\
55 & 10 & 4 & 35,7 & 21,7 & 38,9 \\
55 & 30 & 4 & 35,7 & 30,4 & 40,2 \\
55 & 60 & 4 & 34,4 & 18,2 & 37,3 \\
na & 100 & 4 & 21,4 & 22,8 & 26,5 \\
75 & 30 & 4 & 36,4 & 30,7 & 40,8 \\
55 & 30 & 2 & 35,6 & 22,3 & 38,9 \\
55 & 30 & 1 & 35,1 & 23,7 & 38,7 \\
75 & 20 & 4 & 37,2 & 22 & 40,3 \\
55 & 30 & 8 & 36,1 & 60 & 44,5 \\
55 & 38.3 & 4 & 36,1 & 41,2 & 42 \\
55 & 10 & 1 & 36,5 & 19,8 & 39,4 \\
55 & 5 & 4 & 36,1 & 7 & 37,1 \\
65 & 15 & 4 & 34,8 & 21,7 & 38,2 \\
\hline
\end{tabular}

Embora haja contribuição dos mecanismos de reforço, também foi observada em altas pressões confinantes que a resistência ao cisalhamento é frequentemente inferior ao obtido para areia pura. Consequentemente, estruturas sujeitas a baixas pressões confinantes podem ser beneficiadas com a adição de pedaços de pneus.

Bałachowski \& Gotteland, 2007 realizaram uma série de ensaios de compressão triaxial em condições drenadas e adensadas (CD) para amostras de areia pura, para pedaços de pneus puro e para misturas de areia com pedaços e lascas de pneu. Os resultados encontram-se apresentados na Tabela 2.13. Para cada série de testes foram feitos ensaios sob tensões confiantes de 100, 200, $300 \mathrm{kPa}$. O procedimento de preparação das amostras foi adaptado dependendo do material testado, sendo feita a instalação das amostras de modo orientado ou não orientado (Figura 2.30). No estudo foram utilizados pedaços de pneus de $100 \mathrm{~mm}$ de diâmetro e os testes foram conduzidos sob um modo de controle de deslocamento, com uma 
taxa de deformação ajustada para o material a ser testado, a partir de $0,04 \mathrm{~mm} / \mathrm{min}$ para areia e $0,4 \mathrm{~mm} / \mathrm{min}$ para amostras de pedaços de pneu.

As amostras na falha estão apresentadas na Figura 2.30. Na figura (a) pode-se ver algumas zonas de cisalhamento, deformações individuais e flexão da amostra de pedaços de pneus com elementos orientados horizontalmente. Na figura (b) observa-se que a mistura de areia com pedaços e lascas de pneus tende a ter muitos planos de ruptura devido aos planos de fraqueza gerados entre as zonas de contato dos pedaços de pneu com a areia. Nos ensaios com amostras de pedaços de pneu puro, a resistência ao cisalhamento de máxima obtida foi equivalente a $20 \%$ da deformação axial, uma vez que este tipo de material não chegou à ruptura.
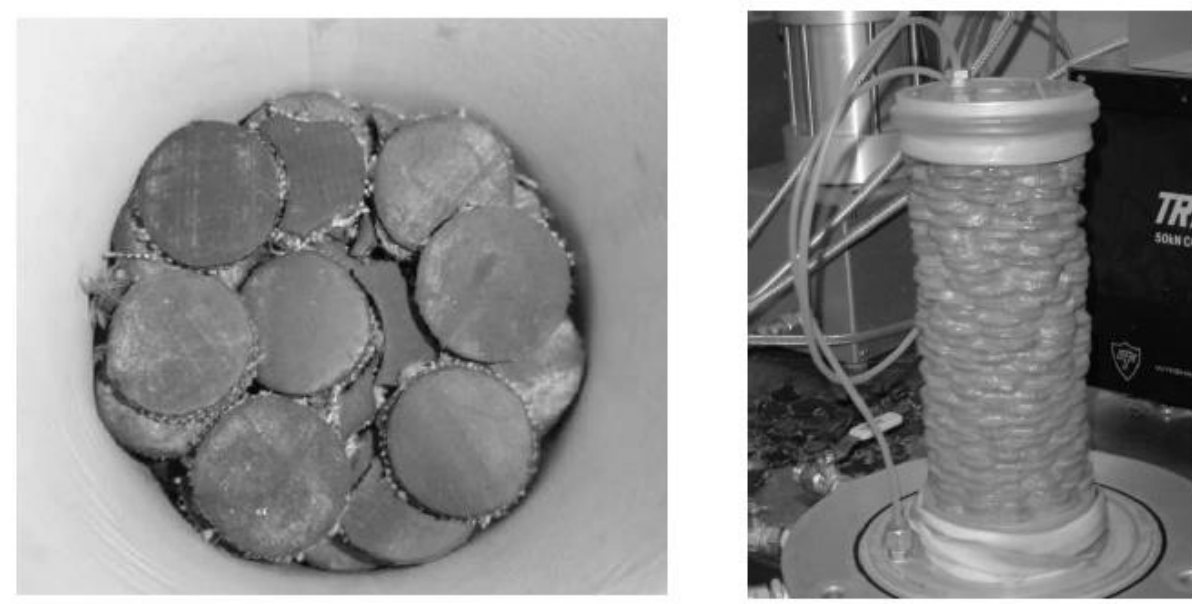

(a)
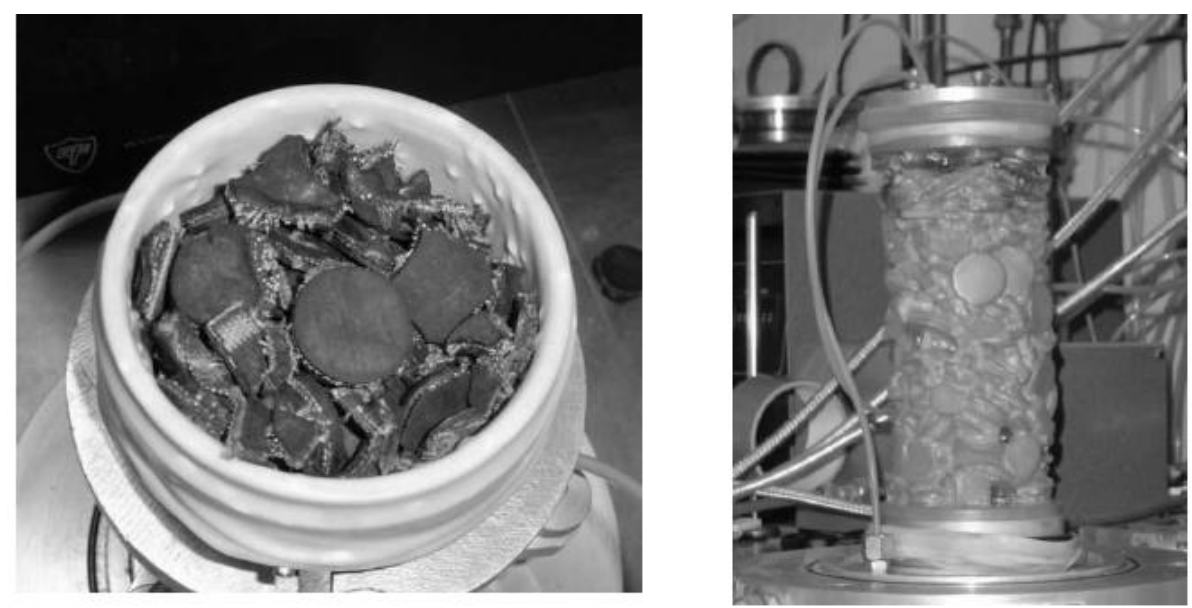

(b)

Figura 2.30. Amostras preparadas para o ensaio de compressão triaxial na pesquisa (a) Pedaços de pneu orientados, e (b) Mistura de pedaços de pneus e lascas de pneus não orientados. (Bałachowski \& Gotteland, 2007). 
Tabela 2.13. Programa de ensaios de compressão triaxial (Bałachowski \& Gotteland, 2007).

\begin{tabular}{|c|c|c|c|c|c|}
\hline $\begin{array}{c}\text { Teor de lascas de } \\
\text { pneus }(\%)\end{array}$ & $\begin{array}{c}\text { Orientação dos } \\
\text { pedaços de pneu }\end{array}$ & $\begin{array}{c}\gamma \\
(\mathrm{kN} / \mathrm{m} 3)\end{array}$ & $\phi\left(\left(^{\circ}\right)\right.$ & $\begin{array}{c}\mathbf{c}^{\prime} \\
(\mathbf{k P a})\end{array}$ & Observações \\
\hline 0 & NA & 16,21 & 42,9 & 0 & Areia pura \\
\hline 14.2 & NO & 15,50 & 34,5 & 37 & $\begin{array}{c}\text { Areia - lascas/pedaços de } \\
\text { pneu } 50 / 50\end{array}$ \\
\hline 15.2 & NO & 14,52 & 35,5 & 32 & Areia - pedaços de pneus \\
\hline 23 & NO & 13,95 & 33,9 & 55 & Areia - pedaços de pneus \\
\hline 30 & NO & 13,30 & 33,6 & 60 & Areia - pedaços de pneus \\
\hline 50 & NO & 6,59 & 12,2 & 42 & Lascas/pedaços - 50/50 \\
\hline 100 & $\mathrm{H}$ & 7,72 & 39,3 & 34 & Lascas de pneus \\
\hline
\end{tabular}

NA: não aplicável, H: horizontal, NO: não orientados.

Os resultados dos ensaios triaxiais realizados para amostras compostas por pedaços de pneus orientados horizontalmente e por pedaços de pneus não orientados estão apresentados na Figura 2.31. Para pedaços de pneus orientados, a resistência ao cisalhamento máxima aparece para grandes deformações, maiores que 15\%, e a tensão axial na falha, aumenta com a pressão confinante. A diferença é que as amostras com pedaços de pneus não orientados não apresentam uma resistência máxima, de modo que o critério de falha assumida foi $20 \%$ da deformação axial.

Na Figura 2.32 são apresentados os resultados dos ensaios realizados por Bałachowski \& Gotteland (2007) em amostras compostas por misturas de areia e por pedaços de pneus, com diferentes teores $(14.2 \%, 15.2 \%, 22 \%$ e $30 \%$ em peso). Também estão apresentados os resultados relativos a uma amostra de areia pura. A tensão desviadora atinge seu valor máximo numa deformação axial perto do 3\%, já para as misturas de areia e pedaços de pneu a tensão desviadora máxima tende a aumentar com a elevação do teor de borracha. O conteúdo de pedaços de pneu encontrado neste estudo foi de $30 \%$ em peso, concordado com valores apresentados por Zornberg et al. (2004), onde o aumento da resistência ao cisalhamento das misturas foi devido a dois mecanismos: cisalhamento interno devido ao atrito entre a areia e o material de reforço; contribuição da resistência a tração que acontece nos pedaços dentro das misturas. 


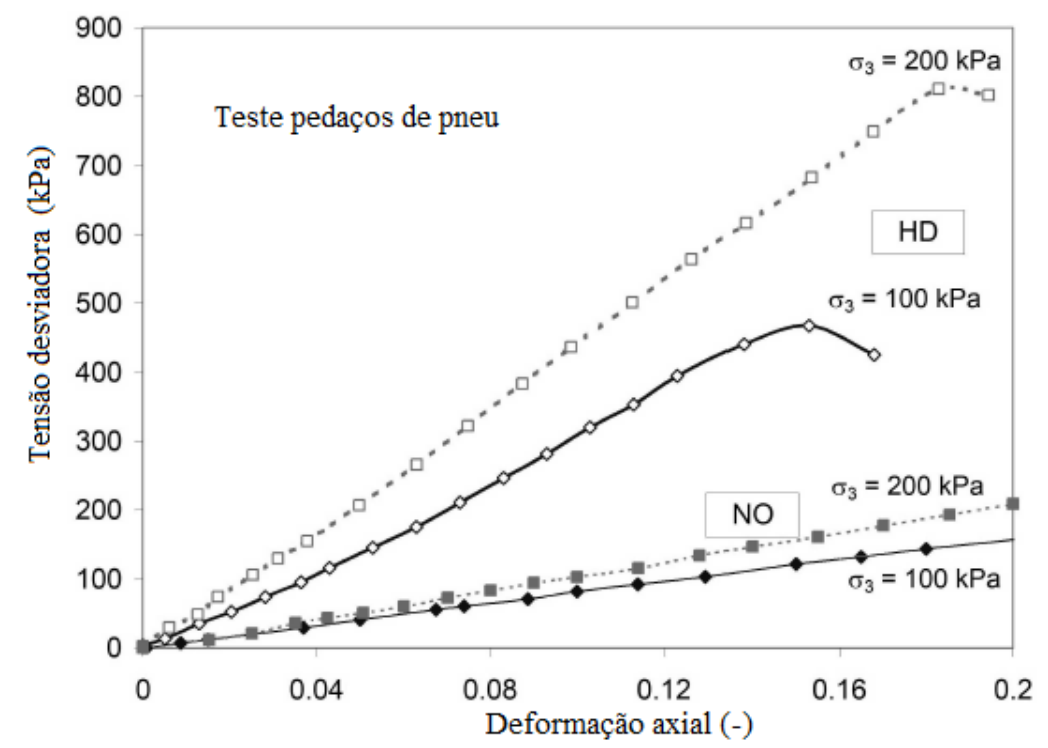

Figura 2.31. Influência da orientação nos ensaios com pedaços de pneus: HD - Pedaços orientados horizontalmente, $\mathrm{NO}$ - pedaços não orientados (distribuição aleatória) (Bałachowski \& Gotteland, 2007).

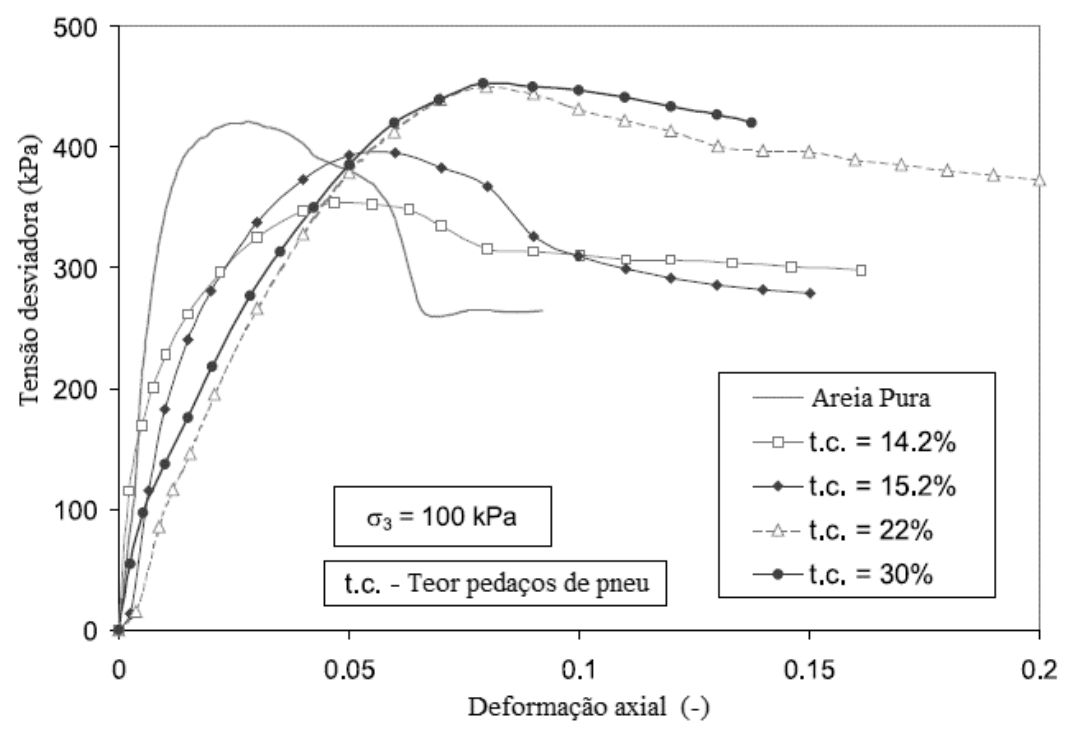

Figura 2.32. Comportamento tensão - deformação das misturas areia com pedaços de pneus (não orientados) para diferentes teores (Bałachowski \& Gotteland, 2007).

Na Figura 2.33 estão apresentados os resultados do comportamento da variação volumétrica nos ensaios triaxiais. O comportamento desta depende do teor de borracha utilizado nas misturas que, ao chegar a um teor de borracha ótimo, aumentam sua resistência ao cisalhamento e aumenta sua resistência a grandes deformações. Neste gráfico pode-se observar que as maiores deformações volumétricas ocorrem no solo puro e vão diminuindo com o aumento do teor de borracha. 


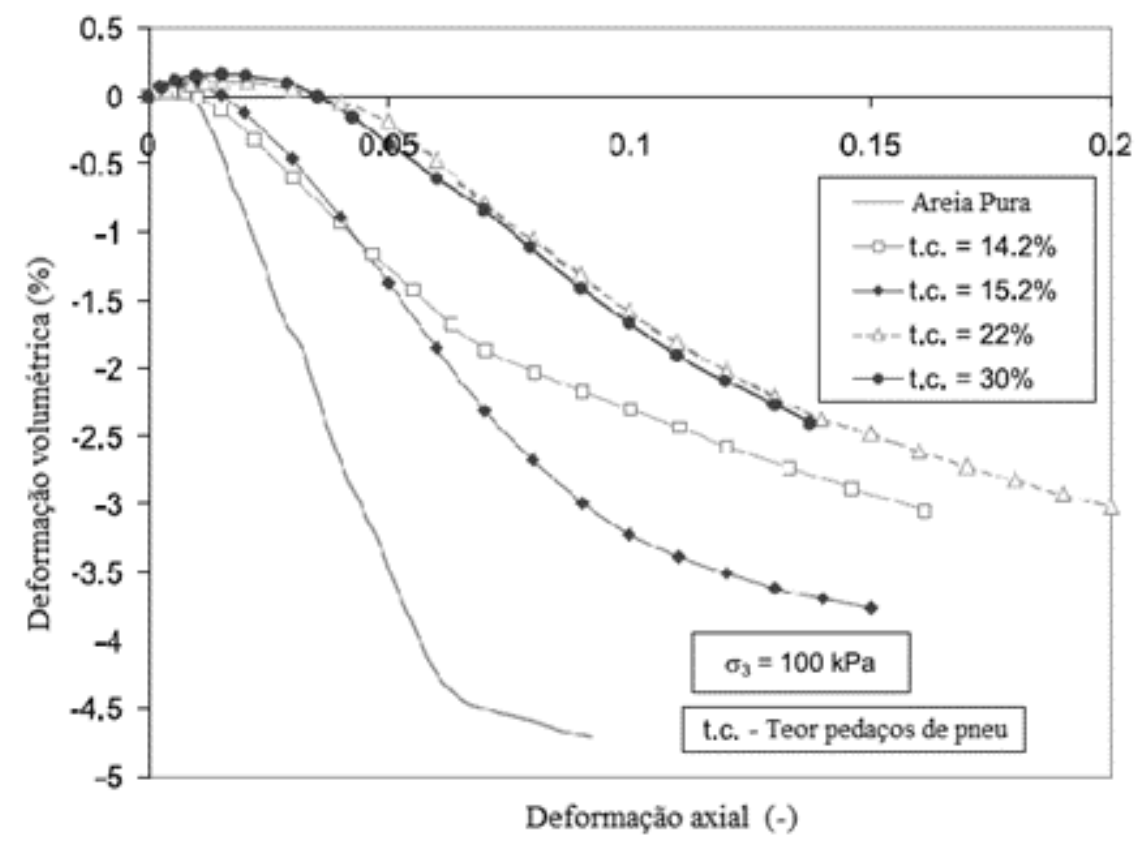

Figura 2.33. Comportamento deformação volumétrica - deformação axial das misturas areia pedaços de pneus (não orientados) para diferentes teores (Bałachowski \& Gotteland, 2007).

Finalmente Bałachowski \& Gotteland (2007) concluem que, a adição de pedaços de pneus no solo arenoso melhora seu comportamento mecânico, aumentando sua resistência ao cisalhamento e diminuindo as deformações volumétricas.

Chrusciak, (2013) realiza um estudo para avaliar os parâmetros de resistência da mistura do solo argiloso, encontrado no Distrito Federal, com material reciclável de borracha de pneus (pedaços de pneu), para aplicação de preenchimento em estruturas de contenção.

O autor em questão utilizou um equipamento de cisalhamento direto de média escala $(300 \mathrm{~mm}$ x $300 \mathrm{~mm}$ x $175 \mathrm{~mm}$ ) para estudar o comportamento destas misturas com pedaços até $30 \mathrm{~mm}$. Foram realizados procedimentos de caracterização dos materiais estudados (solo e borracha) e das misturas com teores de 2,5\%, 3,75\%, $5 \%$ e 7,5\% de pedaços de pneus em relação ao peso. Em seguida, foram realizados ensaios de compactação e de cisalhamento direto em dimensões maiores que as convencionalmente utilizadas.

Na Figura 2.34 estão apresentados os resultados dos ensaios de compactação feitos por Chrusciak (2013), onde observa-se que à medida que o teor de resíduo de borracha é acrescentado este exerce certa influência sobre o peso específico seco máximo das misturas, 
diminuindo até 4,66\% para misturas com teor de 7,5\%, com relação à mistura de solo puro. Quanto à variação da umidade ótima, esta sofre pouca alteração. Considerando-se em termos práticos a variação de $2 \%$ para mais ou menos, a umidade ótima permaneceu a mesma.

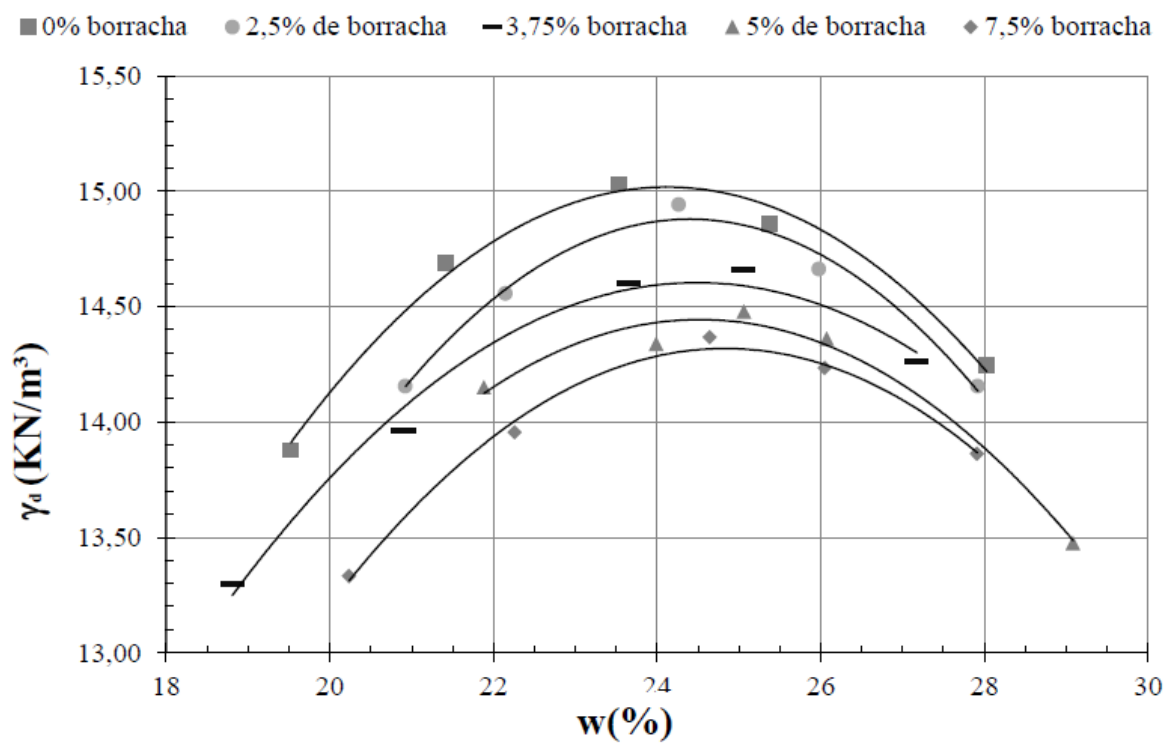

Figura 5.5- Curvas de compactação para todos os teores.

Figura 2.34. Curvas de compactação para todos os teores (Chrusciak, 2013).

Nas Figura 2.35 e na Figura 2.36 estão apresentadas as curvas de tensão de cisalhamento versus deslocamento horizontal, e de deslocamento vertical versus deslocamento horizontal dos diferentes teores de borracha, para uma mesma tensão normal, obtidos por Chrusciak ( 2013). O autor encontra que, à medida que é acrescentado o resíduo de borracha na mistura, esta passa a apresentar menor valor de resistência para todas as tensões estudadas. Esta redução no valor de resistência pode ser explicada pelo fato dos fragmentos de borracha absorverem certa energia aplicada ao solo. Tendo em vista que são mais deformáveis, essa absorção acaba reduzindo a variação volumétrica do solo. O resumo destes resultados pode ser observado na Tabela 2.14.

Quanto aos efeitos da variação de altura, todas as misturas estudadas apresentaram uma pequena contração inicial, com deslocamentos horizontais de 2 a $5 \mathrm{~mm}$. Em seguida observase uma constante dilatação para as tensões de $25 \mathrm{kPa}$ e $50 \mathrm{kPa}$ e um trecho constante para 80 $\mathrm{kPa}$. Estes resultados podem ser justificados por uma possível movimentação vertical da caixa durante o ensaio devido aos carregamentos aplicados (Chrusciak, 2013). 


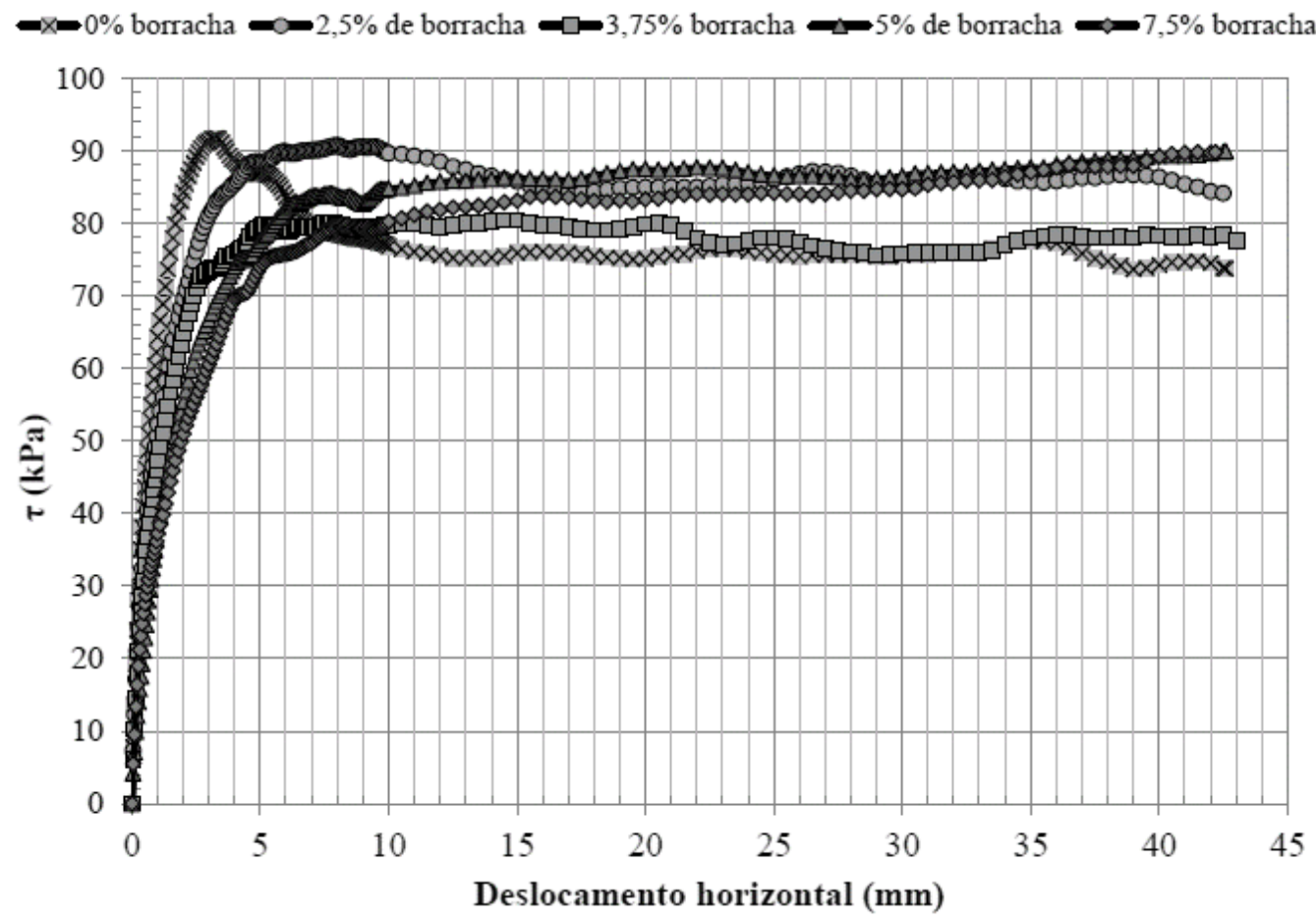

Figura 2.35. Tensão de cisalhamento versus deslocamento horizontal para tensão confinante de $80 \mathrm{kPa}$ (Chrusciak, 2013).

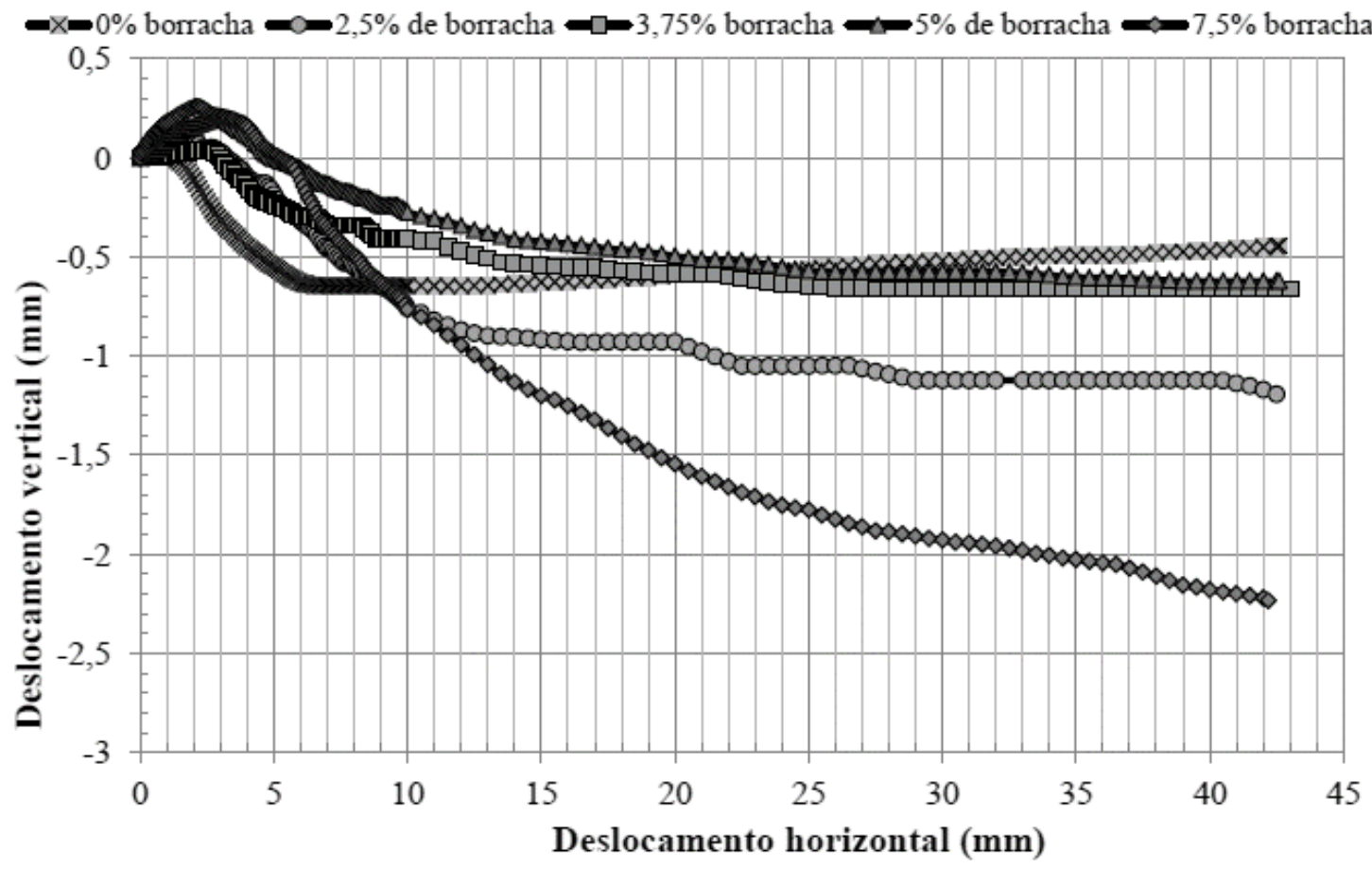

Figura 2.36. Deslocamento vertical versus deslocamento horizontal para tensão confinante de $80 \mathrm{kPa}$ (Chrusciak, 2013). 
Tabela 2.14. Valores de tensão máxima de cisalhamento, coesão e ângulo de atrito para os ensaios realizados na caixa de medias dimensões (Chrusciak, 2013).

\begin{tabular}{|c|c|c|c|c|}
\hline Teor de Borracha (\%) & $\sigma_{N}(\mathbf{k P a})$ & $\tau_{\text {máx}} \cdot(\mathbf{k P a})$ & c' (kPa) & $\phi\left({ }^{\circ}\right)$ \\
\hline \multirow{3}{*}{0} & 34,23 & 56,69 & \multirow{3}{*}{35,60} & \multirow{3}{*}{29,35} \\
\hline & 62,85 & 67,63 & & \\
\hline & 98,39 & 92,42 & & \\
\hline \multirow{3}{*}{2,5} & 31,03 & 48,08 & \multirow{3}{*}{27,98} & \multirow{3}{*}{32,64} \\
\hline & 60,32 & 66,21 & & \\
\hline & 97,95 & 90,88 & & \\
\hline \multirow{3}{*}{3,75} & 30,32 & 43,94 & \multirow{3}{*}{24,35} & \multirow{3}{*}{32,26} \\
\hline & 59,66 & 61,09 & & \\
\hline & 88,94 & 80,93 & & \\
\hline \multirow{3}{*}{5} & 32,22 & 46,11 & \multirow{3}{*}{20,64} & \multirow{3}{*}{37,60} \\
\hline & 60,37 & 65,82 & & \\
\hline & 89,08 & 89,88 & & \\
\hline \multirow{3}{*}{7,5} & 30,14 & 39,86 & \multirow{3}{*}{13,51} & \multirow{3}{*}{39,65} \\
\hline & 57,08 & 58,34 & & \\
\hline & 90,89 & 89,93 & & \\
\hline
\end{tabular}

Na Figura 2.37 e na Figura 2.38 estão apresentadas as relações entre a coesão e o ângulo de atrito, variando-se os teores de resíduo de borracha. Chrusciak (2013) mostra que a relação entre coesão e o teor de borracha é linear. Porém, para o ângulo de atrito, não há esse comportamento de forma tão evidente.

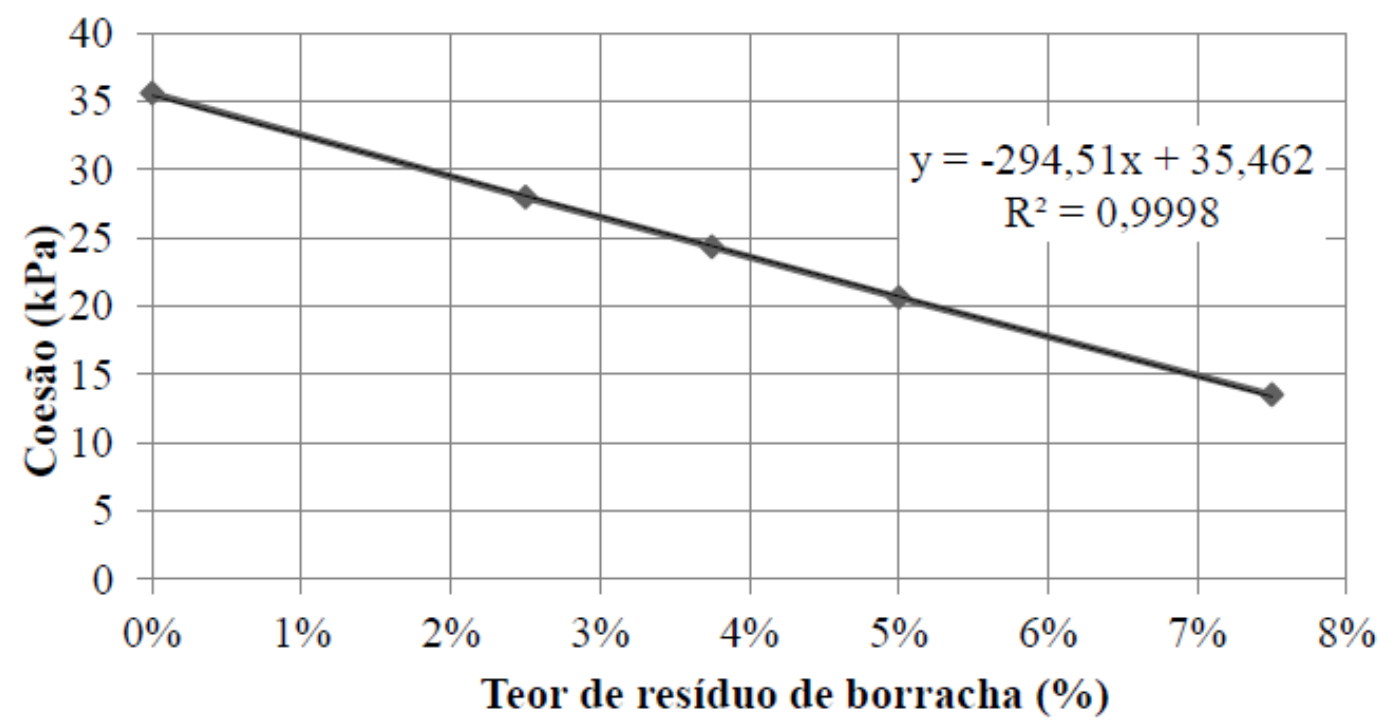

Figura 2.37. Relação entre coesão e o teor de resíduo de pneu (Chrusciak, 2013). 


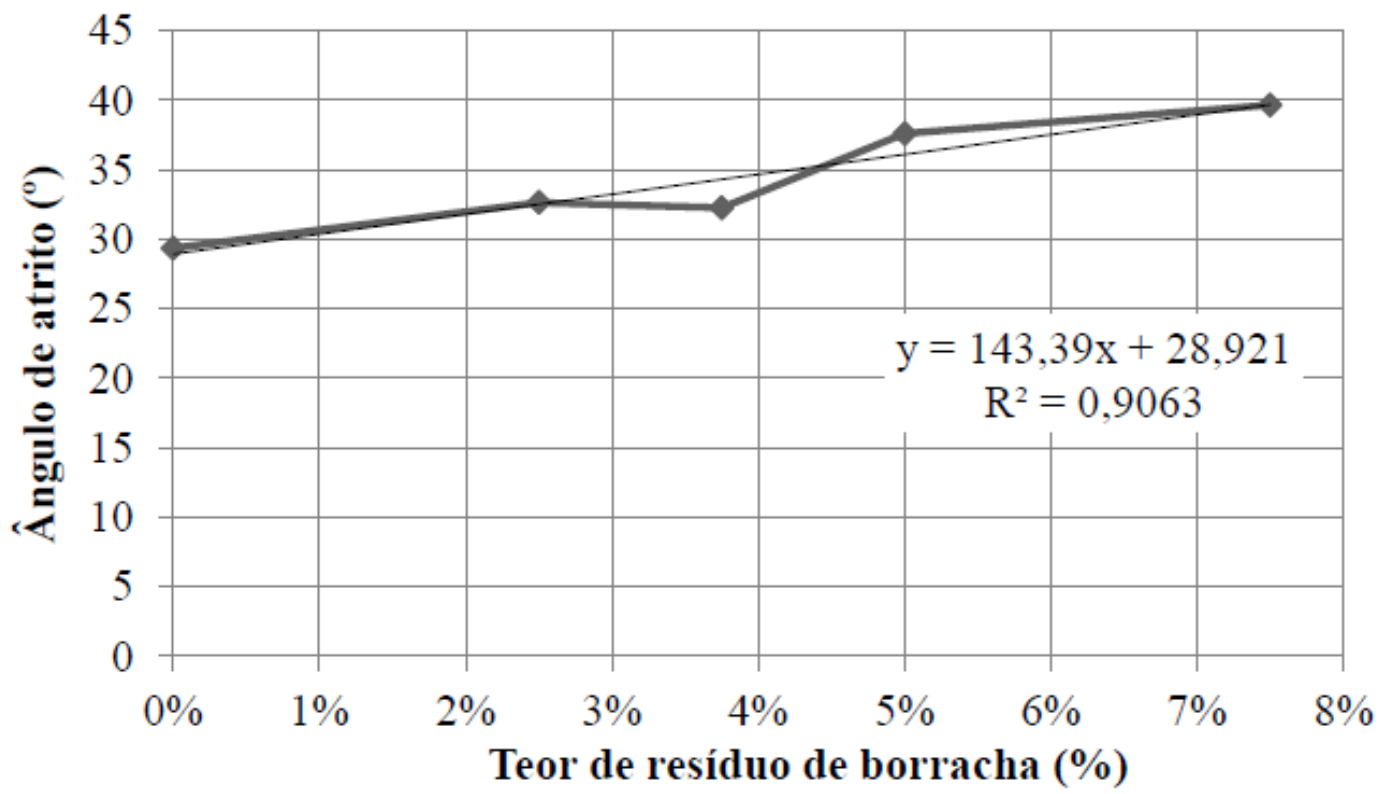

Figura 2.38. Relação entre o ângulo de atrito e o teor de resíduo de pneu (Chrusciak, 2013).

Chrusciak (2013) conclui que, apesar de certa queda na resistência ao cisalhamento das misturas, o uso dos resíduos de pneus pode ser realizado desde que sejam levados em consideração os aspectos financeiros. Assim, esta solução pode ser utilizada para minimizar o descarte de pneus como uma destinação técnica no campo da engenharia civil. 


\section{EQUIPAMENTOS E MATERIAIS UTILIZADOS NA PESQUISA}

\subsection{EQUIPAMENTO DE CISALHAMENTO DIRETO EM ESCALA MÉDIA}

Na pesquisa foi utilizado o equipamento utilizado por Chrusciak (2013), o qual consiste em uma caixa de cisalhamento de tamanho maior que o convencional, com dimensões de $300 \mathrm{~mm}$ x $300 \mathrm{~mm}$ x $175 \mathrm{~mm}$. Tal caixa está submetida a um sistema de carregamento composto por um circuito hidráulico, com dois cilindros de capacidade de carga de 10 t que aplicam esforços de compressão e tração, com um curso máximo de 50 mm (Figura 3.1). Este sistema foi adaptado por Souza (2011), tendo o equipamento original sido desenvolvido inicialmente por Palmeira (1988) e utilizado para execução de ensaios de tração confinada em geotêxteis.

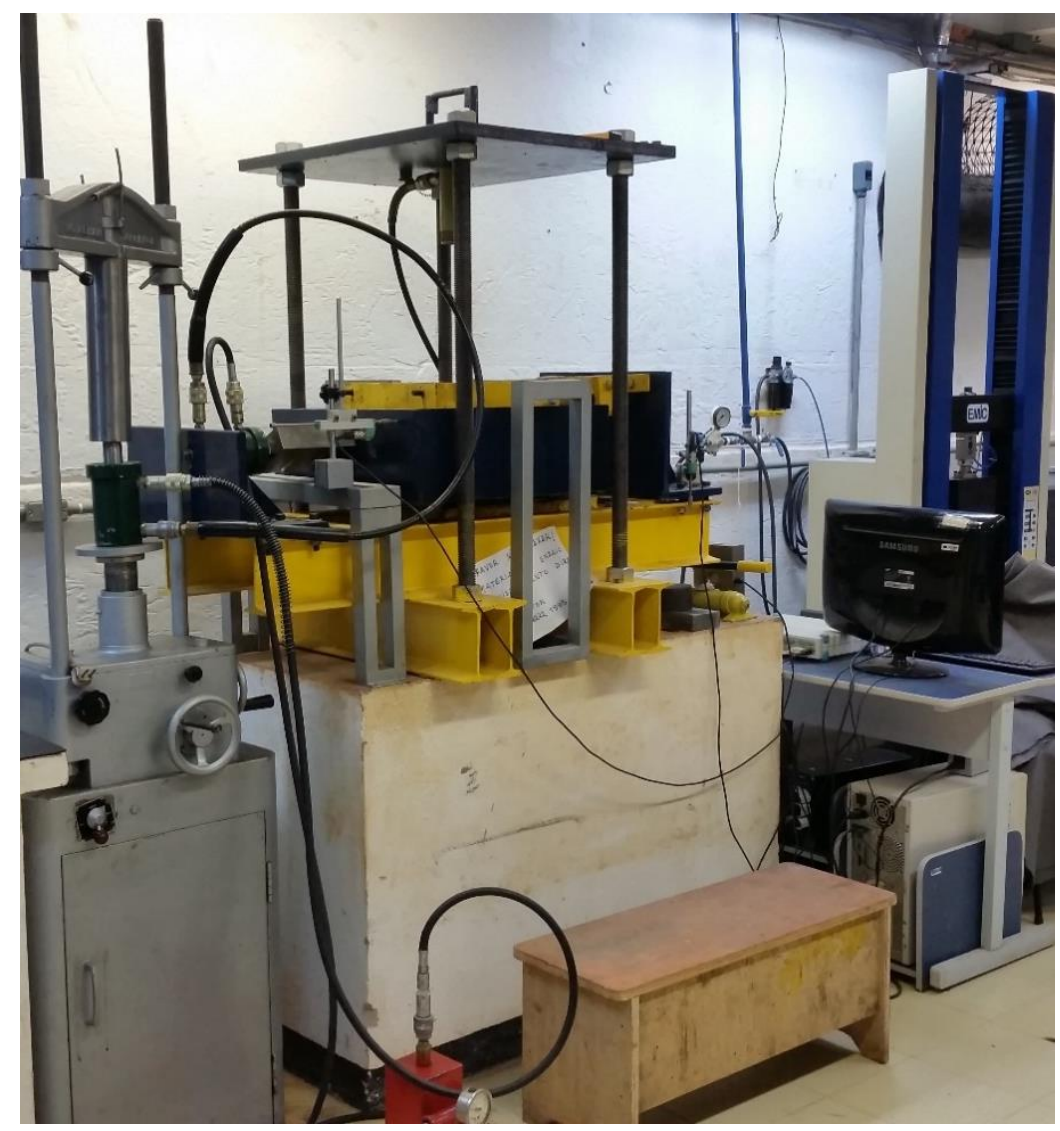

Figura 3.1. Equipamento de cisalhamento direto em escala média - laboratório do programa de pós-graduação em geotecnia da Universidade de Brasília. 
O funcionamento ocorre da seguinte forma: um dos cilindros hidráulicos é posicionado na prensa (originalmente utilizada em ensaios triaxiais), com o curso aberto que, ao ser ligada, faz com que esse curso seja fechado e, à medida que é comprimido, injeta óleo para o outro cilindro hidráulico por meio de ligação de mangueiras hidráulicas, permitindo que esta transferência de carga se dê em velocidades constantes e preestabelecidas (Chrusciak, 2013).

O equipamento tem implementado um sistema de instrumentação composto por duas células de carga de capacidade de até 10 t, para medir as tensões de cisalhamento e de confinamento; três transdutores de deslocamento, para medir o deslocamento horizontal (durante o ensaio de cisalhamento) e vertical (durante o ensaio de adensamento e cisalhamento). Todo este conjunto de sensores está ligado a um sistema de aquisição de dados (SPIDER 8) e, por meio do software Catman v 2.0 ®, são obtidos valores a cada 1 segundo. Na Figura 3.2 está apresentado cada um dos sistemas da instrumentação.

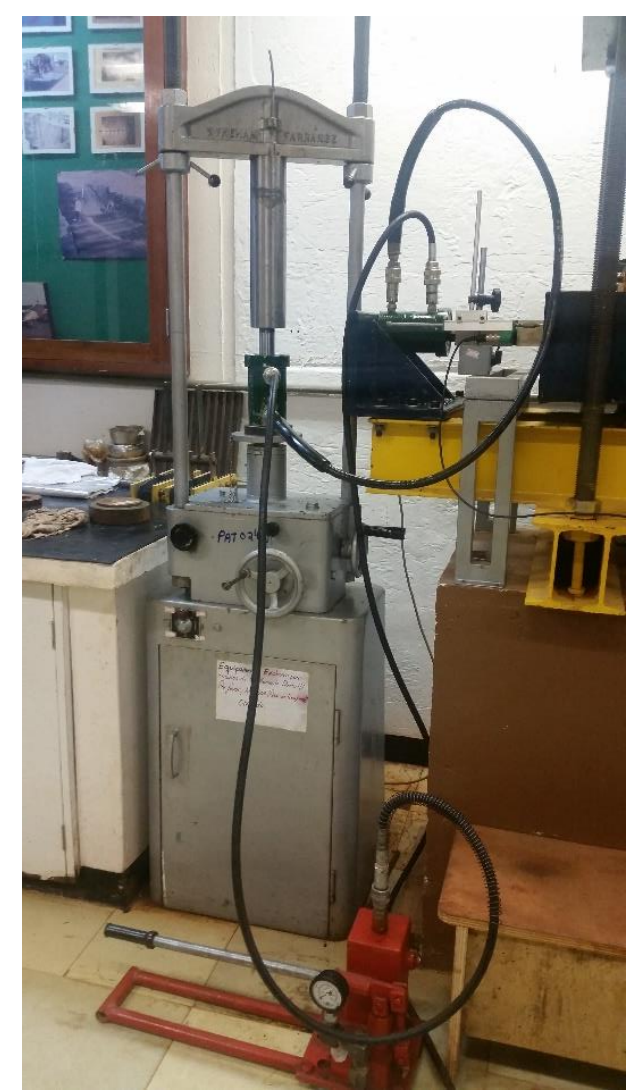

(a)

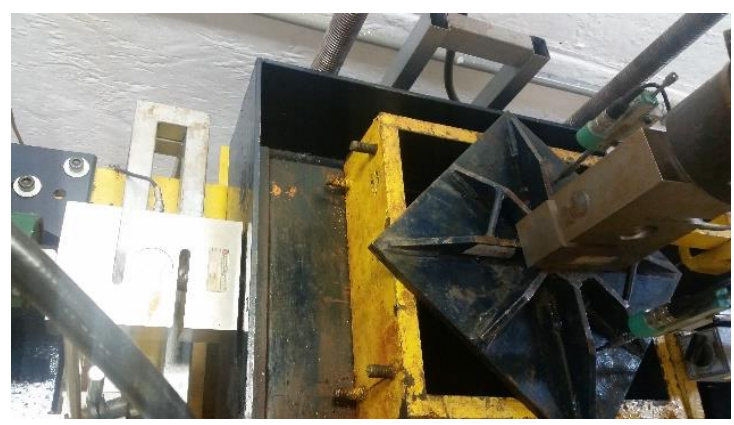

(b)

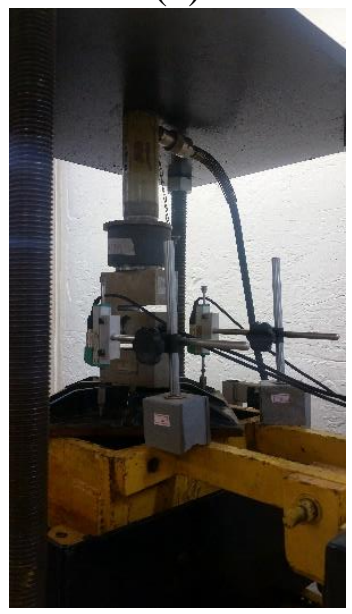

(c)

Figura 3.2. Visão geral dos sistemas mecânicos e de instrumentação (a) e (b) horizontal e (c) vertical. 


\subsection{MATERIAIS UTILIZADOS}

\subsubsection{SOLO LATERÍTICO ARGILOSO DO DISTRITO FEDERAL}

O solo empregado na pesquisa, conhecido no meio técnico como solo argiloso do Distrito Federal, foi coletado no campus experimental da Pós-Graduação em Geotecnia da Universidade de Brasília, com variação profundidades entre 2,0 - 2,5 m, localizado no campus Darcy Ribeiro da Universidade de Brasília, no Distrito Federal. A área está localizada nas coordenadas $15^{\circ} 45^{\prime} 58,37^{\prime}$ 'S $47^{\circ} 52$ '22,68'O (Figura 3.3). O processo de amostragem foi feito por meio de escavação manual e foram coletados aproximadamente $1 \mathrm{~T}$ (tonelada) de material (Figura 3.4).

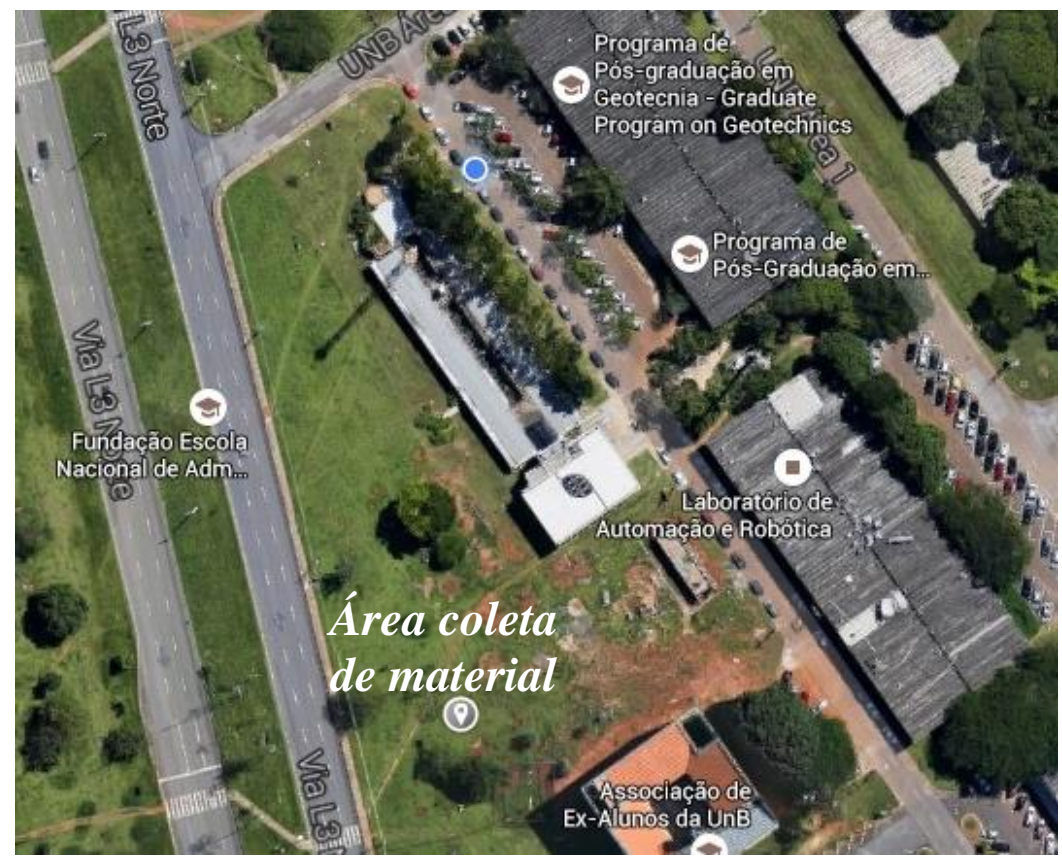

Figura 3.3. Área de coleta do material (Google Earth, 2015).

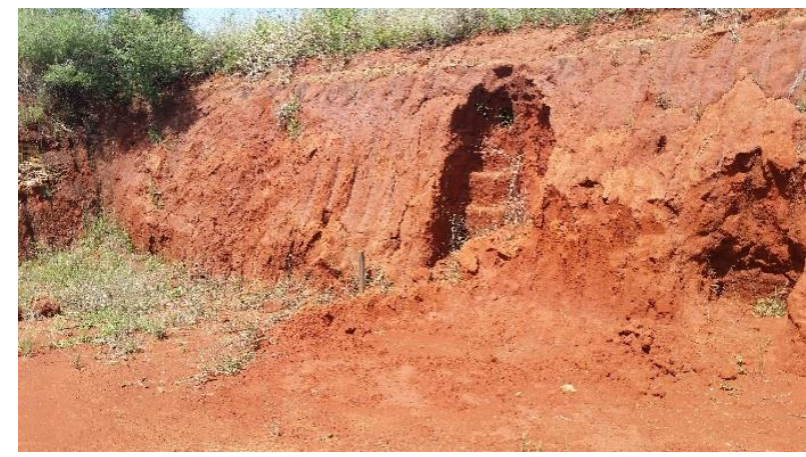

(a)

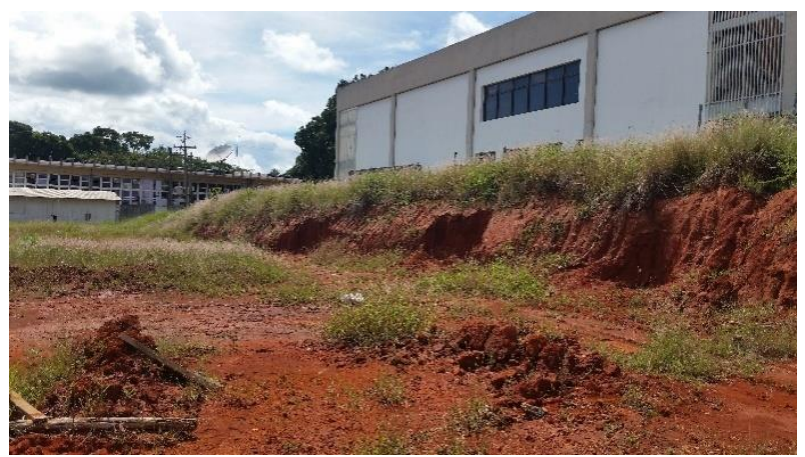

(b)

Figura 3.4. Campus experimental da Pós-Graduação em Geotecnia da UnB: (a) Zona de coleta, e; (b) Condição atual da zona de coleta. 
Após a coleta dosolo, foram feitos os seguintes ensaios de caraterização: Limites de Atterberg, massa específica dos grãos e granulometria com sedimentação. As normas utilizadas como referência foram respectivamente a NBR 6459 (ABNT, 1984), NBR7180 (ABNT, 1984), NBR 6508 (ABNT, 1984) e ABNT 7181 (ABNT, 1984).

Com relação aos Limites de Atterberg, foram obtidos os seguintes resultados: limite de liquidez igual a $37 \%$ e limite de plasticidade igual a $23 \%$, resultando um índice de plasticidade de 14\%. Segundo a SUCS o solo é classificado como CL (argila de baixa plasticidade). Pelo sistema HRB, por sua vez, o solo é classificado como um solo do grupo A6 (solo argiloso). O valor da massa especifica dos grãos foi de 2,68, e curva granulométrica que representa um solo fino com presença de material grosso está apresentada na Figura 3.5.

Chrusciak (2013) realiza ensaios de cisalhamento direto com solo argiloso, em esta pesquisa foi utilizado um solo argiloso com presença de material grosso, este material não passa por processos de seleção e peneiramento, na Figura 3.6 são apresentadas as curvas granulométricas solo utilizado na pesquisa comparado com o solo utilizado por Chrusciak (2013).

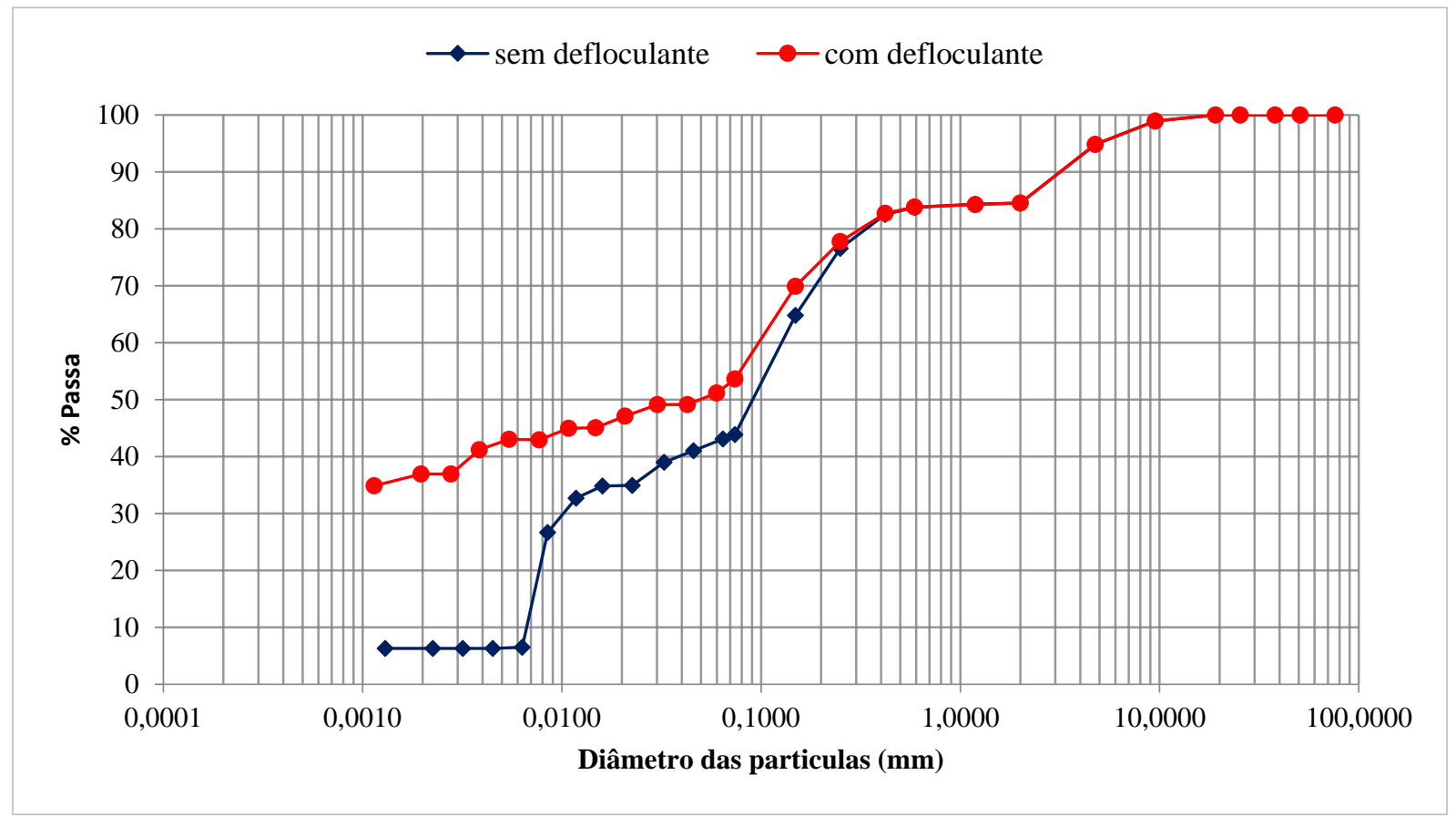

Figura 3.5. Curva granulométrica do solo laterítico utilizado na pesquisa. 


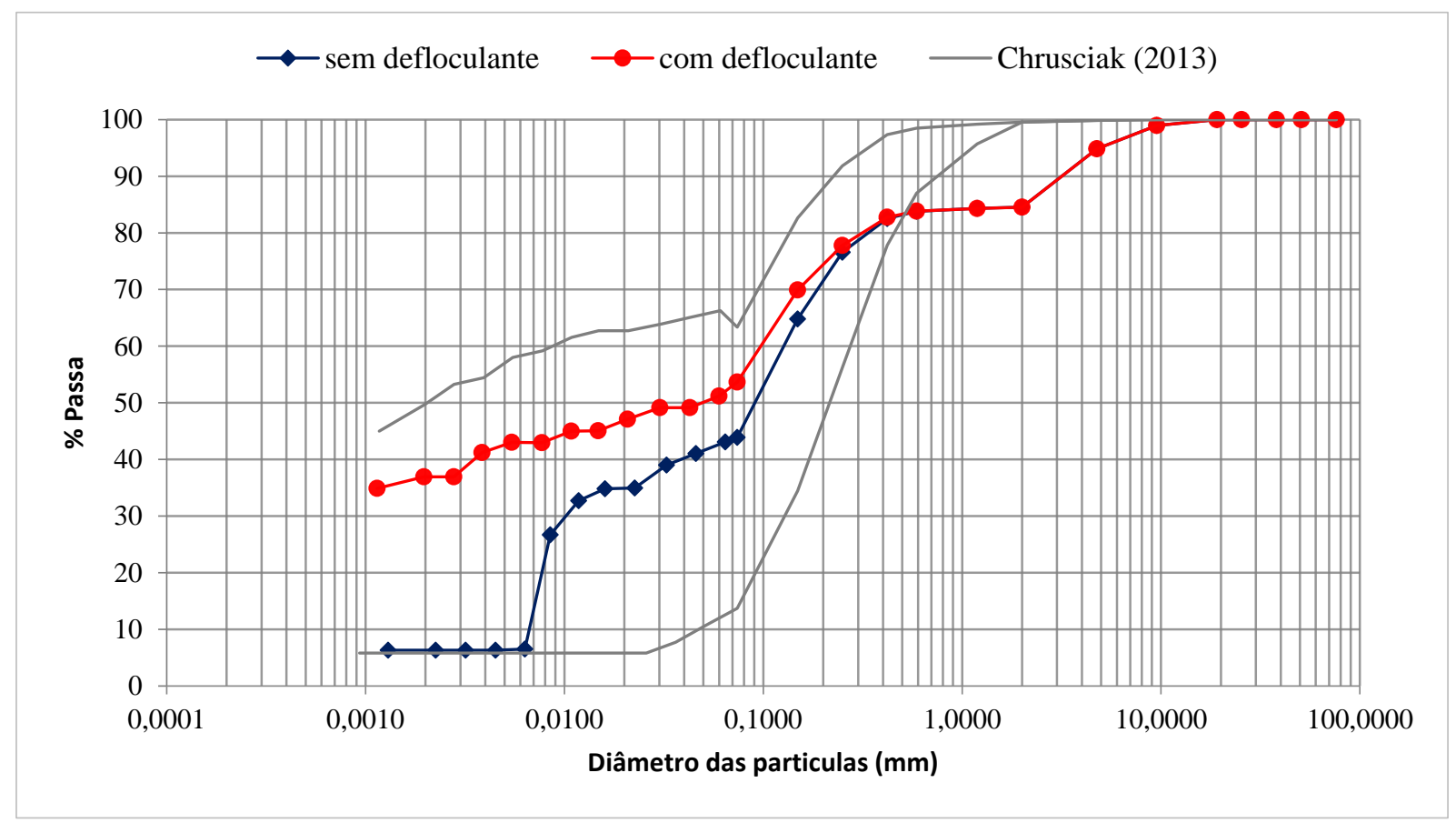

Figura 3.6. Curva granulométrica do solo laterítico utilizado na pesquisa comparado com o solo utilizado por Chrusciak (2013).

\subsubsection{PEDAÇOS DE PNEUS}

Foram utilizados fragmentos de borracha resultantes da trituração primária e secundária de pneus, sendo que os mesmos também foram utilizados por Chrusciak (2013). Este material é proveniente da empresa JLS transportes, com sede em Abadia de Goiás/GO. Segundo a classificação da normativa D6270 (ASTM, 1998) e por Edinçliler et al. (2010), este material é classificado como pedaços de pneus (tire Shred), devido ao tamanho das partículas (diâmetro médio de $20 \mathrm{~mm}$ ) e presença de malha de aço. 


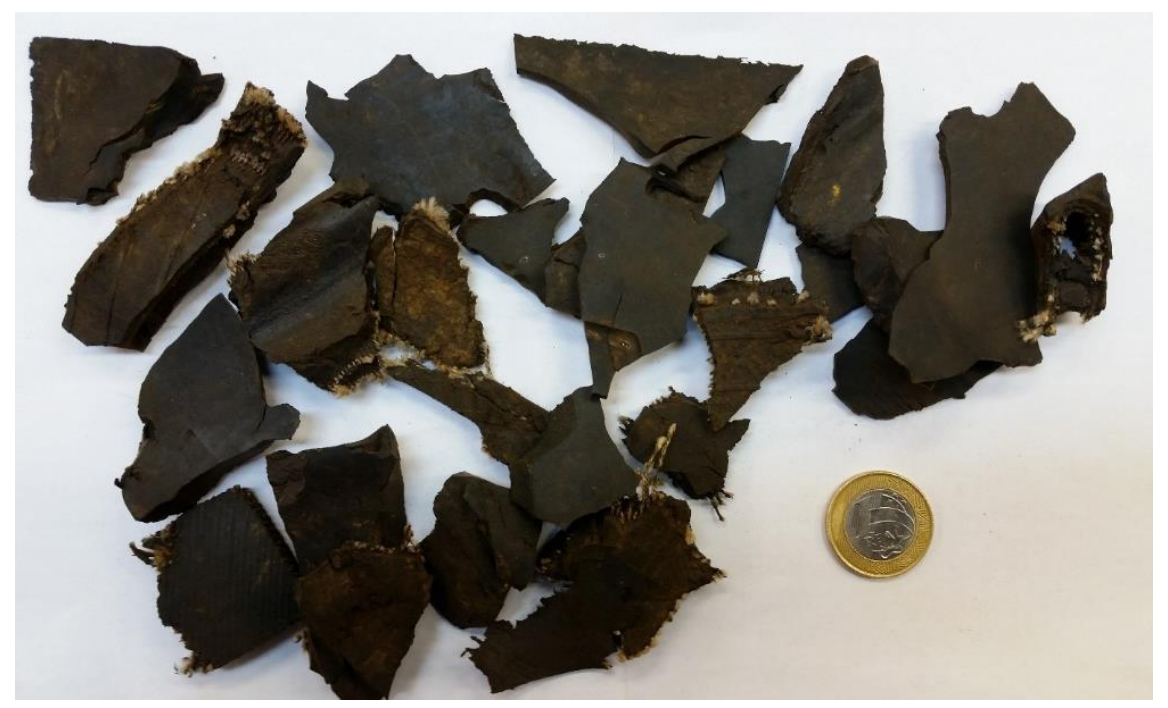

Figura 3.7. Pedaços de pneus utilizados na pesquisa.

Os pedaços de pneus apresentaram um valor de massa específica dos grãos igual a 1,19, conforme Chrusciak (2013). Segundo Benson (1995), as partículas mais finas dos fragmentos de pneus podem afetar significativamente o valor da tensão cisalhamento máxima do solo. Por esse motivo, o material utilizado passou por um processo de peneiramento (Figura 3.8). Tal procedimento visou descartar todo material passante pela peneira de 9,5 mm (separação de desbastes de pneus e material fino como, por exemplo, migalhas de pneu, pó de pneu e pó fino de pneu).

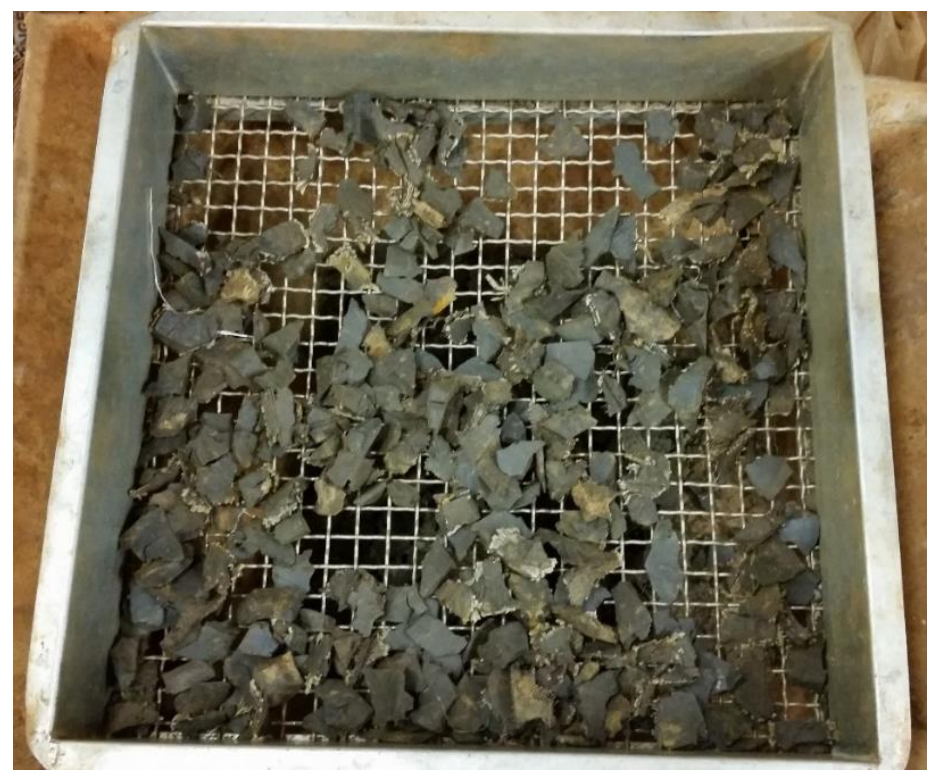

Figura 3.8. Peneiramento e separação de material com tamanho nominal inferior a 9,5 mm. 
Após o peneiramento, o material foi caracterizado por meio de análise granulométrica, seguindo-se a norma brasileira NBR7180 (ABNT, 1984). Para utilização da norma em questão, foi feita analogia ao comportamento da borracha como um material graúdo.

O resultado do ensaio de granulometria está apresentado na Figura 3.10. Das curvas, observou-se que existe predomínio de fragmentos com tamanho nominal entre 9,5 mm e 25,4 mm. O tamanho médio ( $\left.\mathrm{D}_{50}\right)$ das partículas é $20,0 \mathrm{~mm}, 15$ vezes menor que a parede lateral da caixa de cisalhamento utilizada.

Segundo Forsyth \& Egan (1976), este material é de baixo peso específico $(2,4$ a 7,0 kN/m³). Para esta pesquisa, foi realizado um ensaio peso especifico e absorção do material grosso (pedaços de borracha), avaliou-se um peso especifico de $5,1 \mathrm{kN} / \mathrm{m}^{3}$ e uma absorção de 2,6\%, realizando um processo de saturação do material durante 48 horas (Figura 3.9).

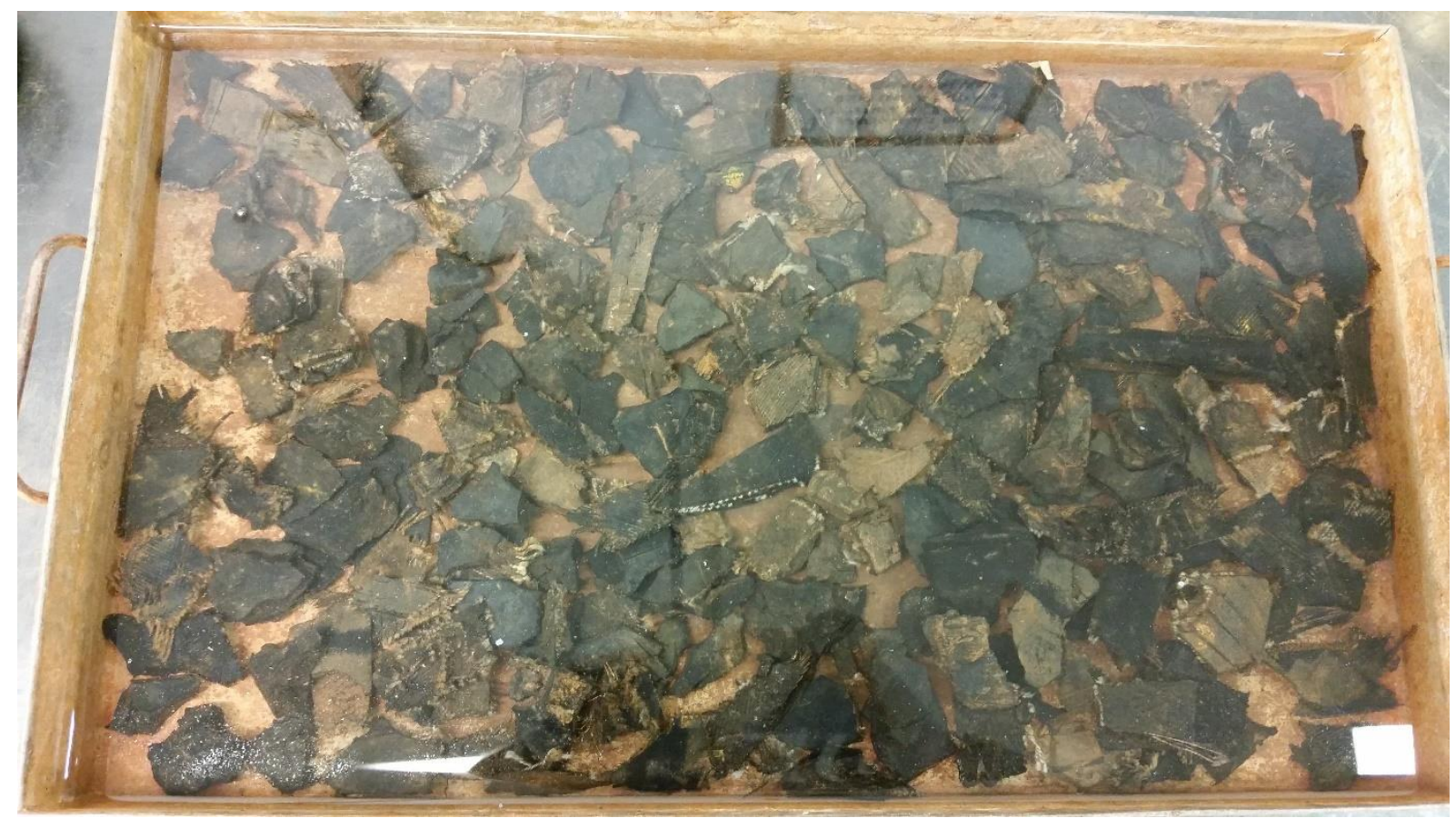

Figura 3.9. Processo de saturação dos pedaços de pneus durante 48 horas.

Chrusciak, (2013) realiza misturas de solo - borracha utilizando um material denominado resíduos de pneu, que está composto principalmente por pedaços de pneu, mas com presença material como migalhas e desbastes de pneu que segundo a revisão bibliográfica, podem afetar o valor de tensão cisalhante máxima das amostras. Na pesquisa, este material foi retirado por meio de processo de seleção e peneiramento, a Figura 3.11 apresenta uma 
comparação das curvas granulométricas utilizadas na pesquisa atual e na pesquisa realizada por Chrusciak (2013).

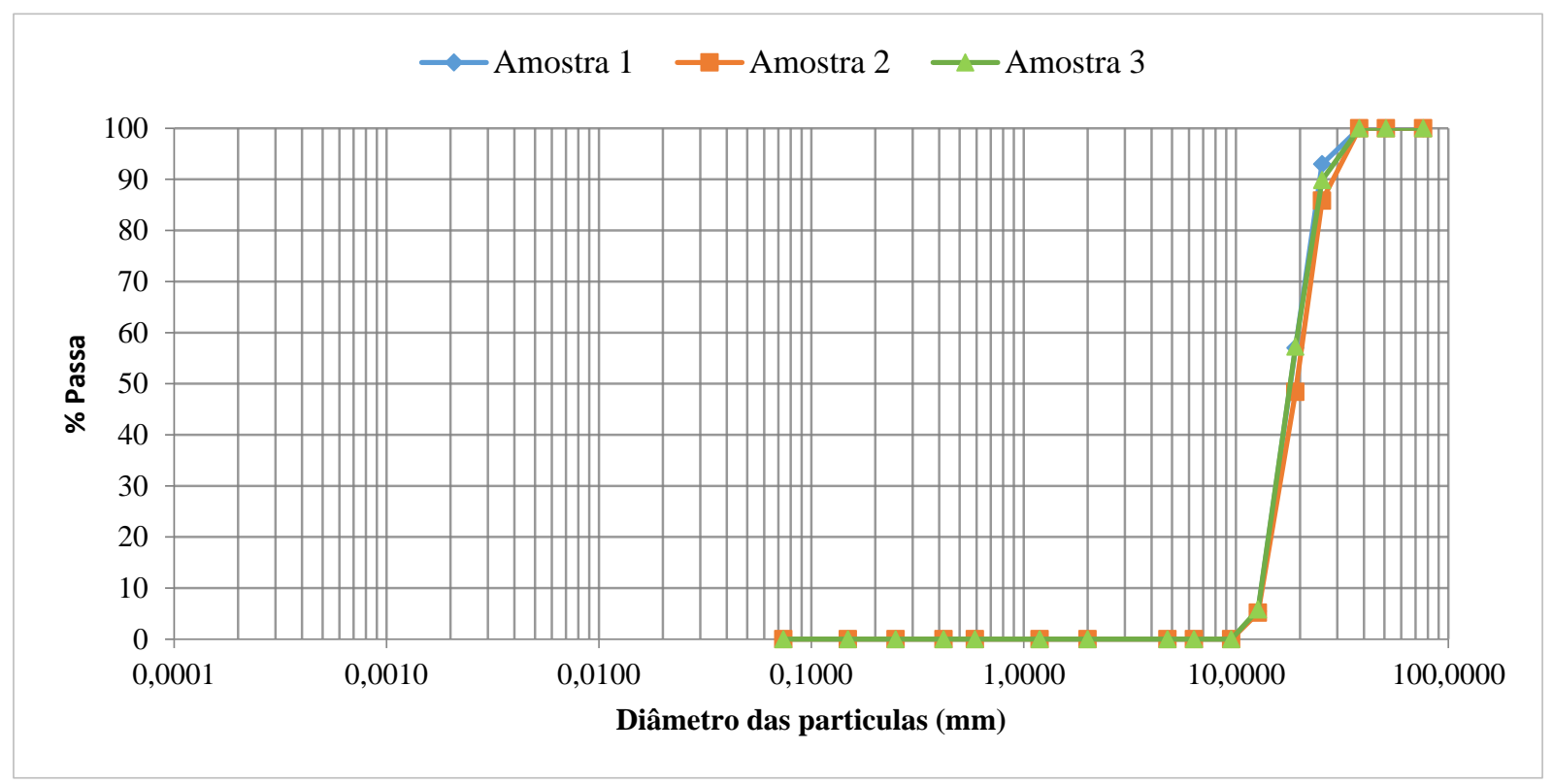

Figura 3.10. Curva granulométrica dos pedaços de pneus utilizados na pesquisa.

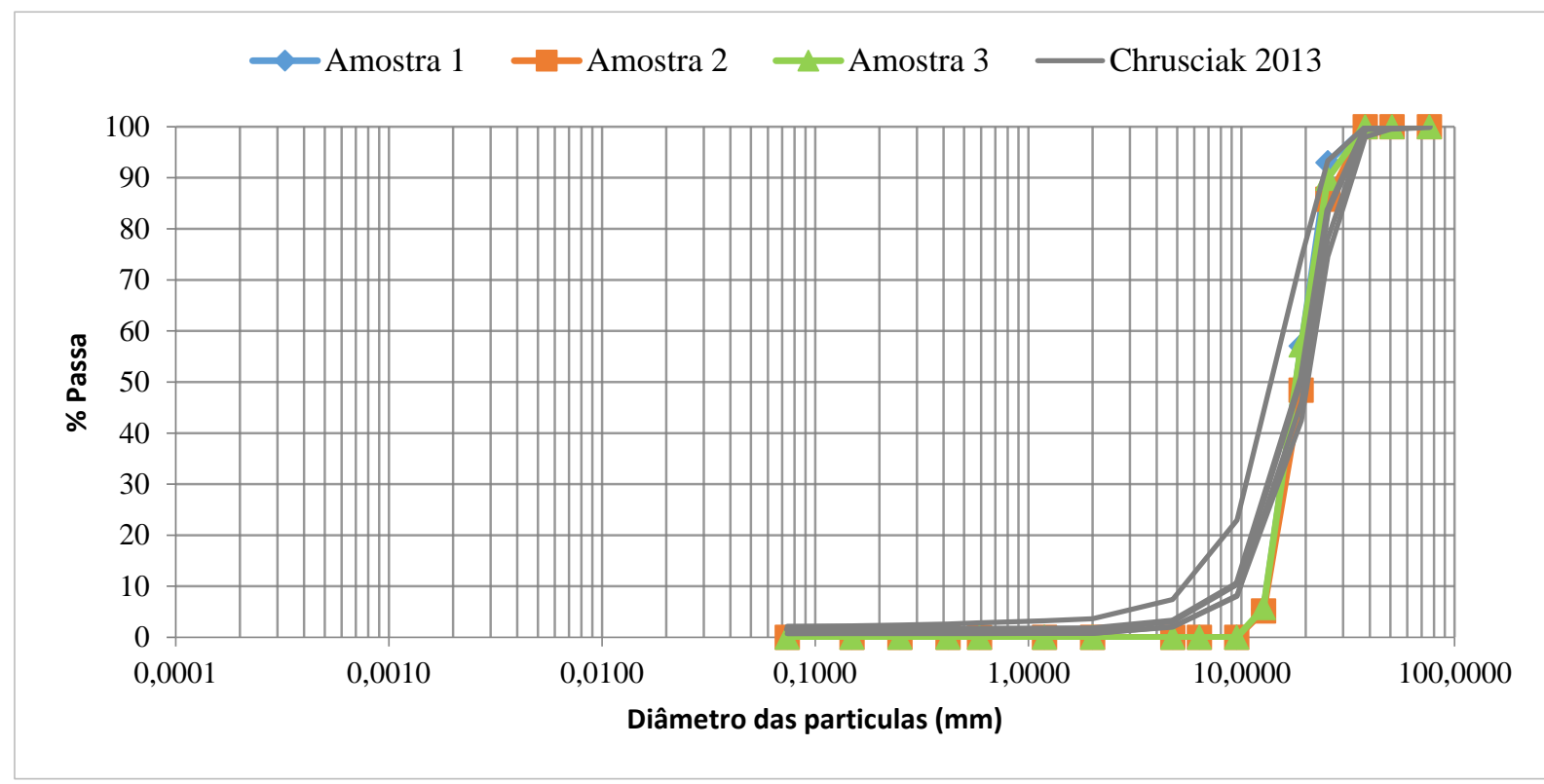

Figura 3.11. Curva granulométrica dos pedaços de pneus utilizados na pesquisa comparados com a curva granulométrica da borracha utilizada por (Chrusciak, 2013). 


\section{METODOLOGIA DA PESQUISA}

A metodologia da presente pesquisa foi baseada no trabalho desenvolvido por Chrusciak (2013) e em pesquisas prévias como Franco (2012) e Szeliga et al. (2014) que empregaram misturas de resíduos pneus com solo tropicais em equipamentos de menor escala.

Assim, a metodologia da presente pesquisa é baseada no estudo do teor ideal de mistura entre solo e borracha, obtido por meio de ensaios de cisalhamento direto em média escala para o solo puro. Foram feitos ensaios em amostras com 100\% de borracha e em amostras compostas pela mistura de solo laterítico e diferentes teores de borracha. Tendo em vista que os resultados obtidos por Chrusciak (2013) indicaram que não houve melhoria relevante da resistência ao cisalhamento das misturas quando compactadas sob uma energia de compactação normal, nesta pesquisa foi usada energia de compactação modificada e também solo com granulometria diferente.

Cada uma das misturas foi submetida a ensaios de compactação e de cisalhamento direto em equipamento de média escala. Os teores e a descrição das amostras estão apresentados na Tabela 4.1.

Tabela 4.1. Misturas utilizadas na pesquisa.

\begin{tabular}{|c|c|c|}
\hline No. Mistura & Teor de Borracha (\%) & Descrição \\
\hline M0 & 0 & Solo puro \\
\hline M2,5 & 2,5 & $97,5 \%$ solo $-2,5 \%$ pedaços de pneus \\
\hline M3,75 & 3,75 & $96,25 \%$ solo $-3,75 \%$ pedaços de pneus \\
\hline M5,0 & 5 & $95 \%$ solo $-5 \%$ pedaços de pneus \\
\hline M7,5 & 7,5 & $92,5 \%$ solo $-7,5 \%$ pedaços de pneus \\
\hline M10 & 10 & $90 \%$ solo $-10 \%$ pedaços de pneus \\
\hline M100 & 100 & Pedaços de pneu - puro \\
\hline
\end{tabular}

O peso da borracha misturado foi definido segundo a metodologia de Zornberg et al. (2004) e encontra-se apresentado na Equação 4.1:

$$
\mathrm{W}_{\mathrm{ts}}=\mathrm{W}_{\mathrm{S}} \frac{\mathrm{X}_{\mathrm{bor}}}{100-\mathrm{X}_{\mathrm{bor}}}
$$

Onde $\mathrm{W}_{\text {ts }}$ é o peso seco dos pedaços de borracha, $\mathrm{W}_{\mathrm{s}}$ o peso do solo seco e $\mathrm{X}_{\text {bor }}$ a porcentagem de borracha. 


\subsection{ENSAIO DE COMPACTAÇÃO}

Os ensaios de compactação foram realizados para o solo puro e para cada uma das misturas entre solo e borracha de pneus, sem reuso de material e seguindo-se os procedimentos descritos na normativa NBR 7182 (ABNT, 1986). As amostras de solo tiveram uma fase de secagem prévia até que fosse atingida a umidade higroscópica.

Os procedimentos de preparação das amostras e realização dos ensaios foram baseados nos ensaios realizados por Chrusciak (2013). Após o processo de secagem, foram separados $5 \mathrm{~kg}$ de solo para cada ponto da curva de compactação, adicionando-se água até que fosse atingida a umidade desejada. Após a mistura do solo com água, a borracha era adicionada e misturada (Figura 4.1).

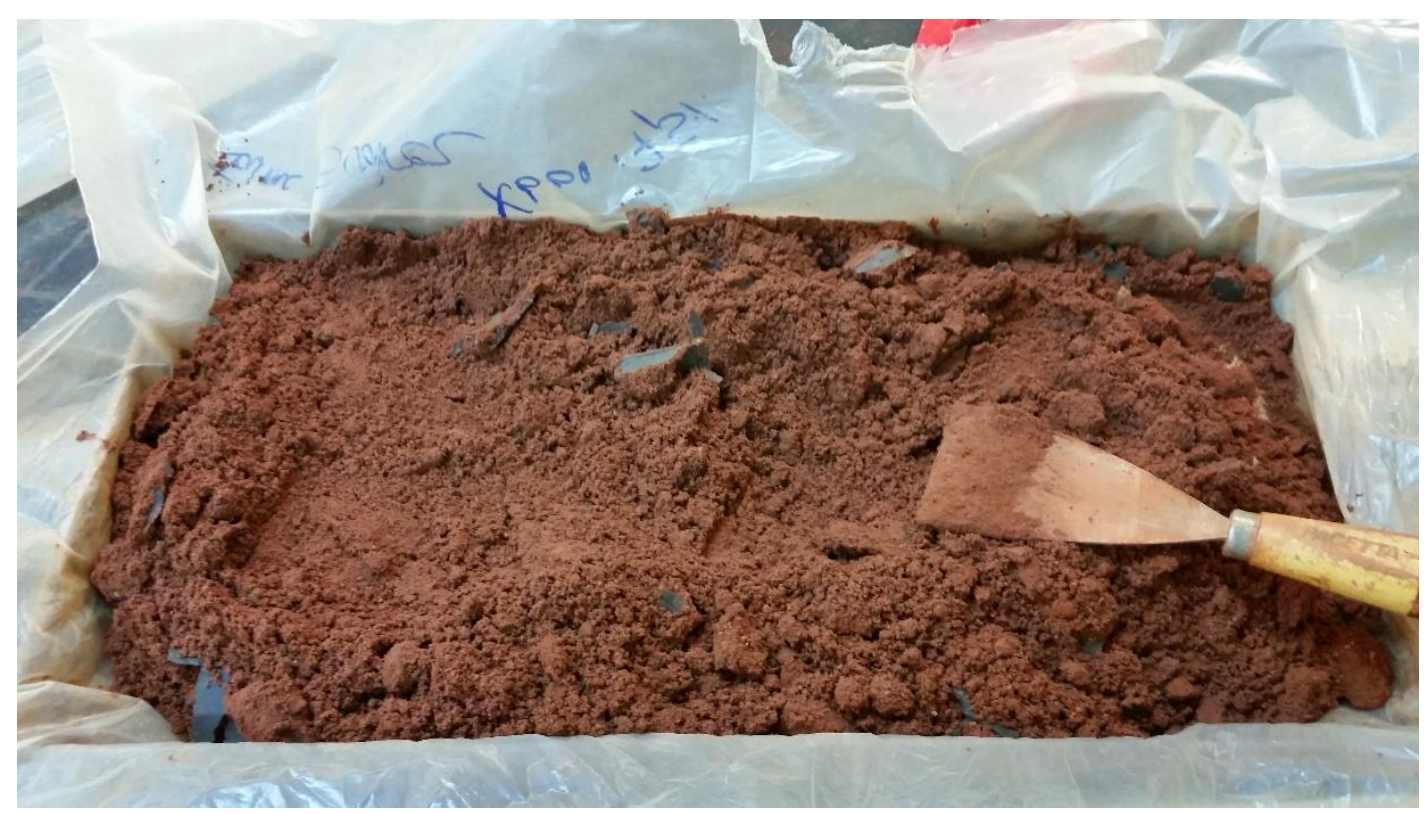

Figura 4.1. Preparação das misturas para os ensaios de compactação.

O cálculo do peso da borracha foi realizado empregando-se a Equação 4.1 e o cálculo da água a ser inserida foi realizado por meio da Equação 4.2. As quantidades de solo e de borracha, para cada uma das compactações realizadas, estão apresentadas na Tabela 4.2.

$$
V_{w}=\frac{W_{D}-W_{h}}{100} * M_{S}
$$


Onde: $V_{\mathrm{w}}$ é o volume de água a adicionar (igual ao valor em massa) para atingir-se a umidade desejada, em mililitros (ml), $\mathrm{W}_{\mathrm{D}}$ é a umidade desejada, em porcentagem (\%), $\mathrm{W}_{\mathrm{h}}$ é a umidade higroscópica, em porcentagem (\%) e $\mathrm{M}_{\mathrm{s}}$ é a massa da mistura solo-borracha em gramas (g).

Tabela 4.2. Porcentagens calculadas para realização dos ensaios de compactação.

\begin{tabular}{|c|c|c|c|c|}
\hline Amostra & $\begin{array}{c}\text { Teor de } \\
\text { Borracha }(\boldsymbol{\%})\end{array}$ & $\begin{array}{c}\text { Umidade } \\
\mathbf{( \% )}\end{array}$ & $\begin{array}{c}\text { Peso da } \\
\text { borracha } \\
\text { seca }(\mathbf{k g})\end{array}$ & $\begin{array}{c}\text { Peso do } \\
\text { solo seco } \\
(\mathbf{k g})\end{array}$ \\
\hline M0-16 & 0 & 16,32 & 0 & 5,00 \\
M0-18 & 0 & 18,11 & 0 & 5,00 \\
M0-19 & 0 & 18,82 & 0 & 5,00 \\
M0-21 & 0 & 21,07 & 0 & 5,00 \\
M0-22 & 0 & 22,48 & 0 & 5,00 \\
M2,5-16 & 2,5 & 16,73 & 0,125 & 4,88 \\
M2,5-18 & 2,5 & 18,54 & 0,125 & 4,88 \\
M2,5-19 & 2,5 & 19,21 & 0,125 & 4,88 \\
M2,5-21 & 2,5 & 20,82 & 0,125 & 4,88 \\
M2,5-22 & 2,5 & 21,42 & 0,125 & 4,88 \\
M2,5-16 & 3,75 & 16,51 & 0,188 & 4,81 \\
M3,75-18 & 3,75 & 18,35 & 0,188 & 4,81 \\
M3,75-19 & 3,75 & 19,43 & 0,188 & 4,81 \\
M3,75-21 & 3,75 & 20,45 & 0,188 & 4,81 \\
M3,75-22 & 3,75 & 22,34 & 0,188 & 4,81 \\
M5-16 & 5 & 16,51 & 0,250 & 4,75 \\
M5-18 & 5 & 18,30 & 0,250 & 4,75 \\
M5-19 & 5 & 19,39 & 0,250 & 4,75 \\
M5-21 & 5 & 20,29 & 0,250 & 4,75 \\
M5-22 & 5 & 21,01 & 0,250 & 4,75 \\
M7,5-16 & 7,5 & 16,29 & 0,375 & 4,63 \\
M7,5-18 & 7,5 & 18,44 & 0,375 & 4,63 \\
M7,5-19 & 7,5 & 19,23 & 0,375 & 4,63 \\
M7,5-21 & 7,5 & 20,37 & 0,375 & 4,63 \\
M7,5-22 & 7,5 & 22,47 & 0,375 & 4,63 \\
M10-16 & 10 & 16,22 & 0,500 & 4,50 \\
M10-18 & 10 & 18,07 & 0,500 & 4,50 \\
M10-19 & 10 & 19,47 & 0,500 & 4,50 \\
M10-21 & 10 & 20,81 & 0,500 & 4,50 \\
M10-22 & 10 & 22,53 & 0,500 & 4,50 \\
\hline
\end{tabular}

Após a execução das misturas entre solo, borracha e água, cada um dos conjuntos resultantes foi conservado em câmara úmida por vinte e quatro horas para completar sua 
homogeneização. A umidade do solo foi controlada antes e depois de sua homogeneização, seguindo-se as recomendações descritas na normativa NBR 6457 (ABNT, 1986).

Após os processos de preparação e homogeneização das amostras, foram realizadas as compactações das misturas, empregando-se os equipamentos convencionais do ensaio: cilindro de compactação, soquete grande e disco espaçador. Foi empregada a energia de compactação modificada, onde o cilindro é dividido em 5 camadas e são realizados 55 golpes com o soquete em cada camada. Após o processo da compactação (Figura 4.2), determinou-se o peso dos corpos de prova e foram recolhidas amostras para determinação da umidade.

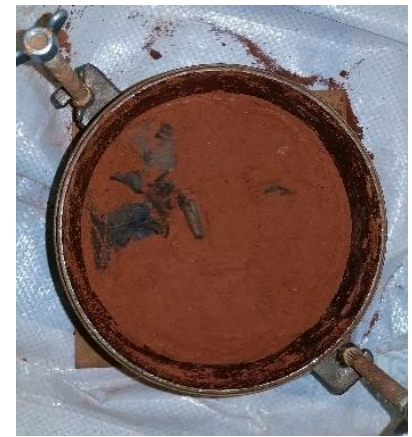

(a)

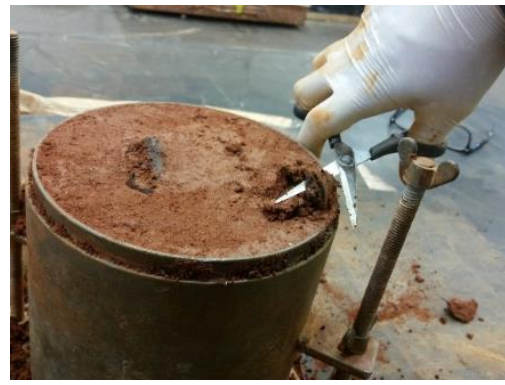

(b)

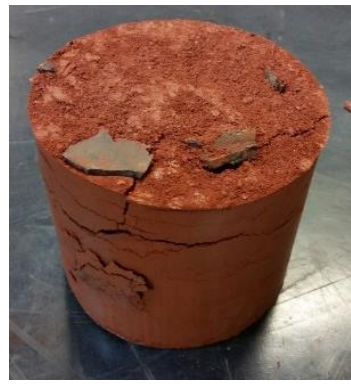

(c)

Figura 4.2. Realização dos ensaios de compactação:(a) Colocação da mistura no cilindro de compactação, (b) Nivelação dos cilindros e, (c) Estado final da amostra compactada e nivelada.

Com base nos resultados dos ensaios, determinou-se o peso especifico aparente seco máximo e a umidade ótima de compactação de cada amostra.

A partir dos valores de peso especifico aparente seco máximo, foi possível fazer uma análise da influência da introdução do material não coesivo no solo, por meio da variação de 
parâmetros como a massa específica dos sólidos e o índice de vazios. A massa específica dos sólidos da mistura pôde ser calculada por meio da Equação 4.3, a qual representa uma média ponderada entre os teores utilizados e o valor de $\mathrm{G}_{\mathrm{s}}$ para a borracha e para o solo. A influência no índice de vazios de cada uma das misturas utilizadas na pesquisa foi calculada de acordo com a Equação 4.4 .

$$
\mathrm{G}_{\mathrm{S}_{\mathrm{eq}}}=\frac{\mathrm{G}_{\mathrm{S}_{\mathrm{bor}}} * \mathrm{X}_{\mathrm{bor}}+\mathrm{G}_{\mathrm{S}_{\text {solo }}} * \mathrm{X}_{\text {solo }}}{100}
$$

Onde: Gseq é a massa específica dos sólidos da mistura, o Gsbor é a massa específica dos sólidos dos pedaços de pneus, Gssolo é a massa específica dos sólidos do solo, Xbor é o teor de borracha da mistura, e Xsolo é o teor de solo da mistura.

$$
\mathrm{e}=\frac{\mathrm{G}_{\mathrm{s}_{\mathrm{eq}}} * \gamma_{\mathrm{w}}-\gamma_{\mathrm{d}_{\text {máx }}}}{\gamma_{d_{\text {máx }}}}
$$

Onde: e é o índice de vazios, Gseq é a massa específica unitária dos sólidos da mistura, $\gamma$ dmáx é o peso especifico aparente seco máximo da mistura e $\gamma_{w}$ é o peso específico da água.

Com a variação da massa específica dos sólidos equivalente calculada para cada uma das misturas foi possível traçar as curvas de saturação, aplicando-se a Equação 4.5:

$$
\gamma_{d}=\frac{G_{s_{e q}} * \gamma_{w}}{1+\frac{W * G_{s_{e q}}}{s}}
$$

Onde: $\gamma_{\mathrm{d}}$ é o peso específico aparente seco, Gseq é a massa específica dos sólidos da mistura, $\gamma_{w}$ é o peso especifico da água, $W$ é a umidade, e $S$ é a saturação. 


\subsection{ENSAIO DE CISALHAMENTO DIRETO EM MÉDIA ESCALA}

Todos os procedimentos realizados nos ensaios de cisalhamento direto em equipamento de média escala foram baseados na norma ASTM D 3080/98 e na experiência obtida no trabalho de Chrusciak (2013).

Após a realização dos ensaios de compactação, onde foram encontrados os valores de peso específico aparente seco máximo e de umidade ótima para cada uma das misturas, foram preparadas as amostras a serem utilizadas em cada nos ensaios de cisalhamento em equipamento de média escala.

O processo de preparação de material a ser ensaiado foi realizado de maneira similar ao processo de preparação das amostras para os ensaios de compactação, salvo pequenas diferenças. Após processo de secagem prévia do material até a umidade higroscópica, foram separados cerca de trinta e dois quilos de material para cada ensaio, adicionando-se água até que a amostra atingisse a umidade ótima, para cada um dos teores de borracha das misturas estabelecidas na pesquisa.

Após preparação das misturas, as mesmas foram inseridas em câmara úmida para melhor homogeneização durante vinte e quatro horas. Foram feitas medições da umidade do material após a homogeneização assim como logo após a realização dos ensaios de cisalhamento, de acordo a normativa NBR6457 (ABNT, 1986), com o objetivo de verificar a variação da umidade durante a realização dos ensaios de cisalhamento.

Após a homogeneização do material, o mesmo foi compactado dentro do equipamento de cisalhamento em média escala por meio de compactação estática. A fim de realizar uma compactação homogênea, o processo de compactação do corpo de prova foi dividido em três camadas: duas de 58,3 mm e uma de 58,4 mm, totalizando uma altura de $175 \mathrm{~mm}$. Assim, foram separados três sacos com material suficiente para compactar cada camada do corpo de prova. A sequência de instalação dos corpos de prova dentro do equipamento de cisalhamento direto de média escala encontra-se apresentada na Figura 4.3.

Os cálculos dos pesos de material necessário para cada saco, com a finalidade de moldar os corpos de prova dentro do equipamento de cisalhamento direto foram feitos por meio da 


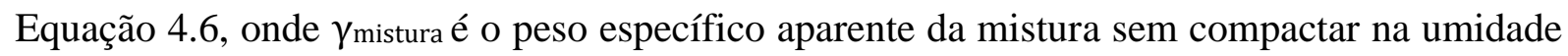
ótima, $\gamma$ dmáx é o peso específico seco máximo da mistura no ensaio de compactação e $W$ é a umidade ótima. Os valores das quantidades do material utilizado nos ensaios de cisalhamento direto estão apresentados na Tabela 4.3.

Tabela 4.3. Quantidades calculadas de material para realização dos ensaios de cisalhamento direto de média escala.

\begin{tabular}{|c|c|c|c|c|c|c|}
\hline \multicolumn{7}{|c|}{ M0 } \\
\hline \multirow{4}{*}{$\begin{array}{c}\text { Teor de borracha }(\%) \\
\gamma_{\text {dmáx }}\left(\mathrm{kN} / \mathrm{m}^{\mathbf{3}}\right) \\
\text { Umidade Otima }(\%) \\
\text { Densidade }\left(\mathrm{g} / \mathrm{cm}^{\mathbf{3}}\right) \\
\end{array}$} & \multirow{4}{*}{$\begin{array}{c}0,00 \\
16,98 \\
19,13 \\
2,06 \\
\end{array}$} & \multicolumn{2}{|c|}{ Volume da Caixa $\mathrm{cm}^{3}$} & \multicolumn{3}{|c|}{15750,00} \\
\hline & & Camada & 1 & 2 & 3 & Total \\
\hline & & Volume $\mathrm{cm}^{3}$ & 5247,00 & 5247,00 & 5256,00 & 15750,00 \\
\hline & & Peso (g) & 10830,38 & 10830,38 & 10848,96 & 32509,73 \\
\hline \multicolumn{7}{|c|}{ M2,5 } \\
\hline Teor de borracha $(\%)$ & 2,50 & \multicolumn{2}{|c|}{ Volume da Caixa $\mathrm{cm}^{3}$} & \multicolumn{3}{|c|}{15750,00} \\
\hline$\gamma_{\text {dmáx }}\left(k N / m^{3}\right)$ & 16,83 & Camada & $\mathbf{1}$ & 2 & 3 & Total \\
\hline Umidade Otima (\%) & 19,25 & Volume $\mathbf{c m}^{3}$ & 5247,00 & 5247,00 & 5256,00 & 15750,00 \\
\hline Densidade $\left(\mathrm{g} / \mathrm{cm}^{3}\right)$ & 2,04 & Peso (g) & 10745,52 & 10745,52 & 10763,95 & 32255,00 \\
\hline \multicolumn{7}{|c|}{ M3,75 } \\
\hline Teor de borracha $(\%)$ & 3,75 & \multicolumn{2}{|c|}{ Volume da Caixa $\mathrm{cm}^{3}$} & \multicolumn{3}{|c|}{15750,00} \\
\hline$\gamma_{\text {dmáx }}\left(k N / m^{3}\right)$ & 16,59 & Camada & 1 & 2 & 3 & Total \\
\hline Umidade Otima (\%) & 19,29 & Volume $\mathrm{cm}^{3}$ & 5247,00 & 5247,00 & 5256,00 & 15750,00 \\
\hline Densidade $\left(\mathrm{g} / \mathrm{cm}^{3}\right)$ & 2,01 & Peso (g) & 10595,84 & 10595,84 & 10614,02 & 31805,70 \\
\hline \multicolumn{7}{|c|}{ M5 } \\
\hline Teor de borracha $(\%)$ & 5,00 & \multicolumn{2}{|c|}{ Volume da Caixa $\mathrm{cm}^{3}$} & \multicolumn{3}{|c|}{15750,00} \\
\hline$\gamma_{\text {dmáx }}\left(k N / m^{3}\right)$ & 16,50 & Camada & 1 & 2 & 3 & Total \\
\hline Umidade Otima $(\%)$ & 19,34 & Volume $\mathrm{cm}^{3}$ & 5247,00 & 5247,00 & 5256,00 & 15750,00 \\
\hline Densidade $\left(\mathrm{g} / \mathrm{cm}^{3}\right)$ & 2,00 & Peso (g) & 10542,78 & 10542,78 & 10560,86 & 31646,41 \\
\hline \multicolumn{7}{|c|}{ M7,5 } \\
\hline Teor de borracha $(\%)$ & 7,50 & \multicolumn{2}{|c|}{ Volume da Caixa $\mathrm{cm}^{3}$} & \multicolumn{3}{|c|}{15750,00} \\
\hline$\gamma_{\text {dmáx }}\left(\mathbf{k N} / \mathbf{m}^{3}\right)$ & 16,30 & Camada & 1 & 2 & 3 & Total \\
\hline Umidade Otima (\%) & 19,40 & Volume $\mathbf{c m}^{3}$ & 5247,00 & 5247,00 & 5256,00 & 15750,00 \\
\hline Densidade $\left(\mathrm{g} / \mathrm{cm}^{3}\right)$ & 1,98 & Peso (g) & 10420,22 & 10420,22 & 10438,09 & 31278,54 \\
\hline \multicolumn{7}{|c|}{ M10 } \\
\hline Teor de borracha $(\%)$ & 10,00 & \multicolumn{2}{|c|}{ Volume da Caixa $\mathrm{cm}^{3}$} & \multicolumn{3}{|c|}{15750,00} \\
\hline$\gamma_{\text {dmáx }}\left(k N / m^{3}\right)$ & 16,25 & Camada & 1 & 2 & 3 & Total \\
\hline Umidade Otima (\%) & 19,45 & Volume $\mathbf{c m}^{3}$ & 5247,00 & 5247,00 & 5256,00 & 15750,00 \\
\hline Densidade $\left(\mathrm{g} / \mathrm{cm}^{3}\right)$ & 1,96 & Peso (g) & 10392,61 & 10392,61 & 10410,43 & 31195,95 \\
\hline \multicolumn{7}{|c|}{ M100 } \\
\hline Teor de borracha $(\%)$ & 100,00 & \multicolumn{2}{|c|}{ Volume da Caixa $\mathrm{cm}^{3}$} & \multicolumn{3}{|c|}{15750,00} \\
\hline$\gamma_{\text {dmáx }}\left(\mathbf{k N} / \mathbf{m}^{3}\right)$ & & Camada & 1 & 2 & 3 & Total \\
\hline Umidade Otima (\%) & - & Volume $\mathrm{cm}^{3}$ & 5247,00 & 5247,00 & 5256,00 & 15750,00 \\
\hline Densidade $\left(\mathrm{g} / \mathrm{cm}^{3}\right)$ & 0,53 & Peso (g) & 27780,91 & 2780,91 & 2785,68 & 8347,50 \\
\hline
\end{tabular}




$$
\gamma_{\text {mistura }}=\gamma_{\text {dmáx }}\left(1+W_{\text {ót }}\right)
$$

Equação 4.6.

Onde: $\gamma_{\text {mistura }}$ é o peso especifico da mistura sem compactar, $\gamma_{\text {dmáx }}$ é o peso especifico aparente seco máximo compactado, e Wóté a umidade ótima de compactação.

Além dos ensaios com solo e misturas solo-borracha em deferentes teores, realizaram-se ensaios para amostras compostas por borracha pura (M100), afim de determinar o comportamento mecânico no caso de se utilizar este tipo de material isoladamente. $\mathrm{O}$ ensaio foi realizado fazendo-se uma analogia do material como material graúdo e seguindo-se os procedimentos estabelecidos na normativa ASTM D 3080/98. Na Figura 4.4 apresenta-se um corpo de prova composto por pedaços de pneus instalado dentro do equipamento de cisalhamento direto de média escala.

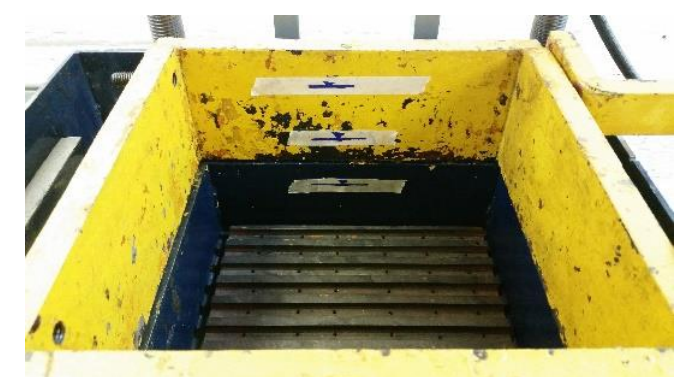

(a)

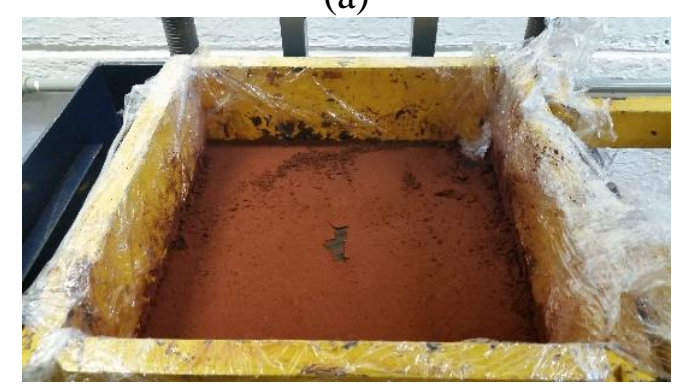

(c)

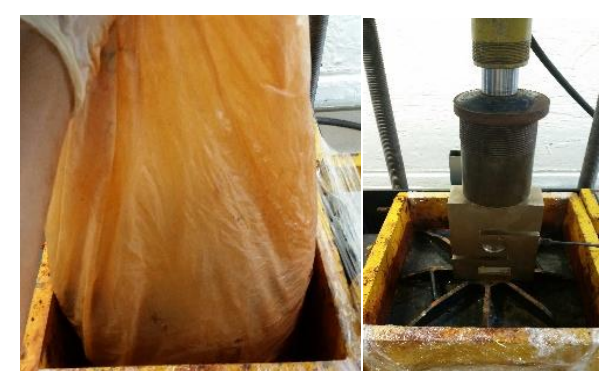

(b)

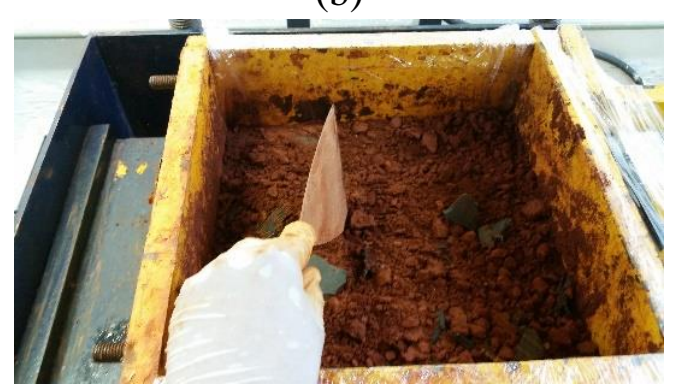

(d)

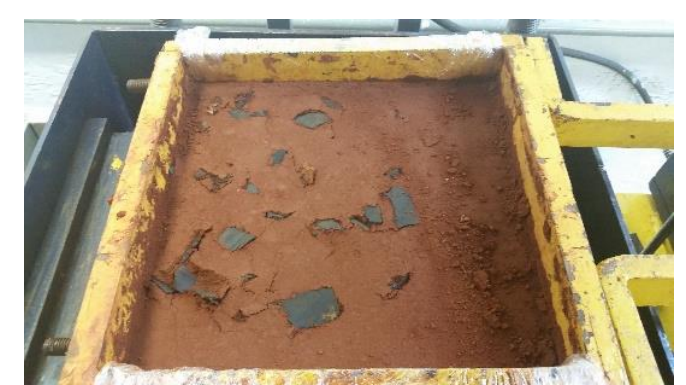

(e)

Figura 4.3. Preparação das amostras para o ensaio de cisalhamento direto de média escala: (a) divisão da caixa e definição das alturas de cada camada; (b) deposição e compactação estática do material; (c) camada compactada; (d) escarificarão entre camadas, e; (d) corpo de prova compactado. 


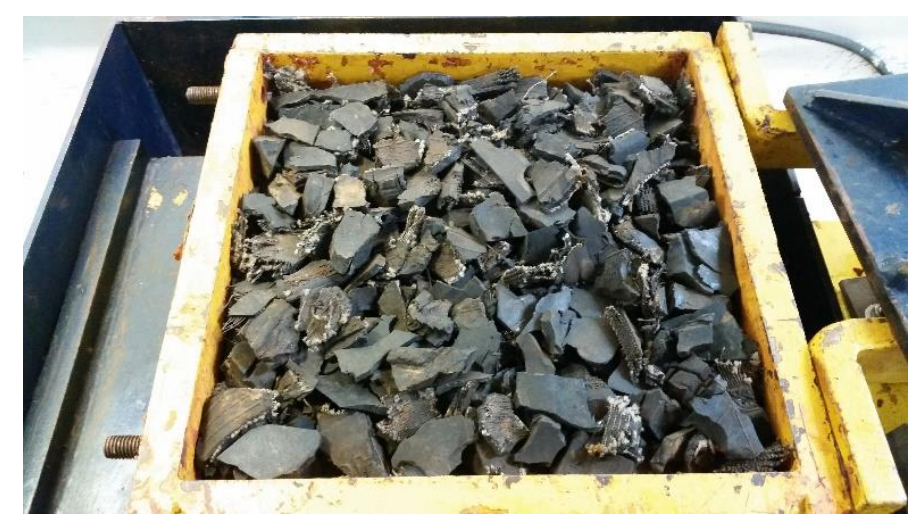

Figura 4.4. Amostras compostas por pedaços de pneu puro (M100) instaladas no equipamento de cisalhamento direto de média escala.

Estudos realizados por Palmeira (2009) evidenciaram a influência do atrito gerado pela rugosidade da face lateral da caixa de cisalhamento na tensão normal e no plano de ruptura, sendo o ensaio realizado com uma caixa de corte fixa parafusada (Figura 4.5). Chrusciak (2013) utiliza a mesma caixa fixa e realiza correção do ensaio por meio da equação proposta por Palmeira (2009) por meio da Equação 4.7, cuja distribuição de tensões atua conforme a Figura 4.6.

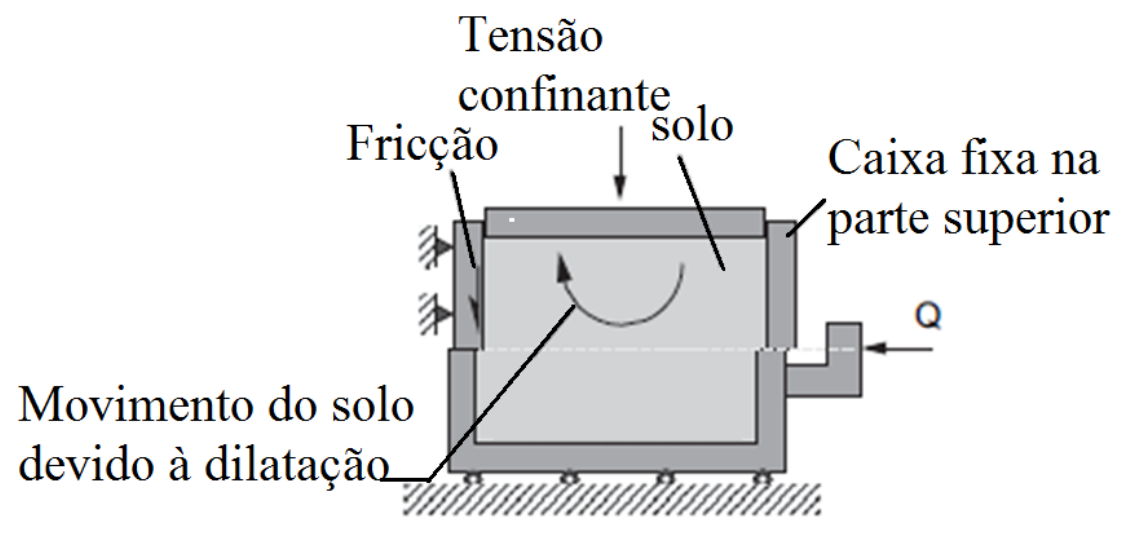

Figura 4.5. Atrito na parede lateral no ensaio de cisalhamento (Palmeira, 2009). 


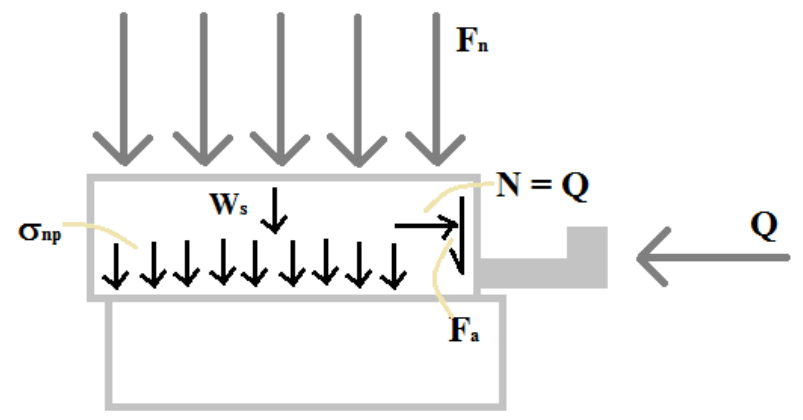

Figura 4.6. Analogia utilizada por Palmeira (2009). Figura apresentada no relatório realizado por (Chrusciak, 2013).

$$
\sigma_{n_{p}}=\sigma_{n}+\frac{W_{S}+\left(Q+\sigma_{n} * A_{L} * K_{0}\right) * \tan \varphi_{S W}}{A}
$$

Equação 4.7.

Onde, $\sigma_{\mathrm{np}}$ é a tensão normal no plano de ruptura, $\sigma_{\mathrm{n}}$ é a tensão normal aplicada pela bomba hidráulica, ws é a força peso da parte superior ao plano de ruptura, Q é a máxima força de cisalhamento, AL é a área lateral de atuação da carga, ko é o coeficiente de empuxo no repouso, $\varphi_{\text {sw }}$ é o ângulo de atrito entre o solo e a parede da caixa e A é a área de atuação da força normal.

$\mathrm{Na}$ pesquisa atual, foram realizadas mudanças na utilização da caixa de corte a fim de diminuir o atrito entre caixa de cisalhamento e o solo. As paredes da caixa foram lubrificadas com óleo e celofane (papel filme) e, além disso, a caixa foi desparafusada para permitir movimentação livre. Assim, o valor de $\varphi_{\text {ws }}$ na Equação 4.7 é reduzido (para efeitos práticos foi utilizado um valor de zero por dificuldades na medição desse valor e aplicando o caso para uma caixa desparafusada). Estas alterações foram feitas baseadas nas recomendações de Palmeira (2009).

Após os processos de instalação e compactação das amostras no equipamento, foram aplicadas tensões confinantes de $25 \mathrm{kPa}, 50 \mathrm{kPa} 80 \mathrm{kPa}$ e $100 \mathrm{kPa}$. As três primeiras tensões foram estabelecidas com a finalidade de comparação com os resultados obtidos por Chrusciak (2013), enquanto que a última tensão foi estabelecida de forma a seguir os procedimentos da norma ASTM D 3080/98. 
Por meio dos procedimentos descritos na norma anteriormente mencionada, aguardou-se um tempo para que ocorresse o adensamento da amostra, em média de 14 horas. Após esse tempo foi dado início o processo de cisalhamento.

Os ensaios foram realizados conforme a norma ASTM D 3080/98 em condições drenadas e adensadas (CD), sendo a velocidade do ensaio iguala $0,1016 \mathrm{~mm} / \mathrm{min}$, baseando-se em pesquisas prévias e no parâmetro t90, obtido das curvas de adensamento do material. Assim, a duração de cada ensaio (etapa de cisalhamento) foi em média de 4 horas, tempo esse bem maior que os valores obtidos pelo cálculo a partir do t90.Terminado cada um dos ensaios foi feita a determinação da umidade das amostras, seguindo-se os procedimentos estabelecidos na norma NBR6457 (ABNT, 1986). 


\section{APRESENTAÇÃO E DISCUSSÃO DE RESULTADOS}

Neste capítulo são apresentados os resultados dos ensaios de compactação e dos ensaios de cisalhamento direto de dimensões médias para cada um dos teores de borracha estabelecidos anteriormente. Os ensaios de compactação foram realizados a fim de se determinar o peso específico aparente seco máximo $\left(\gamma_{\mathrm{d}, \text { máx }}\right)$ associado ao teor de umidade ótima ( $\mathrm{W}_{\text {ót }}$ ), parâmetros estes necessários para compactação estática do material no interior do equipamento de cisalhamento. Os ensaios de cisalhamento direto foram realizados para determinar a influência da inclusão de fragmentos de borracha na tensão cisalhante máxima do solo estudado ( $\left.\tau_{\text {máx }}\right)$.

\subsection{ENSAIO DE COMPACTAÇÃO}

Foram realizados ensaios de compactação seguindo-se os procedimentos estabelecidos na normativa NBR7182 (ABNT, 1986), para os diferentes teores de borracha utilizados na pesquisa, $0 \%$ (solo puro), $2 \%, 3,75 \%, 5 \%, 7,5 \%$ e $10 \%$ sob uma energia de compactação modificada. Os resultados dos ensaios de compactação estão apresentados nas Figura A.1 à Figura A.6 do apêndice A, onde estão destacados os valores de peso específico aparente seco máximo $\left(\gamma_{\text {dmáx }}\right)$ e de umidade ótima (Wót. $)$ para cada uma das misturas. Na Figura 5.1 apresenta-se o resumo de todas as curvas de compactação realizadas, observa-se que o peso específico aparente seco máximo $\left(\gamma_{\mathrm{dmáx}}\right)$ das misturas apresentou diminuição (variação até $4,3 \%$ do valor) com o aumento do teor de borracha, em unidades de peso (de $0 \%$ a $10 \%$ em peso); a variação observada na umidade ótima (Wót) não é significativa teoricamente (variação de $1,7 \%$ ), devido que a borracha é um material leve de baixa absorção. 


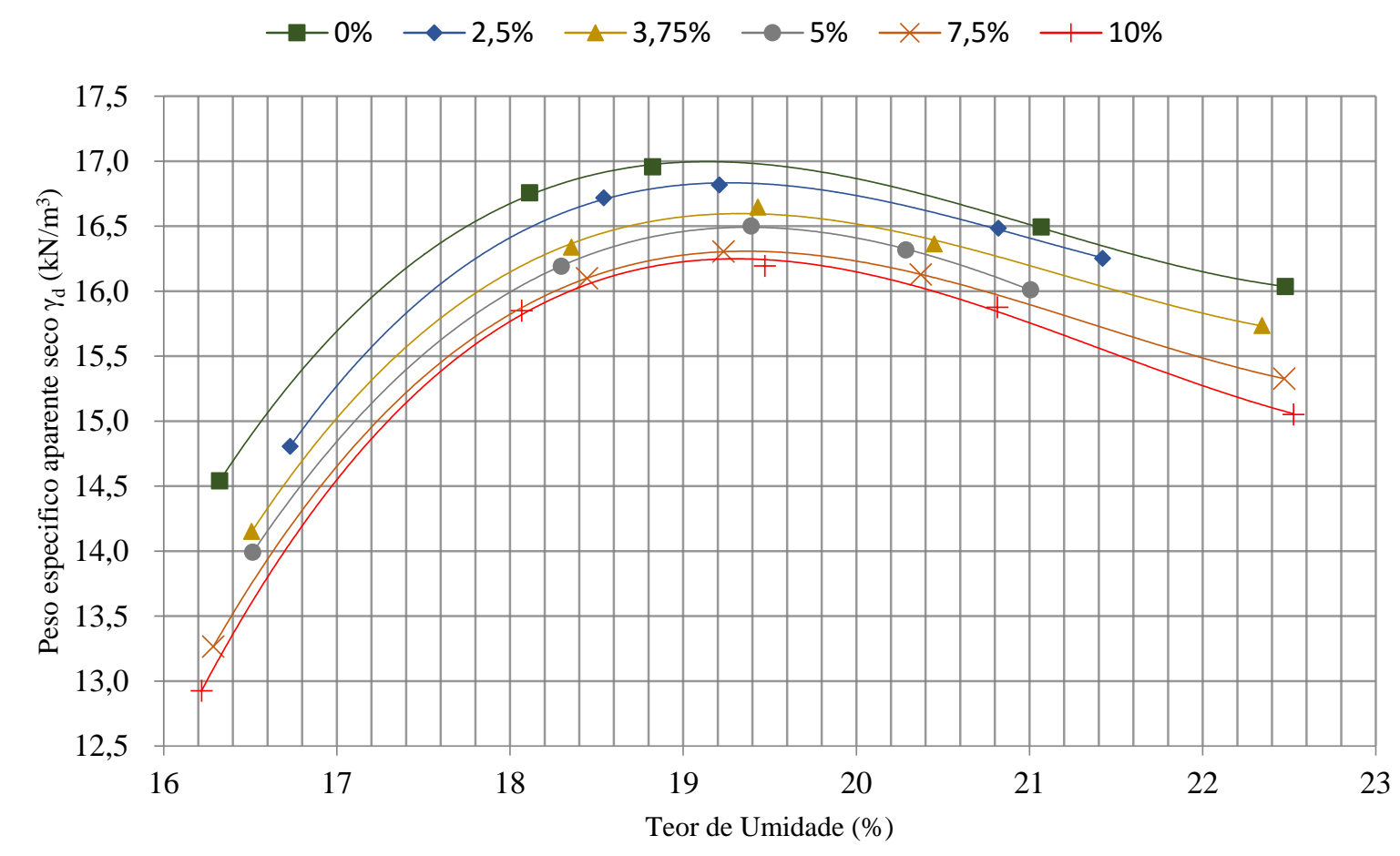

Figura 5.1.Resumo curvas de compactação para todos os teores de borracha.

Estes resultados podem ser observados na Tabela 5.1, onde se apresenta o resumo dos resultados obtidos nas compactações e o coeficiente de determinação de cada uma das curvas de compactação $\left(\mathrm{R}^{2}\right)$. Com os valores de $\mathrm{R}^{2}$ apresentados, verificou-se que as curvas apresentadas estão bem ajustadas.

Tabela 5.1. Valores de $\gamma_{\text {dmáx }}$ e $\mathrm{W}_{\text {ót }}$ nos ensaios de compactação para todos os teores de borracha.

\begin{tabular}{|c|c|c|c|c|}
\hline No. Mistura & Teor de Borracha $(\%)$ & $\gamma d_{\text {máx }}\left(\boldsymbol{k N} / \boldsymbol{m}^{3}\right)$ & $W_{\text {ot }}(\%)$ & $R^{2}$ \\
\hline M0 & 0 & 16,98 & 19,13 & 0,9998 \\
\hline M2,5 & 2,5 & 16,83 & 19,25 & 0,9998 \\
\hline M3,75 & 3,75 & 16,59 & 19,29 & 0,9989 \\
\hline M5 & 5 & 16,50 & 19,34 & 1 \\
\hline M7,5 & 7,5 & 16,30 & 19,4 & 1 \\
\hline M10 & 10 & 16,25 & 19,45 & 0,9993 \\
\hline
\end{tabular}


No ensaio de compactação, quando os corpos de prova são retirados dos cilindros metálicos e desconfiados, observa-se presença de trincas e planos de fraqueza resultantes da inclusão de borracha de pneus. Isso ocorre porque a borracha é um material não coesivo e que, após o desconfinamento, apresenta relaxamento de material (ver Figura 5.2).

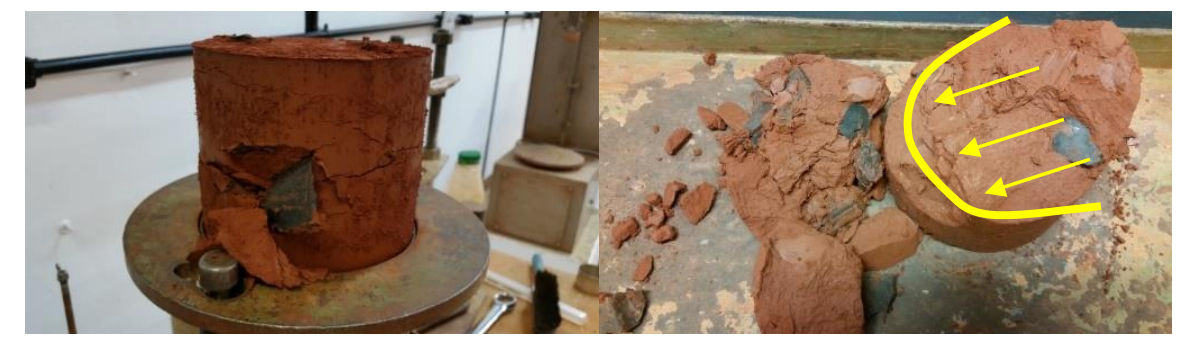

Figura 5.2. Geração de trincas e planos de fraqueza nos corpos de prova pela presença de fragmentos de borracha.

A Figura 5.3 apresenta os corpos de prova realizados durante os ensaios de compactação que variam desde um teor de $0 \%$ até um teor de $10 \%$ de borracha. Observa-se que presença de trincas é maior nos corpos de prova com elevado teor de fragmentos de borracha. Até um teor de borracha igual a 5\%, observa-se que as estruturas dos corpos de prova não se encontram tão afetados pela mistura com o material não coesivo.

Na Tabela 5.2 observam-se os resultados de cada uma das compactações, estando o peso específico aparente seco $\left(\gamma_{\mathrm{d}}\right)$ relacionado a uma umidade para cada um dos corpos de prova.

Por meio da Equação 4.3 e da Equação 4.4, foram calculados os valores de massa específica dos sólidos e índice de vazios para cada uma das misturas em cada um dos corpos de prova. Na Figura 5.4 verifica-se que não existe uma variação significativa da matriz estrutural nos corpos de prova quando eles atingem sua umidade ótima de compactação, já que o valor de índice de vazios é bem próximo, assim como o apresentado na pesquisa de Chrusciack (2013). 


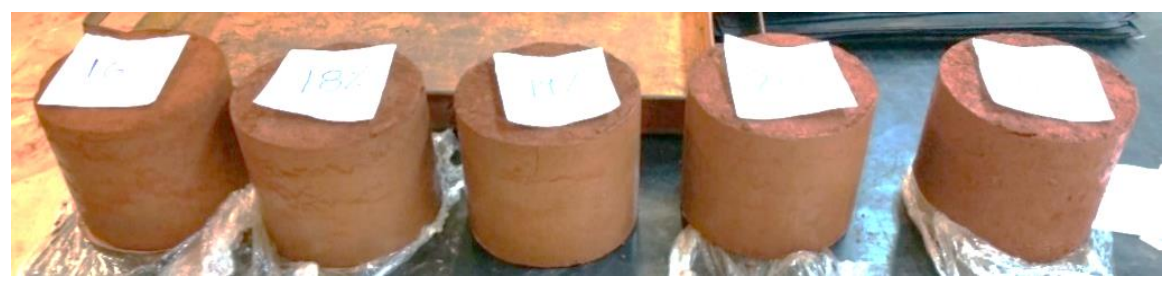

(a)

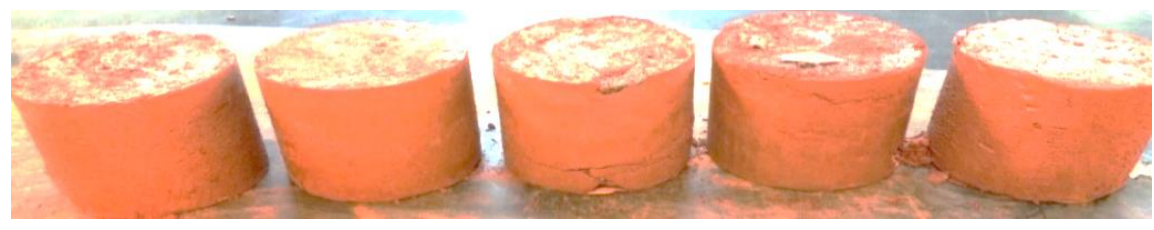

(b)

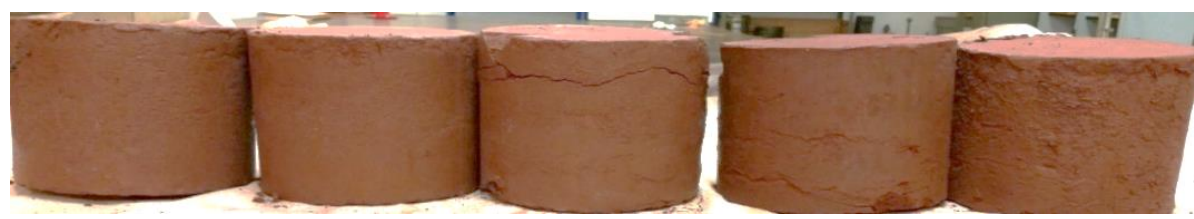

(c)

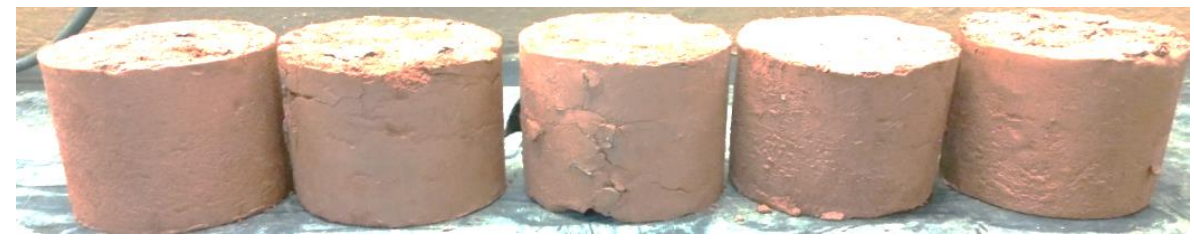

(d)

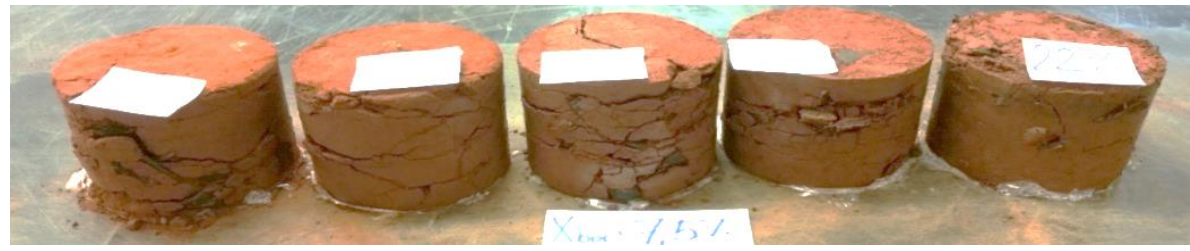

(e)

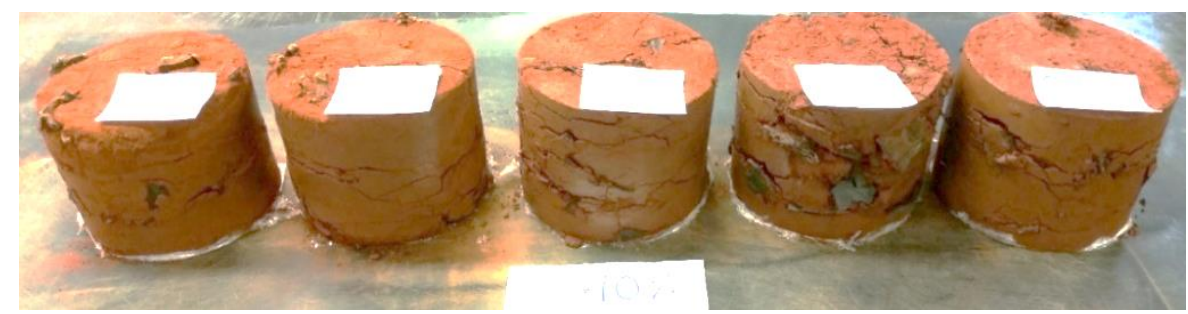

(f)

Figura 5.3.Corpos de prova dos ensaios de compactação para todos os teores de borracha: (a) M0 -0\% de teor de borracha; (b) M2,5 - 2,5\% de teor de borracha; (c) M3,75-3,75\% de teor de borracha; (d) M5-5\% de teor de borracha; (e) M7,5 - 7,5\% de teor de borracha, e; (f) M10 $-10 \%$ de teor de borracha. 
Tabela 5.2. Resumo dos resultados dos ensaios de compactação para todos os teores de borracha.

\begin{tabular}{|c|c|c|c|c|c|}
\hline Amostra & $\begin{array}{c}\text { Teor de } \\
\text { borracha }(\%)\end{array}$ & $\gamma_{d}\left(k N / m^{3}\right)$ & $W(\%)$ & $G_{e q}$ & $e$ \\
\hline \multirow{5}{*}{ M0 } & 0 & 14,54 & 16,32 & \multirow{5}{*}{2,68} & 0,843 \\
\hline & 0 & 16,76 & 18,11 & & 0,599 \\
\hline & 0 & 16,96 & 18,82 & & 0,581 \\
\hline & 0 & 16,49 & 21,07 & & 0,625 \\
\hline & 0 & 16,03 & 22,48 & & 0,671 \\
\hline \multirow{5}{*}{$\mathrm{M} 2,5$} & 2,5 & 14,79 & 16,73 & \multirow{5}{*}{2,64} & 0,785 \\
\hline & 2,5 & 16,70 & 18,54 & & 0,581 \\
\hline & 2,5 & 16,79 & 19,21 & & 0,571 \\
\hline & 2,5 & 16,46 & 20,82 & & 0,603 \\
\hline & 2,5 & 16,21 & 21,42 & & 0,626 \\
\hline \multirow{5}{*}{ M3,75 } & 3,75 & 14,14 & 16,51 & \multirow{5}{*}{2,62} & 0,854 \\
\hline & 3,75 & 16,31 & 18,35 & & 0,606 \\
\hline & 3,75 & 16,61 & 19,43 & & 0,576 \\
\hline & 3,75 & 16,32 & 20,45 & & 0,604 \\
\hline & 3,75 & 15,68 & 22,34 & & 0,667 \\
\hline \multirow{5}{*}{ M5 } & 5 & 13,97 & 16,51 & \multirow{5}{*}{2,61} & 0,862 \\
\hline & 5 & 16,16 & 18,30 & & 0,609 \\
\hline & 5 & 16,46 & 19,39 & & 0,579 \\
\hline & 5 & 15,26 & 20,29 & & 0,597 \\
\hline & 5 & 15,95 & 21,01 & & 0,627 \\
\hline \multirow{5}{*}{ M7,5 } & 7,5 & 13,24 & 16,29 & \multirow{5}{*}{2,57} & 0,936 \\
\hline & 7,5 & 16,05 & 18,44 & & 0,595 \\
\hline & 7,5 & 16,24 & 19,23 & & 0,575 \\
\hline & 7,5 & 16,05 & 20,37 & & 0,592 \\
\hline & 7,5 & 15,22 & 22,47 & & 0,676 \\
\hline \multirow{5}{*}{ M10 } & 10 & 12,82 & 16,22 & \multirow{5}{*}{2,53} & 0,958 \\
\hline & 10 & 15,72 & 18,07 & & 0,597 \\
\hline & 10 & 16,05 & 19,47 & & 0,563 \\
\hline & 10 & 15,72 & 20,81 & & 0,594 \\
\hline & 10 & 14,86 & 22,53 & & 0,681 \\
\hline
\end{tabular}




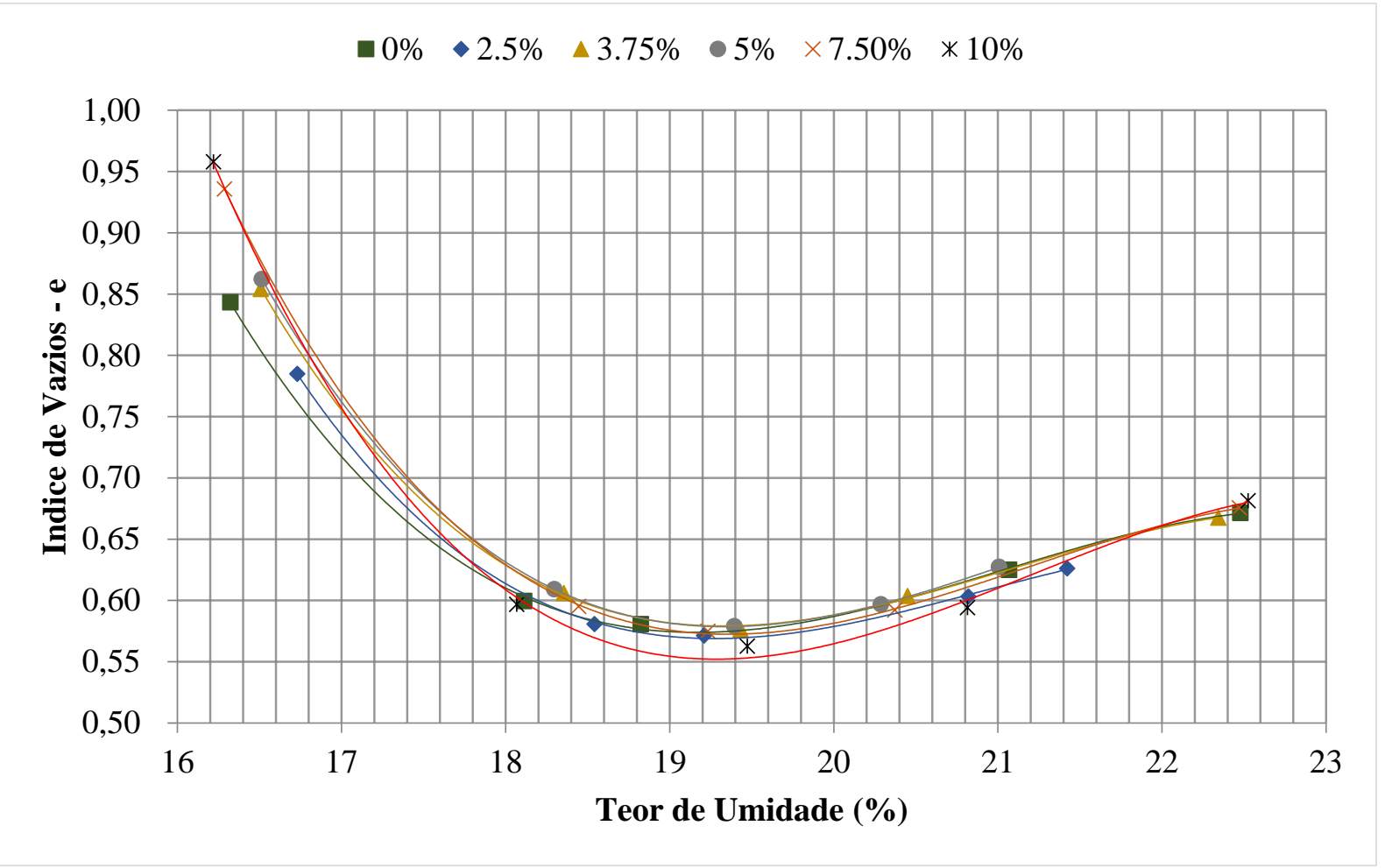

Figura 5.4. Resumo curvas índice de vazios para todos os teores de borracha.

Por meio da Figura 5.5 e da Figura 5.6 verifica-se como ocorre a variação do peso específico aparente seco ( $\gamma$ dmáx) e da umidade ótima de compactação (Wót) com a variação do teor de

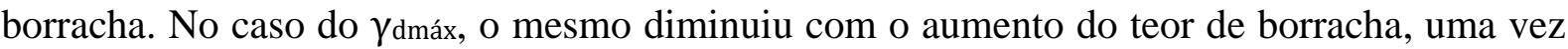
que a densidade do material proveniente dos pneus é menor que a densidade do solo compactado e, por esse motivo, com o acréscimo teor borracha da mistura obtêm-se um material mais leve. No caso da Wót, ocorre um leve aumento com o acréscimo do teor de borracha da mistura, e, por esse motivo, pode-se dizer que o valor da umidade ótima tem um leve aumento devido que a borracha tem uma absorção de agua baixa.

A Figura 5.7 apresenta o resumo das curvas de compactação com amostras submetidas a um energia de compactação modificada realizadas na pesquisa, comparadas com as curvas de compactação realizadas por Chrusciak (2013), a qual realiza ensaios aplicando energia de compactação normal. Verificamos que, com o aumento da energia de compactação o teor ótimo de compactação diminui. 


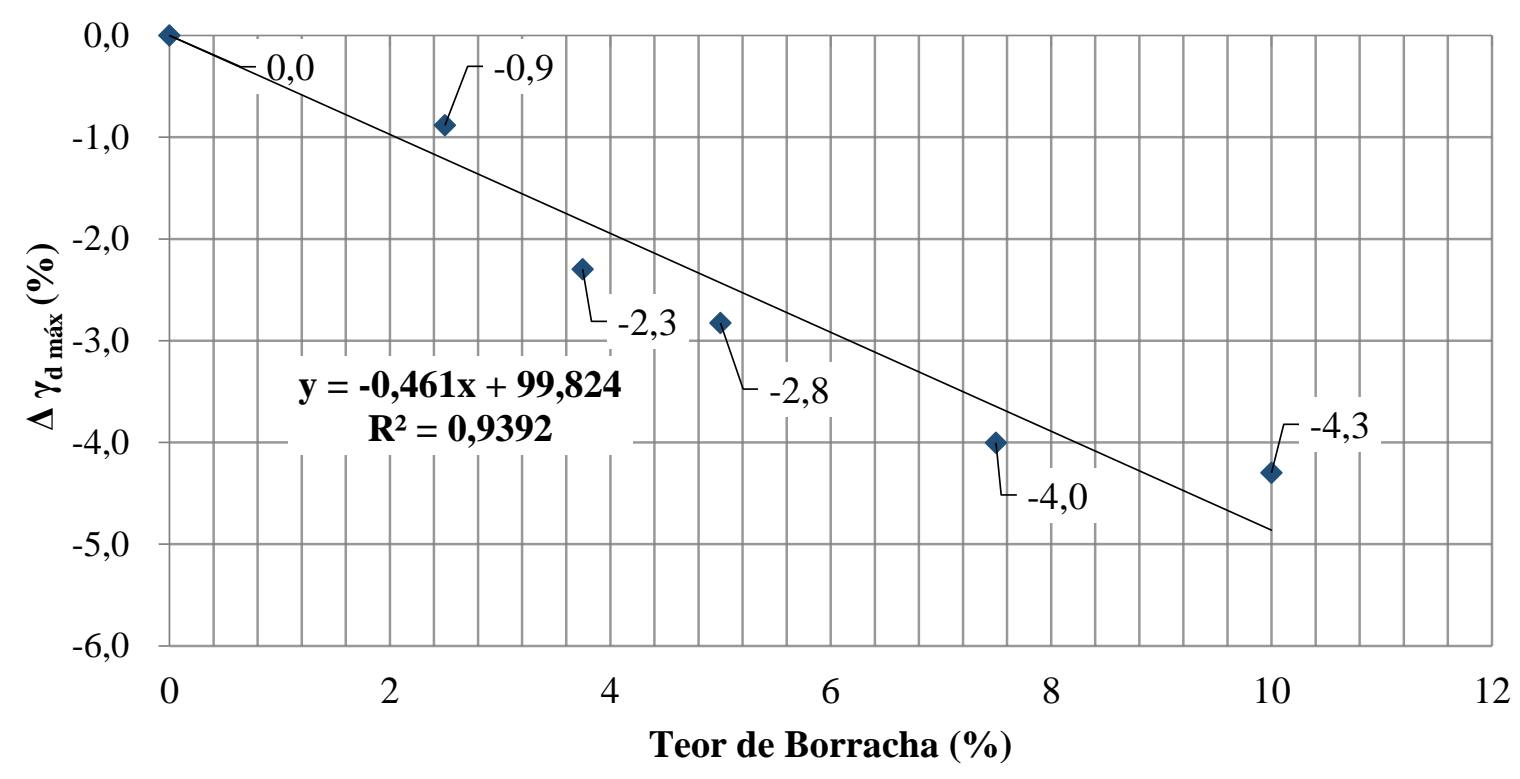

Figura 5.5. Decréscimo do peso específico aparente seco máximo $\left(\gamma_{\mathrm{dmáx}}\right)$ vs teor de borracha.

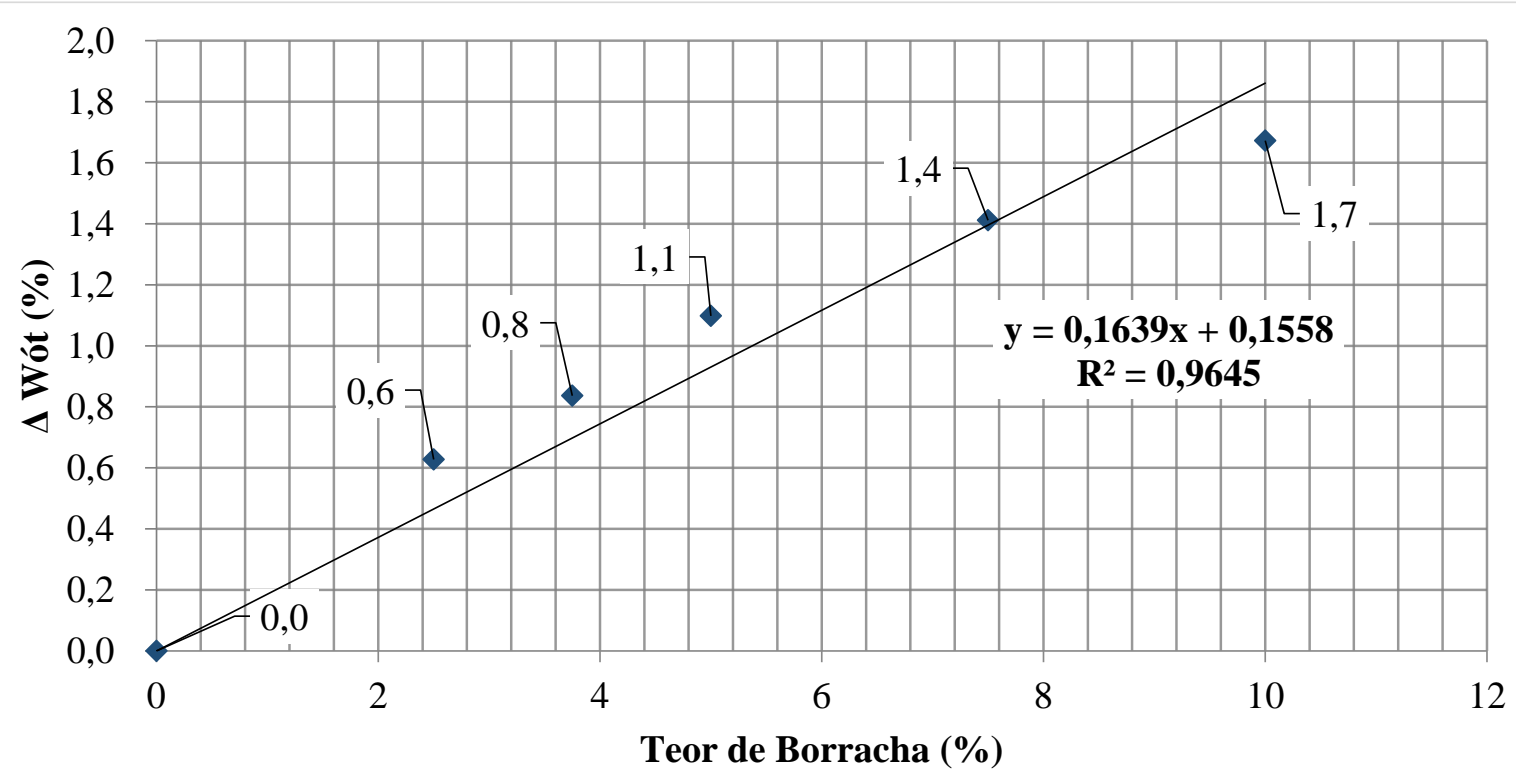

Figura 5.6. Acréscimo da umidade ótima (Wót) vs teor de borracha. 


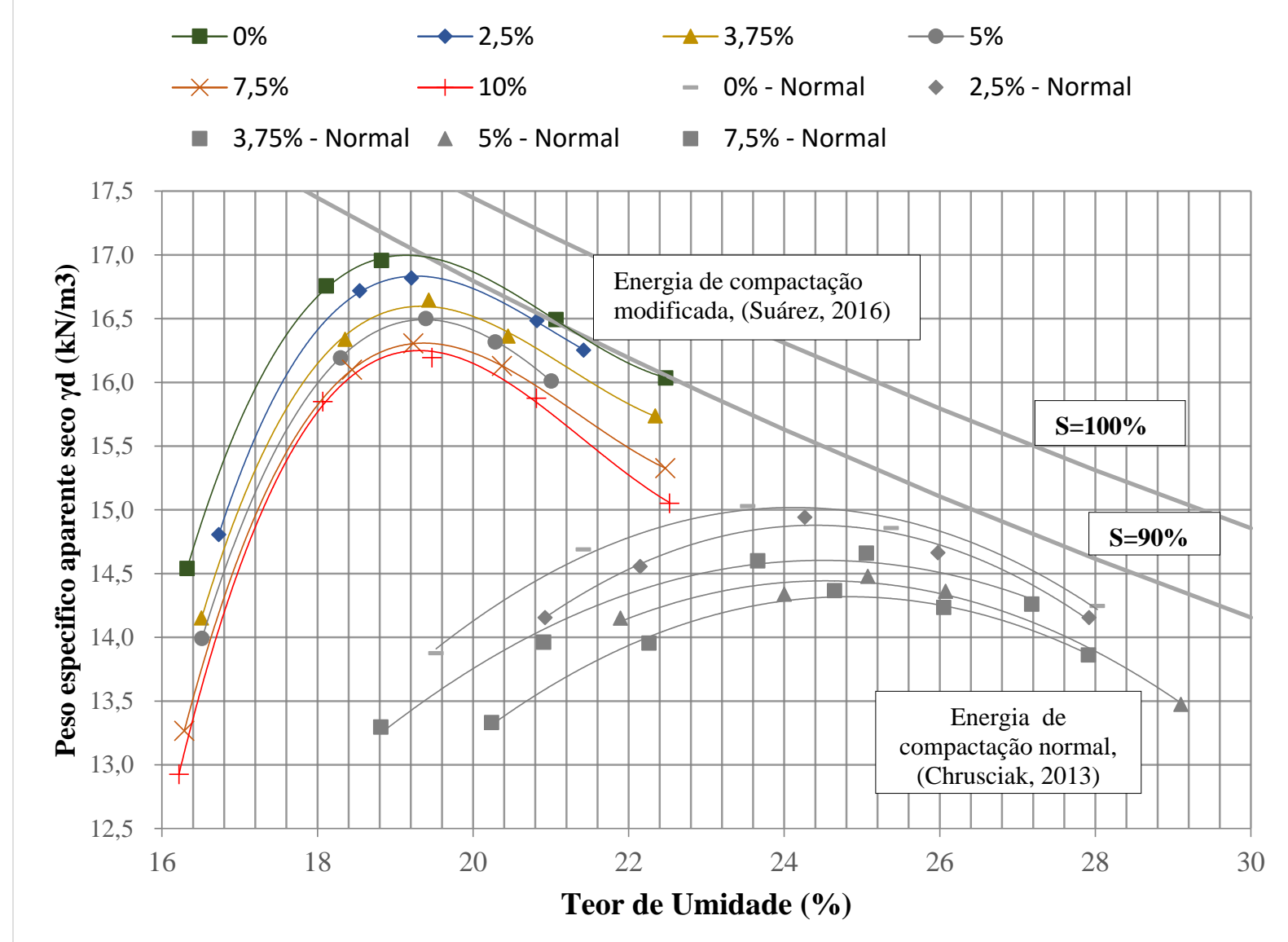

Figura 5.7. Curvas de compactação de misturas solo-borracha submetidas energias de compactação normal e modificada.

\subsection{ENSAIO DE CISALHAMENTO DIRETO}

Para avaliar a resistência ao cisalhamento das misturas, foram realizados ensaios de cisalhamento direto em equipamento de média escala constituído por caixa de cisalhamento de $300 \mathrm{~mm}$ x $300 \mathrm{~mm}$ x $175 \mathrm{~mm}$ devido ao tamanho dos pedaços de pneus. Foram seguidos os procedimentos estabelecidos na norma D3080 (ASTM, 2011), na pesquisa de Franco (2012) e, especialmente, os procedimentos e recomendações estabelecidos na pesquisa realizada por Chrusciak (2013).

Os resultados encontram-se apresentados na Figura B.1 à Figura B.27 do apêndice B, (gráficos ensaio de cisalhamento direto em média escala) que correspondem aos ensaios de cisalhamento direto em dimensões médias para as seguintes amostras: solo puro (0\%), misturas solo - borracha nos diferentes teores anteriormente estabelecidos $(2,5 \%, 3,75 \%$, 
$5,0 \%, 7,5 \%$ e $10 \%)$ e amostras compostas por pedaços de pneu puro (100\%). As tensões confinantes aplicadas foram de $25 \mathrm{kPa}, 50 \mathrm{kPa}, 80 \mathrm{kPa}$ e $100 \mathrm{kPa}$.

Para cada ensaio, foram apresentadas as seguintes informações: curva de tensão cisalhante versus Deslocamento horizontal, a fim de medir a resistência do solo quando está submetido a tensões de cisalhamento para cada uma das tensões confinantes; gráfico da variação volumétrica vs deslocamento horizontal, que representa a influência da tensão cisalhante sobre o volume do corpo de prova; curvas de adensamento sob os diferentes níveis de tensão confinante; e, finalmente, envoltória de Mohr-Coulmb. Para traçar as envoltórias de ruptura de cada uma das misturas estabelecidas, foi tomado o valor tensão máxima cisalhante no valor máximo de deslocamento das curvas de tensão cisalhante vs deslocamento horizontal para cada uma das tensões confinantes que são aplicadas no solo e nas misturas solo borracha. As envoltórias de ruptura apresentadas para cada uma das misturas nas quais houve variação do teor de borracha apresentaram um coeficiente de determinação $\left(\mathrm{R}^{2}\right)$ aproximado a 1 , indicando adequado o ajuste das curvas.

Dos resultados apresentados no Anexo B observasse que, (i) para todas as misturas existe acréscimo na tensão cisalhante máxima da mistura com o aumento da tensão normal confinante, (ii) a tensão cisalhante máxima acrescentou com o amento do teor de borracha, (iii) nos gráficos de deformação volumétrica, ocorrem mudanças volumétricas das amostras durante o ensaio, compressão do material no começo do que quase coincide com a zona elástica das curvas de tensão cisalhante vs deslocamento horizontal, após desta zona ocorre dilatação do material (iv) redução das mudanças volumétricas com o aumento da tensão normal confinante, (v) redução das mudanças volumétricas com o aumento do teor de borracha (misturas solo-borracha), (vi) no adensamento, aumento do deslocamento vertical com o aumento da tensão normal de confinamento, (vii) este deslocamento vertical aumenta com o aumento do teor de borracha, devido que este material é altamente compressível no seu primer ciclo de confinamento, (viii) dos traços das envoltórias de ruptura, existe diminuição da coesão e acréscimo do ângulo de atrito com o aumento do teor de borracha.

No caso dos ensaios realizados para amostras de borracha pura verifica-se que, (i) existe acréscimo na tensão cisalhante com o aumento da tensão confinante, (ii) não se encontrou um valor de tensão cisalhante de ruptura já que a amostra não consegue romper, (iii) comportamento linear das curvas de tensão vs deslocamento, devido a que comporta-se como 
um material elástico que não rompe, (iv) o comportamento da deformação volumétrica é totalmente de compressão, (v) a variação de volume é linear em baixos deslocamentos horizontais e está de acordo com resultados de testes realizados por outros autores como Lee et al.(1999) e Zornberg et al. (2004).

Nas curvas de tensão-deformação foi observado um comportamento semelhante ao obtido nos relatórios feitos por Franco (2012) e Chrusciak (2013): a tensão máxima cisalhante aumenta com o aumento tensão confinante, nas amostras de solo puro e nas misturas solo borracha; já nos ensaios de cisalhamento de amostras compostas unicamente por pedaços de pneus, o comportamento da curva é linear e não se encontra um valor máximo de tensão cisalhante, uma vez que não há ruptura do material.

Em geral, o equipamento utilizado na pesquisa conseguiu romper todos os corpos de prova ensaiados, com exceção da amostra composta por pedaços de pneus (100\% borracha). Neste caso, para determinar o valor de tensão cisalhante máxima da envoltória de ruptura, considerou-se a deformação horizontal máxima gerada no equipamento.

Nos gráficos do comportamento da variação volumétrica (deformação volumétrica da amostra durante os ensaios de cisalhamento em termos de deslocamento vertical) foi observado que a variação volumétrica do solo puro e das misturas de solo com borracha têm um comportamento parecido, ou seja, comportamento linear onde o material está sendo comprimido até atingir um valor máximo (máxima compressão do material). Após atingir o ponto máximo, o material tende a expandir-se em função da movimentação da caixa do equipamento, lembrando que se utilizou uma caixa desparafusada (afim de evitar o atrito que existe entre o solo e a parede da caixa). O valor da compressão máxima do material reduz com o aumento da tensão confinante, como esperado, devido que a borracha trabalha dentro da mistura como material de reforço confinado. Não foi encontrada uma relação linear do comportamento da variação volumétrica quando a borracha foi introduzida para os teores estudados.

Nos ensaios de adensamento foram observados maiores deslocamentos verticais com o aumento do teor de borracha, uma vez que a borracha é um material altamente deformável e compressível no seu primer ciclo de confinamento. 
Na Tabela 5.3, são apresentados os resultados dos ensaios de cisalhamento direto em média escala realizados para todos os teores de borracha, além dos valores da tensão cisalhante máxima ( $\tau$ máx), da tensão confinante $(\sigma)$ e da tensão confinante corrigida no plano de ruptura $\left(\sigma_{\mathrm{Np}}\right)$ conforme descrito na Equação 4.7.

Tabela 5.3. Resultados dos ensaios de cisalhamento direto para todos os teores de borracha.

\begin{tabular}{|c|c|c|c|c|c|c|}
\hline Teor de Borracha (\%) & $\tau_{\text {máx }}(k P a)$ & $\sigma_{n}(k P a)$ & $\sigma_{N p}(k P a)$ & $c^{\prime}(k P a)$ & $\phi\left(^{o}\right)$ & $R^{2}$ \\
\hline \multirow{4}{*}{0} & 40,2 & 25,9 & 28,9 & \multirow{4}{*}{25} & \multirow{4}{*}{27} & \multirow{4}{*}{0,9814} \\
\hline & 50,8 & 49,9 & 52,9 & & & \\
\hline & 70,1 & 78,4 & 81,3 & & & \\
\hline & 76,2 & 99,9 & 102,9 & & & \\
\hline \multirow{4}{*}{2,5} & 42,4 & 25,6 & 28,5 & \multirow{4}{*}{25} & \multirow{4}{*}{32} & \multirow{4}{*}{0,9856} \\
\hline & 60,4 & 50,8 & 53,7 & & & \\
\hline & 73,6 & 78,7 & 82,8 & & & \\
\hline & 91,7 & 100,0 & 102,9 & & & \\
\hline \multirow{4}{*}{3,75} & 43,2 & 25,4 & 28,3 & \multirow{4}{*}{23} & \multirow{4}{*}{35} & \multirow{4}{*}{0,9986} \\
\hline & 58,9 & 50,5 & 53,4 & & & \\
\hline & 78,5 & 78,7 & 81,6 & & & \\
\hline & 94,2 & 99,5 & 102,4 & & & \\
\hline \multirow{4}{*}{5} & 43,1 & 25,2 & 28,0 & \multirow{4}{*}{22} & \multirow{4}{*}{36} & \multirow{4}{*}{0,9974} \\
\hline & 59,9 & 50,0 & 52,8 & & & \\
\hline & 83,5 & 78,8 & 81,4 & & & \\
\hline & 96,8 & 100,2 & 103,0 & & & \\
\hline \multirow{4}{*}{7,5} & 43,7 & 25,5 & 28,0 & \multirow{4}{*}{20} & \multirow{4}{*}{39} & \multirow{4}{*}{0,9972} \\
\hline & 61,2 & 50,1 & 52,8 & & & \\
\hline & 87,8 & 78,3 & 81,6 & & & \\
\hline & 104,0 & 100,1 & 103,1 & & & \\
\hline \multirow{4}{*}{10} & 44,2 & 25,5 & 28,3 & \multirow{4}{*}{18} & \multirow{4}{*}{42} & \multirow{4}{*}{0,9995} \\
\hline & 65,0 & 50,1 & 52,9 & & & \\
\hline & 91,8 & 78,3 & 81,1 & & & \\
\hline & 110,6 & 100,1 & 103,0 & & & \\
\hline \multirow{4}{*}{100} & 14,7 & 24,8 & 27,6 & \multirow{4}{*}{6} & \multirow{4}{*}{21} & \multirow{4}{*}{0,9863} \\
\hline & 21,2 & 43,9 & 52,7 & & & \\
\hline & 32,6 & 78,2 & 81,0 & & & \\
\hline & 36,9 & 99,9 & 102,8 & & & \\
\hline
\end{tabular}

A partir da tabela anteriormente apresentada foi encontrado aumento da tensão de cisalhamento máxima (aprox. 45,2\%), diminuição da coesão $(27,2 \%)$ e aumento do ângulo de atrito $(54,6 \%)$ ao serem comparados resultados de amostras de solo puro com amostras de solo borracha com teor de borracha de $10 \%$ sob uma tensão normal confinante de $100 \mathrm{kPa}$. 
Da Figura 5.8 à Figura 5.19 apresenta-se um resumo da resistência ao cisalhamento (Tensão cisalhante versus deslocamento horizontal) do comportamento da variação volumétrica (deformação volumétrica versus Deslocamento horizontal) e também as curvas de adensamento para todas as amostras submetidas as diferentes tensões confinantes estabelecidas na pesquisa.

Destes gráficos apresentados encontra-se que:

(i) O comportamento da curva tensão cisalhante versus deslocamento vertical para amostras de solo puro, misturas solo-borracha e borrachas pura são diferentes. No caso do solo puro, a tensão cisalhante máxima encontra-se numa deformação especifica menor que as amostras compostas por misturas solo-borracha. Aa adição de borracha dá certa elasticidade às misturas, já no caso das amostras com teor de borracha de $100 \%$ (borracha), existe comportamento linear das curvas de tensão cisalhante versus deslocamento, devido ao fato de a mistura que se comporta como um material elástico que não rompe;

(ii) Existe acréscimo da tensão cisalhante máxima com o aumento do teor de borracha;

(iii) Para o caso da amostra de borracha pura, as tensões cisalhantes deste material são baixas;

(iv) O comportamento da mudança volumétrica das amostras de solo puro, misturas solo-borracha e borracha pura são diferentes. Parao caso do solo puro, existe compressão da amostra até atingir um valor máximo. Por sua vez, para o caso das misturas solo-borracha, existe compressão da amostra até atingir um valor máximo e após este valor o material se expande consideravelmente. O comportamento da deformação volumétrica é totalmente de compressão e a variação de volume é linear em baixos deslocamentos horizontais e está de acordo com resultados de testes realizados por outros autores como Lee et al.(1999) e Zornberg et al. (2004);

(v) Com o acréscimo do teor de borracha, as mudanças volumétricas são reduzidas, concordando com o encontrado pelos autores Ghazavi et al. (2011) e Bałachowski \& Gotteland (2007)

(vi) No processo de adensamento das amostras, existem aumentos dos deslocamentos verticais com o acréscimo do teor de borracha. 


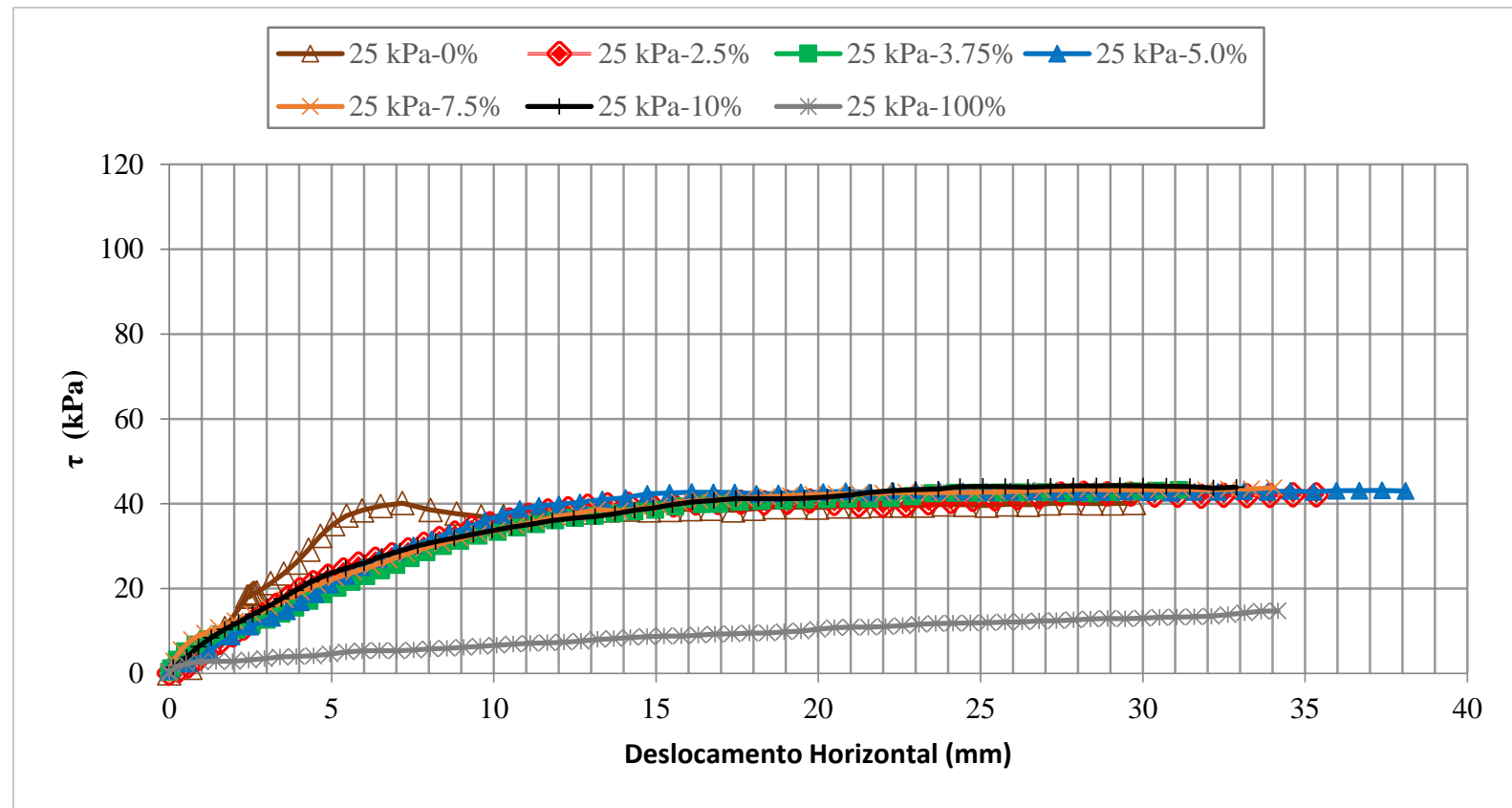

Figura 5.8. Tensão cisalhante versus Deslocamento horizontal para todos os teores de borracha sob uma tensão confinante de $25 \mathrm{kPa}$.

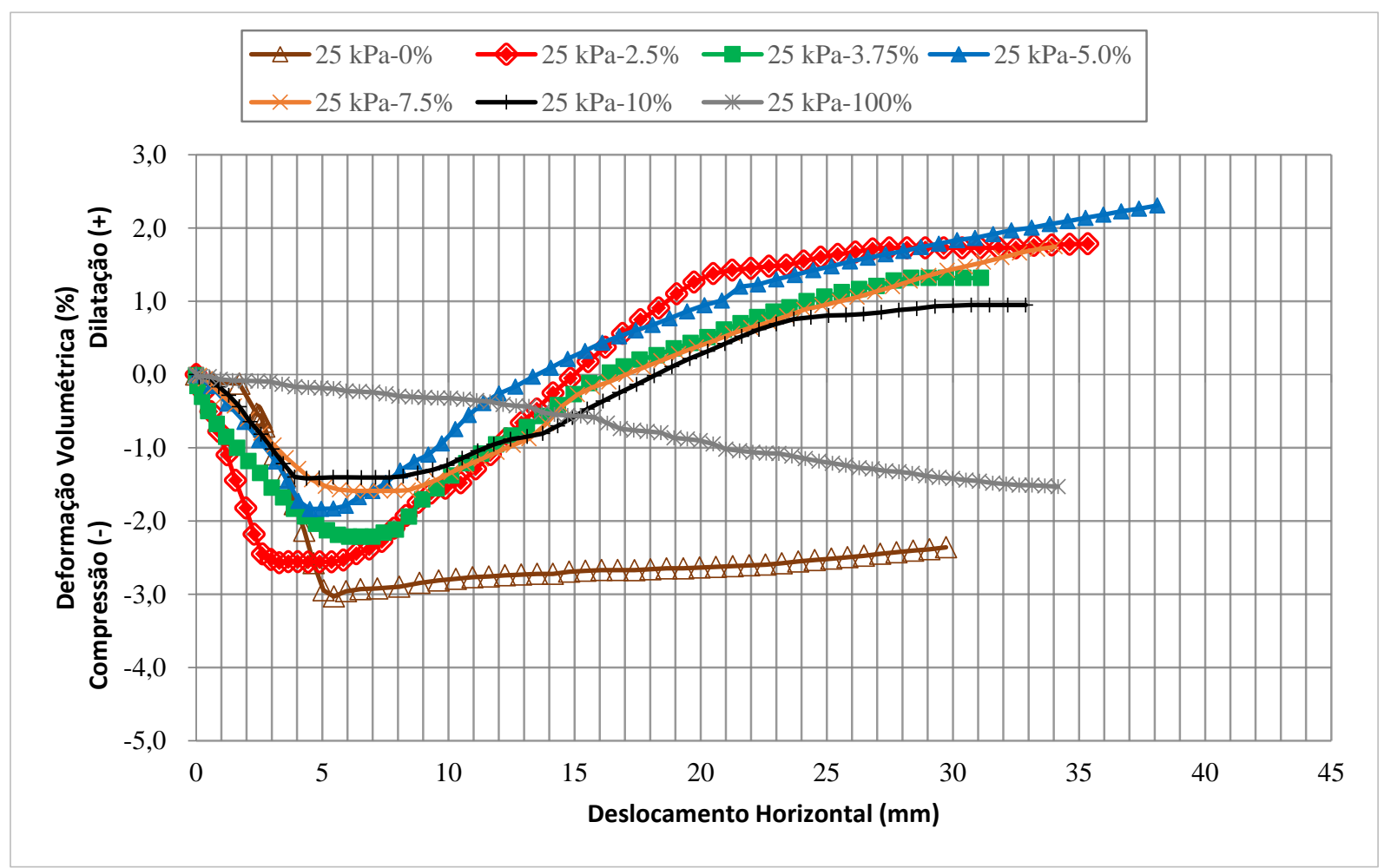

Figura 5.9. Deformação volumétrica versus Deslocamento horizontal para todos os teores de borracha sob uma tensão confinante de $25 \mathrm{kPa}$. 


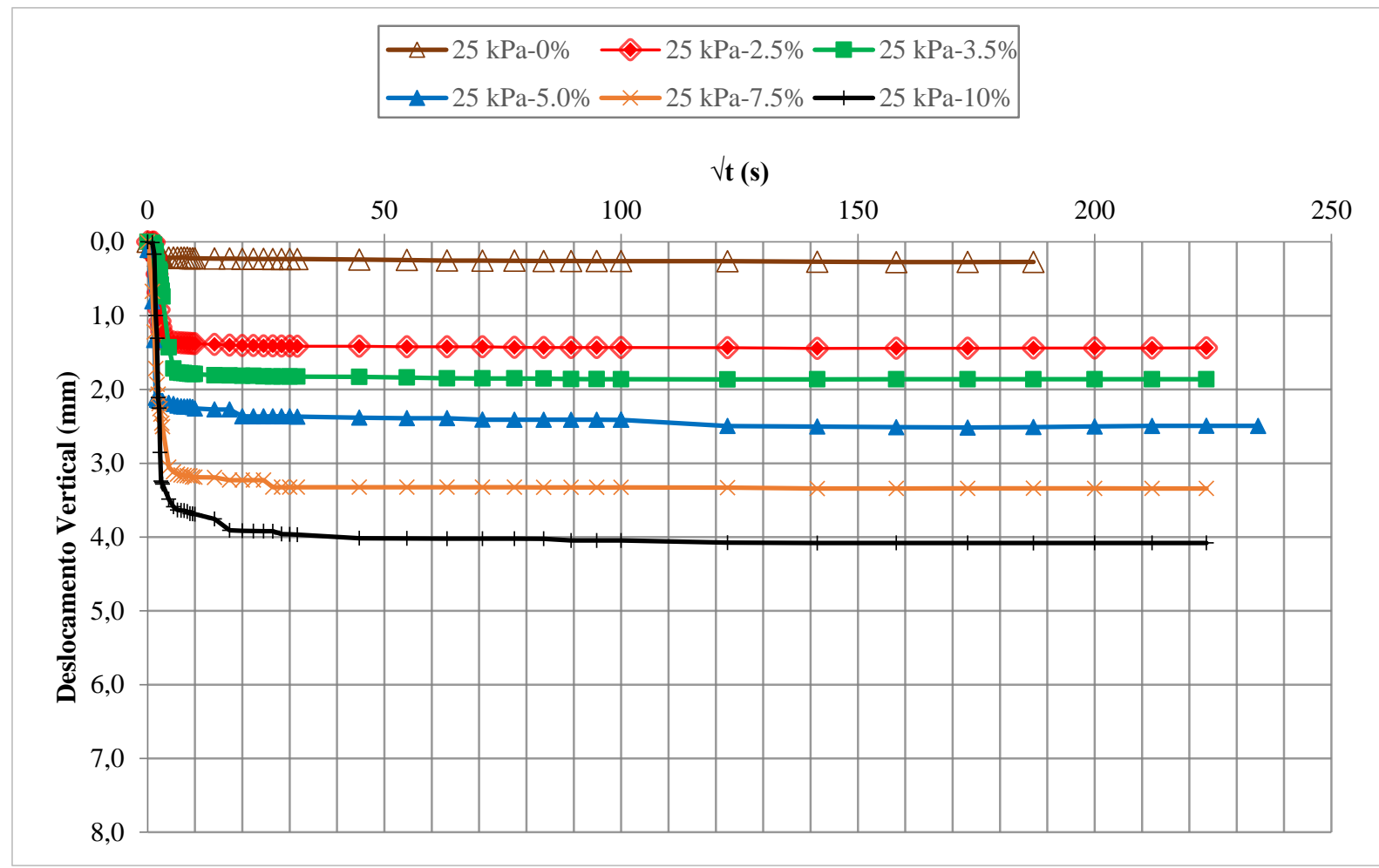

Figura 5.10. Curvas de adensamento para todos os teores de borracha sob uma tensão confinante de $25 \mathrm{kPa}$.

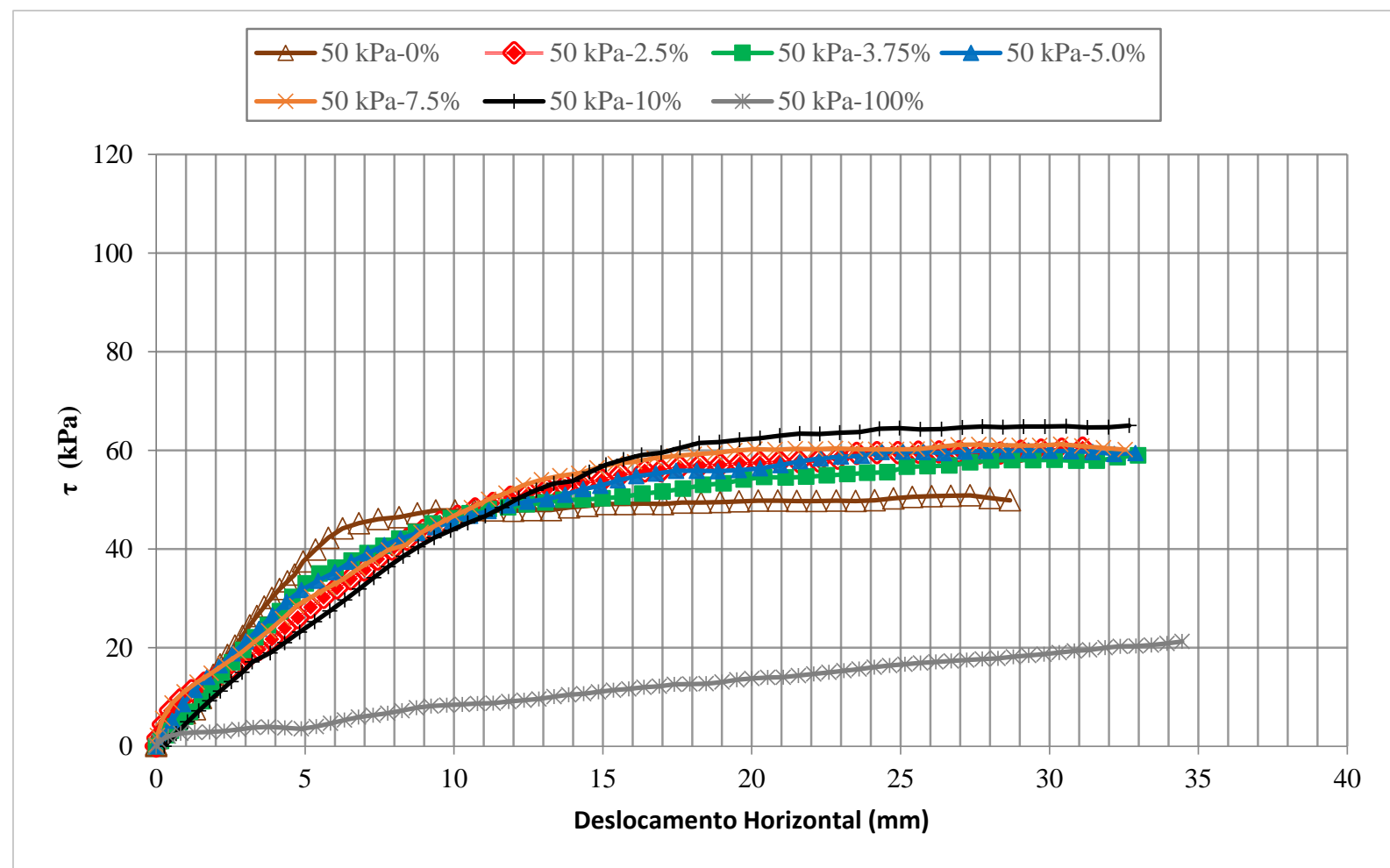

Figura 5.11. Tensão cisalhante versus Deslocamento horizontal para todos os teores de borracha sob uma tensão confinante de $50 \mathrm{kPa}$. 


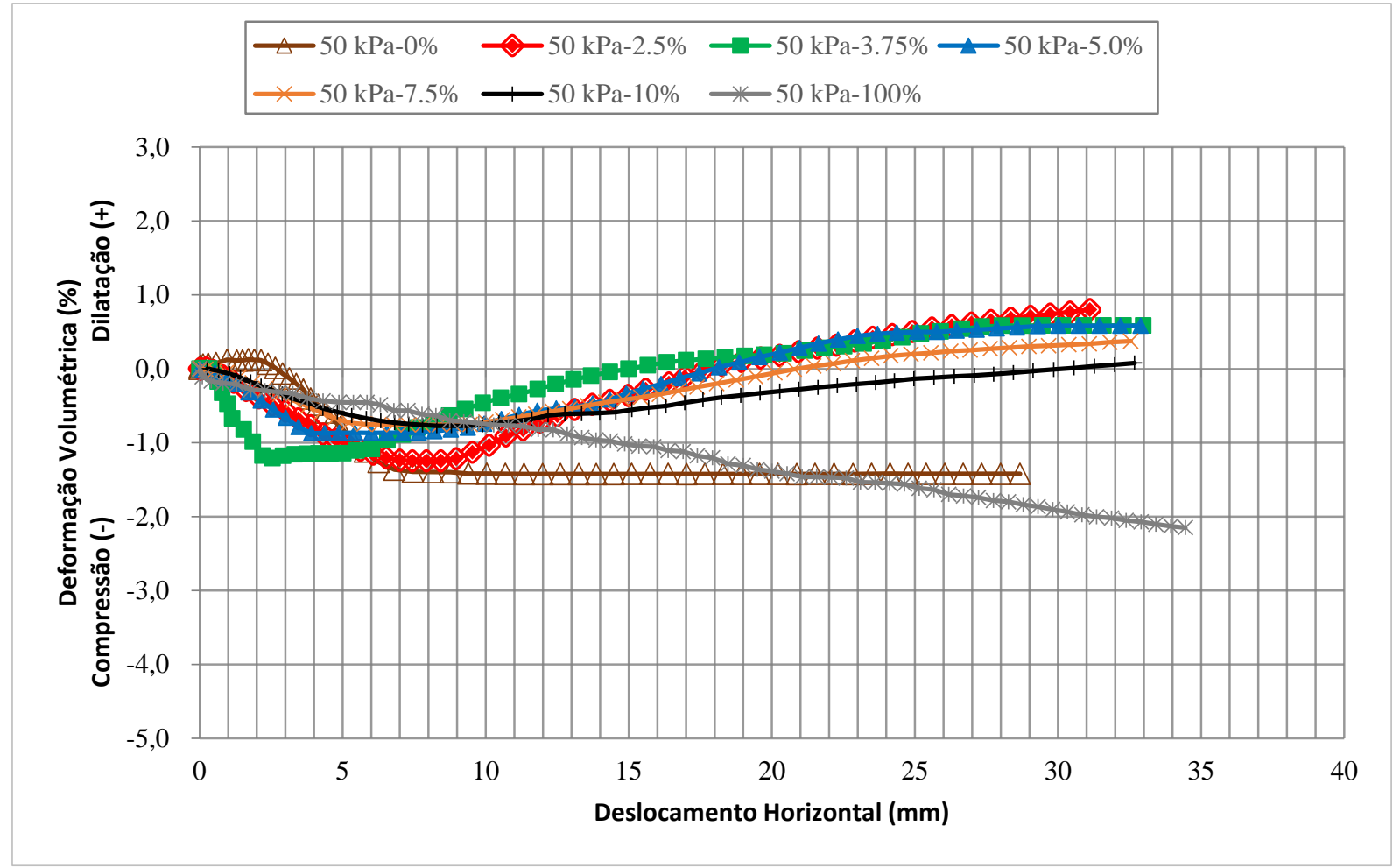

Figura 5.12. Deformação volumétrica versus Deslocamento horizontal para todos os teores de borracha sob uma tensão confinante de $50 \mathrm{kPa}$.

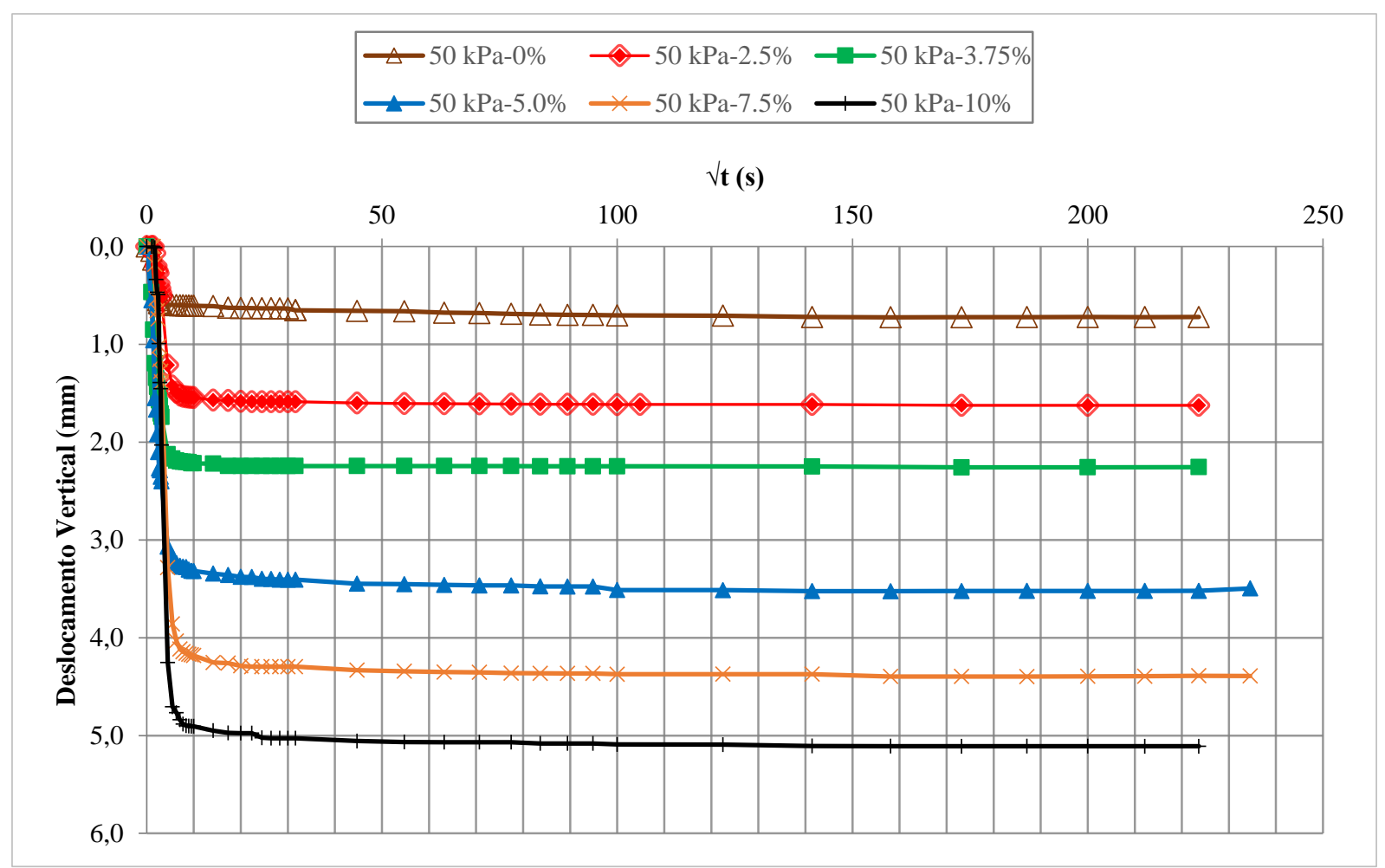

Figura 5.13. Curvas de adensamento para todos os teores de borracha sob uma tensão confinante de $50 \mathrm{kPa}$. 


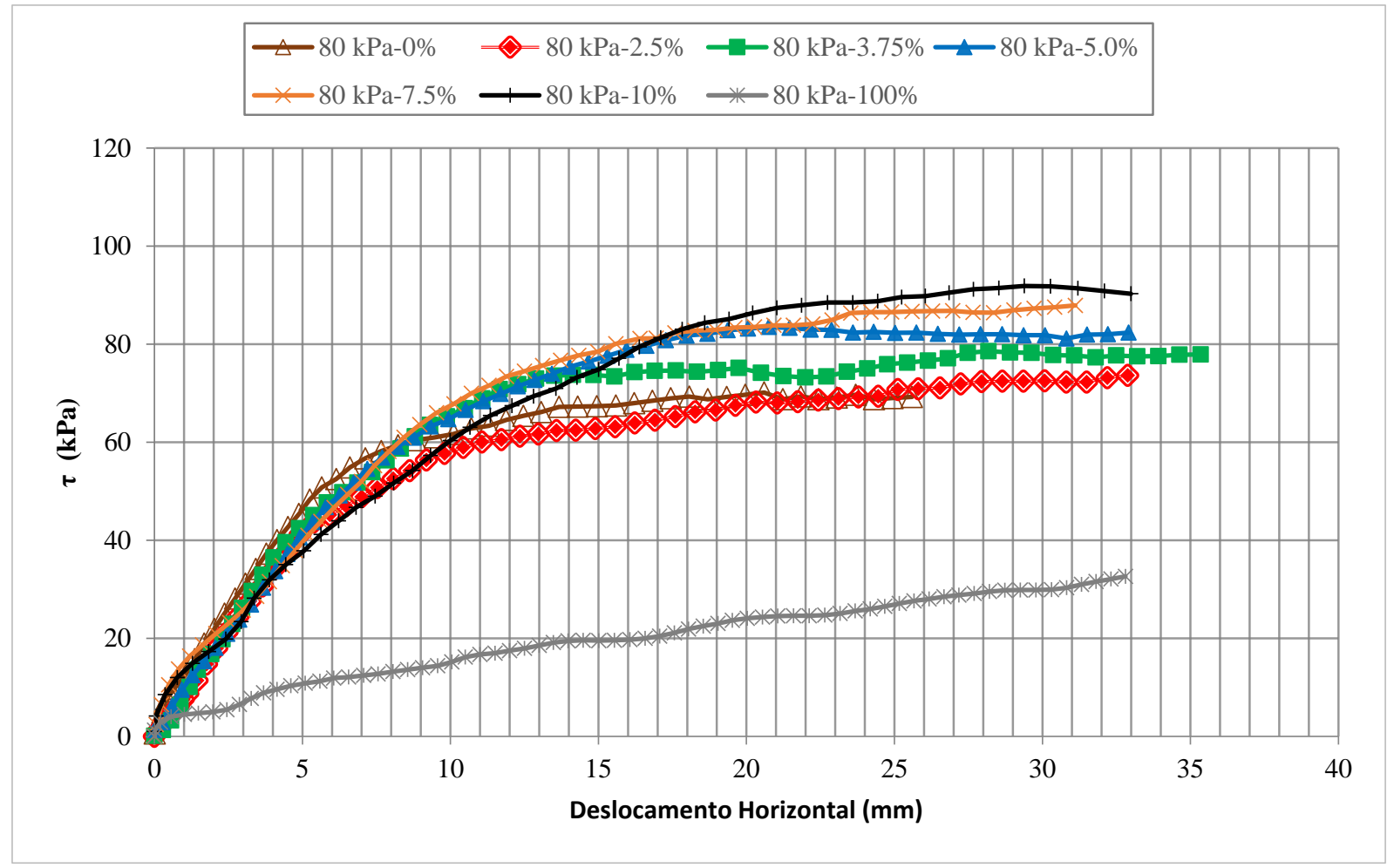

Figura 5.14. Tensão cisalhante versus Deslocamento horizontal para todos os teores de borracha sob uma tensão confinante de $80 \mathrm{kPa}$.

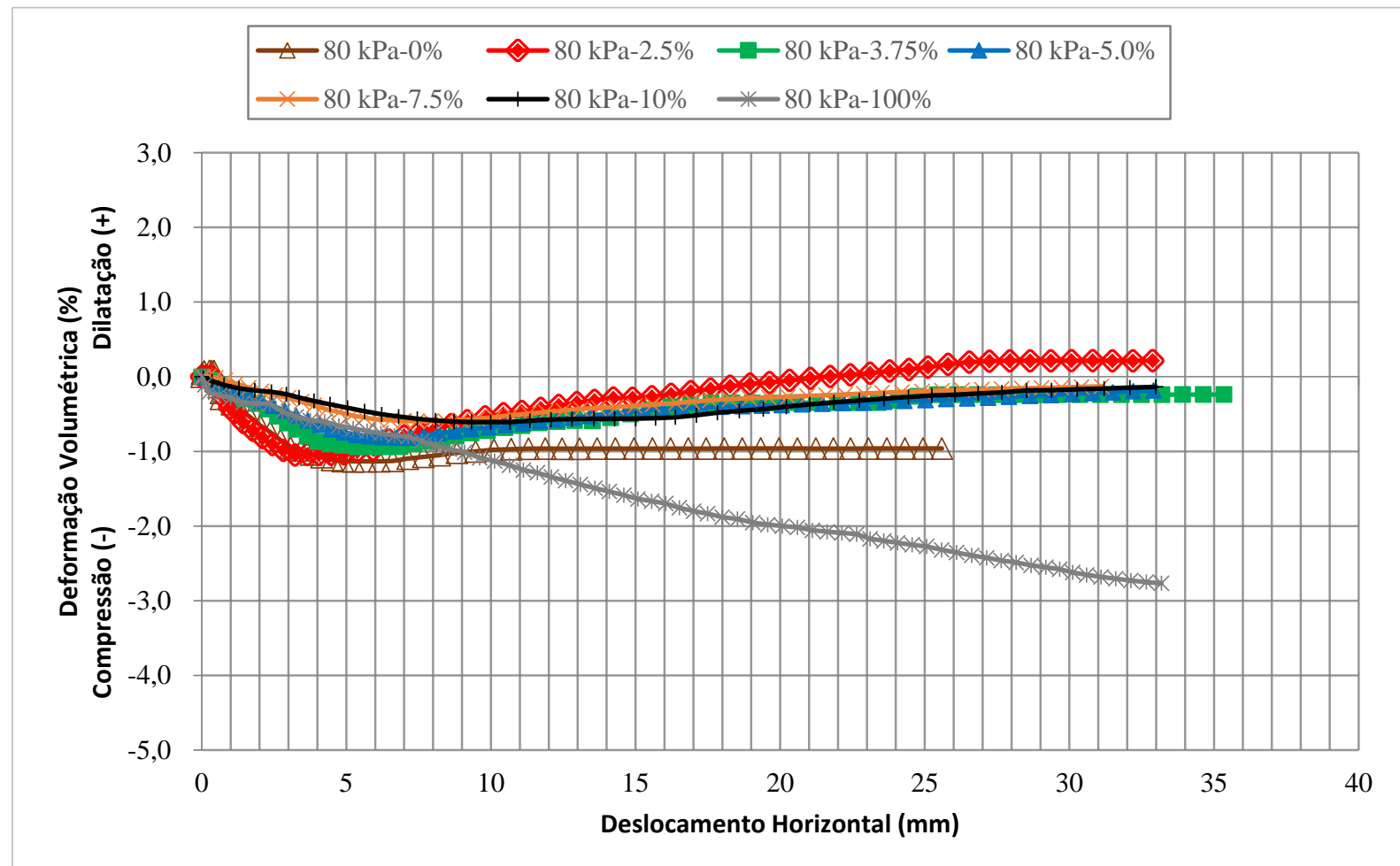

Figura 5.15. Deformação volumétrica versus Deslocamento horizontal para todos os teores de borracha sob uma tensão confinante de $80 \mathrm{kPa}$. 


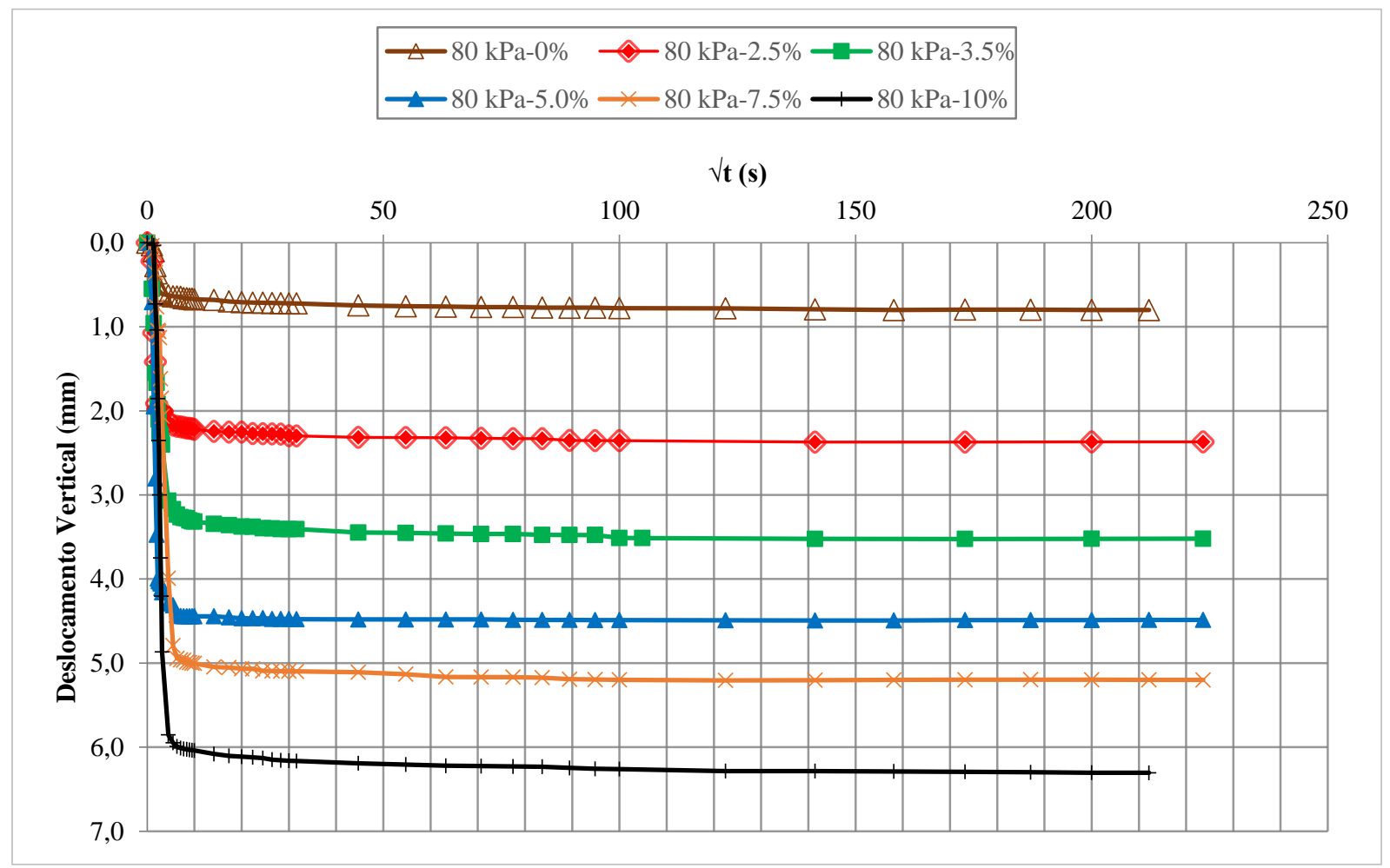

Figura 5.16. Curvas de adensamento para todos os teores de borracha sob uma tensão confinante de $80 \mathrm{kPa}$.

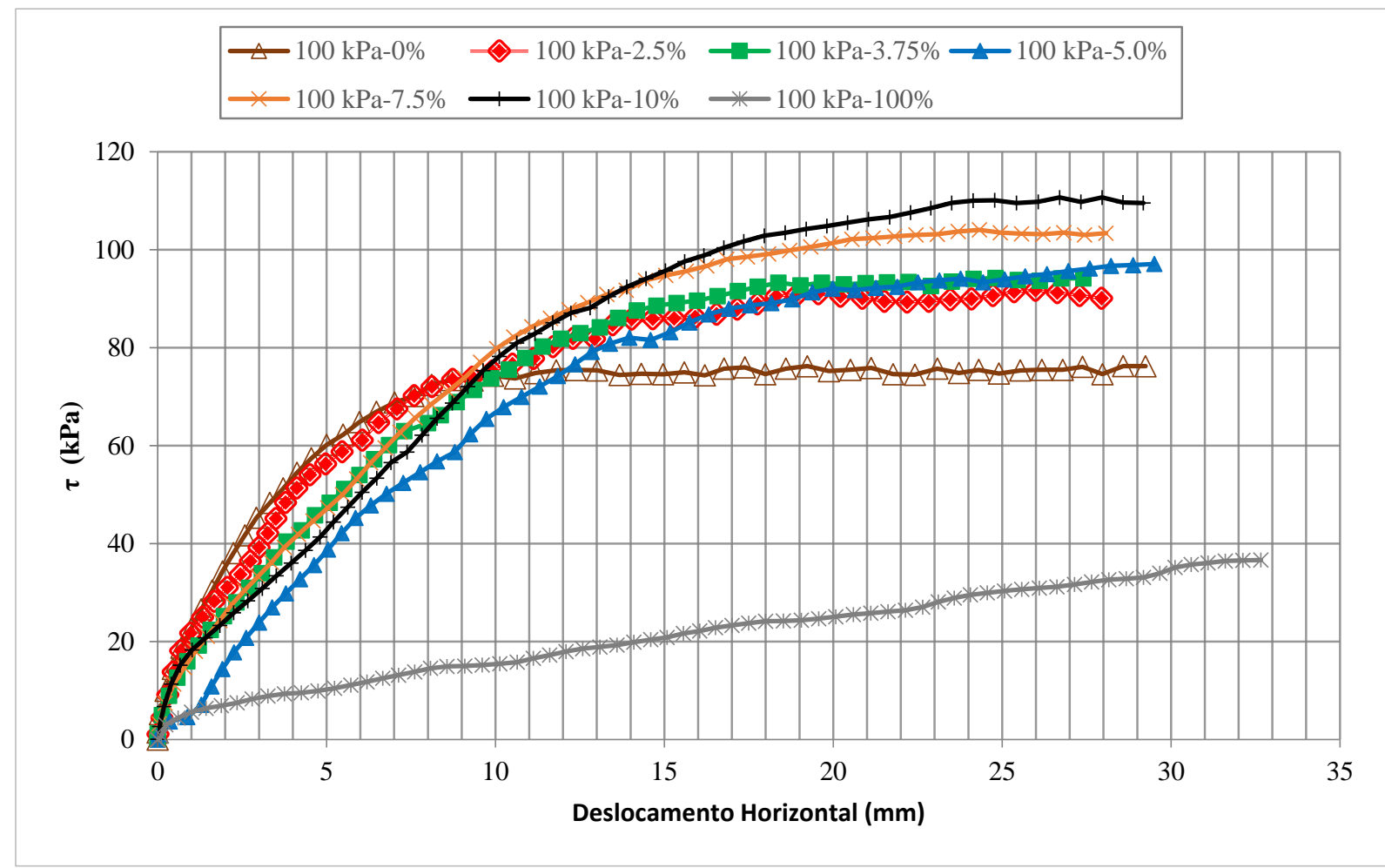

Figura 5.17. Tensão cisalhante versus Deslocamento horizontal para todos os teores de borracha sob uma tensão confinante de $100 \mathrm{kPa}$. 


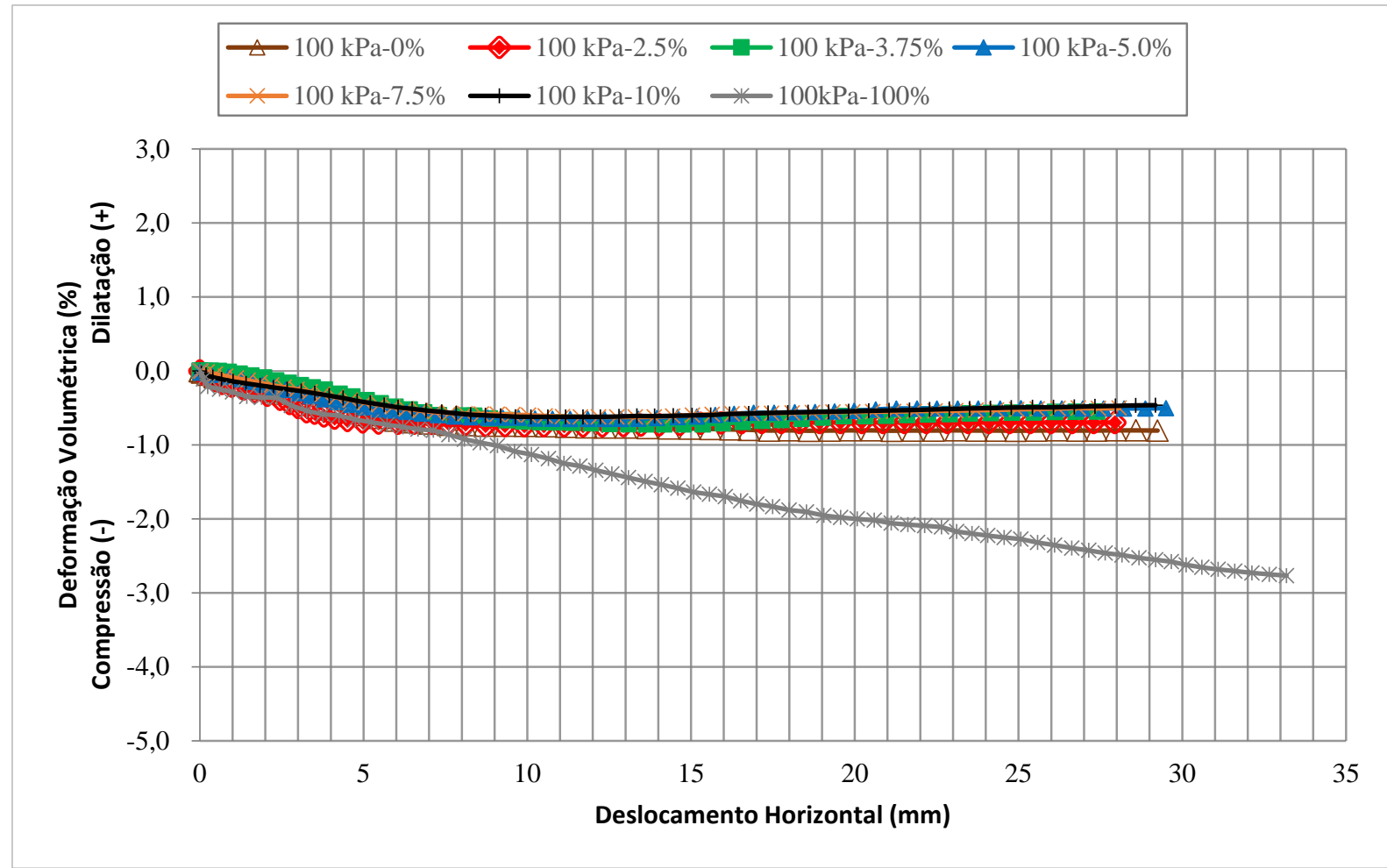

Figura 5.18. Deformação volumétrica versus Deslocamento horizontal para todos os teores de borracha sob uma tensão confinante de $100 \mathrm{kPa}$.

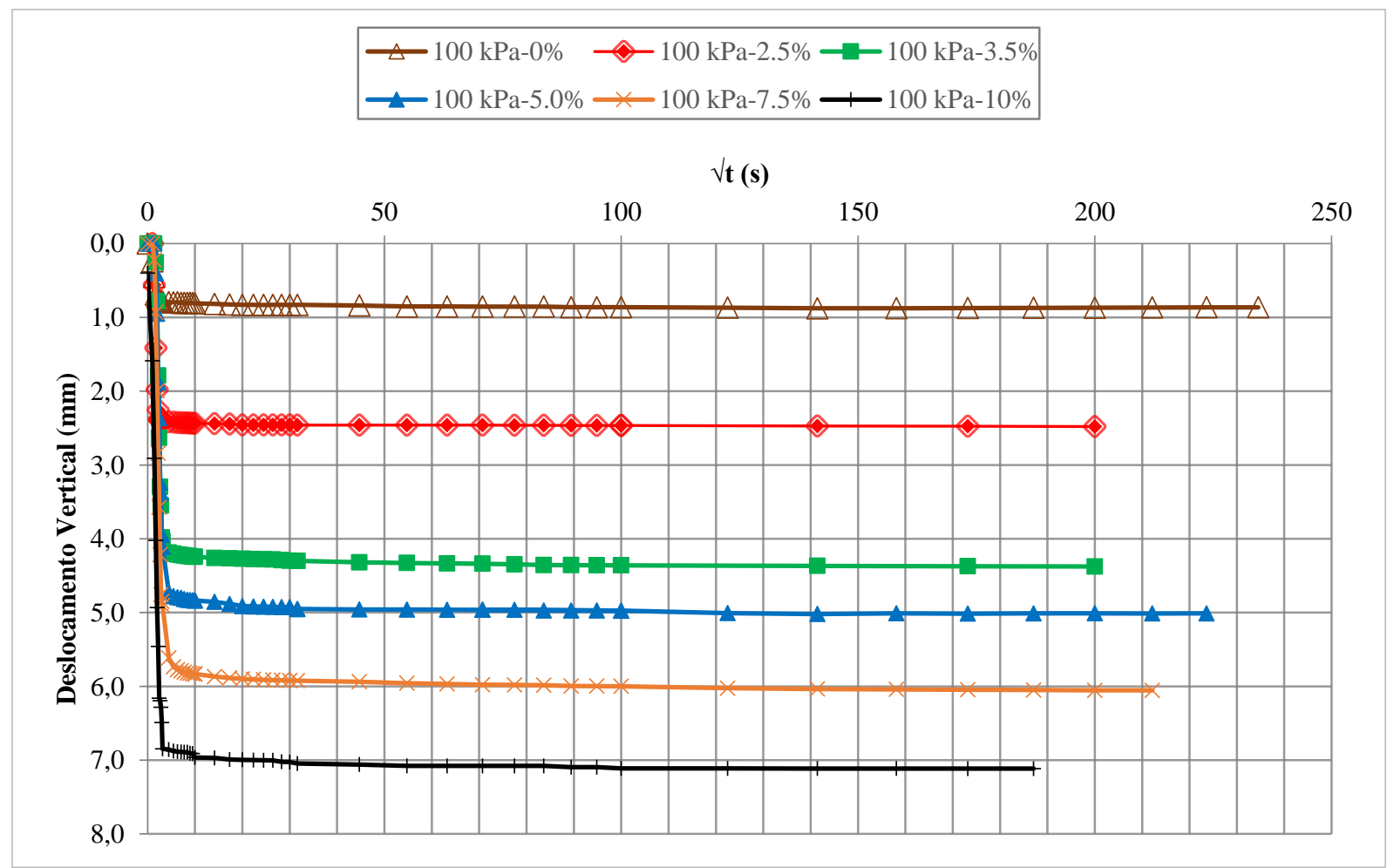

Figura 5.19. Curvas de adensamento para todos os teores de borracha sob uma tensão confinante de $100 \mathrm{kPa}$. 
Baseando-se nos resultados obtidos, foi encontrado acréscimo no ângulo de atrito e diminuição na coesão das misturas com o aumento do teor borracha. Além disso, ocorreram acréscimos na tensão de cisalhamento aplicada com o aumento do teor de borracha. Isso se deve aos seguintes fatores: (i) o material não coesivo atuou como material granular e reforço dentro da mistura; (ii) existência de atrito entre os pedaços de pneu e o solo dentro das misturas e (iii) os pedaços de pneus interferem no plano de ruptura das misturas, aumentando a tensão de cisalhamento máxima, uma vez que este material pode absorver energia aplicada ao solo.

Nos ensaios de adensamento foi observado que com o aumento da quantidade de pedaços de pneus os deslocamentos verticais aumentaram. Isto ocorre porque o material de borracha é altamente deformável e compressível e, ao atingirem-se altos níveis de carregamentos (primeiro ciclo de confinamento), os deslocamentos verticais podem ser consideráveis. Os comportamentos observados nas misturas de solo borracha estão de acordo com os relatórios de autores como Benson (1995), Zornberg et al. (2004), Ghazavi et al. (2011) e Szeliga et al. (2014).

No campo de aplicação em projetos de engenharia geotécnica, o projetista deve ter em conta que com o aumento do teor de borracha obtém-se uma mistura de maior resistência devida a um maior ângulo de atrito. Entretanto, a adição da borracha resulta na ocorrência de trincas, possíveis planos de fraqueza e deslocamentos verticais consideráveis, que podem afetar seu projeto. Por esse motivo, estes materiais devem ser misturados num teor que melhore as propriedades de resistência do solo e ao mesmo tempo gere o menor número de trincas possível. Baseando-se nos resultados obtidos por meio da inspeção visual e dos resultados dos ensaios de cisalhamento direto, este trabalho concorda com o sugerido por Chrusciak (2013), ao recomendar, para o solo e o tipo de borracha empregados na pesquisa, que um teor de pedaços de pneu de $5 \%$ é recomendável em projetos de engenharia onde necessita-se o aumento da resistência do solo, com deslocamentos verticais controlados e número de trincas e planos de ruptura reduzidos.

Nas curvas anteriormente apresentadas, foi observado que o comportamento mecânico das amostras compostas por pedaços de pneu e suas curvas tensão cisalhante-deslocamento 
horizontal representaram um material não coesivo e linear que não chega à ruptura. Por outro lado, as amostras de solo puro e as misturas solo borracha representaram um material com comportamento tensão-deslocamento não linear e que aumenta suas propriedades mecânicas com acréscimo do teor de borracha.

Na Figura 5.20 são apresentadas as tensões de cisalhamento máximas do solo e das misturas solo borracha submetidas às diferentes tensões normais de confinamento $(25 \mathrm{kPa}, 50 \mathrm{kPa}, 80$ $\mathrm{kPa}$ e $100 \mathrm{kPa}$ ). Pode-se observar que o valor da tensão cisalhante máxima aumenta com incremento do teor de borracha. Quando são aplicadas tensões confinantes mais baixas (25 $\mathrm{kPa})$ o acréscimo da $\tau_{\text {máx }}$ é leve em comparação quando são aplicadas tensões de confinamento maiores $(80 \mathrm{kPa}$ e $100 \mathrm{kPa})$.

Em geral, o comportamento dos aumentos na tensão cisalhante das misturas de solo-borracha estão de acordo com os trabalhos realizados por autores como Benson (1995), Zornberg et al.(2004), Bałachowski \& Gotteland (2007), Ghazavi et al. (2011) e Szeliga et al. (2014). Eles relatam que existe aumento na $\tau_{\text {máx }}$ das misturas até certo teor de borracha e que, após tal valor, existe redução de $\tau_{\text {máx }}$ até chegar aos valores encontrados para amostras compostas por borracha pura. Pelos resultados apresentados na pesquisa, houve um aumento da tensão cisalhante máxima e diminuição da variação volumétrica com o aumento do teor de borracha, ao contrário dos resultados apresentados por Chrusciak (2013). Isso pode ter sido devido à diferença de granulometria do material argiloso e do resíduo do pneu e à mudança da energia de compactação utilizada entre as duas pesquisas.

Foi também realizada uma análise da influência da intrusão de borracha nos corpos de prova sobre a tensão de cisalhamento para pequeno9s deslocamentos $(2 \%$ do deslocamento horizontal máximo). Os resultados são apresentados na Figura 5.21. Como pode-se observar, com o aumento do teor de borracha existe decréscimo na tensão cisalhante máxima, quando este material está submetido a tensões confinantes altas (100 kPa). Já no caso das demais tensões confinantes, não se encontra um comportamento claro da variação do valor da tensão cisalhante máxima. 


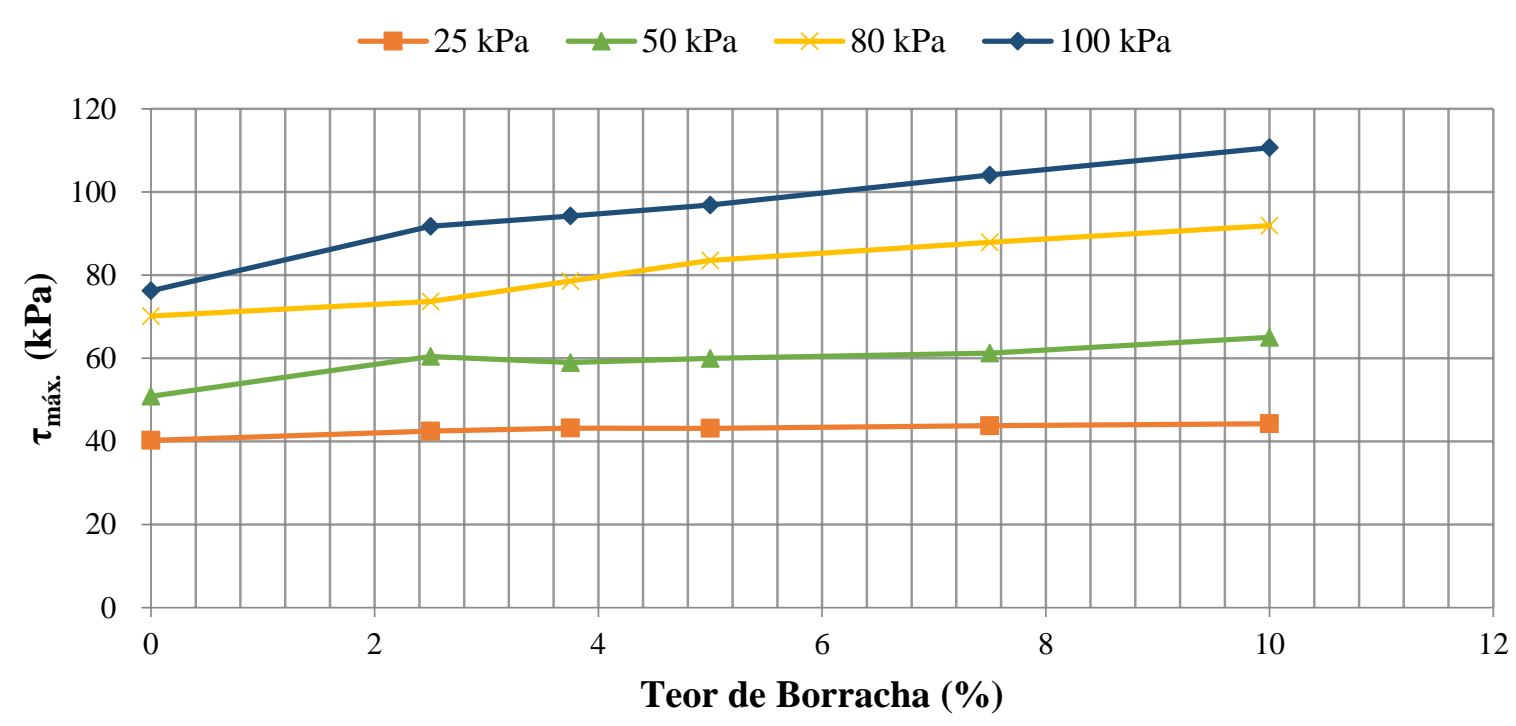

Figura 5.20. Variação tensão cisalhante máxima com o aumento do teor de borracha submetidas a tensões confinantes de 25, 50, 80 e $100 \mathrm{kPa}$.

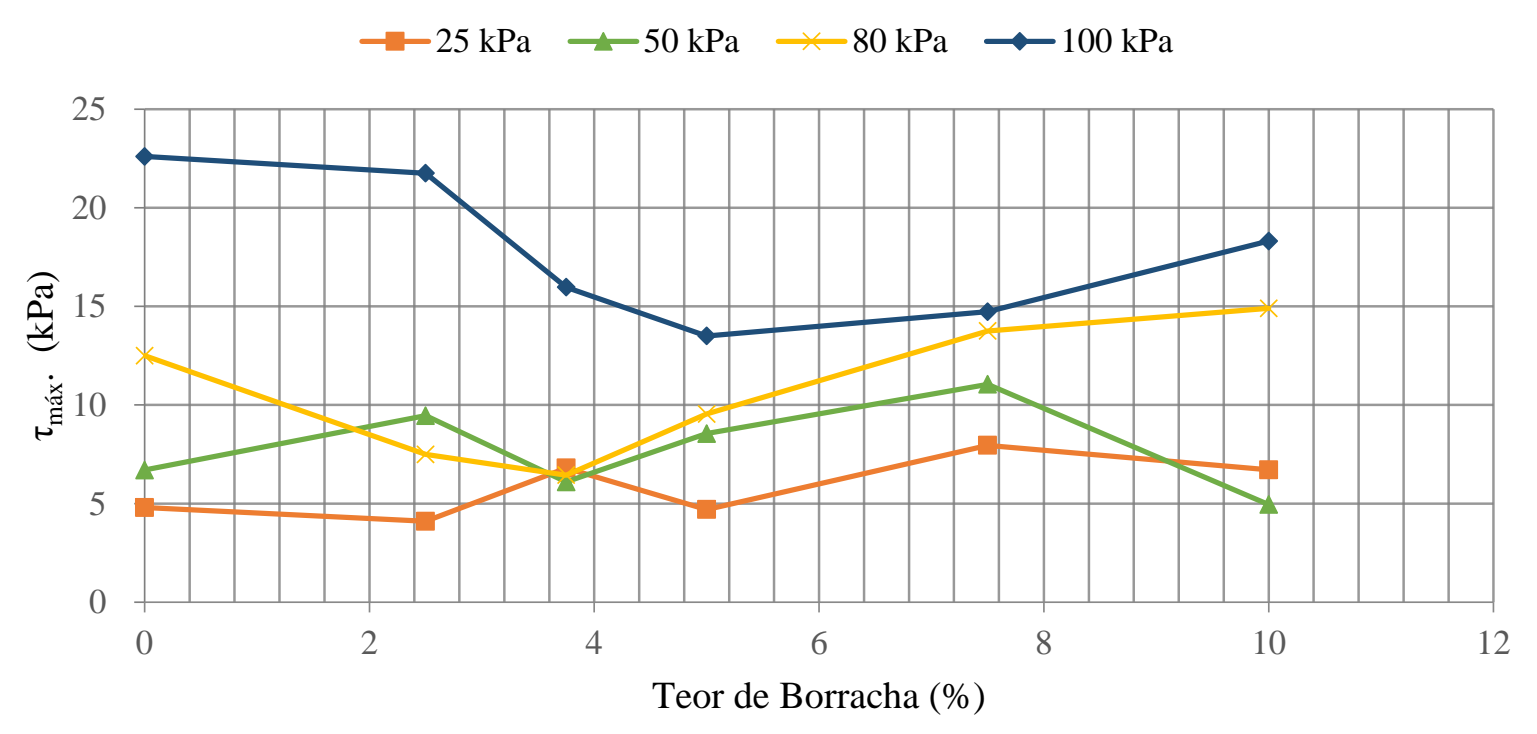

Figura 5.21. Variação tensão cisalhante máxima com o aumento do teor de borracha submetidas a tensões confinantes de $25,50,80$ e $100 \mathrm{kPa}$ (pequenas deformações $-2 \%$ da do deslocamento máximo).

A Figura 5.23 apresenta uma comparação do comportamento da variação da tensão cisalhante máxima com o acréscimo do teor de borracha da pesquisa atual com os resultados obtidos por Chrusciak (2013) e verifica-se que o tamanho dos pedaços de pneus empregados tem grande influência sobre o valor da tensão cisalhante máxima submetida a diferentes tensões de 
confinamento. Ao retirar-se material como migalhas e desbastes de pneus, avaliou-se uma melhoria nas propriedades mecânicas das misturas, lembrando que esta análise foi realizada para caso de grandes deslocamentos da amostra.

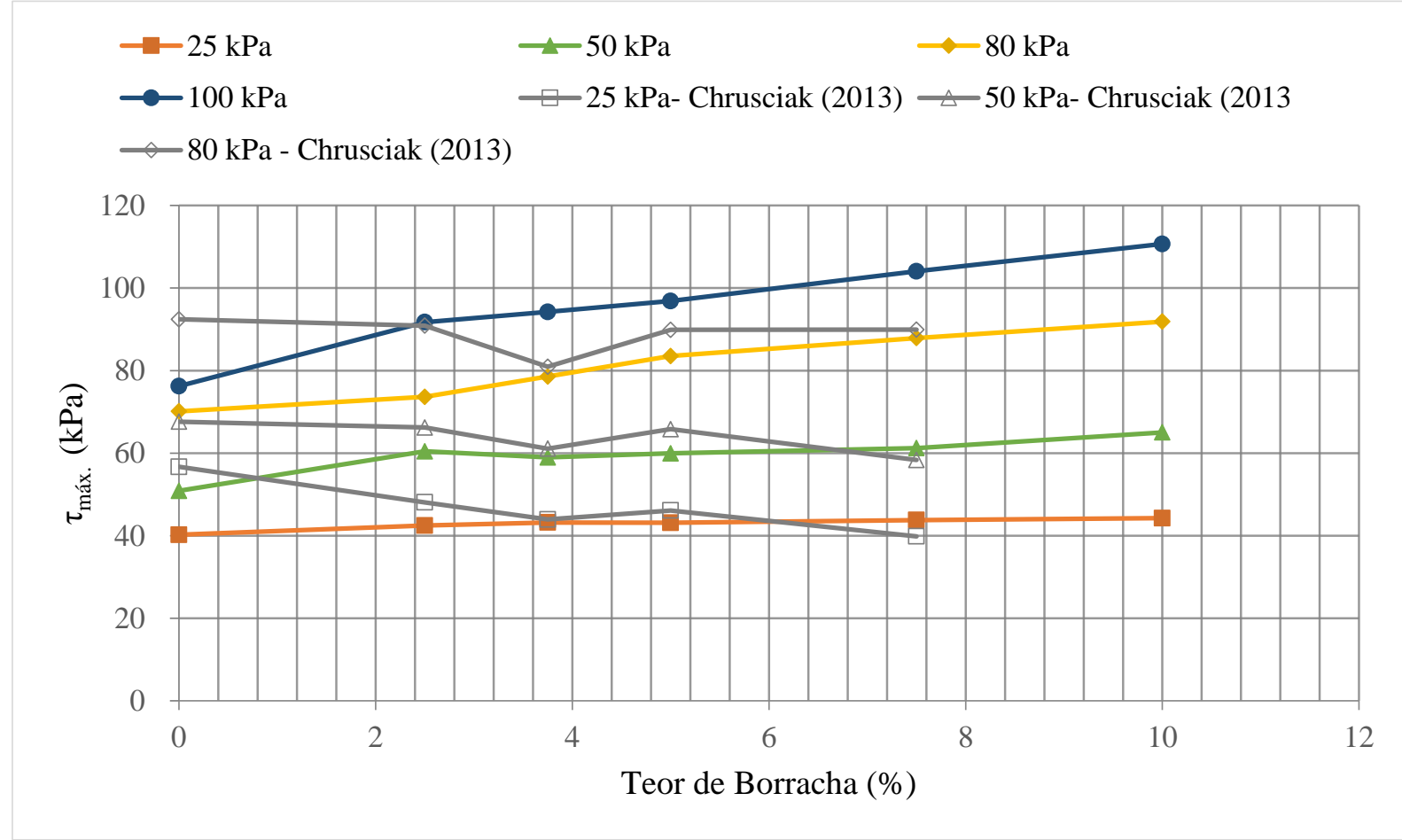

Figura 5.22. Variação tensão cisalhante máxima com o aumento do teor de borracha submetidas a tensões confinantes de $25,50,80$ e $100 \mathrm{kPa}$ comparados com os resultados de Chrusciak (2013).

A variação da coesão e do ângulo de atrito com o aumento do teor de borracha encontram-se apresentados nas Figura 5.23 à Figura 5.26. O comportamento observado está de acordo com os resultados apresentados por Chrusciak (2013), pois houve redução da coesão e acréscimo do ângulo de atrito, com o aumento do teor de borracha. Ao escolher o teor de borracha a ser utilizado, é importante ter em conta que, além aumentar o ângulo de atrito, a redução da coesão evidencia que a mistura solo-borracha pouco a pouco se torna um material quebradiço, com trincas que podem gerar planos de fraqueza. Finalmente na Figura 5.27 são apresentadas todas a envoltórias de ruptura para cada um dos teores de borracha utilizados na pesquisa. 


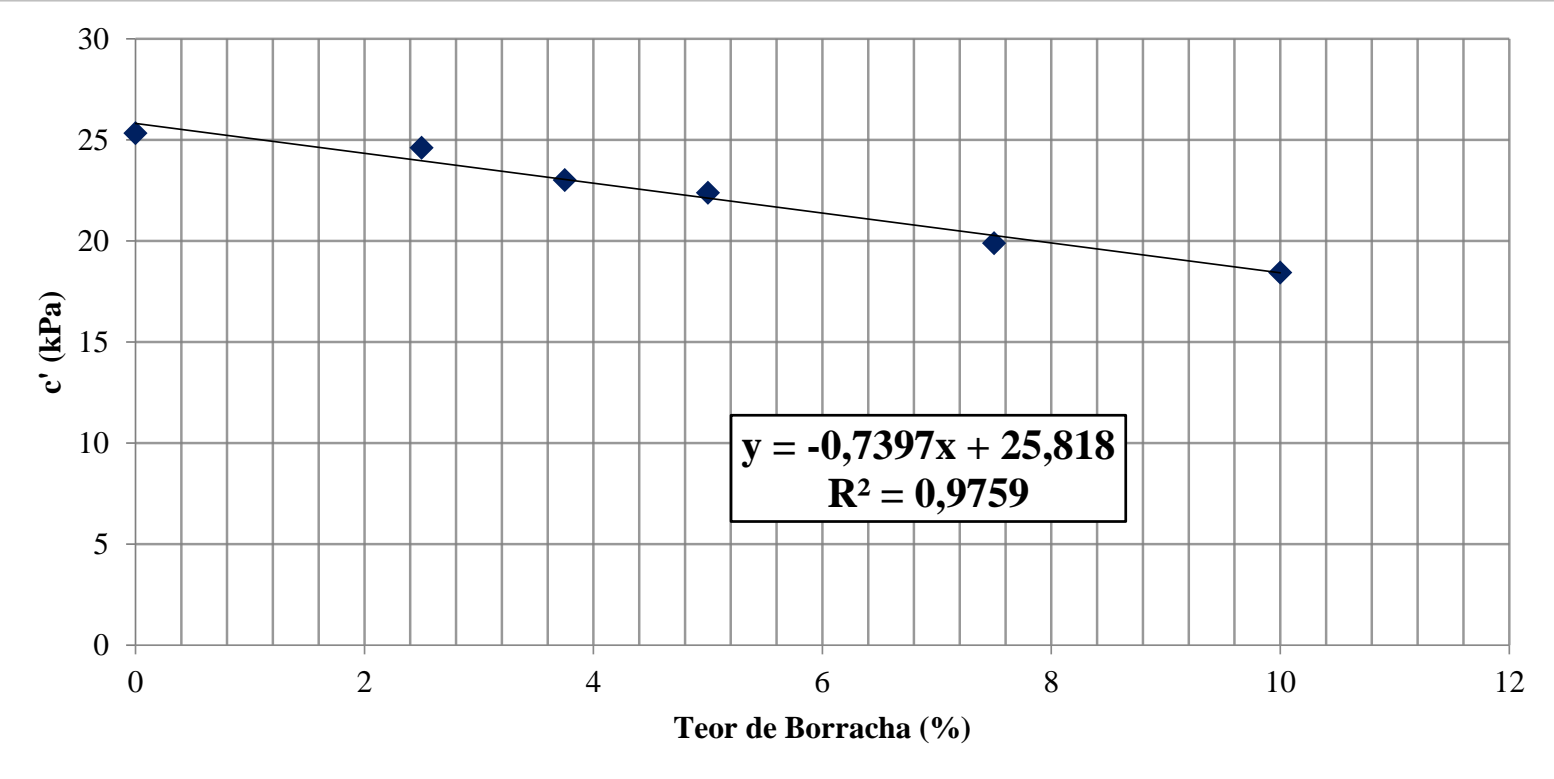

Figura 5.23. Variação da coesão com o aumento do teor de borracha.

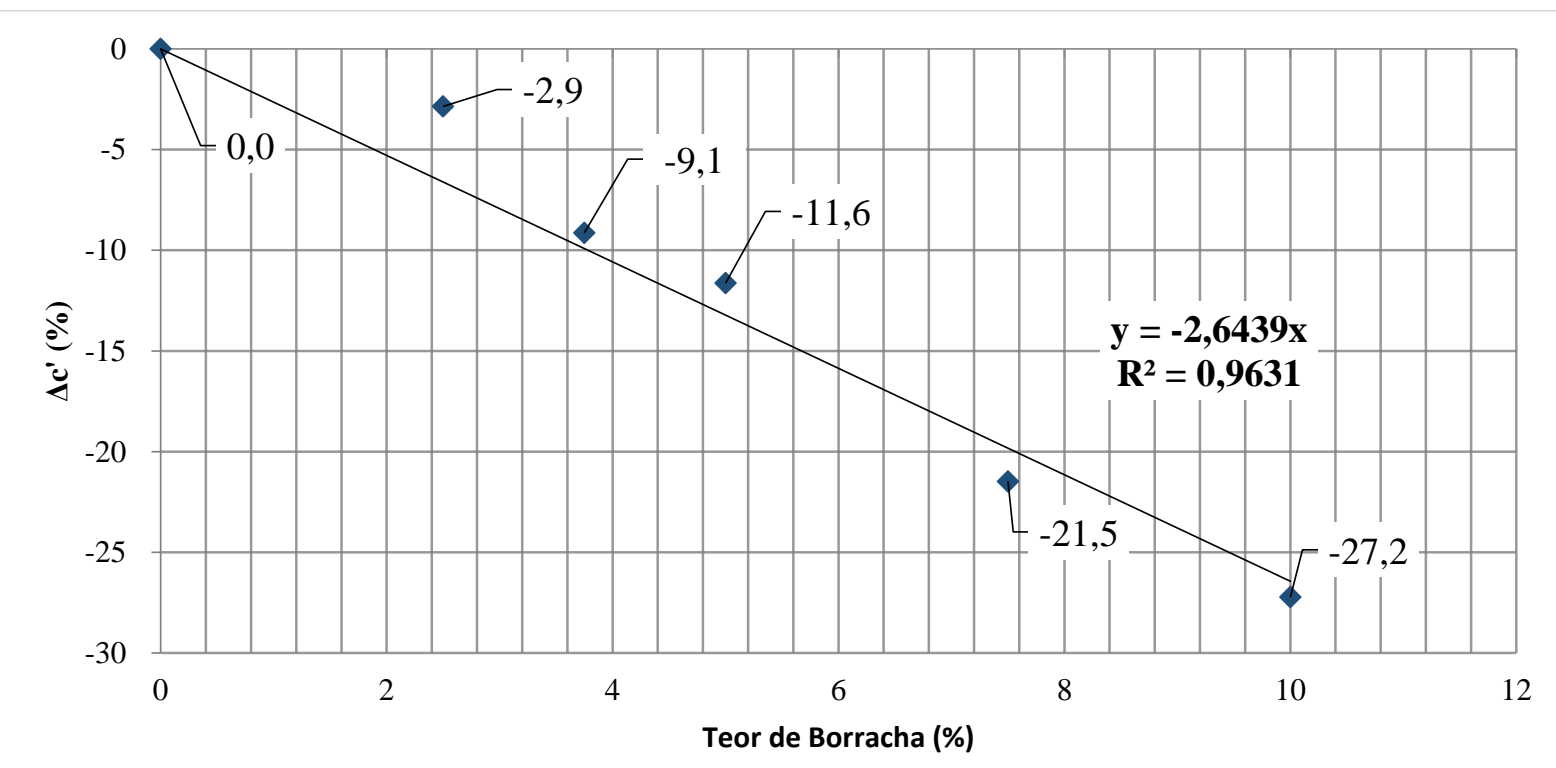

Figura 5.24. Decréscimo da coesão com o aumento do teor de borracha. 


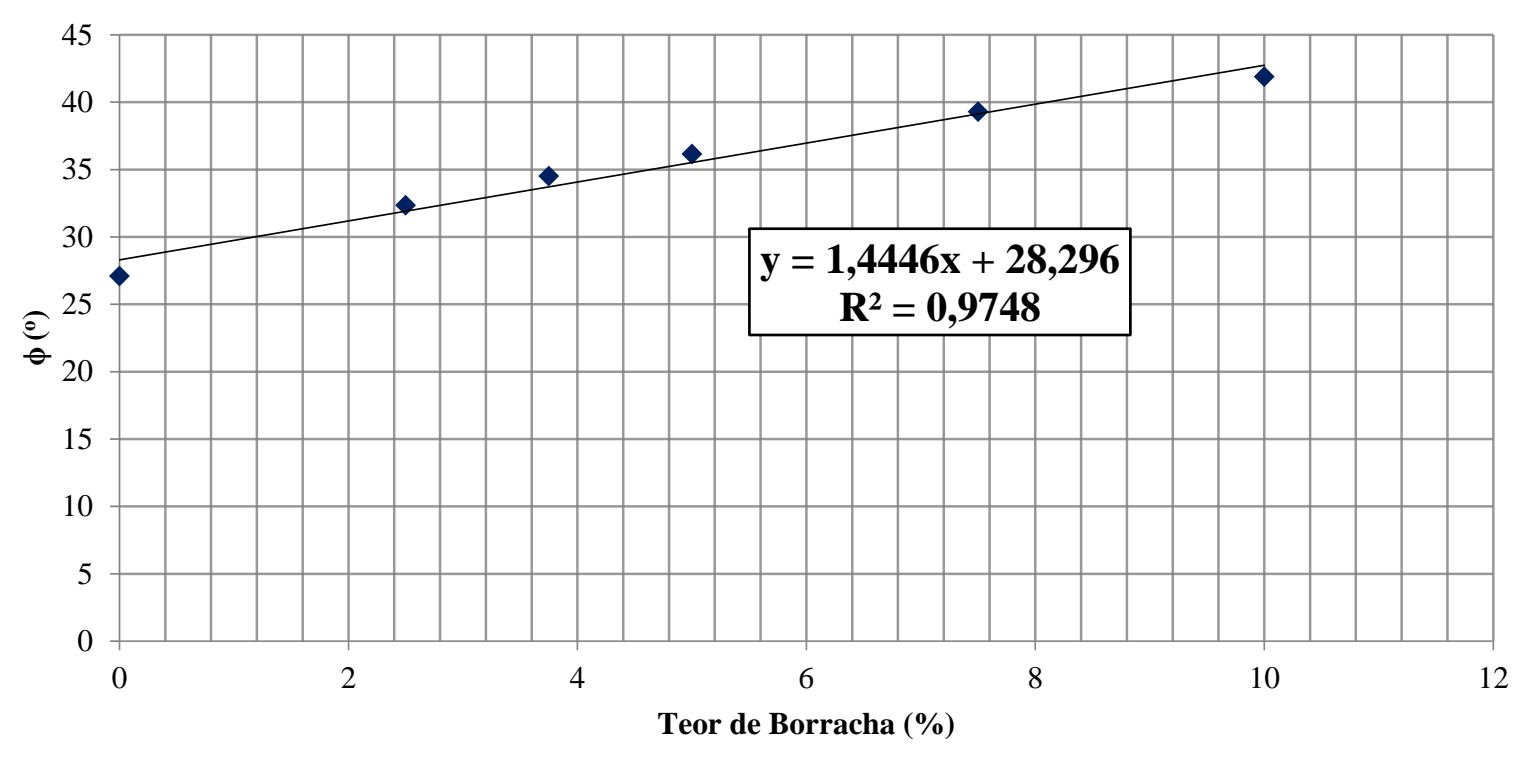

Figura 5.25. Variação do ângulo de atrito com o aumento do teor de borracha.

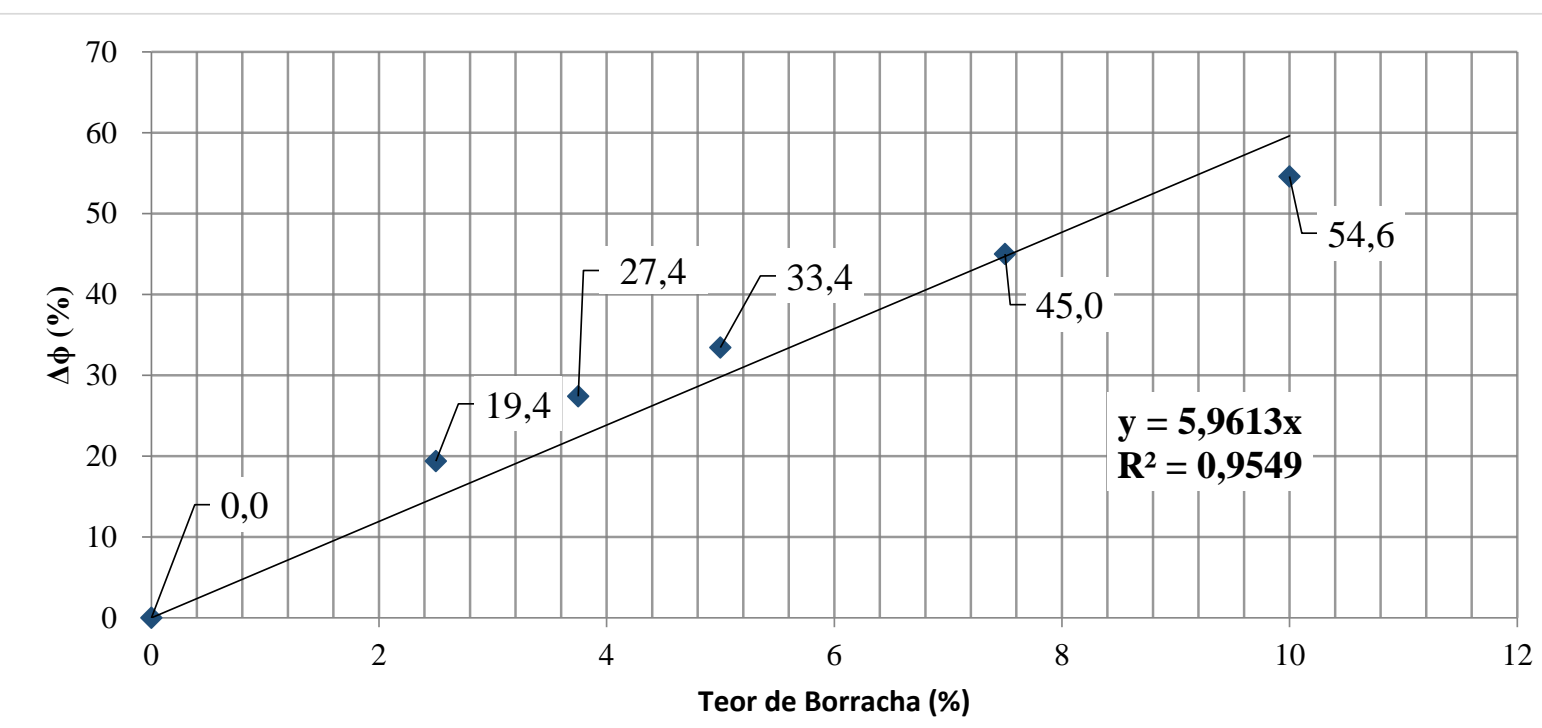

Figura 5.26. Acréscimo do ângulo de atrito com o aumento do teor de borracha. 


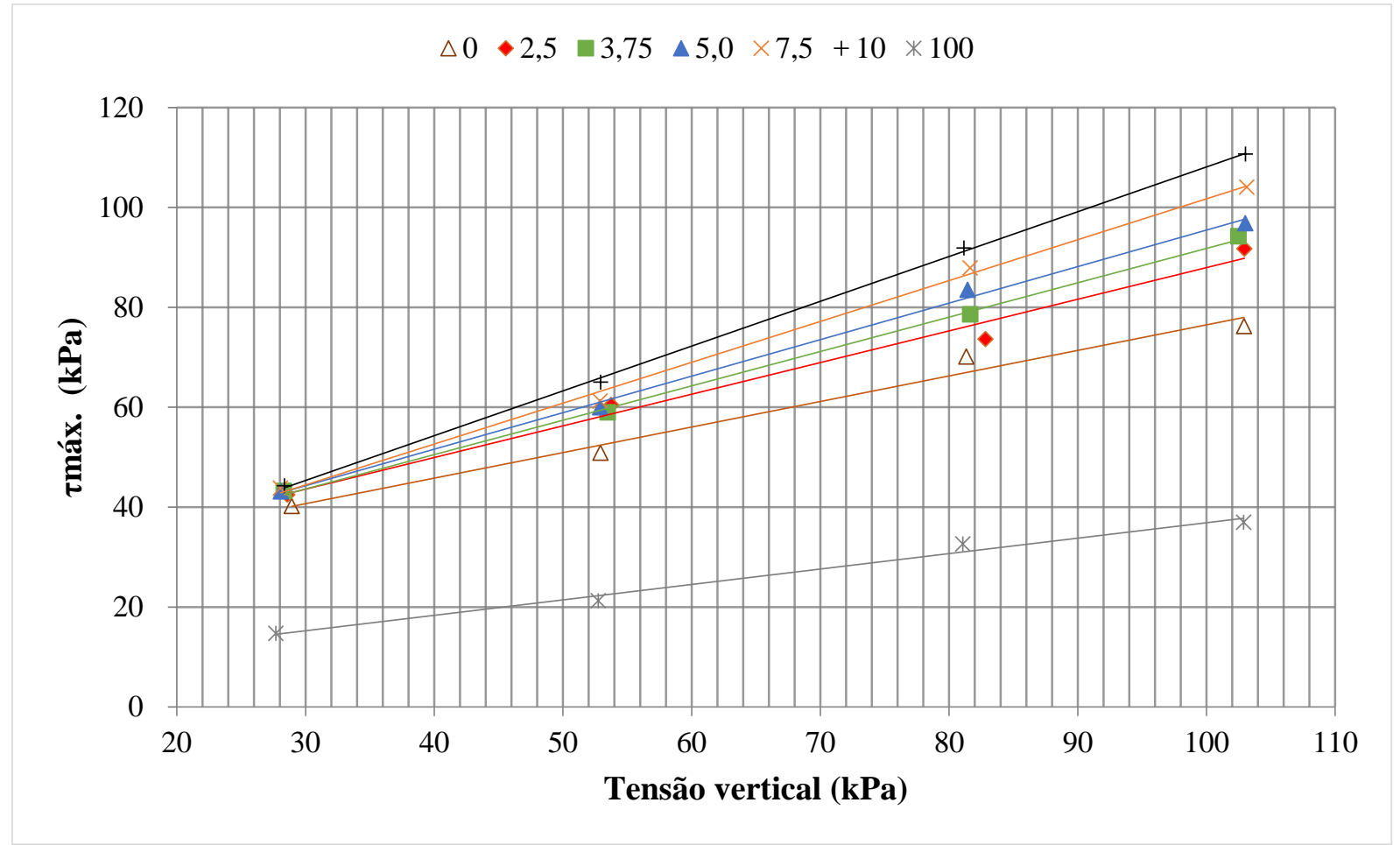

Figura 5.27. Envoltórias de ruptura para todos os teores de borracha utilizados na pesquisa.

\subsection{ANALISE DOS RESULTADOS APRESENTADOS}

Realizando comparações das granulometrias dos matérias utilizados na pesquisa com os materiais utilizados por Chrusciak (2013), encontrou-se que existe grande influência do tamanho dos pedaços de pneus sobre resultados da tensão cisalhante máxima dos ensaios de cisalhamento direto. Foi observado um acréscimo em tal valor da quando é feita a analise em grandes deformações devido ao fato de que o material de pequeno tamanho como migalhas e desbastes de pneu foram descartados. Autores como Al-Tabbaa \& Aravinthan (1998) e Cetin et al. (2006) concordam que esse tipo de material (migalhas e desbastes) podem afetar a resistência ao cisalhamento do solo.

A partir das compactações realizadas na pesquisa atual, foi observado que o peso aparente seco máximo de cada uma das misturas estabelecidas apresentou redução (variação até 4,3\%) com o aumento do teor de borracha (de $0 \%$ até $10 \%$ em peso). Isso ocorreu devido ao fato de que a densidade do material proveniente dos pneus é menor que a densidade do solo 
compactado. Observou-se também que a diferença da variação da umidade ótima de compactação não é significativa teoricamente (variação de 1,6\%), pois a borracha tem absorção de agua baixa.

Segundo Chrusciak (2013), nos ensaios de compactação foi observado que, devido ao tamanho das partículas de borracha utilizadas, este material absorveu parte da energia de compactação. Portanto, nesta pesquisa foi decidido submeter a mistura a uma maior energia de compactação, a fim de torná-la mai compacta. Por meio do cálculo da variação do índice de vazios para cada uma das misturas solo-borracha, comparando-se com amostras de solo puro, avaliou-se que não ocorreu uma mudança significativa em tal valor quando em relação a sua umidade de compactação ótima: assim, a presença da borracha em cada uma das misturas não alterou a matriz da estrutura dos corpos de prova.

Como a borracha é um material altamente compressível, nos ensaios de compactação, quando os corpos de prova foram desconfinados, a borracha foi descomprimida, gerando trincas na estrutura do corpo de prova da mistura e possíveis planos de fraqueza. Por esse motivo, para que as misturas trabalhem de maneira adequada numa obra de engenharia, deve o material permanecer confinado ao máximo.

Por meio do exame visual das amostras compactadas desconfinadas, observou-se que até 5\% de teor de borracha (mistura M04) não se formaram grande número de trincas e possíveis planos de fraqueza. Após este teor, os corpos de prova se mostraram muito fissurados, devido à alta descontinuidade que acontece dentro da estrutura.

Foi encontrado um comportamento linear da variação do peso específico aparente seco máximo (decrescente) e da variação da umidade ótima de compactação (crescente), com relação ao aumento do teor de borracha utilizados em cada uma das misturas.

Nos ensaios de cisalhamento direto em média escala foi observado que ocorreu aumento na tensão de cisalhamento máximo (aprox. 45,17\%), uma vez que os pedaços de pneus se comportam como material granular dentro da mistura, interferem no plano teórico de ruptura e se comportam como reforço. Esse resultado está de acordo com Bosscher et al. (1994), que também salienta que a influência dos pedaços é maior se estas interferem no plano verticalmente. 
Foi realizada uma análise da influência da intrusão de borracha nos corpos de prova sobre a tensão de cisalhamento a pequenas deformações ( $2 \%$ do deslocamento horizontal máximo). Foi possível notar que, com o aumento do teor de borracha, existe decréscimo na tensão cisalhante máxima quando este material está submetido a tensões confinantes altas (100 kPa). Já no caso das tensões confinantes restantes, não se encontra um comportamento claro da variação do valor da tensão cisalhante máxima. Assim verifica-se que a melhoria do valor da tensão cisalhante máxima quando aumentamos somente o teor de borracha é valido quando realizamos um análise em termos de grandes deformações.

Comparando os valores de tensão cisalhante máxima obtidos na pesquisa com os valores presentados por Chrusciak (2013), para grandes deslocamentos, avaliou-se que existe grande influência do tamanho da borracha utilizada sobre os parâmetros de resistência do solo. Quando retiramos material como migalhas e desbastes de pneus, encontramos um melhor comportamento mecânico das misturas.

Foi observado também que ocorre acréscimo no ângulo de atrito $(54,6 \%)$ com o aumento do teor de borracha. Isso ocorre devido à granulometria do solo empregado, que interagiu com os pedaços de borracha e gerou o referido aumento. Esse resultado foi semelhante ao encontrado por Zornberg et al (2004), o qual afirma que existe atrito entre o solo e a borracha, aumentando o ângulo de atrito da estrutura.

No caso da coesão, ocorreu redução com o aumento do teor de borracha, uma vez os fragmentos de borracha tornam a mistura um material não continuo. Dessa forma, os pedaços de pneu atuam como materiais não coesivos que acabam desestruturando o solo.

Nas curvas de tensão cisalhante versus deslocamento horizontal, para os materiais puros (amostra de solo puro e amostra de borracha pura), foram encontrados baixos valores de tensão de cisalhamento máxima. Assim, embora não sejam materiais compatíveis, a mistura de ambos pode resultar em um material com maior tensão de cisalhamento máxima. Também foi observado que as amostras de borracha pura se comportaram como um material linear que não chega à ruptura. 
Foi ainda observada uma tendência linear no aumento da tensão cisalhante máxima, este acréscimo não é linear possivelmente devido à aleatoriedade na distribuição das partículas no processo de conformação da estrutura.

O comportamento da mudança volumétrica das amostras de solo puro, misturas solo-borracha e borracha pura são diferentes e, no caso do solo puro, existe compressão até um valor máximo. Após deste valor, as mudanças volumétricas não são significativas; no caso das misturas solo-borracha, existe compressão até um valor máximo e, após este valor, o material se expande consideravelmente; no caso da amostra de borracha pura, o comportamento da deformação volumétrica é totalmente de compressão, a variação de volume é linear em baixos deslocamentos horizontais e está de acordo com resultados de testes realizados por outros autores como Lee et al.(1999) e Zornberg et al. (2004). Este tipo de comportamento é evidenciado nas amostras que estão submetidas a tensões normais confinantes de 25,50 e 80 $\mathrm{kPa}$.

No caso da tensão de uma tensão normal confinante de $100 \mathrm{kPa}$, as mudanças volumétricas que ocorrem com amostras de solo puro e das misturas solo-borracha são semelhantes. Com o acréscimo do teor de borracha, as mudanças volumétricas são reduzidas, concordando com autores como Ghazavi et al. (2011) e Bałachowski \& Gotteland (2007). Por outro lado, a borracha pura tem um comportamento de compressão pura com a aplicação das cargas, resultando em um comportamento linear.

Como o material proveniente de pneus é altamente compressível, nas curvas de adensamento ocorreram acréscimos nos deslocamentos verticais com o aumento do teor de borracha.

Com os resultados obtidos dos ensaios de cisalhamento direto em escala média e a revisão bibliográfica realizada na pesquisa, é possível complementar a Tabela 2.5 de Edinçliler et al. (2010) com os valores novos obtidos. Os valores novos são apresentados na Tabela 5.4. 
Tabela 5.4. Parâmetros de resistência de misturas de solo com fragmentos de pneus usados (Modificado de Edinçliler et al., 2010).

\begin{tabular}{|c|c|c|c|}
\hline Referência & Material & $\begin{array}{c}\gamma_{\mathrm{d}} \\
(\mathrm{kN} / \mathrm{m} 3)\end{array}$ & $\begin{array}{l}\text { Parâmetros de } \\
\text { resistência }\end{array}$ \\
\hline $\begin{array}{l}\text { (Humphrey } \\
\text { et al., 1999) }\end{array}$ & $\begin{array}{l}\text { Produto } 1(<76 \mathrm{~mm} \text { pedaços }-1) \\
\text { Produto } 2(<76 \mathrm{~mm} \text { pedaços }-1) \\
\text { Produto } 3(<76 \mathrm{~mm} \text { pedaços }-1) \\
\text { Produto } 3(<76 \mathrm{~mm} \text { pedaços }-2)\end{array}$ & $\begin{array}{c}7,01 \\
6,82 \\
7,24 \\
-\end{array}$ & $\begin{aligned} c^{\prime} & =8,6 \mathrm{kPa} \phi=25^{\circ} \\
c^{\prime} & =11,5 \mathrm{kPa} \phi=19^{\circ} \\
\mathrm{c}^{\prime} & =7,7 \mathrm{kPa} \phi=21^{\circ} \\
\mathrm{c}^{\prime} & =4,3 \mathrm{kPa} \phi=26^{\circ}\end{aligned}$ \\
\hline $\begin{array}{c}\text { (Ahmed \& } \\
\text { Lovell, 1993) }\end{array}$ & $\begin{array}{l}\text { Pedaços de pneus (tamanho: } 1.3 \mathrm{~cm} \text { ) } \\
\text { Pedaços de pneus (tamanho: } 2,5 \mathrm{~cm} \text { ) } \\
\text { Pedaços de pneus (tamanho: } 2,5 \mathrm{~cm} \text { ) } \\
\text { Pedaços de pneus (tamanho: } 2,5 \mathrm{~cm} \text { ) }\end{array}$ & $\begin{array}{l}4,67 \\
6,71 \\
6,29 \\
6,45\end{array}$ & $\begin{array}{l}\mathrm{c}^{\prime}=35,8 \mathrm{kPa} \phi=20,5^{\circ} \\
\mathrm{c}^{\prime}=39,2 \mathrm{kPa} \phi=24,6^{\circ} \\
\mathrm{c}^{\prime}=33,2 \mathrm{kPa} \phi=25,3^{\circ} \\
\mathrm{c}^{\prime}=37,3 \mathrm{kPa} \phi=22,6^{\circ}\end{array}$ \\
\hline $\begin{array}{c}\text { (Wu et al., } \\
1997 b)\end{array}$ & $\begin{array}{l}\text { Lascas de Pneus - Produto } 1 \text { (máx. } 38 \mathrm{~mm} \text { ) } \\
\text { Lascas de Pneus - Produto } 2 \text { (máx. } 19 \mathrm{~mm} \text { ) } \\
\text { Lascas de Pneus - Produto } 3 \text { (máx. } 9.5 \mathrm{~mm} \text { ) } \\
\text { Lascas de Pneus - Produto } 4 \text { (máx. } 9.5 \mathrm{~mm} \text { ) } \\
\text { Migalhas - Produto } 5 \text { (máx. } 2 \mathrm{~mm} \text { ) }\end{array}$ & $\begin{array}{l}5,89 \\
5,69 \\
4,95 \\
5,89 \\
5,69\end{array}$ & $\begin{array}{l}\mathrm{c}^{\prime}=0 \mathrm{kPa} \phi=57^{\circ} \\
\mathrm{c}^{\prime}=0 \mathrm{kPa} \phi=54^{\circ} \\
\mathrm{c}^{\prime}=0 \mathrm{kPa} \phi=54^{\circ} \\
\mathrm{c}^{\prime}=0 \mathrm{kPa} \phi=47^{\circ} \\
\mathrm{c}^{\prime}=0 \mathrm{kPa} \phi=45^{\circ}\end{array}$ \\
\hline $\begin{array}{l}\text { (Tatlisoz et } \\
\text { al., 1998) }\end{array}$ & $\begin{array}{c}100 \% \text { lascas de pneus } \\
100 \% \text { Areia } \\
90 \% \text { de areia }+10 \% \text { lascas de pneus } \\
80 \% \text { de areia }+20 \% \text { lascas de pneus } \\
70 \% \text { de areia }+30 \% \text { lascas de pneus } \\
100 \% \text { Silte arenoso } \\
90 \% \text { Silte arenoso }+10 \% \text { lascas de pneus } \\
80 \% \text { Silte arenoso }+20 \% \text { lascas de pneus } \\
70 \% \text { Silte arenoso }+30 \% \text { lascas de pneus }\end{array}$ & $\begin{array}{c}5,9 \\
16,8 \\
15,6 \\
14,5 \\
13,3 \\
18,3 \\
17,6 \\
17,0 \\
18,9\end{array}$ & $\begin{aligned} c^{\prime} & =0 \mathrm{kPa} \phi=30^{\circ} \\
c^{\prime} & =2 \mathrm{kPa} \phi=34^{\circ} \\
c^{\prime} & =2 \mathrm{kPa} \phi=46^{\circ} \\
c^{\prime} & =2 \mathrm{kPa} \phi=50^{\circ} \\
c^{\prime} & =2 \mathrm{kPa} \phi=52^{\circ} \\
c^{\prime} & =21 \mathrm{kPa} \phi=30^{\circ} \\
c^{\prime} & =8 \mathrm{kPa} \phi=53^{\circ} \\
c^{\prime} & =38 \mathrm{kPa} \phi=54^{\circ} \\
c^{\prime} & =39 \mathrm{kPa} \phi=53^{\circ}\end{aligned}$ \\
\hline $\begin{array}{c}\text { (Foose et al., } \\
1996)\end{array}$ & $\begin{array}{c}90 \% \text { de areia }+10 \% \text { pedaços de pneus }(15 \mathrm{~cm} \text { aleatório) } \\
90 \% \text { de areia }+10 \% \text { pedaços de pneus }(15 \mathrm{~cm} \text { espessura }) \\
90 \% \text { de areia }+10 \% \text { pedaços de pneus }(15 \mathrm{~cm} \text { aleatório) } \\
70 \% \text { de areia }+30 \% \text { pedaços de pneus }(5 \mathrm{~cm} \text { espessura }) \\
70 \% \text { de areia }+30 \% \text { pedaços de pneus }(5 \mathrm{~cm} \text { aleatório }) \\
70 \% \text { de areia }+30 \% \text { pedaços de pneus }(5 \mathrm{~cm} \text { espessura) } \\
70 \% \text { de areia }+30 \% \text { pedaços de pneus }(5 \mathrm{~cm} \text { aleatório }) \\
70 \% \text { de areia }+30 \% \text { pedaços de pneus }(5 \mathrm{~cm} \text { espessura) } \\
90 \% \text { de areia }+10 \% \text { pedaços de pneus }(15 \mathrm{~cm} \text { espessura }) \\
90 \% \text { de areia }+10 \% \text { pedaços de pneus }(5 \mathrm{~cm} \text { aleatório }) \\
90 \% \text { de areia }+10 \% \text { pedaços de pneus }(5 \mathrm{~cm} \text { espessura }) \\
70 \% \text { de areia }+30 \% \text { pedaços de pneus }(15 \mathrm{~cm} \text { espessura }) \\
70 \% \text { de areia }+30 \% \text { pedaços de pneus }(15 \mathrm{~cm} \text { espessura }) \\
90 \% \text { de areia }+10 \% \text { pedaços de pneus }(5 \mathrm{~cm} \text { espessura }) \\
70 \% \text { de areia }+30 \% \text { pedaços de pneus }(15 \mathrm{~cm} \text { aleatório) } \\
90 \% \text { de areia }+10 \% \text { pedaços de pneus }(5 \mathrm{~cm} \text { aleatório) }\end{array}$ & $\begin{array}{l}16,8 \\
16,8 \\
14,7 \\
14,7 \\
14,7 \\
16,8 \\
16,8 \\
14,7 \\
14,7 \\
16,8 \\
14,7 \\
16,8 \\
16,8 \\
16,8 \\
14,7 \\
14,7\end{array}$ & $\begin{aligned} \tau & =37,9 \mathrm{kPa}(\sigma=25,5 \mathrm{kPa}) \\
\tau & =18,6 \mathrm{kPa}(\sigma=25,5 \mathrm{kPa}) \\
\tau & =8,3 \mathrm{kPa}(\sigma=25,5 \mathrm{kPa}) \\
\tau & =37,2 \mathrm{kPa}(\sigma=25,5 \mathrm{kPa}) \\
\tau & =11,0 \mathrm{kPa}(\sigma=25,5 \mathrm{kPa}) \\
\tau & =20,7 \mathrm{kPa}(\sigma=25,5 \mathrm{kPa}) \\
\tau & =55,2 \mathrm{kPa}(\sigma=25,5 \mathrm{kPa}) \\
\tau & =32,4 \mathrm{kPa}(\sigma=25,5 \mathrm{kPa}) \\
\tau & =32,4 \mathrm{kPa}(\sigma=25,5 \mathrm{kPa}) \\
\tau & =32,4 \mathrm{kPa}(\sigma=25,5 \mathrm{kPa}) \\
\tau & =13,8 \mathrm{kPa}(\sigma=25,5 \mathrm{kPa}) \\
\tau & =78,6 \mathrm{kPa}(\sigma=25,5 \mathrm{kPa}) \\
\tau & =22,8 \mathrm{kPa}(\sigma=25,5 \mathrm{kPa}) \\
\tau & =29,0 \mathrm{kPa}(\sigma=25,5 \mathrm{kPa}) \\
\tau & =42,1 \mathrm{kPa}(\sigma=25,5 \mathrm{kPa}) \\
\tau & =19,3 \mathrm{kPa}(\sigma=25,5 \mathrm{kPa})\end{aligned}$ \\
\hline $\begin{array}{l}\text { (Edinçliler et } \\
\text { al., 2004) }\end{array}$ & $\begin{array}{c}100 \% \text { Desbastes de pneus } \\
100 \% \text { Areia } \\
90 \% \text { Areia+10\% Desbastes de pneus }\end{array}$ & $\begin{array}{c}5,1 \\
15,3 \\
13,0 \\
\end{array}$ & $\begin{array}{l}\mathrm{c}^{\prime}=3,1 \mathrm{kPa} \phi=22^{\circ} \\
\mathrm{c}^{\prime}=6,9 \mathrm{kPa} \phi=33^{\circ} \\
\mathrm{c}^{\prime}=8,7 \mathrm{kPa} \phi=29^{\circ}\end{array}$ \\
\hline $\begin{array}{c}\text { (Ghazavi, } \\
\text { 2004) }\end{array}$ & $\begin{array}{l}100 \% \text { Areia } \\
\text { 90\% Areia }+10 \% \text { migalhas de pneus } \\
85 \% \text { Areia }+15 \% \text { migalhas de pneus } \\
80 \% \text { Areia }+20 \% \text { migalhas de pneus } \\
50 \% \text { Areia }+50 \% \text { migalhas de pneus } \\
30 \% \text { Areia }+70 \% \text { migalhas de pneus } \\
\text { 100\% migalhas de pneus }\end{array}$ & $\begin{array}{c}14-14,5 \\
13-13,5 \\
12,3-13 \\
11-12,4 \\
7,7-8 \\
6,4-6,7 \\
4,7-5,1\end{array}$ & $\begin{array}{c}\phi=31,2^{\circ}-37^{\circ} \\
\phi=31^{\circ}-37^{\circ} \\
\phi=35,3^{\circ}-37,6^{\circ} \\
\phi=34,5^{\circ}-33,5^{\circ} \\
\phi=33^{\circ}-35^{\circ} \\
\phi=33^{\circ} \\
\phi=31^{\circ}\end{array}$ \\
\hline
\end{tabular}


Tabela 5.4. Parâmetros de resistência de misturas de solo com fragmentos de pneus usados (Modificado de Edinçliler et al., 2010). (Continuação)

\begin{tabular}{|c|c|c|c|}
\hline Referência & Material & $\begin{array}{c}\gamma_{\mathrm{d}} \\
(\mathrm{kN} / \mathrm{m} 3)\end{array}$ & $\begin{array}{l}\text { Parâmetros de } \\
\text { resistência }\end{array}$ \\
\hline $\begin{array}{l}\text { (Attom, } \\
2006)\end{array}$ & $\begin{array}{l}100 \% \text { areia } \mathrm{A} \\
10 \% \text { pedaços de pneu }+90 \% \text { areia } \mathrm{A} \\
20 \% \text { pedaços de pneu }+80 \% \text { areia } \mathrm{A} \\
30 \% \text { pedaços de pneu }+70 \% \text { areia } \mathrm{A} \\
40 \% \text { pedaços de pneu }+60 \% \text { areia } \mathrm{A} \\
100 \% \text { areia } \mathrm{B} \\
10 \% \text { pedaços de pneu }+90 \% \text { areia } \mathrm{B} \\
20 \% \text { pedaços de pneu }+80 \% \text { areia } \mathrm{B} \\
30 \% \text { pedaços de pneu }+70 \% \text { areia } \mathrm{B} \\
40 \% \text { pedaços de pneu }+60 \% \text { areia } \mathrm{B} \\
100 \% \text { areia } \mathrm{C} \\
10 \% \text { pedaços de pneu }+90 \% \text { areia } \mathrm{C} \\
20 \% \text { pedaços de pneu }+80 \% \text { areia } \mathrm{C} \\
30 \% \text { pedaços de pneu }+70 \% \text { areia } \mathrm{C} \\
40 \% \text { pedaços de pneu }+60 \% \text { areia } \mathrm{C}\end{array}$ & $\begin{array}{c}15,5 \\
14 \\
15 \\
15,5 \\
16 \\
15,9 \\
14 \\
15 \\
15,9 \\
16 \\
16,6 \\
15 \\
16 \\
16,5 \\
16,6\end{array}$ & $\begin{array}{l}\phi=25^{\circ} \\
\phi=30^{\circ} \\
\phi=37^{\circ} \\
\phi=41^{\circ} \\
\phi=45^{\circ} \\
\phi=28^{\circ} \\
\phi=35^{\circ} \\
\phi=42^{\circ} \\
\phi=47^{\circ} \\
\phi=49^{\circ} \\
\phi=36^{\circ} \\
\phi=42^{\circ} \\
\phi=45^{\circ} \\
\phi=48^{\circ} \\
\phi=50^{\circ}\end{array}$ \\
\hline $\begin{array}{l}\text { (Bałachowski } \\
\text { \& Gotteland, } \\
\text { 2007) }\end{array}$ & $\begin{array}{c}100 \% \text { areia } \\
14,2 \% \text { pedaços de pneu }+85,8 \% \text { areia } \\
15,2 \% \text { pedaços de pneu }+84,8 \% \text { areia } \\
23 \% \text { pedaços de pneu }+77 \% \text { areia } \\
30 \% \text { pedaços de pneu }+70 \% \text { areia } \\
50 \% \text { pedaços de pneu }+50 \% \text { areia } \\
100 \% \text { pedaços de pneus (orientados horizontalmente) }\end{array}$ & $\begin{array}{c}16,2 \\
15,50 \\
14,52 \\
13,95 \\
13,30 \\
6,59 \\
7,72\end{array}$ & 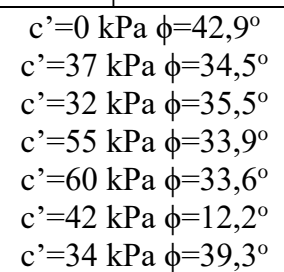 \\
\hline $\begin{array}{l}\text { (Edinçliler, } \\
\text { al., 2007) }\end{array}$ & $\begin{array}{c}100 \% \text { Desbastes de pneus } \\
100 \% \text { Areia } \\
95 \% \text { Areia+5\% Desbastes de pneus } \\
90 \% \text { Areia+10\% Desbastes de pneus } \\
80 \% \text { Areia+20\% Desbastes de pneus } \\
70 \% \text { Areia+30\% Desbastes de pneus }\end{array}$ & $\begin{array}{c}5,1 \\
15,3 \\
15,2 \\
14,9 \\
14,2 \\
13,5\end{array}$ & 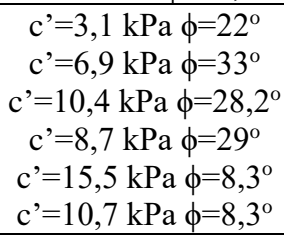 \\
\hline $\begin{array}{c}\text { (Ghazavi et } \\
\text { al., 2011) }\end{array}$ & $\begin{array}{c}100 \% \text { Areia } \\
\text { 85\% Areia+15\% lascas pneus } \\
75 \% \text { Areia+25\% lascas de pneus } \\
\text { 70\% Areia+30\% lascas de pneus } \\
65 \% \text { Areia+35\% lascas de pneus } \\
100 \% \text { lascas de pneus } \\
\text { 100\% Areia - interface com geogrelhia } \\
\text { 85\% Areia+15\% lascas pneus - interface com geogrelhia } \\
75 \% \text { Areia+25\% lascas de pneus - interface com geogrelhia } \\
70 \% \text { Areia+30\% lascas de pneus - interface com geogrelhia } \\
65 \% \text { Areia+35\% lascas de pneus - interface com geogrelhia } \\
100 \% \text { lascas de pneus - interface com geogrelhia }\end{array}$ & $\begin{array}{c}14 \\
13,7 \\
13,5 \\
13,4 \\
13,3 \\
7,5 \\
14 \\
13,7 \\
13,5 \\
13,4 \\
13,3 \\
7,5\end{array}$ & $\begin{aligned} \mathrm{c}^{\prime} & =0,8 \mathrm{kPa} \phi=30,2^{\circ} \\
\mathrm{c}^{\prime} & =5,1 \mathrm{kPa} \phi=35,8^{\circ} \\
\mathrm{c}^{\prime} & =6,8 \mathrm{kPa} \phi=38,2^{\circ} \\
\mathrm{c}^{\prime} & =7,3 \mathrm{kPa} \phi=39,7^{\circ} \\
\mathrm{c}^{\prime} & =9,4 \mathrm{kPa} \phi=38,2^{\circ} \\
\mathrm{c}^{\prime} & =2,5 \mathrm{kPa} \phi=24,2^{\circ} \\
\mathrm{c}^{\prime} & =2,3 \mathrm{kPa} \phi=27,9^{\circ} \\
\mathrm{c}^{\prime} & =3,3 \mathrm{kPa} \phi=34^{\circ} \\
\mathrm{c}^{\prime} & =4,5 \mathrm{kPa} \phi=36,7^{\circ} \\
\mathrm{c}^{\prime} & =5,8 \mathrm{kPa} \phi=38,5^{\circ} \\
\mathrm{c}^{\prime} & =8,3 \mathrm{kPa} \phi=37,2^{\circ} \\
\mathrm{c}^{\prime} & =3,7 \mathrm{kPa} \phi=22,2^{\circ}\end{aligned}$ \\
\hline $\begin{array}{c}\text { (Franco, } \\
\text { 2012) }\end{array}$ & $\begin{array}{c}100 \% \text { solo argiloso } \\
80 \% \text { solo argiloso }+20 \% \text { desbastes de pneus } \\
70 \% \text { solo argiloso }+30 \% \text { desbastes de pneus } \\
60 \% \text { solo argiloso }+40 \% \text { desbastes de pneus } \\
50 \% \text { solo argiloso }+50 \% \text { desbastes de pneus } \\
100 \% \text { solo argiloso } \\
\end{array}$ & $\begin{array}{l}18,8 \\
17,5 \\
16,0 \\
14,3 \\
12,2 \\
7,0 \\
\end{array}$ & $\begin{array}{c}\mathrm{c}^{\prime}=8,0 \mathrm{kPa} \phi=31^{\circ} \\
\mathrm{c}^{\prime}=7,9 \mathrm{kPa} \phi=35^{\circ} \\
\mathrm{c}^{\prime}=11,8 \mathrm{kPa} \phi=33^{\circ} \\
\mathrm{c}^{\prime}=32,1 \mathrm{kPa} \phi=34^{\circ} \\
\mathrm{c}^{\prime}=15,5 \mathrm{kPa} \phi=32^{\circ} \\
\mathrm{c}^{\prime}=0 \mathrm{kPa} \phi=25^{\circ}\end{array}$ \\
\hline $\begin{array}{c}\text { (Chrusciak, } \\
\text { 2013) }\end{array}$ & $\begin{array}{c}100 \% \text { solo argiloso } \\
97,5 \% \text { solo argiloso }+2,5 \% \text { pedaços de pneus } \\
96,25 \% \text { solo argiloso }+3,75 \% \text { pedaços de pneus } \\
95 \% \text { solo argiloso }+5,0 \% \text { pedaços de pneus } \\
92,5 \% \text { solo argiloso }+7,5 \% \text { pedaços de pneus }\end{array}$ & $\begin{array}{l}15,02 \\
14,88 \\
14,60 \\
14,44 \\
14,32 \\
\end{array}$ & $\begin{aligned} \mathrm{c}^{\prime} & =35,6 \mathrm{kPa} \phi=29,4^{\circ} \\
\mathrm{c}^{\prime} & =28 \mathrm{kPa} \phi=32,6^{\circ} \\
\mathrm{c}^{\prime} & =24,4 \mathrm{kPa} \phi=32,3^{\circ} \\
\mathrm{c}^{\prime} & =20,6 \mathrm{kPa} \phi=37,6^{\circ} \\
\mathrm{c}^{\prime} & =13,5 \mathrm{kPa} \phi=39,7^{\circ}\end{aligned}$ \\
\hline
\end{tabular}


Tabela 5.4. Parâmetros de resistência de misturas de solo com fragmentos de pneus usados (Modificado de Edinçliler et al., 2010). (Continuação)

\begin{tabular}{|c|c|c|c|}
\hline Referência & Material & $\begin{array}{c}\gamma_{\mathrm{d}} \\
(\mathrm{kN} / \mathrm{m} 3)\end{array}$ & $\begin{array}{l}\text { Parâmetros de } \\
\text { resistência }\end{array}$ \\
\hline $\begin{array}{c}\text { (Szeliga et } \\
\text { al., 2014) }\end{array}$ & $\begin{array}{l}100 \% \text { solo argiloso } \\
80 \% \text { solo argiloso }+20 \% \text { migalhas de pneus } \\
70 \% \text { solo argiloso }+30 \% \text { migalhas de pneus } \\
60 \% \text { solo argiloso }+40 \% \text { migalhas de pneus }\end{array}$ & $\begin{array}{c}15,55 \\
14,2 \\
13,43 \\
13,10\end{array}$ & 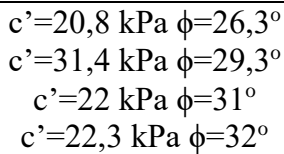 \\
\hline $\begin{array}{c}\text { (Suárez, } \\
\text { 2016) }\end{array}$ & $\begin{array}{c}100 \% \text { solo argiloso } \\
97,5 \% \text { solo argiloso }+2,5 \% \text { pedaços de pneus } \\
96,25 \% \text { solo argiloso }+3,75 \% \text { pedaços de pneus } \\
95 \% \text { solo argiloso }+5,0 \% \text { pedaços de pneus } \\
92,5 \% \text { solo argiloso }+7,5 \% \text { pedaços de pneus } \\
90 \% \text { solo argiloso }+10 \% \text { pedaços de pneus } \\
100 \% \text { pedaços de pneus }\end{array}$ & $\begin{array}{l}16,98 \\
16,79 \\
16,55 \\
16,45 \\
16,25 \\
16,10\end{array}$ & 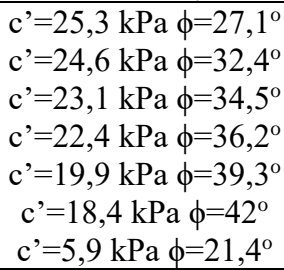 \\
\hline
\end{tabular}




\section{CONCLUSÕES E SUGESTÕES}

A finalidade desta dissertação foi dar continuidade ao trabalho feito por Chrusciak (2013), modificando a granulometria do solo, ao tamanho da borracha e a energia de compactação, a fim de avaliar a mudança do comportamento mecânico das misturas estabelecidas. Na atualidade existe uma série de pesquisas que utilizaram fragmentos de borracha com menor diâmetro nominal, como adição para melhorar propriedades mecânicas de solos granulares. Entretanto, ainda não existem muitas pesquisas que estudaram o comportamento mecânico de misturas de fragmentos maiores de borracha, classificados como "pedaços de pneus" segundo a normativa D6270 (ASTM, 1998), misturados com solos lateríticos.

Foi observado que a mudança realizada nas granulometrias dos materiais resultaram na melhoria do comportamento mecânico das misturas. Ao contrário dos resultados apresentados por Chrusciak (2013), foram observados acréscimos na tensão cisalhante máxima e redução das variações volumétricas com o aumento do teor de borracha, lembrando este comportamento somente ocorre com os teores utilizados na pesquisa. Além disso, foram feitos ensaios para amostras compostas por borracha pura (teor de $100 \%$ de pedaços de pneus) e um teor de borracha adicional de $10 \%$ em peso seco do solo, a fim de complementar a pesquisa prévia. Dessa forma, foram obtidas as seguintes conclusões, lembrando que a pesquisa está baseada no analise do comportamento do material quando está submetida a grandes deformações:

- Com os ensaios de compactação observou-se redução no peso aparente seco máximo da mistura solo-borracha com o aumento do teor de borracha, ao contrário do que ocorre com o valor da umidade ótima de compactação, que não foi afetado pela adição de fragmentos de pneus;

- A borracha pode absorver certa energia de compactação. Assim, pelos resultados obtidos, são necessárias maiores energias de compactação para garantir que a mistura irá trabalhar como um material contínuo;

- Para aplicação deste tipo de misturas como material leve em projetos geotécnicos, o material deve ser mantido confinado ao máximo pois, ao ocorrer o desconfinamento, são geradas fissuras, trincas e possíveis planos de fraqueza; 
- Por meio do exame visual das amostras compactadas desconfinadas avaliou-se, que até a mistura M5 (5\% de teor de borracha) não foram encontrados um grande número de fissuras, trincas e possíveis planos de fraqueza. Após este teor, os corpos de prova se apresentaram altamente fissurados devido à alta descontinuidade que acontece dentro da estrutura da mistura;

- Nos ensaios de cisalhamento direto de média escala avaliou-se que existe um aumento na tensão de cisalhamento máxima (aprox. 45,2\%), devido à interação que ocorre entre o solo e os pedaços de pneus, os quais atuam dentro da mistura como material granular, dando forte contribuição da borracha como material de reforço. Não se encontra uma relação linear precisa deste comportamento, devido à aleatoriedade na posição das partículas dentro da estrutura de cada uma das misturas;

- Ocorreu uma redução da coesão com o aumento do teor de borracha, pois o aumento da presença dos pedaços de borracha dentro da mistura tornou material não continuo. Os pedaços de pneus são materiais não coesivos que acabam desestruturando o solo. Avaliouse um comportamento linear da queda deste valor com a variação do teor de borracha;

- Ocorre um acréscimo no ângulo de atrito $(56,4 \%)$ com o aumento do teor de borracha, pois existe atrito entre o solo e os pedaços de pneus dentro da mistura. Avaliou-se um comportamento linear do aumento deste valor com a variação do teor de borracha;

Foi realizada uma análise da influência da intrusão de borracha nos corpos de prova sobre a tensão de cisalhamento para pequenas deformações ( $2 \%$ do deslocamento horizontal máximo) para as tensões confinantes estabelecidas na pesquisa. Pode-se observar que, com o aumento do teor de borracha, existe decréscimo na tensão cisalhante máxima, quando este material está submetido a tensões confinantes altas (100 kPa). Já no caso das tensões confinantes menores, não se observou um comportamento claro da variação do valor da tensão cisalhante máxima.

Assim com uma análise do comportamento mecânico das misturas submetidas a pequenas deformações, avaliou-se que não existe melhora no comportamento mecânico do solo com a intrusão da borracha dentro de sua estrutura embora (realizando analise de pequenas deformações) este processo de reciclagem do material proveniente de pneus usados continua sendo uma alternativa interessante para o descarte final deste material. 
Estes tipos de misturas podem ser de grande importância para geração de material leve com propriedades mecânicas melhores que seus componentes originais. Portanto, recomenda-se o uso deste tipo de material, tendo em conta as seguintes recomendações:

- Disponibilidade e facilidade na obtenção do material de adição;

- A mistura dentro de uma estrutura de contenção sendo utilizada como material leve deve ser mantida confinada durante toda sua vida útil;

- Fatores econômicos, como o valor do material de adição e custos de transporte, devem entrar na análise da viabilidade de qualquer projeto de engenharia que pretenda utilizar este tipo de material;

- Estudos ambientais prévios da influência e de possíveis danos ambientais que o uso deste tipo de misturas possa causar ao entorno devem ser realizados e avaliados, antes de tomar a decisão do uso deste material.

O aproveitamento de resíduos de pneus é de grande importância, uma vez que permite a reutilização deste material para melhorar as propriedades mecânicas de solos e, ao mesmo tempo, reduz os impactos ambientais relativos à disposição final dos pneus. No Brasil, muitas vezes ocorre o descarte indevido, resultando em problemas nos aterros sanitários e em dificuldade na compactação.

Para dar continuidade ao uso de borracha como material de adição para melhorar propriedades mecânicas de solos, sugere-se a realização de ensaios similares aos propostos nesta pesquisa, com pedaços de borracha uniformes, como aqueles utilizados por Bałachowski \& Gotteland (2007), realizando ensaios com pedaços orientados e não orientados. Na sequência, pode ser feita a avaliação da influência do número de pedaços pneus que inferem nos planos de ruptura, como foi realizado por Bosscher et al.(1994).

Sugere-se ainda a realização de um estudo da interação das misturas utilizadas nesta pesquisa com reforços, como geogrelhas como também um estudo da variação do coeficiente de empuxo em repouso $\left(\mathrm{K}_{0}\right)$ quando utilizamos misturas solo-borracha como material de enchimento leve em estruturas de contenção. 


\section{REFERENCIAS}

ABNT (1984b). NBR 7180/1984: Determinação do Limite de Plasticidade. Associação Brasileira de Normas Técnicas, Rio de Janeiro/RJ, 3 p.

ABNT (1984d). NBR 7181/1984: Solo - Análise Granulométrica. Associação Brasileira de Normas Técnicas, Rio de Janeiro/RJ, 13 p.

ABNT (1984a). NBR 6459/1984: Solo - Determinação do Limite de Liquidez. Associação Brasileira de Normas Técnicas, Rio de Janeiro/RJ, 6 p.

ABNT (1986a). NBR 7182/1986: Solo - Ensaio de Compactação. Associação Brasileira de Normas Técnicas, Rio de Janeiro/RJ, 10 p.

ABNT (1986b). NBR 6457/1986: Amostra de solo - Preparação para ensaios de compactação e ensaios de caracterização. Associação Brasileira de Normas Técnicas, Rio de Janeiro/RJ, 9 p.

ABNT (1984c). NBR 6508/1984: Grãos de solos que passam na peneira de 4,8mm Determinação da massa específica. Associação Brasileira de Normas Técnicas, Rio de Janeiro/RJ, 8p.

AHMED, I., LOVELL, C. W. (1993). Rubber Soils as Lightweight Geomaterials. Transportation Research Record, 1422: 61-70.

AL-TABBAA, A. \& ARAVINTHAN, T. (1998). Natural clay-shredded tire mixtures as landfill barrier materials. Waste Management, 18: 9-16.

ANIP (2015). Disponível em: < http://www.anip.com.br//>. Acessado em 05/05/2015.

ASTM (2008). ASTM D6270/08 - Standard Practice for Use of Scrap Tires in Civil Engineering Applications. American Society for Testing and Materials, Estados Unidos, 20p.

ASTM (1998). ASTM D3080/98 - Standard Test Method for Direct Shear Test of Soils Underconsolodated Drained. American Society for Testing and Materials, Estados Unidos, 6 p. 
ATTON, M. F. (2006). The use of shredded waste tires to improve the geotechnical engineering properties of sands. Environ Geol 49: 497-503.

BADER, C. (2012). Where will all the tires go?. Solid Waste Manager, 2(7): 26-34.

BAŁACHOWSKI, L. \& GOTTELAND, P. (2007). Characteristics of tyre chips-sand mixtures from triaxial tests. Archives of hydro-engineering and environmental mechanics. Vol 54 (1): 25-36.

BASHEER, I.A., NAJJAR, Y.M., DAY, R.W., POH, P.S.H. \& BROMS, B.B. (1996). Discussions and closure: slope stabilization using old rubber tires and geotextiles. Journal of Performance of Constructed Facilities, 10(1): 40-41.

BENSON, C. H. (1995). Using shredded scrap tires in civil and environmental construction. Resource Recycling, 95 (2): 1-4.

BOSSCHER, P.J., EDIL, T.B. \& ELDIN, N.N. (1992). Construction and performance of a shredded waste tire test embankment. Transportation Research Record, (1345): 44-52.

BOSSCHER, P.J., EDIL, T.B. \& ELDIN, N.N. (1994). Engineering propierties of tire chips and soil mixtures. Geotechnical Testing Journal, 17(4): 453-464.

BOSSCHER, P.J., EDIL, T.B. \& KURAOKA, S. (1997). Design of highway embankments using tire chips. Journal of Geotechnical and Geoenvironmental Engineering, 123(4): 295304.

CASTRO, G. (2007). Reutilización, reciclado y disposición final de neumáticos. 60 p.

CETIN, H., FENER, M. GUNAYDIN, O. (2006). Geotechnical Properties of Tire-cohesive Clayey Soil Mixtures as a Fill Material. Engineering Geology, 88:110-120.

CHRUSCIAK, M. R. (2012). Análise da melhoria de solos utilizando fragmentos de borracha. Dissertação (Mestrado), Universidade de Brasília. Faculdade de Tecnologia. Programa de Pós-graduação em Geotecnia. Departamento de Engenharia Civil, G.DM-221/13 109 p.

CONAMA (2012). Resolução no 258/1999. Disponível em: < http://www.mma.gov.br/port/ conama/res/res99/res25899.html>. Acessado em 21/09/2015. 
CONSENTINO, P.J., BLEAKLEY, A.M., ARMSTRONG, A.T., SAJJADI, A.M. \& MISILO, T.J. (2014). Ground tire rubber as a stabilizer for subgrade soils. Draft Final Report. BDK81 977-03: 1-21.

CWA. (2002). Post-consumer tyre materials and applications. CEN Workshop Agreement. 14243-2002.

EDINÇLILER, A., BAYKAL, G., SAYGILI, A. (2004). Determination of static and dynamic behavior of recycled materials for highways. Resources, conservation and Recycling, 42: 223-237.

EDINÇLILER, A., BAYKAL, G., SAYGILI, A. (2010). Influence of different processing techniques on the mechanical properties of used tires in embankment construction. Waste Management, 30: 1073-1080.

ELDIN, N.N., SENOUCI, A.B. (1993). Rubber-tire particles as concrete aggregate. Journal of Materials in Civil Engineering, 5(4): 478-496.

FOOSE, G.J., BENSON, C.H., BOSSCHER, P.J. (1996). Sand reinforced with shredded waste tires. Journal of Geotechnical Engineering, 122 (9): 760-767.

FORSYTH, R.A., EGAN, J.P. (1976). Use of waste materials in embankment construction. $55^{\text {th }}$ Annual meeting of transportation research board. 76-06: $42 \mathrm{p}$.

FRANCO, K. L. B. (2012). Caracterização do Comportamento Geotécnico de Misturas de Resíduo de Pneus e Solo Laterítico. Dissertação (Mestrado), Programa de Pós-graduação em Engenharia Sanitária da Universidade Federal do Rio Grande do Norte, Natal, RN, 139 p.

GARGA, V.K., O'SHAUGHNESSY, V. (2011). Tire-reinforced earthfill. part 1: construction of a test fill, performance, and retaining wall design. Canadian Geotechnical Journal. Vol. 37, (1): 75-96.

GHAZAVI, M. (2004). Shear strength characteristics of sand-mixed with granular rubber. Geotechnical and Geological Engineering, 22: 401-416. 
GHAZAVI M.GHAFFARI, J., FARSHADFAR, A. (2011). Experimental Determination of Waste Tire chip-Sand-Geogrid Interface Parameters Using Large Direct Shear Tests.5th Symposium on Advances in Science \& Technology Khavaran Higher-education Institute, Mashhad, Iran 1- 9.

GIROUD, J., SWAN, R., RICHTER, P., SPOONER, P. (1990). Geotextiles, geomembranes and related products. Proceedings of the 4th International Conference on Geotextiles, Geomembranes, Related Products, (3) 893-896.

HALL, T. (1991). Reuse of shredded tire material for leachate collection system. Proceedings. 14th. Annual Conference, Department of Engineering Professional Development, University of Wisconsin, Madison, 367-376.

GOOGLE EARTH (2012), Disponível em: <https://maps.google.com.br/>. Acessado em $10 / 05 / 2015$.

HEIMDAHL, T.C., DRESCHER, A. (1999). Elastic anisotropy of tire shreds. Journal of Geotechnical and Geoenvironmental Engineering, 383-389.

HEITZMAN, M. (1992). Design and construction of asphalt paving materials with crumb rubber modifier. Transportation Research Record, (1339):1-8.

HUMPHREY, D.N., KATZ, L.E., HALL, B. (1999). Five-year study of the water ouality effects of tire shreds placed above the water table. Transportation Research Record, (1714): $18-24$.

HUMPHREY, D., SANDFORD, T. C. (1993). Lightweight Subgrade Fill and Retaining Wall Backfill. Symposium on Recovery and Effective Reuse of Discarded Materials and Byproducts for Construction of Highway Facilities Denver, Denver, Colorado, 19-22.

LEE, J.H., SALGADO, R., BERNAL, A., LOVELL, C.W. (1999). Shredded tires and rubbersand as lightweight backfill. Journal of Geotechnical and Geoenvironmental Engineering, 125(2): 132-141.

LUND, H. F. (1993). The McGraw Hill Recycling Handbook. McGraw Hill, Michigan, Estados Unidos, 2 ed., 976 p. 
NIGHTINGALE, D. \& GREEN, W. (1997). Testing Soil Mixed with Waste or Recycled Materials. ASTM International, 1-21.

OIKONOMOU, N., MAVRIDOU, S. (2009). The use of waste tyre rubber in civil engineering works. Aristotle University of Thessaloniki, 213- 238.

PALMEIRA, E.M. (1998). Equipamento Para Ensaios de Tração Confinada de Geotêxteis em Solos - Versão 2. Relatório de Pesquisa. Programa de Pós-Graduação em Geotecnia, Universidade de Brasília.

PALMEIRA, E.M. (2009). Soil-geosynthetic interaction: modelling and analysis. Geotextiles and Geomembranes, 27(2009): 368-390.

POH, P.S.H. \& BROMS, B.B. (1995). Slope stabilization using old rubber tires and geotextiles. Journal of Performance of Constructed Facilities, 9(1): 76-79.

SELlAF, H., TROUZINE, H., HAMHAMI, M. \& ASROUN, A. (2014). Geotechnical properties of rubber tires and sediments mixtures. Engineering, Technology \& Applied Science Research, 4(2): 618-624.

SHALABY, A., KHAN, R. A. (2005). Design f unsurfaced roads constructed with large-size shredded rubber tires: a case study. Resources Conservation \& Recycling, 22: 318-332.

SOUZA, M. V. R. (2011). Relatório cisalhamento Direto, concepção e dimensionamento da prensa de cisalhamento de grande escala do PPG-UNB. Relatório, Programa de Pósgraduação em Geotecnia da Universidade de Brasília, Brasília, DF, 29 p.

SUMANARATHNA I.H.D., D.P. MALLAWARCTCHIE, KULATHILAKA, S.A.S . (1997). Stabilization of slopes by anchored type retaining structures. Proceedings 14th international conference of soil mechanics and foundation engineering, 1261-1264.

SZELIGA, L., RAMIREZ, G. D., CASAGRANDE, M. D. T. (2014). Estudo experimental de soloreforçado com borracha moída de pneus inservíveis para aplicação em obras geotécnicas. XVI Congresso brasileiro de mecânica dos solos e engenharia geotécnica - COBRAMSEG, Associação brasileira de mecânica dos solos e engenharia geotécnica - ABMS, Porto de Galinhas, PE, ref. 231, 8p. 
TATLISOZ, N., EDIL, T. B., BENSON, C. H. (1998). Interaction between reinforcing geosynthetics and soil-tire chip mixtures. Journal of geotechnical and geoenvironmental engineering, 124 (11): 1109-1119.

TUNCAN, M., CETIN, A., AND KOYUNCU, H. (1998). Assessment of waste tires and plastic on asphalt concrete pavement mixtures. Proceedings of Third International Congress on Environmental Geotechnics, Lisbon, Portugal, 667-672.

WU, W.Y., BENDA, C.C., CAULEY, R.F. (1997). Triaxial determination of shear strength of tire chips. Journal of Geotechnical and Geoenvironmental Engineering, 123(5): 479-482.

YOON, S., PREZZI, M., SIDDIKI, N.Z. \& KIM, B. (2006). Construction of a test embankment using a sand-tire shred mixture as fill material. Waste Management, 26(9): 1033-1044.

ZORNBERG, J. G., CABRAL, A. R., VIRATJANDR, C. (2004). Behaviour of tire shred sand mixtures. Canadian Geotechnical Journal, 41: 227-241. 


\section{APÊNDICES.}

\section{APÊNDICE A. ENSAIOS DE COMPACTAÇÃO}

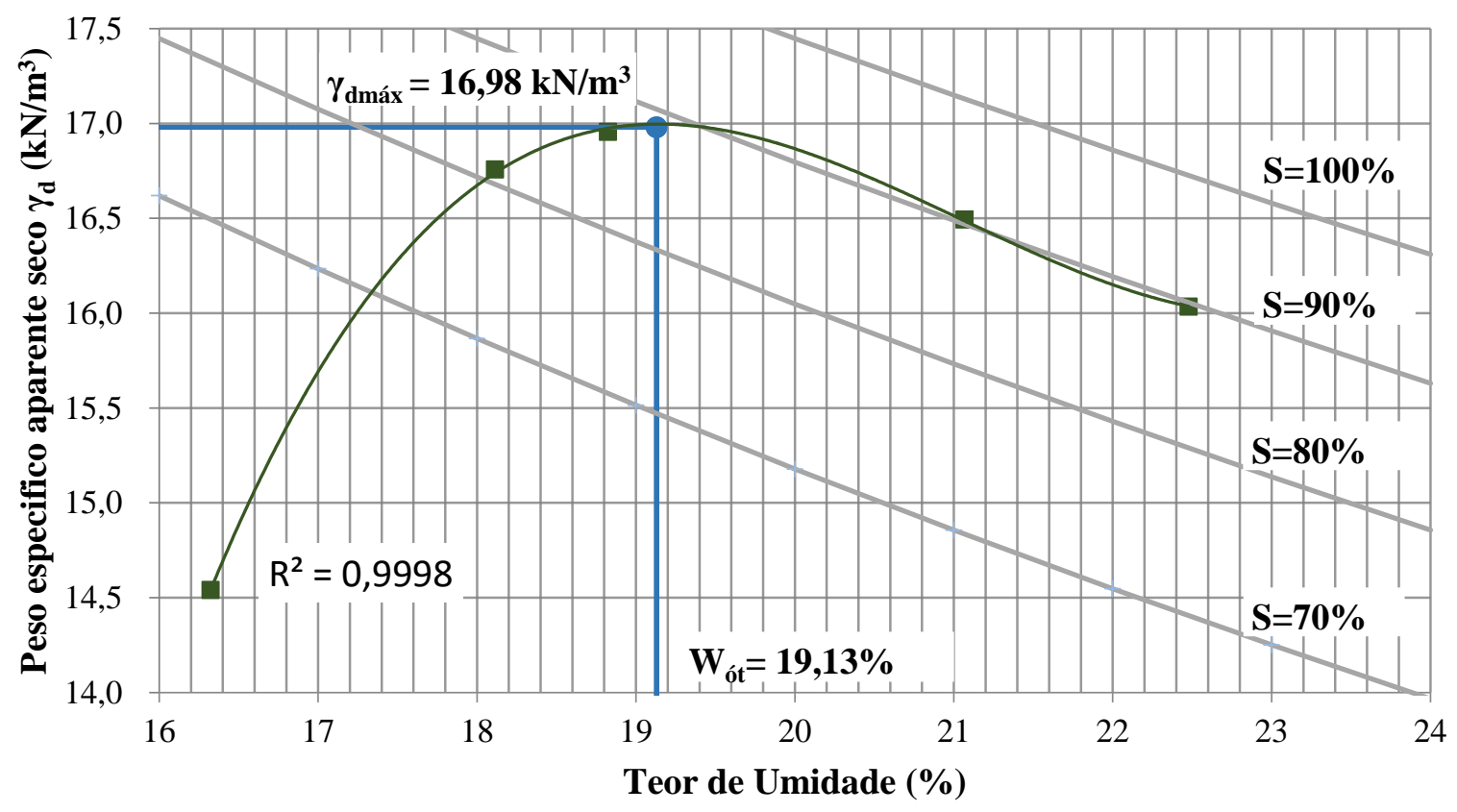

Figura A.1. Curva de compactação solo estudado, solo puro (M0).

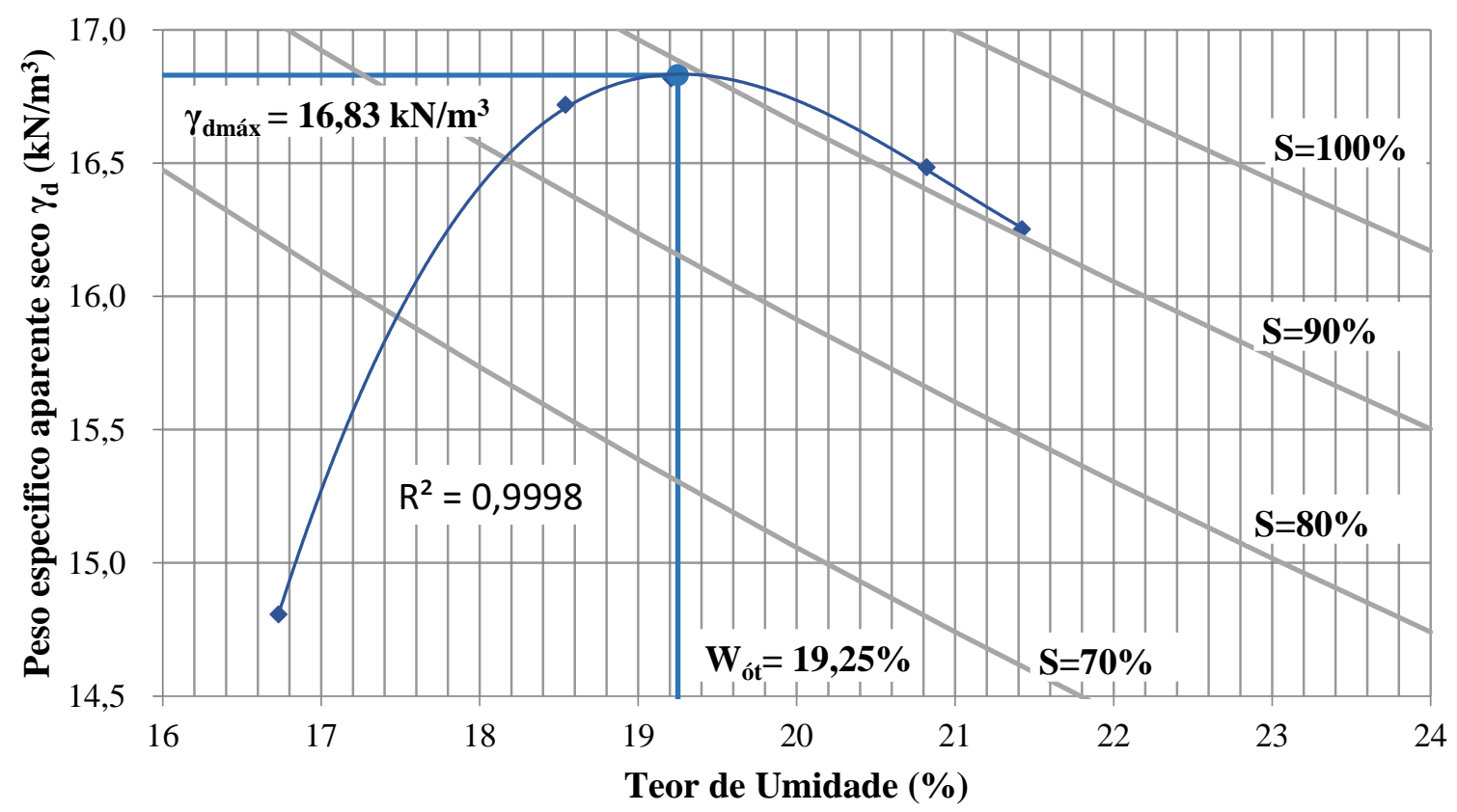

Figura A.2. Curva de compactação solo estudado, teor de borracha de 2,5\% (M2,5). 


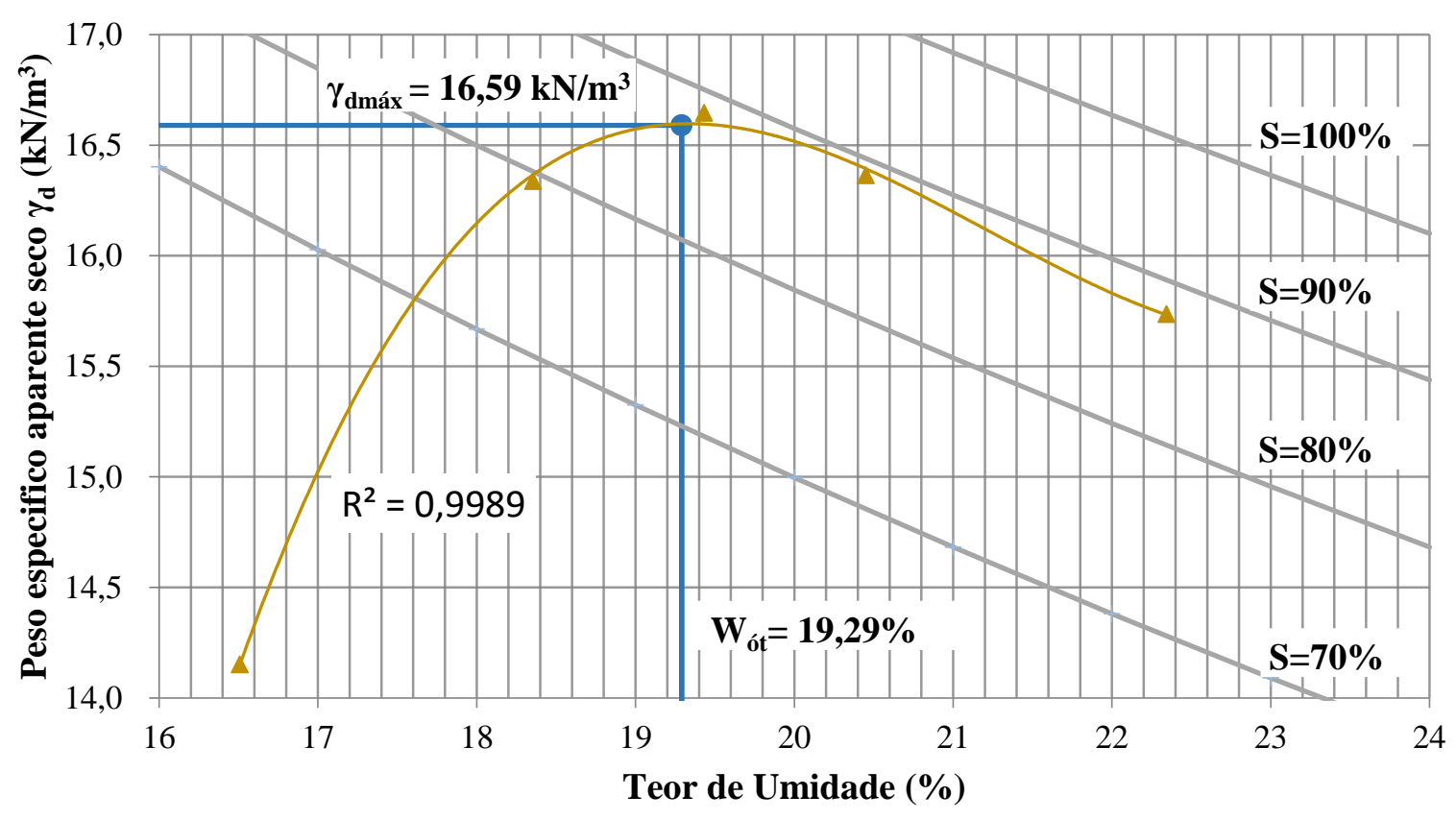

Figura A.3. Curva de compactação solo estudado, teor de borracha de 3,75\% (M3,75).

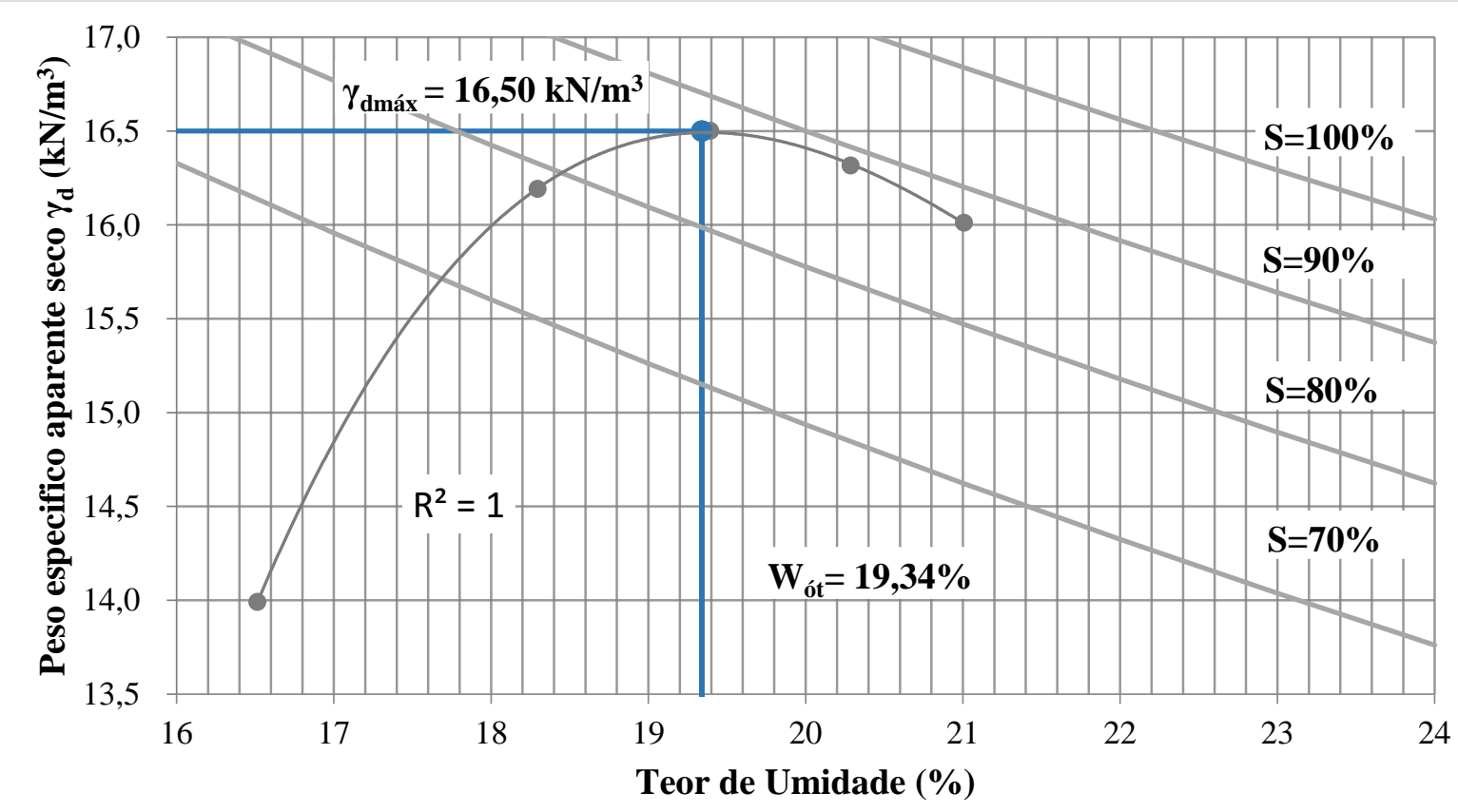

Figura A.4. Curva de compactação solo estudado, teor de borracha de 5,0\% (M5). 


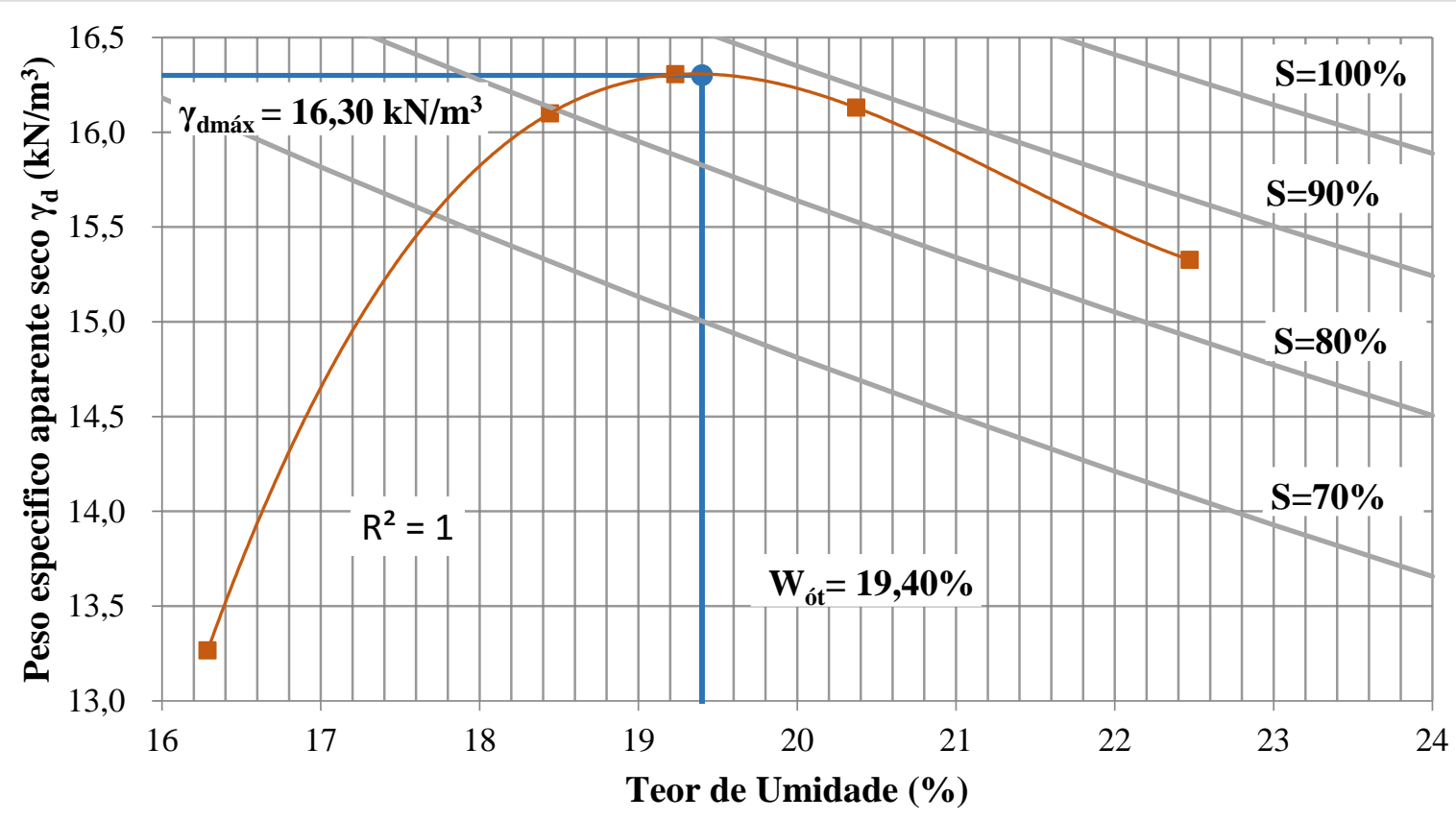

Figura A.5. Curva de compactação solo estudado, teor de borracha de 7,5\% (M7,5).

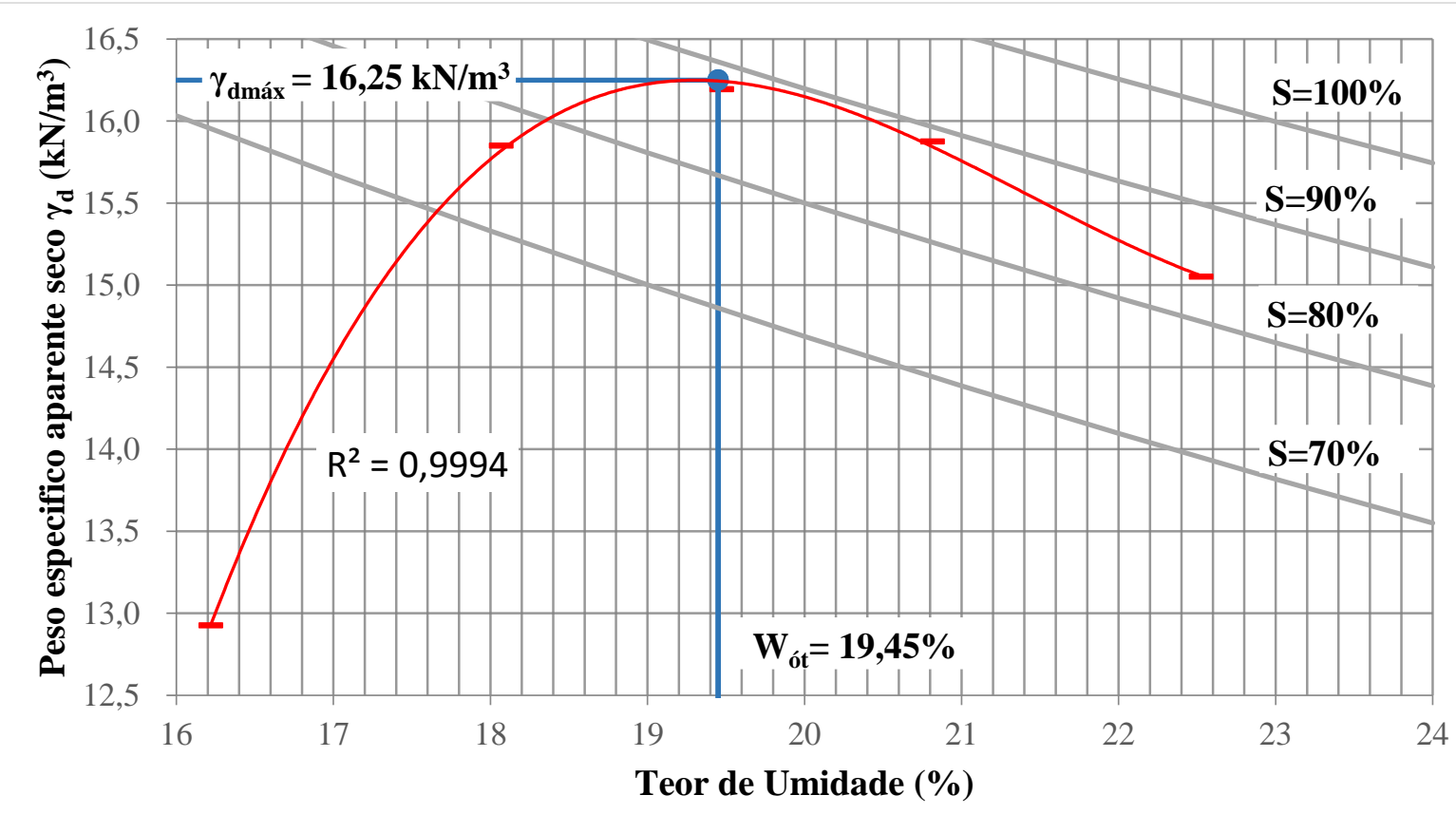

Figura A.6. Curva de compactação solo estudado, teor de borracha de 10\% (M10). 
APÊNDICE B. ENSAIOS DE CISALHAMENTO DIRETO EM MÉDIA ESCALA

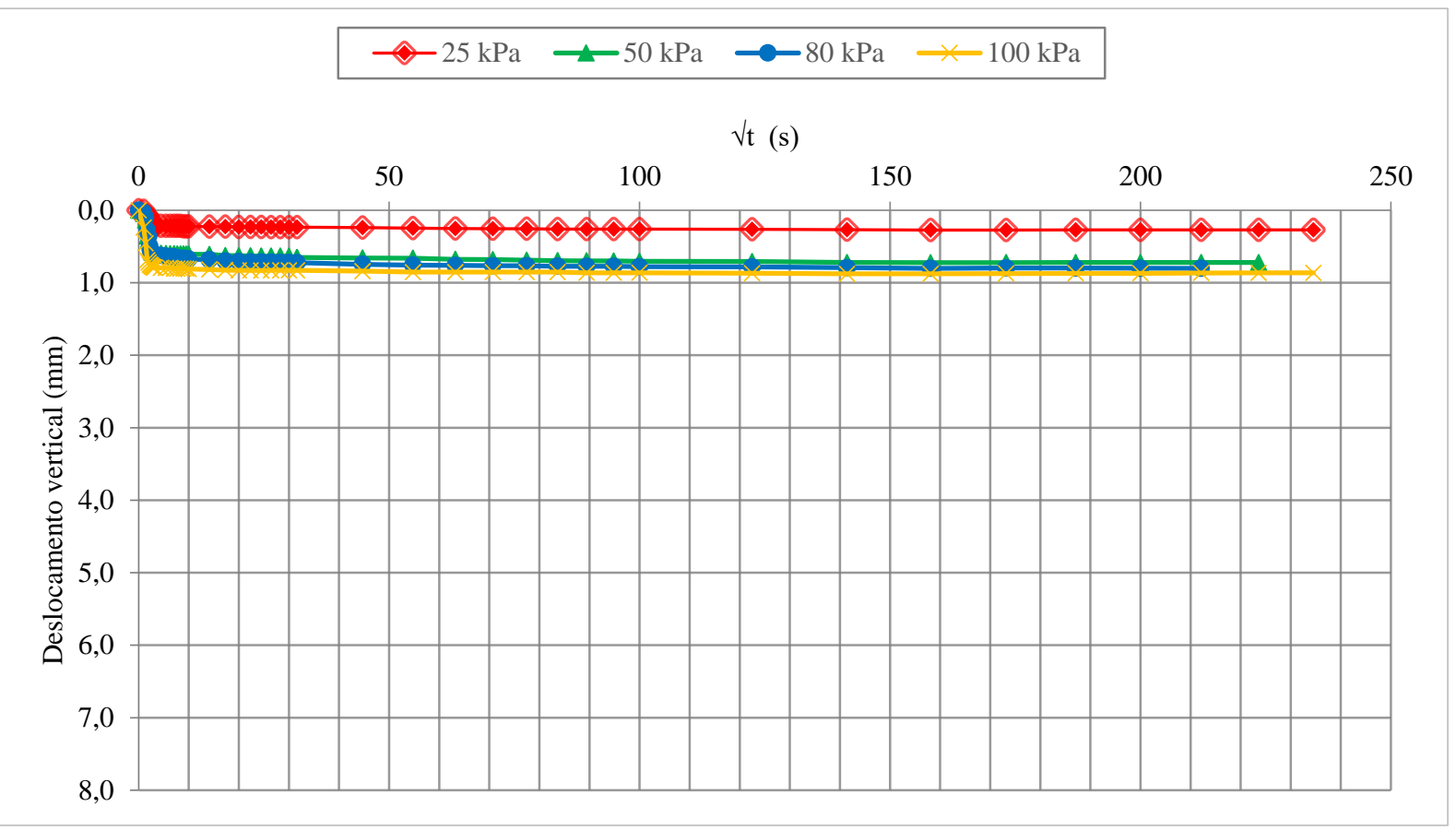

Figura B.1. Curva de adensamento do solo puro (M0).

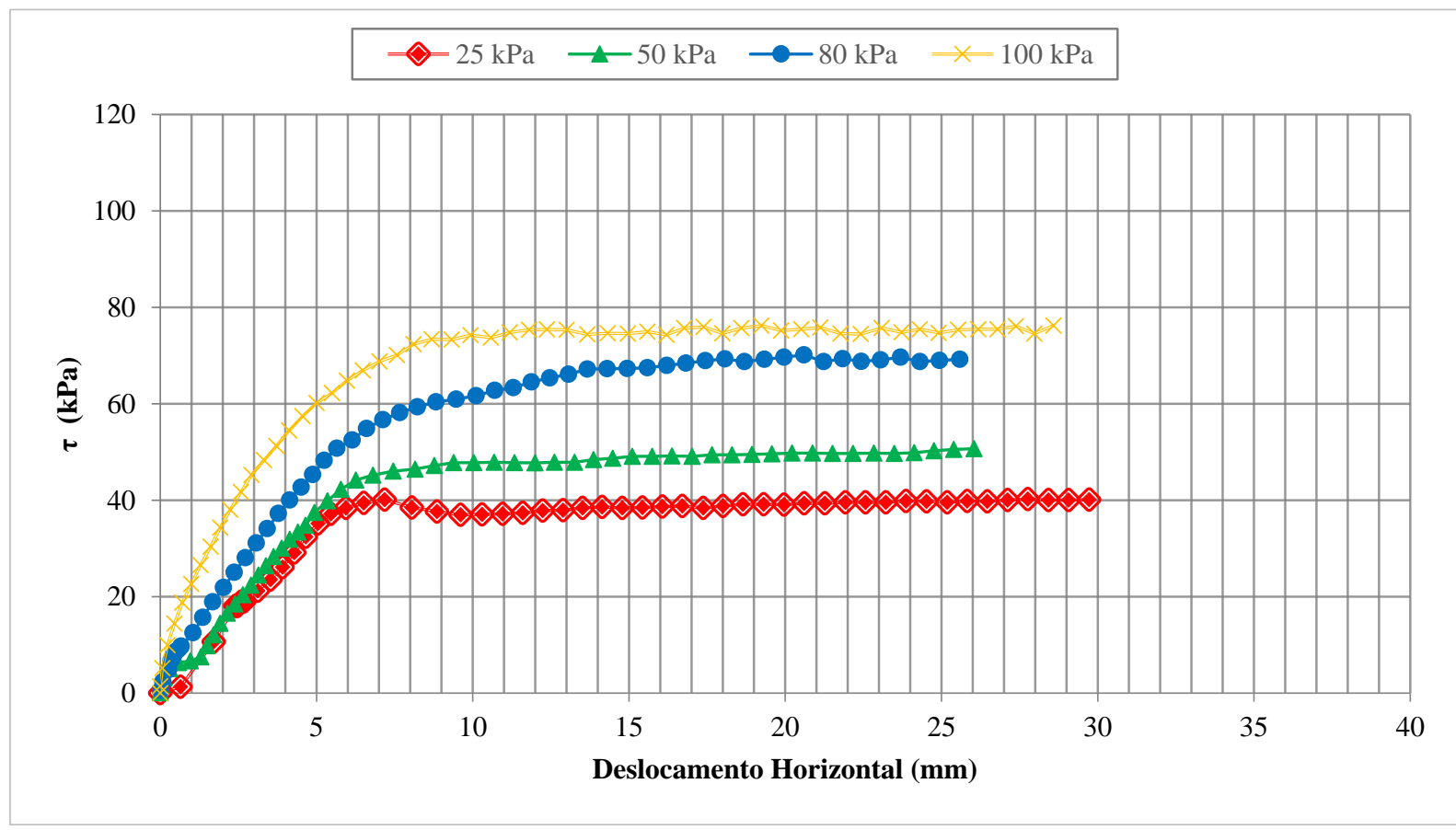

Figura B.2. Tensão cisalhante versus deslocamento horizontal, solo puro (M0). 


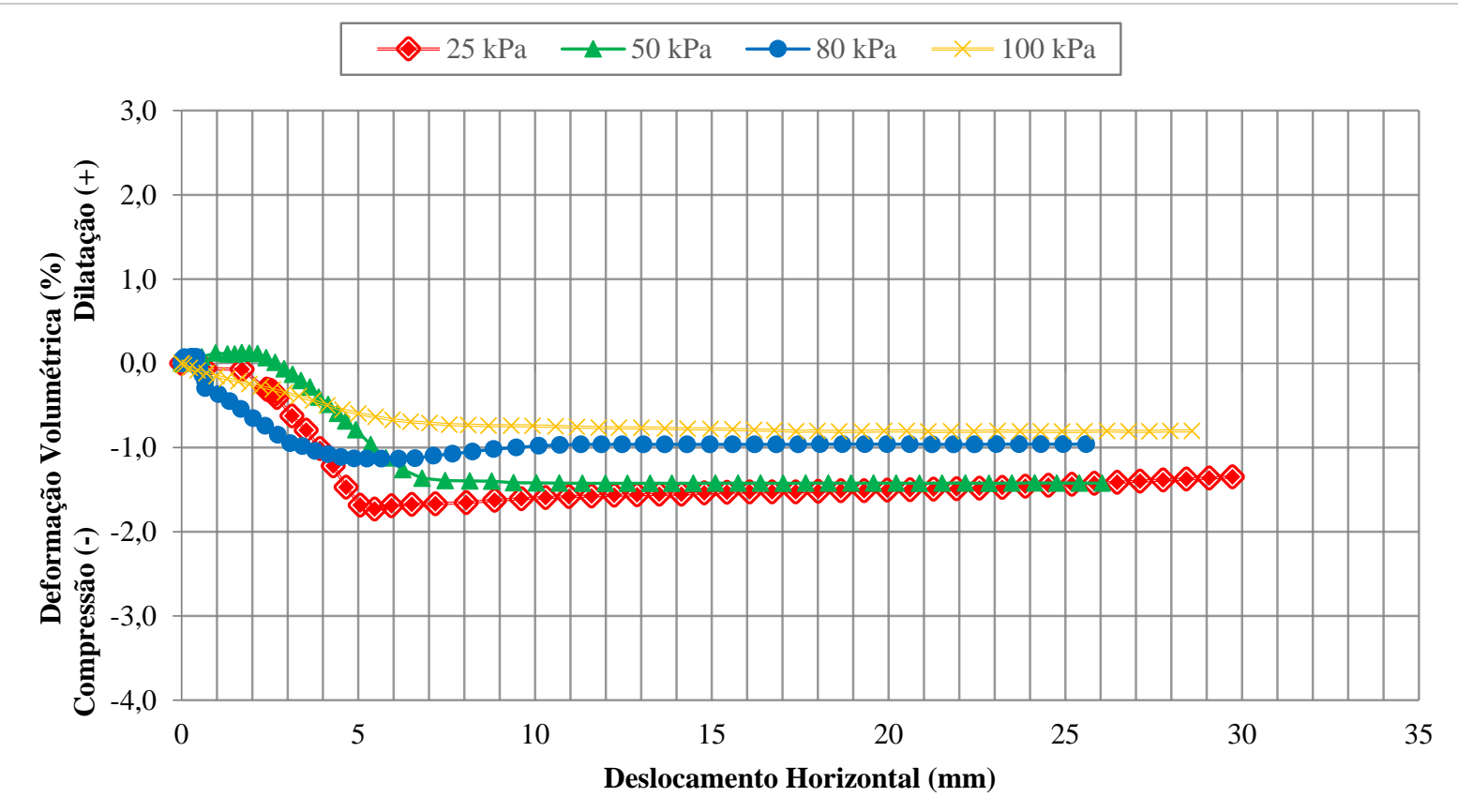

Figura B.3. Deformação volumétrica versus deslocamento horizontal, solo puro (M0).

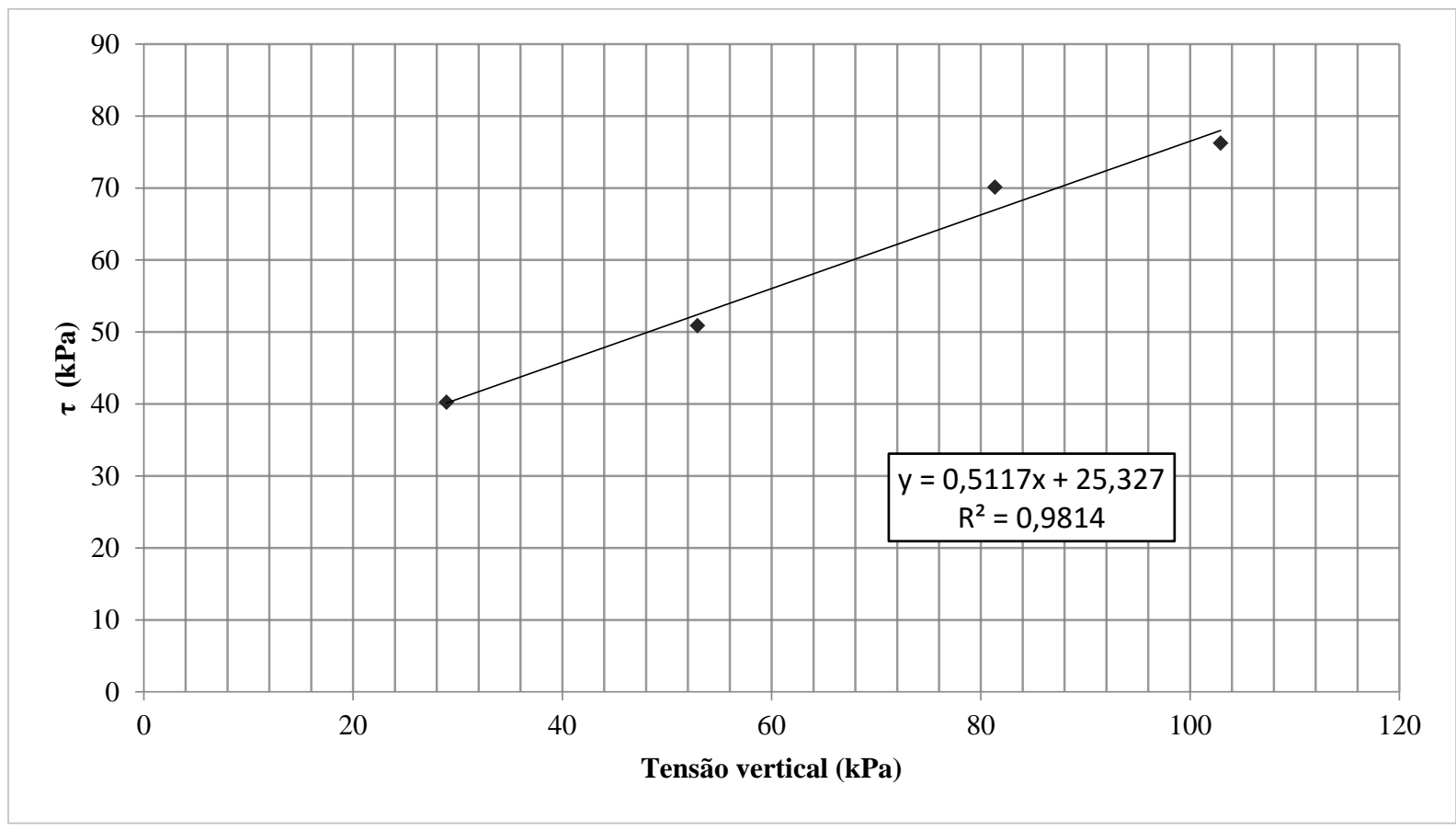

Figura B.4. Envoltória de Mohr-Coulomb, solo puro (M0). 


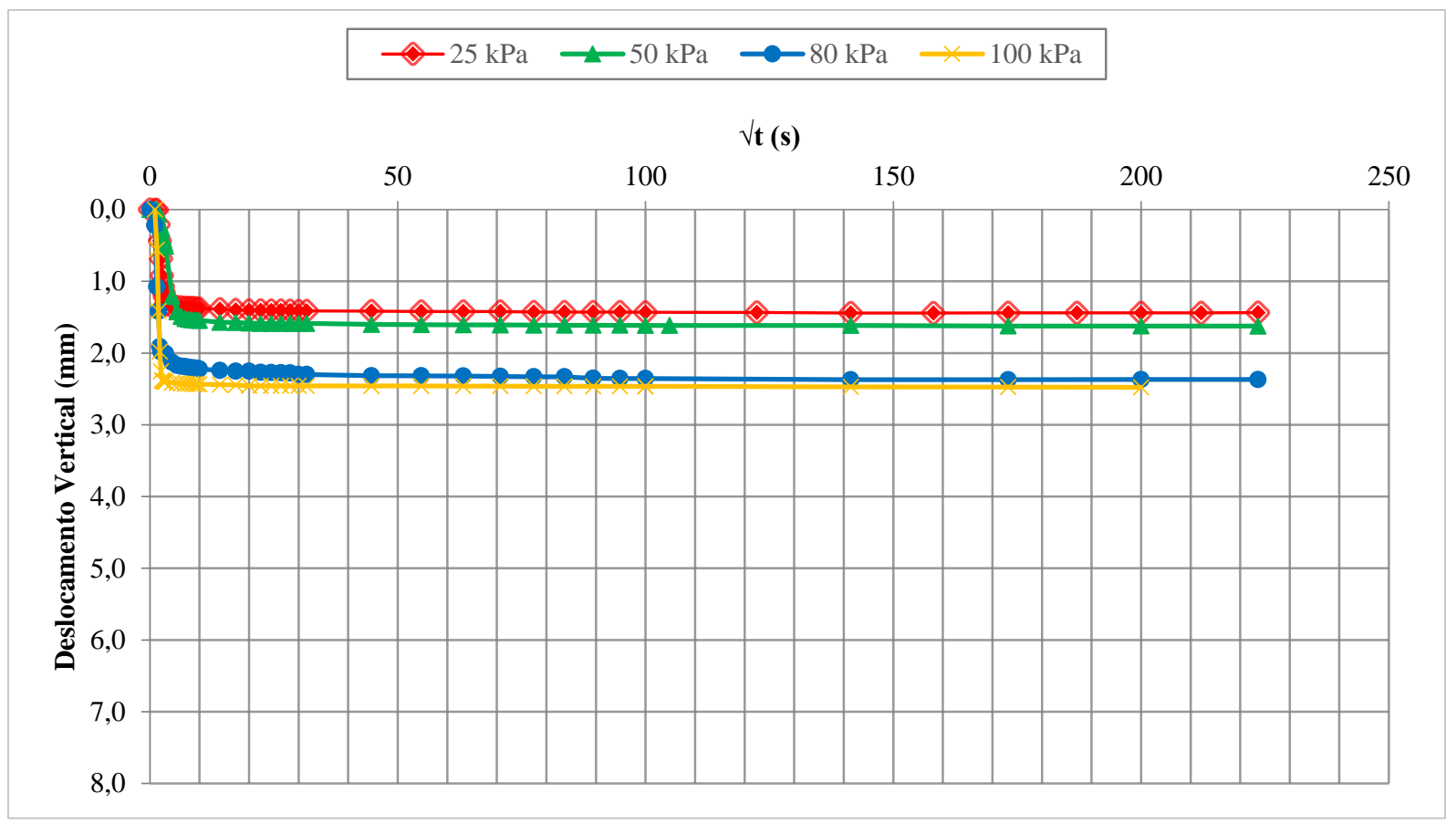

Figura B.5. Curva de adensamento da mistura M2,5.

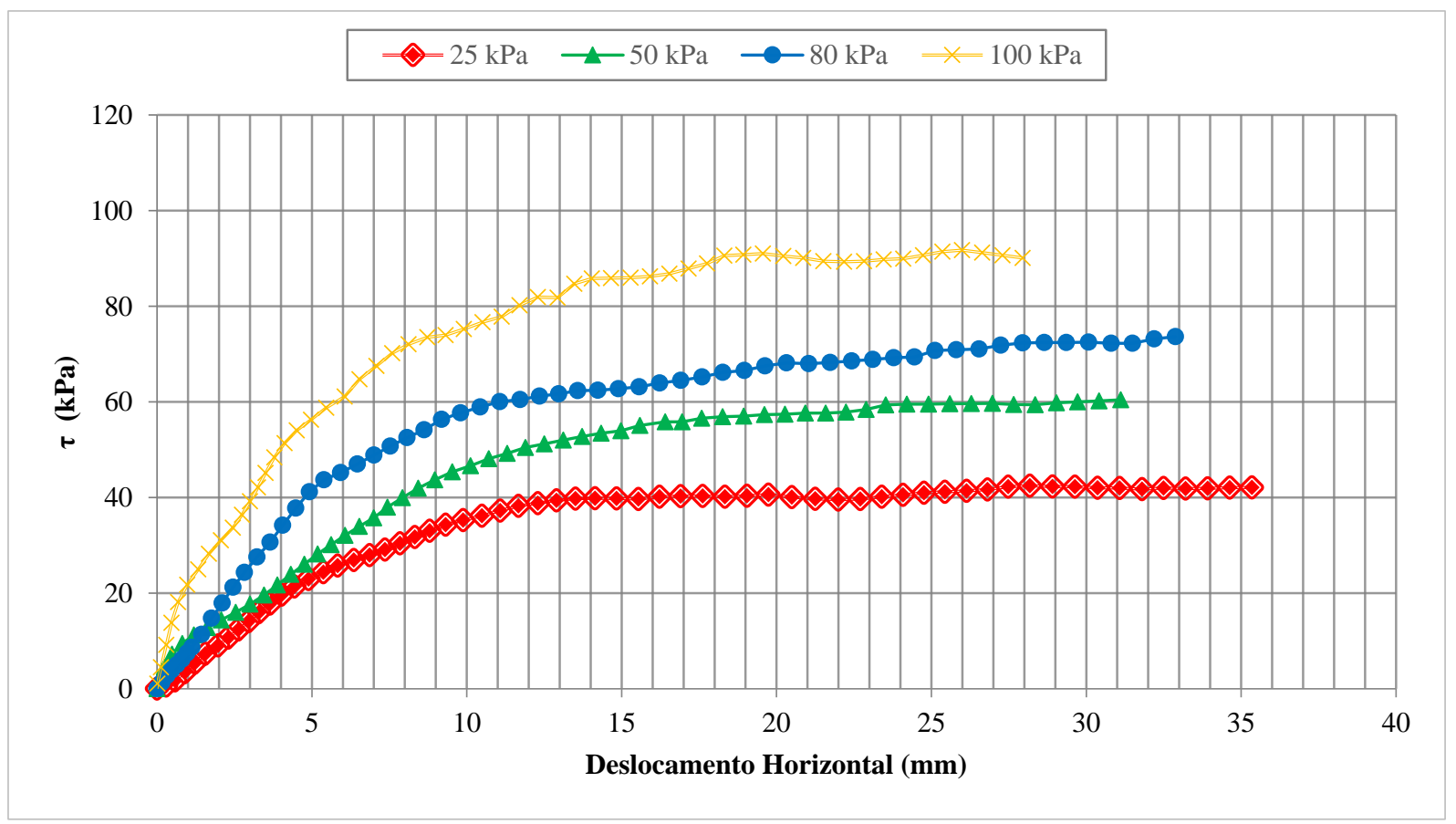

Figura B.6. Tensão cisalhante versus Deslocamento horizontal da mistura M2,5. 


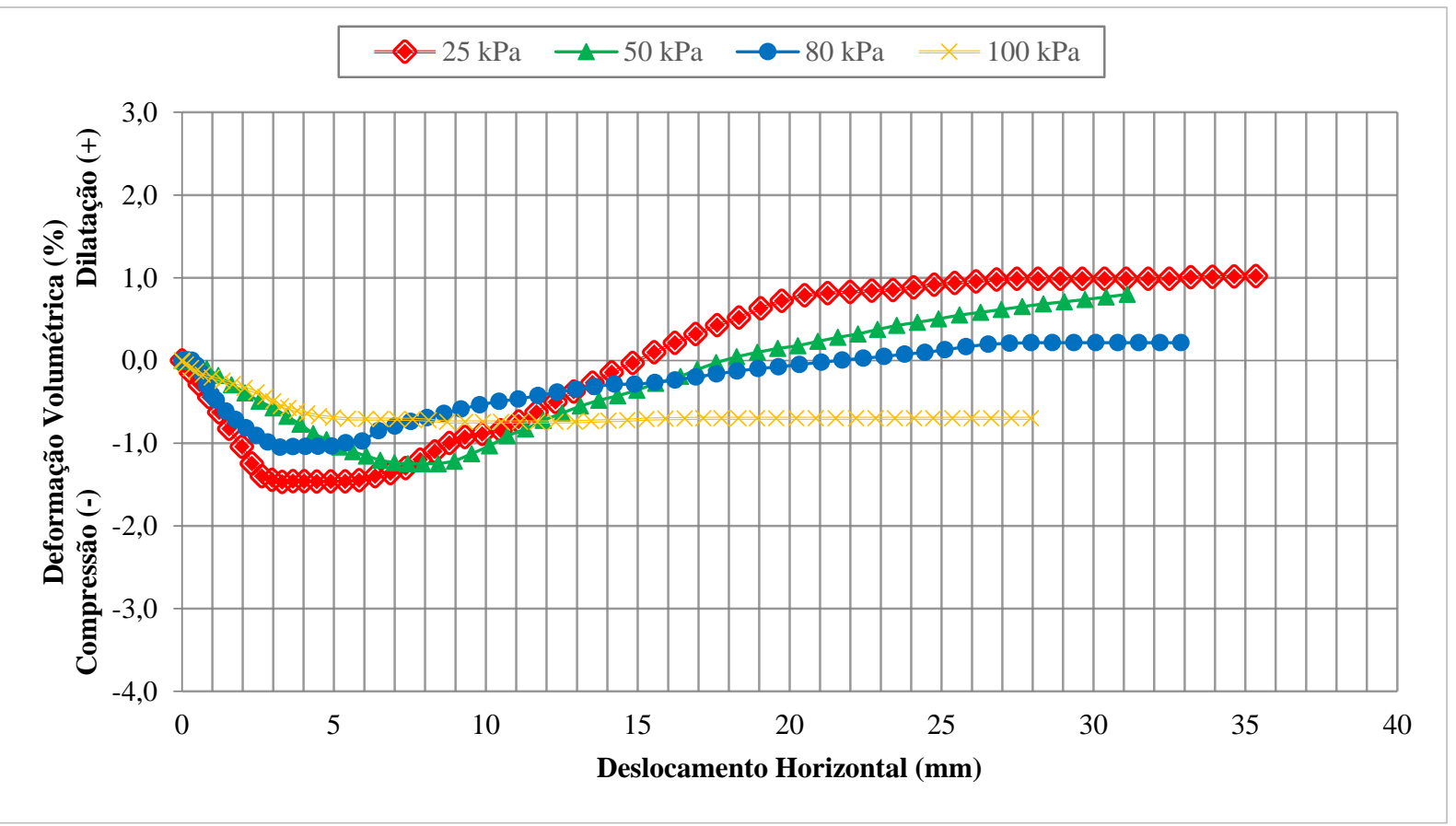

Figura B.7. Deformação volumétrica versus Deslocamento horizontal da mistura M2,5.

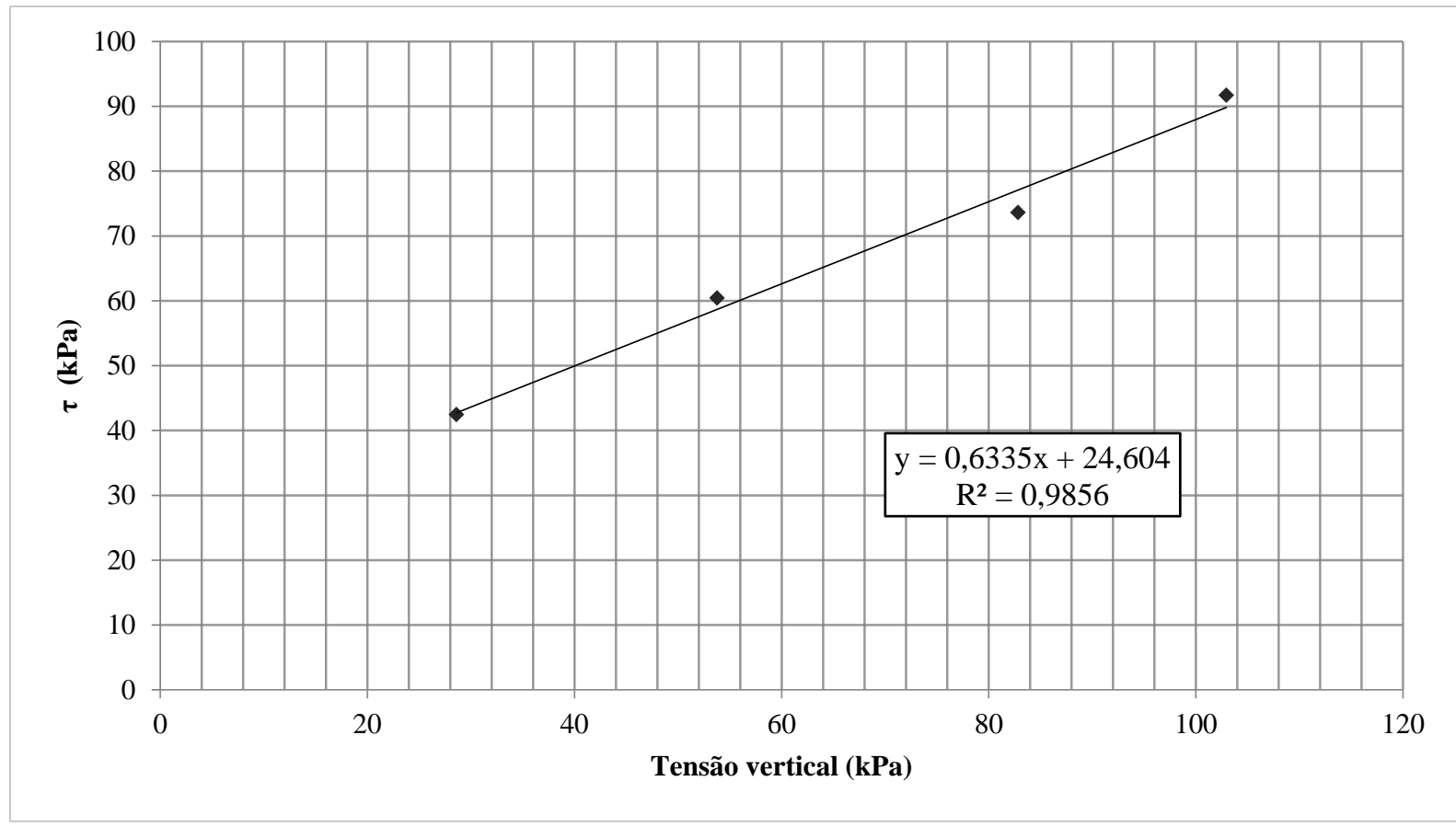

Figura B.8. Envoltória de Mohr-Coulomb da mistura M2,5. 


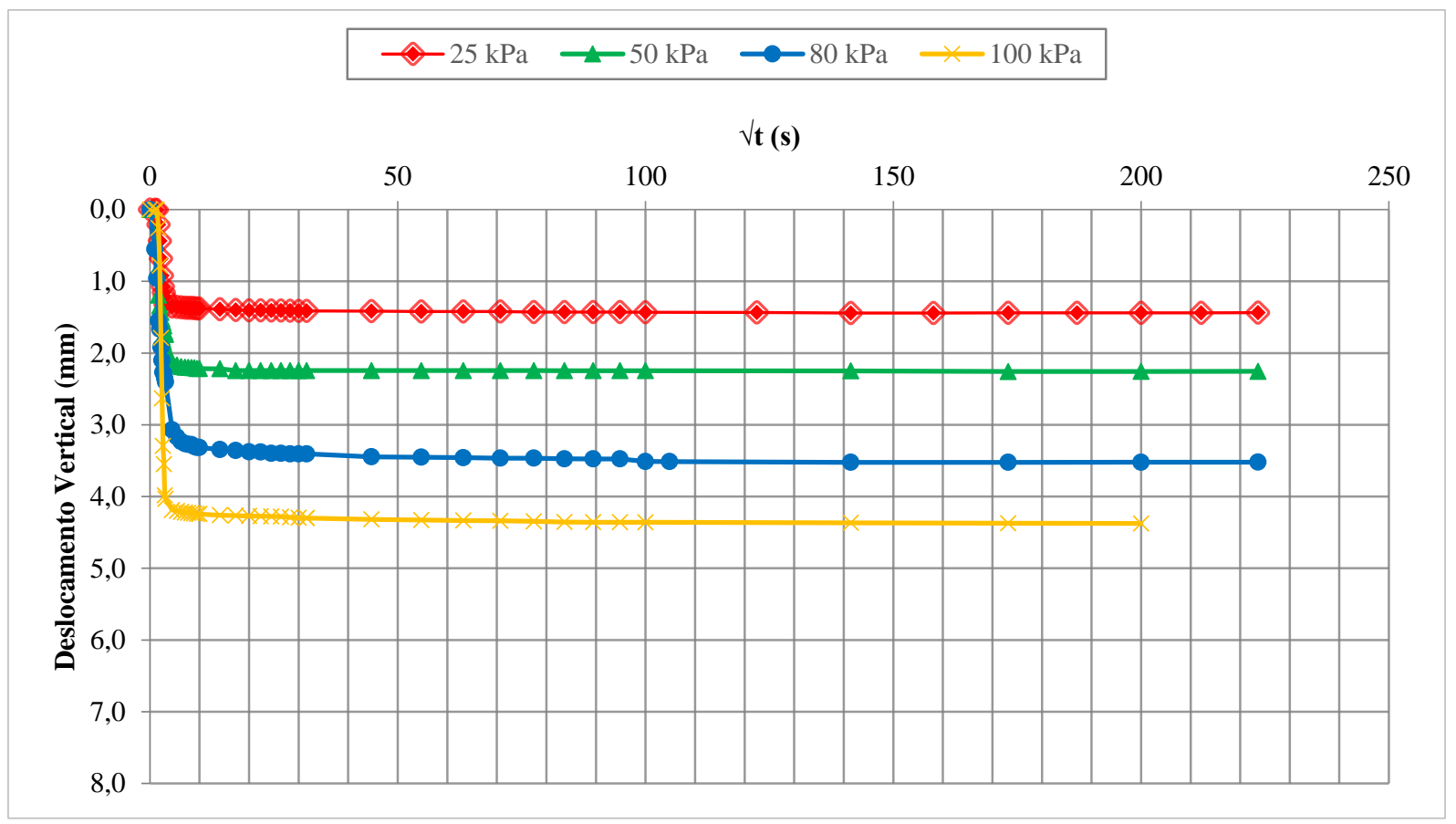

Figura B.9. Curva de adensamento da mistura M3,75.

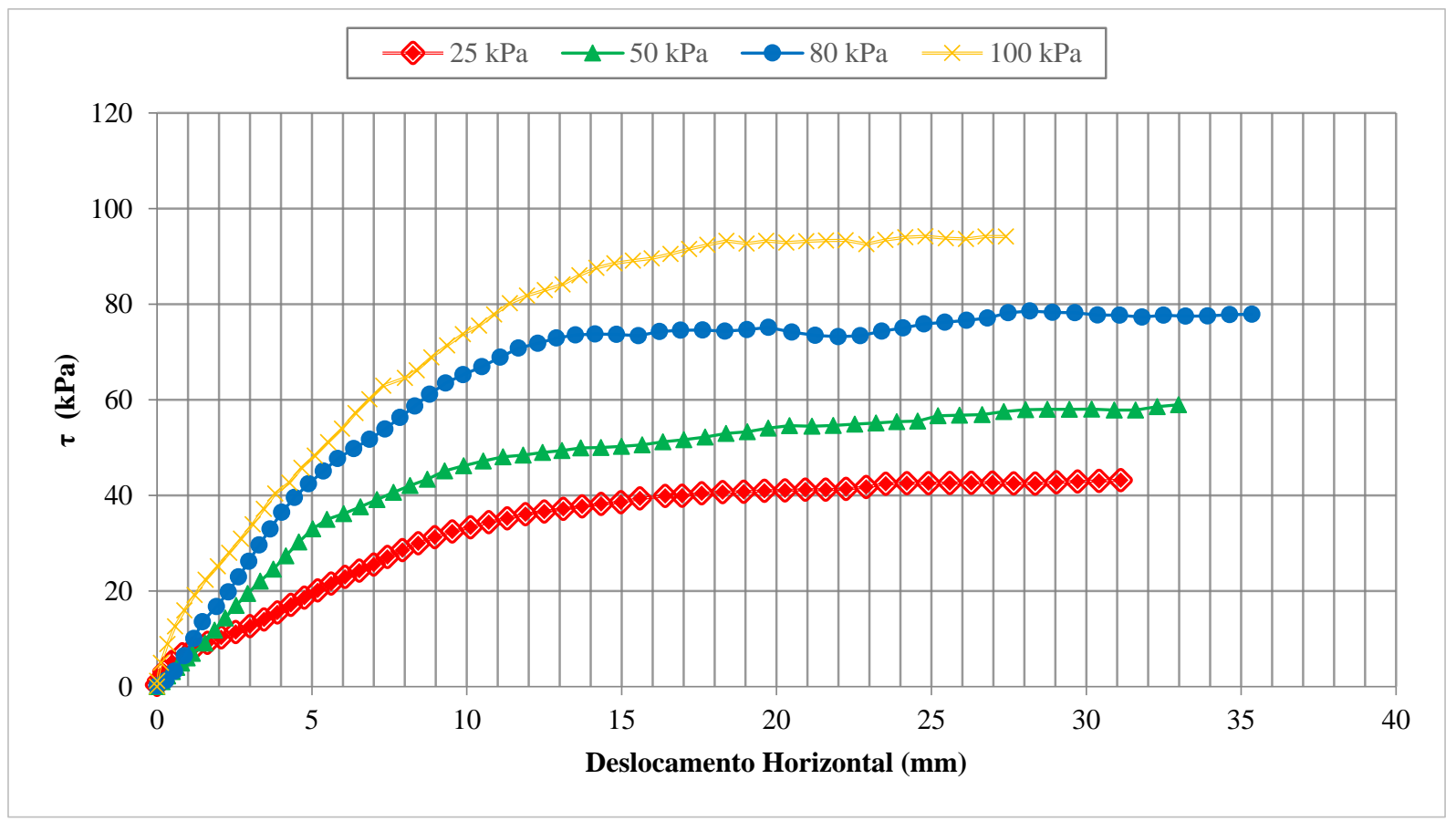

Figura B.10. Tensão cisalhante versus Deslocamento horizontal da mistura M3,75. 


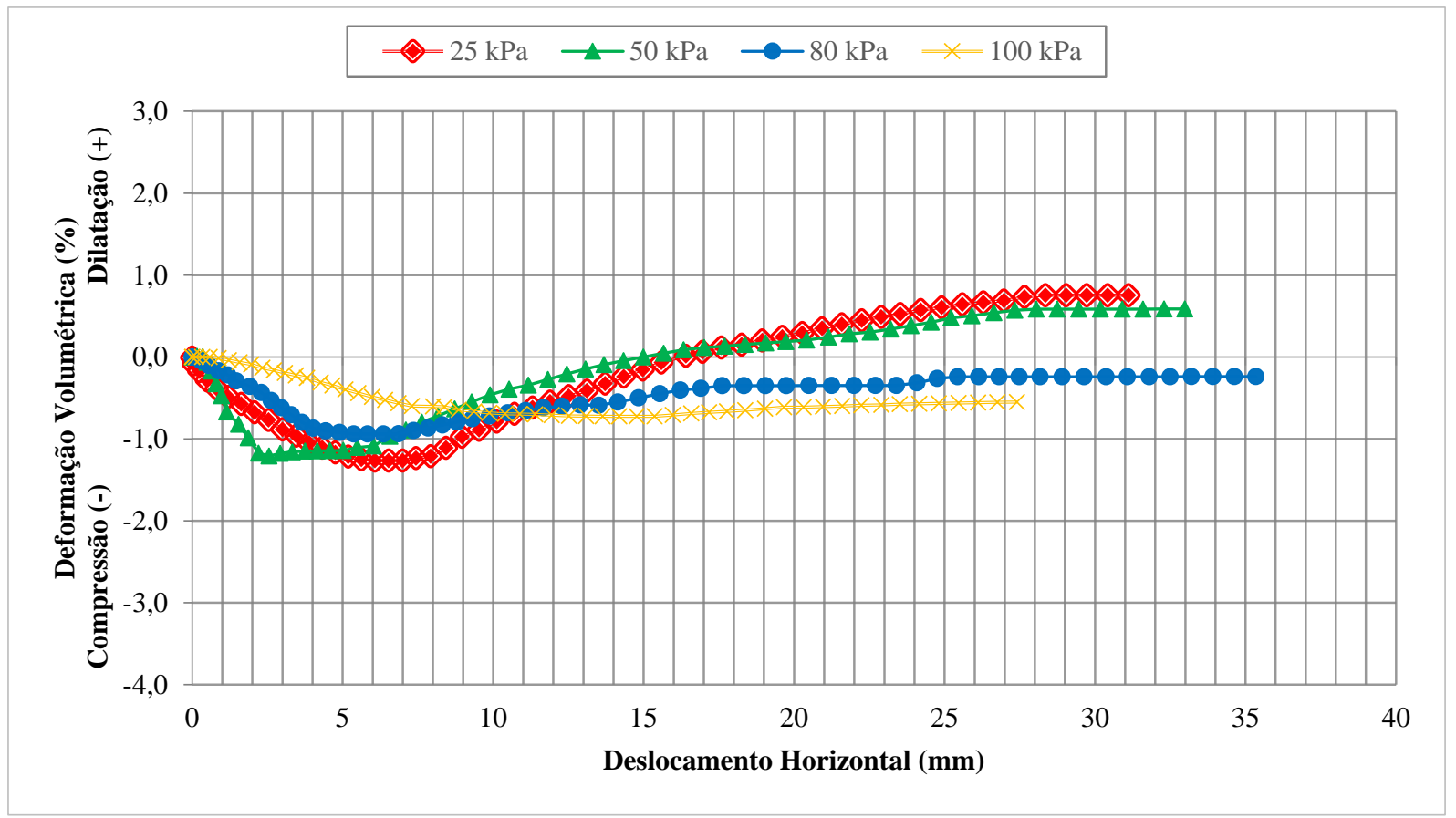

Figura B.11. Deformação volumétrica versus Deslocamento horizontal da mistura M3,75.

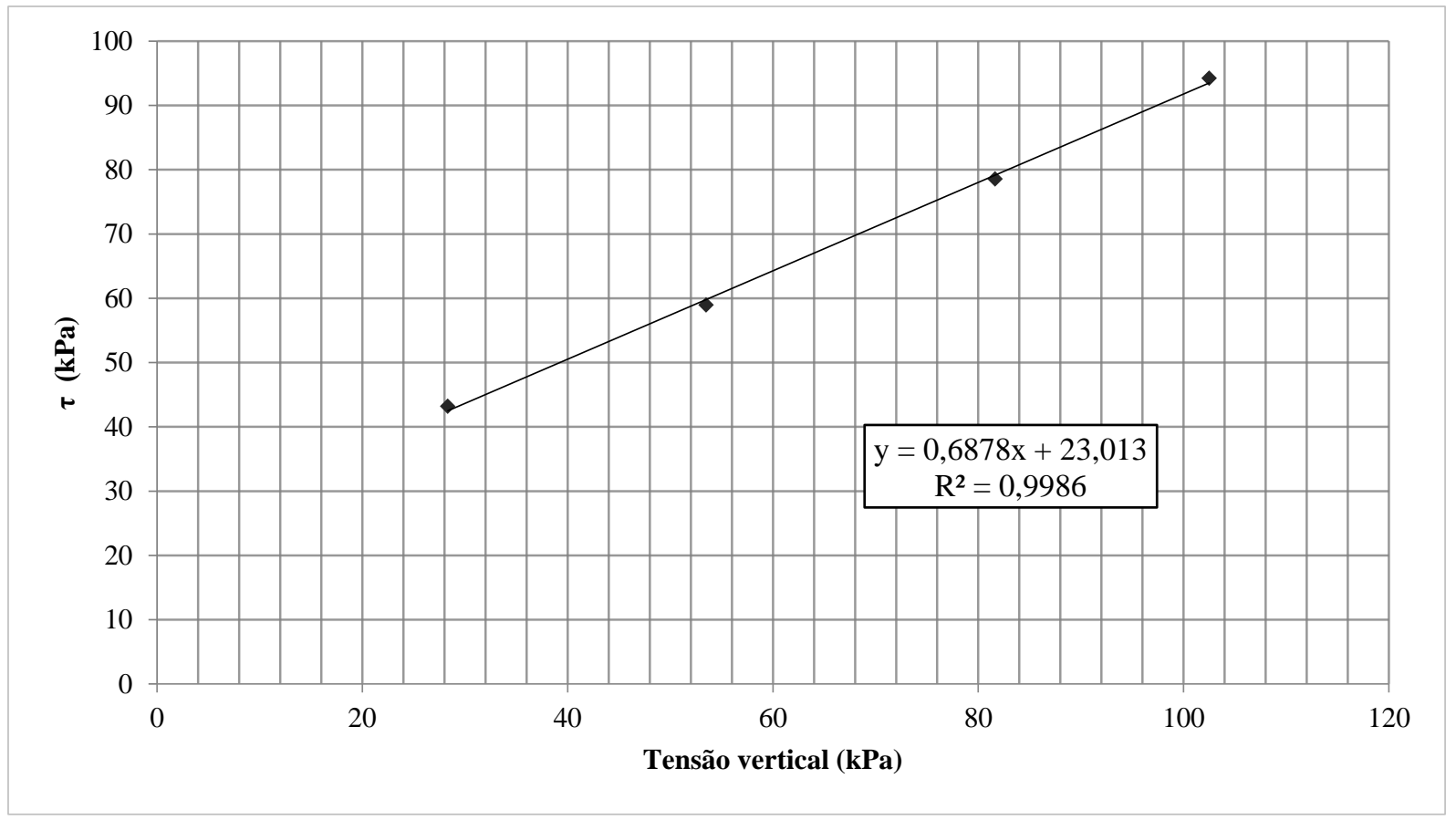

Figura B.12. Envoltória de Mohr-Coulomb da mistura M3,75. 


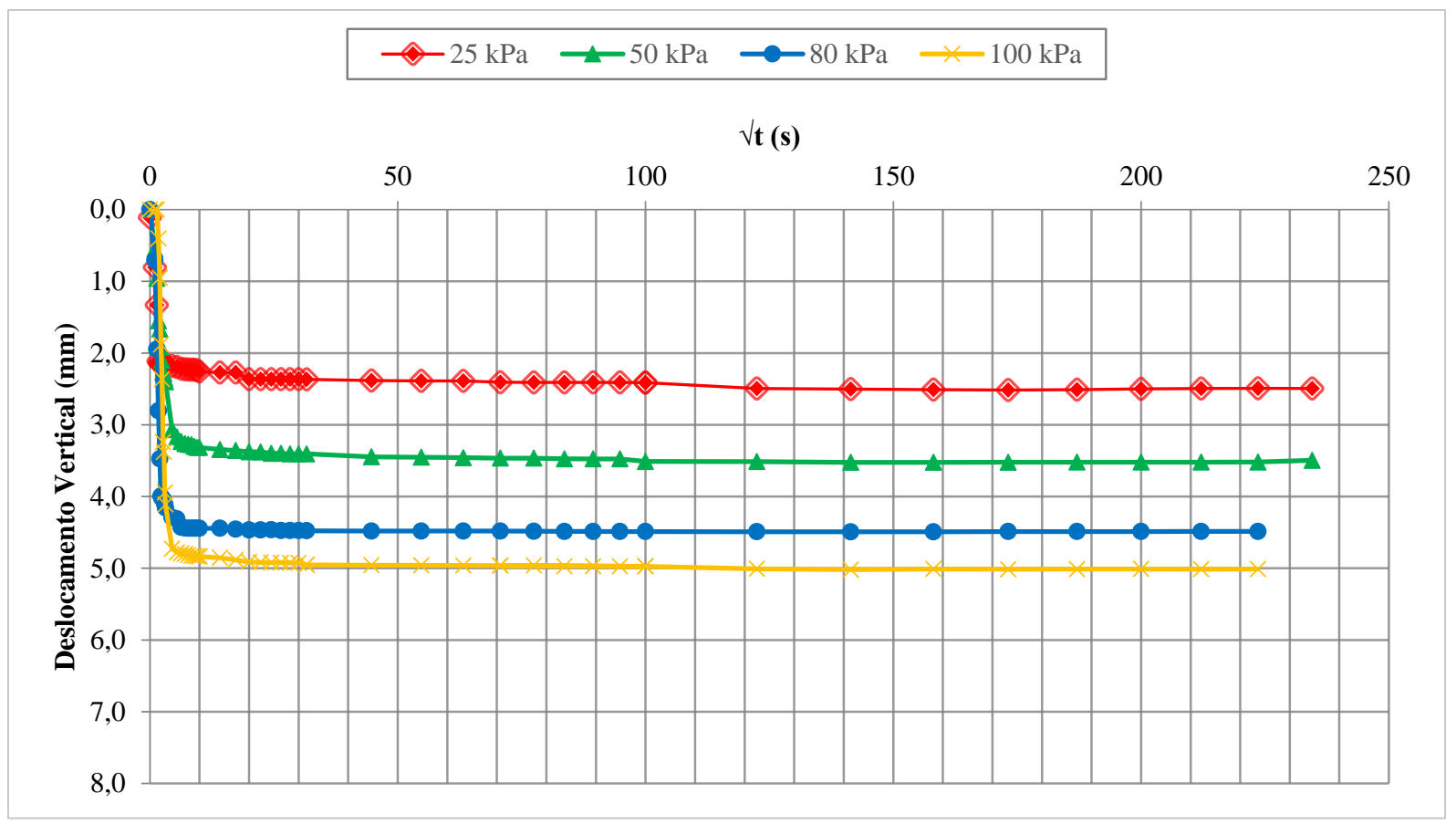

Figura B.13. Curva de adensamento da mistura M5.

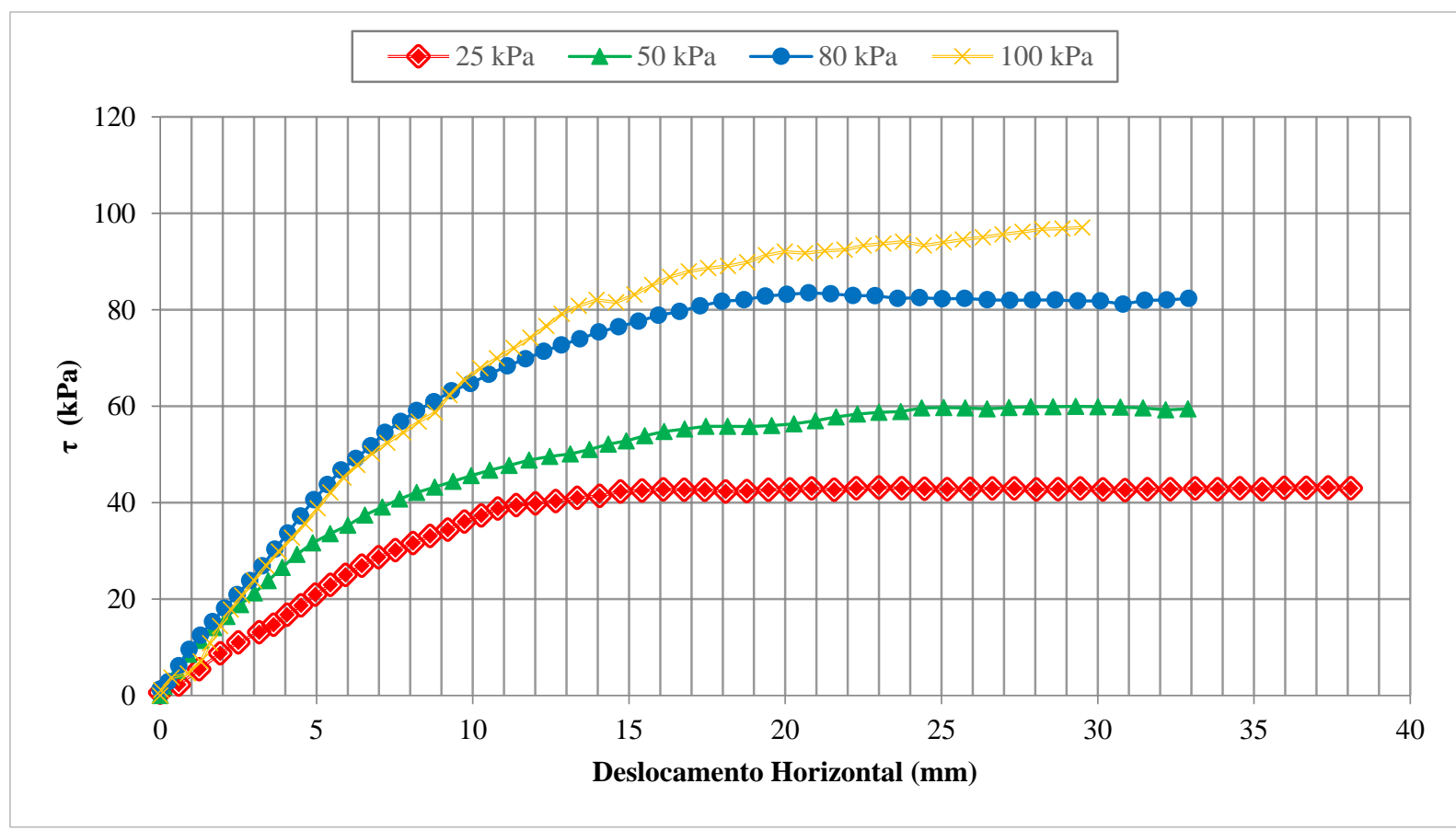

Figura B.14. Tensão cisalhante versus Deslocamento horizontal da mistura M5. 


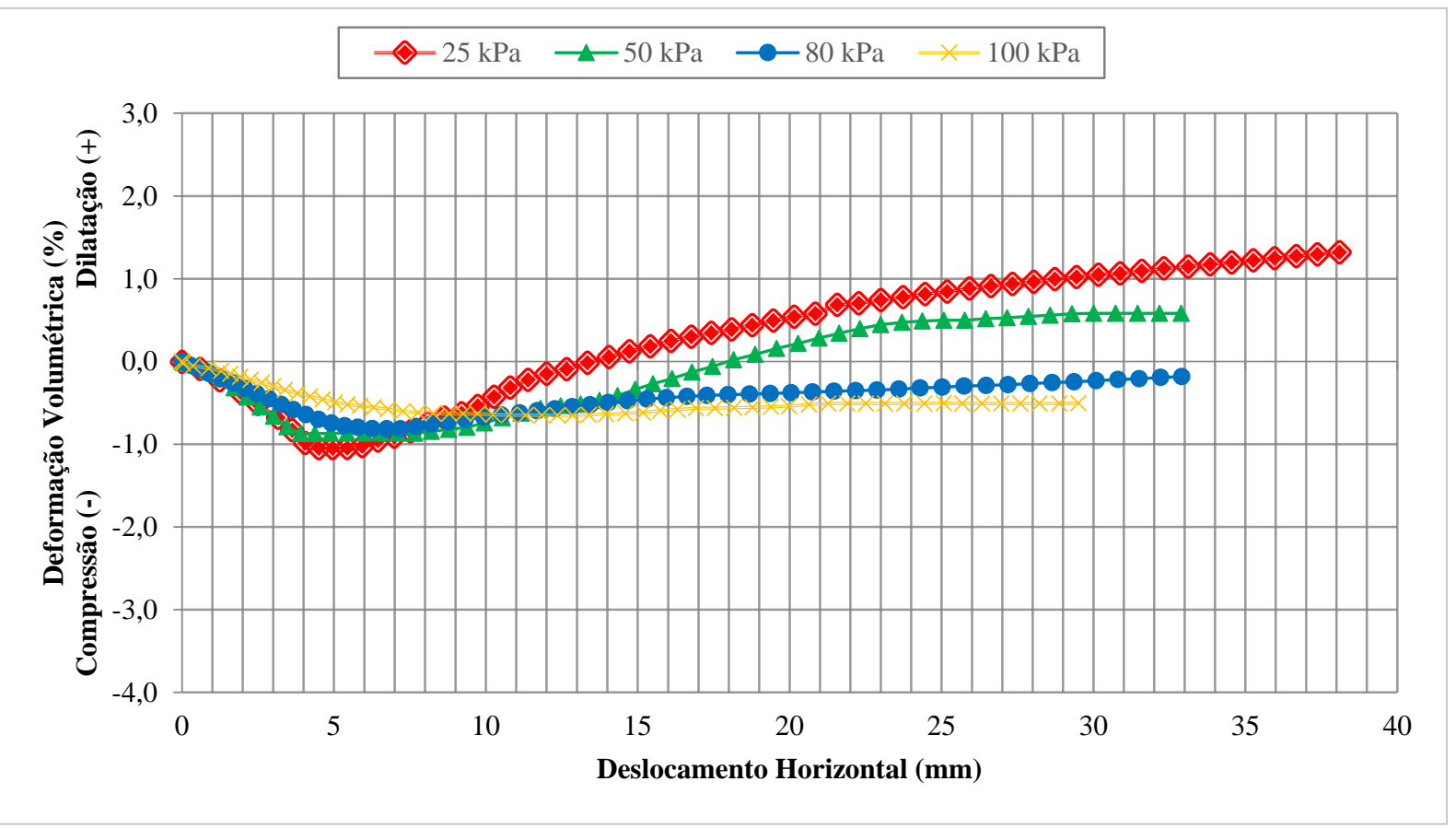

Figura B.15. Deformação volumétrica versus Deslocamento horizontal da mistura M5.

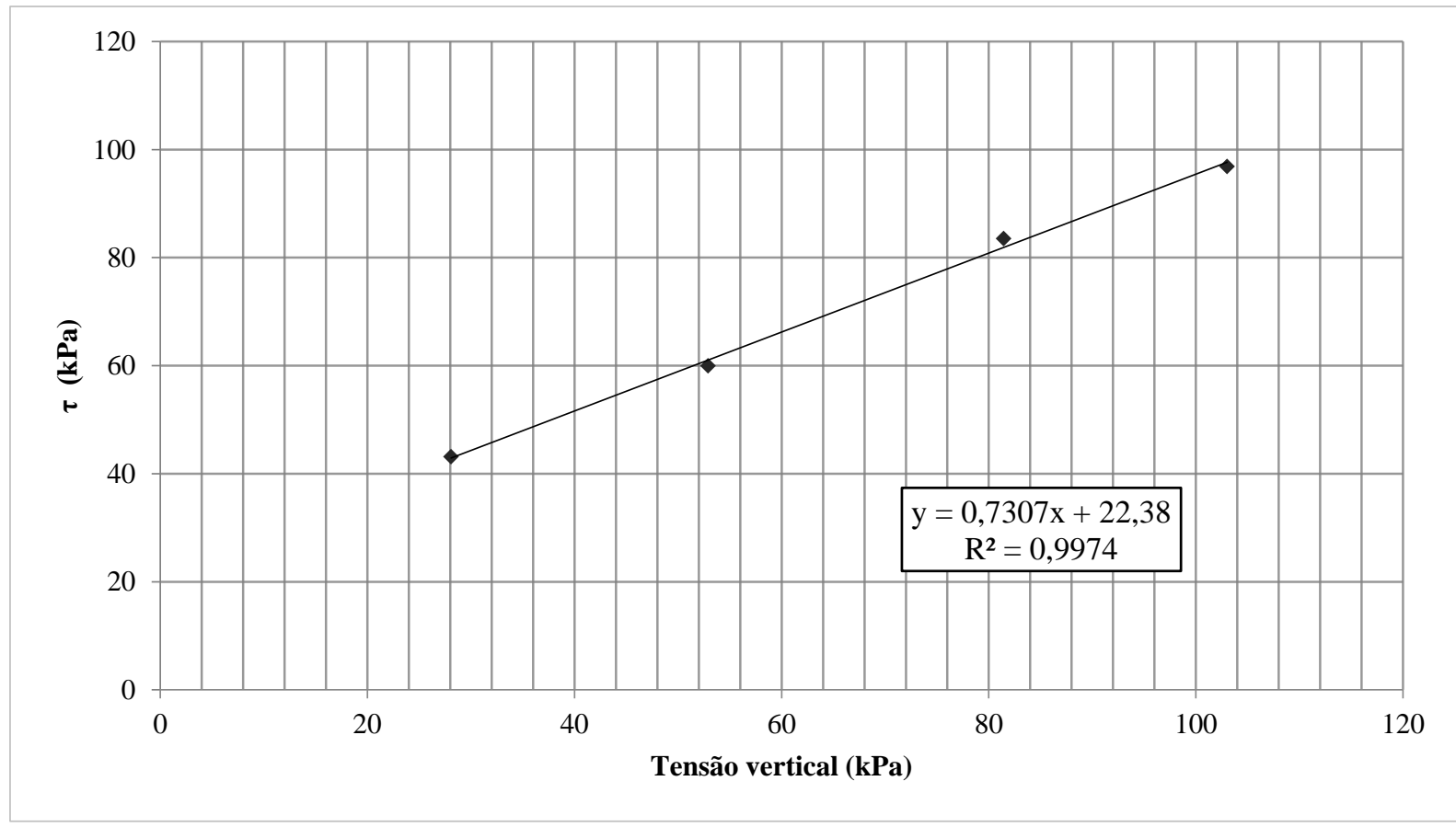

Figura B.16. Envoltória de Mohr-Coulomb da mistura M5. 


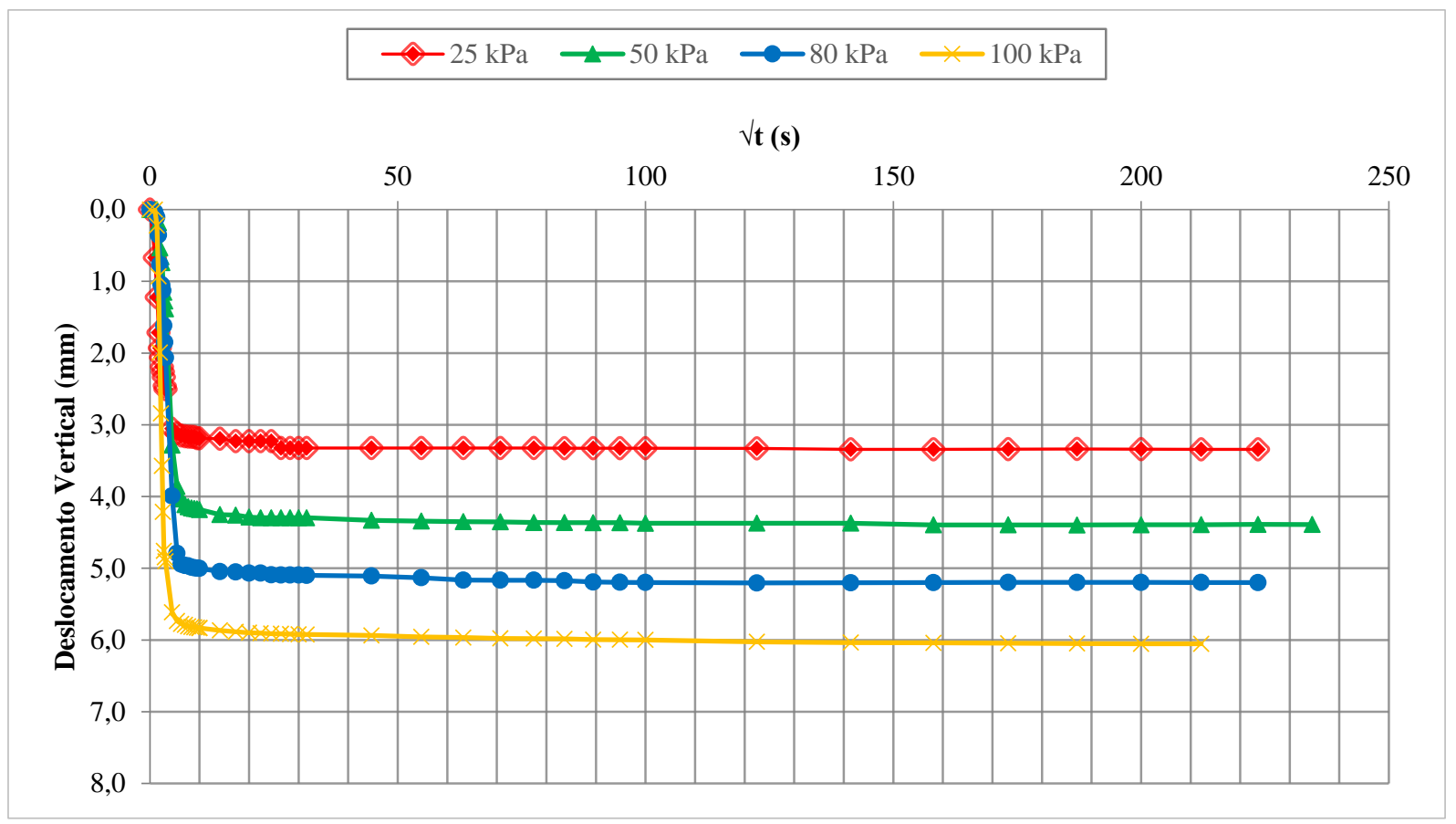

Figura B.17. Curva de adensamento da mistura M7,5.

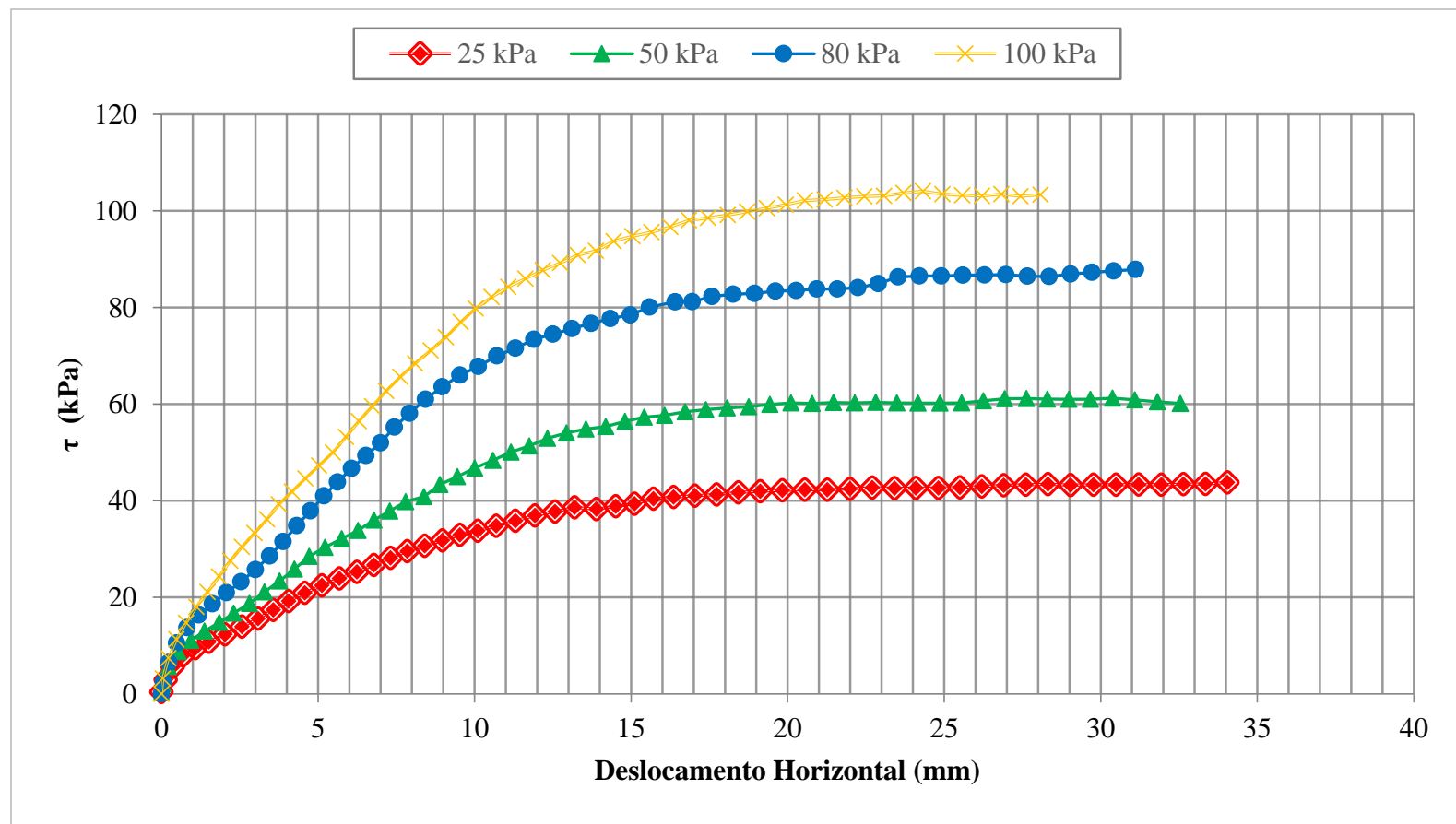

Figura B.18. Tensão cisalhante versus Deslocamento horizontal da mistura M7,5. 


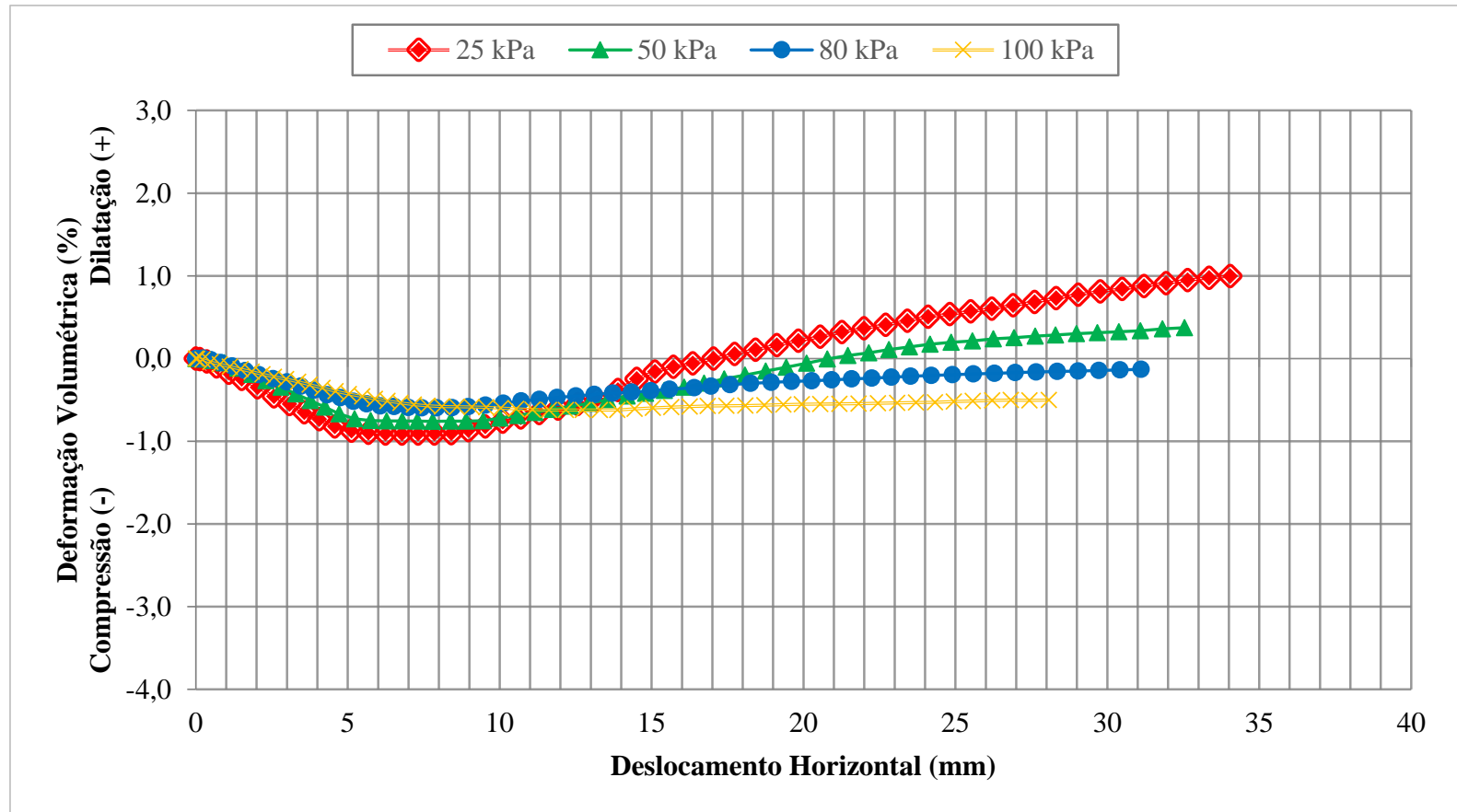

Figura B.19. Deformação volumétrica versus Deslocamento horizontal da mistura M7,5.

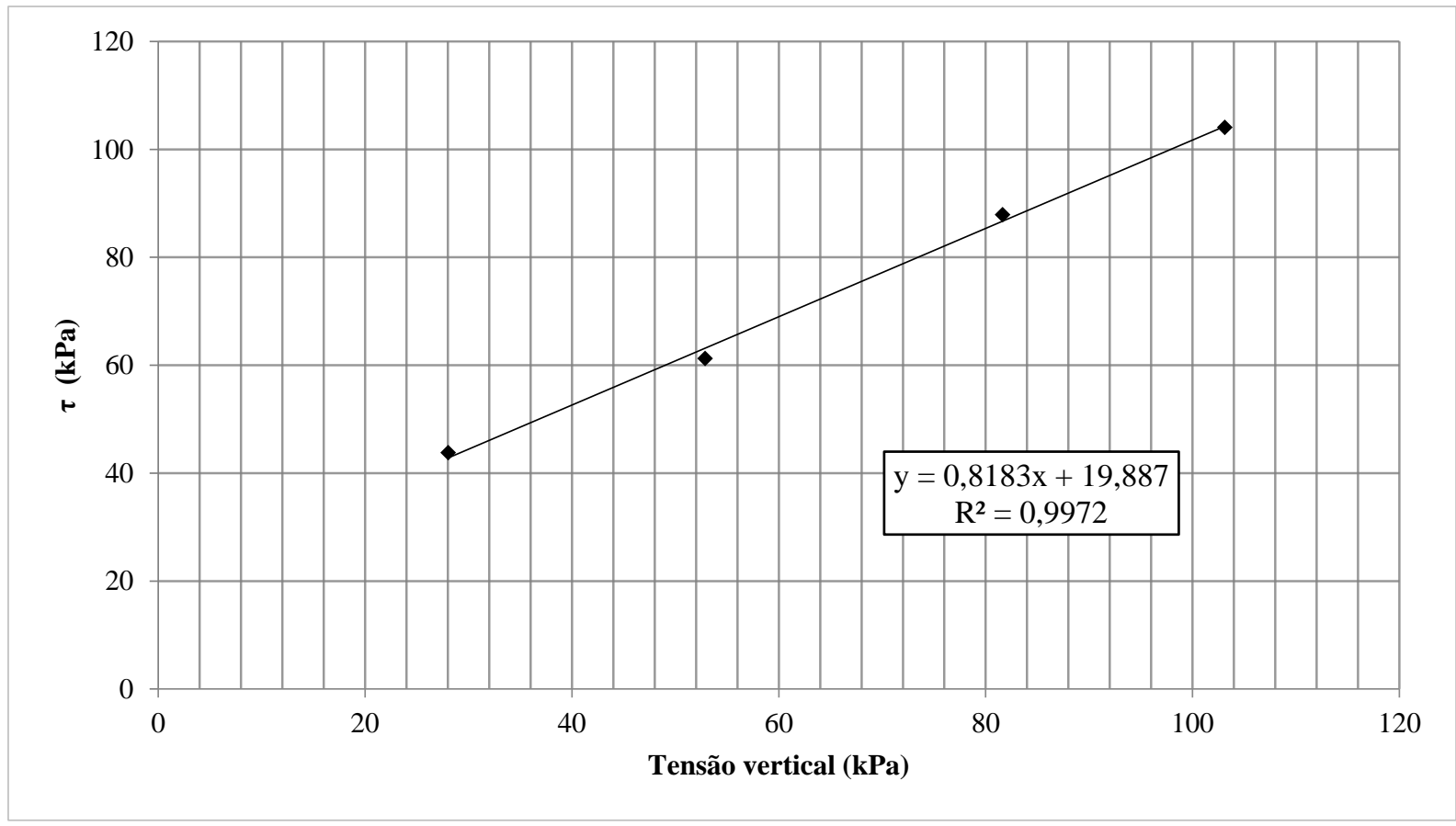

Figura B.20. Envoltória de Mohr-Coulomb da mistura M7,5. 


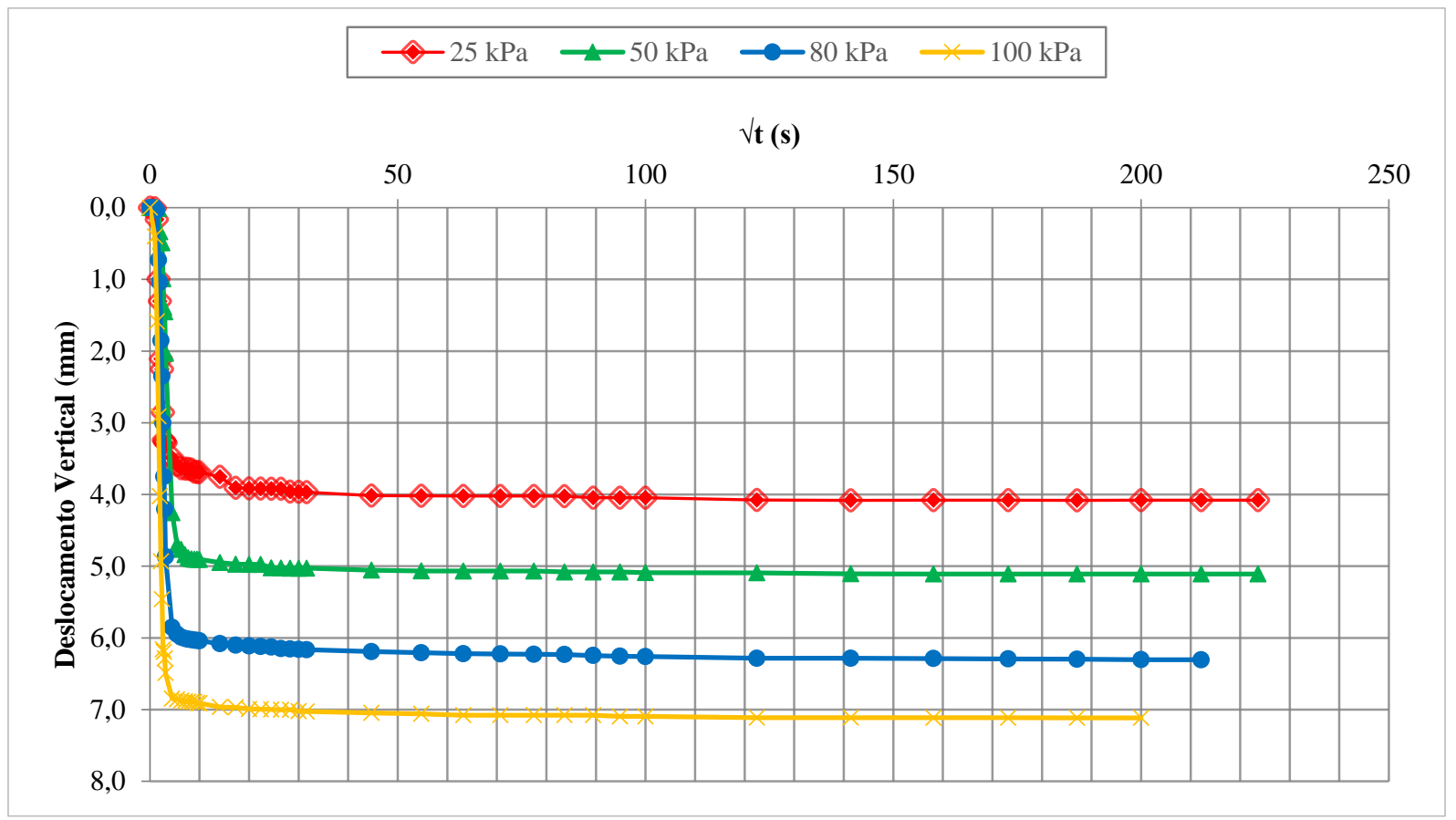

Figura B.21. Curva de adensamento da mistura M7,5.

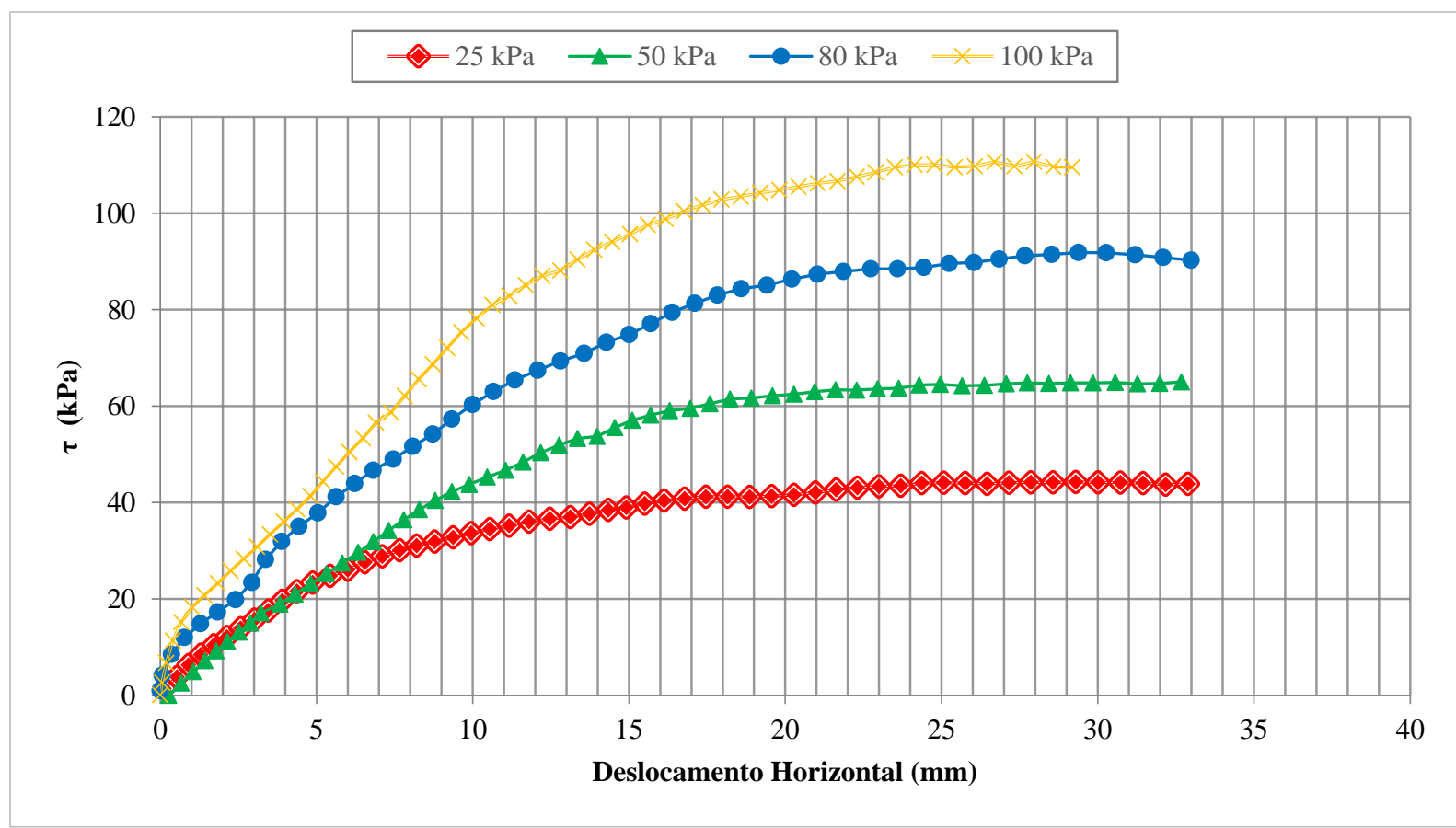

Figura B.22. Deformação volumétrica versus Deslocamento horizontal da mistura M10. 


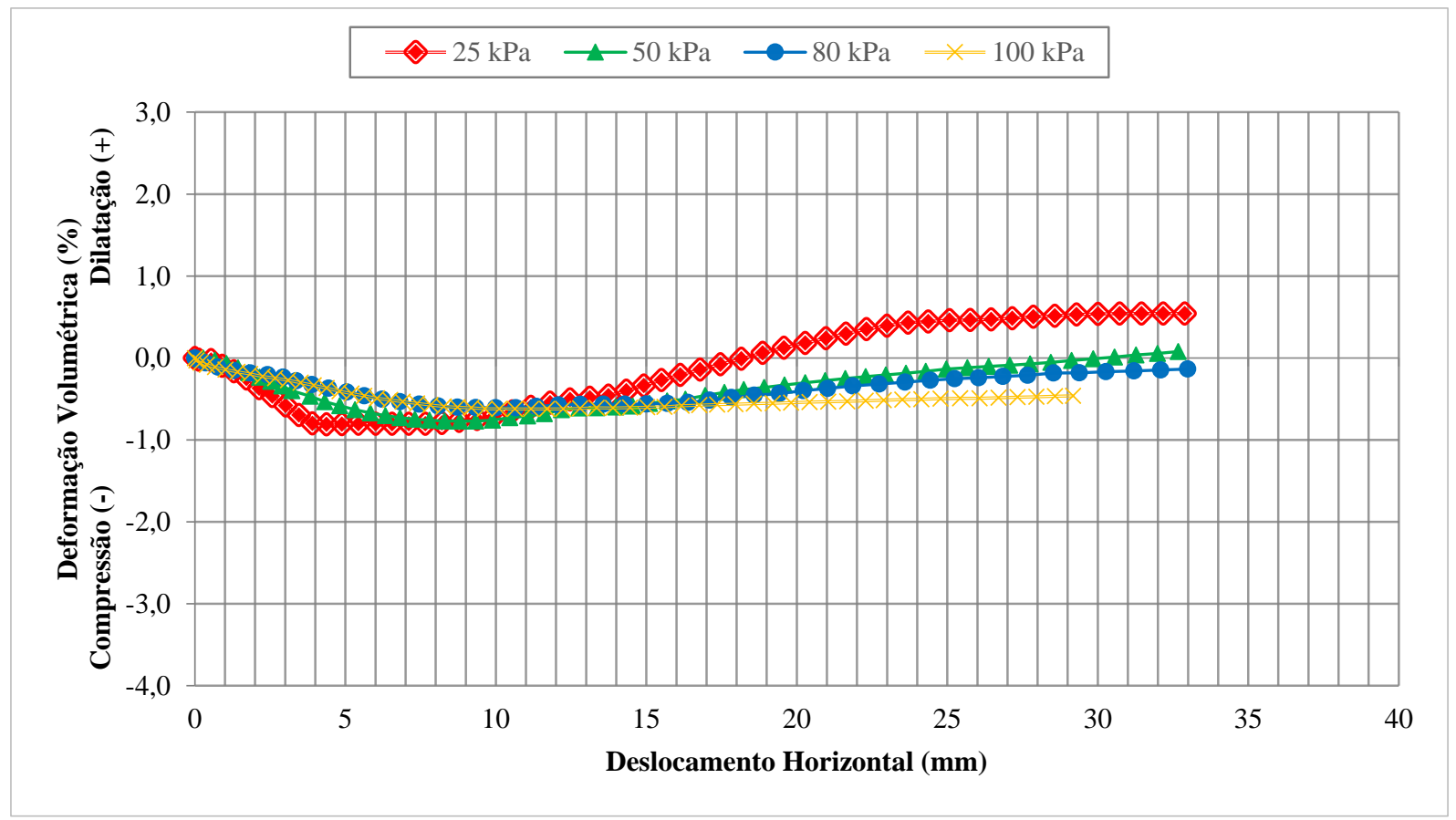

Figura B.23. Deformação volumétrica versus Deslocamento horizontal da mistura M10.

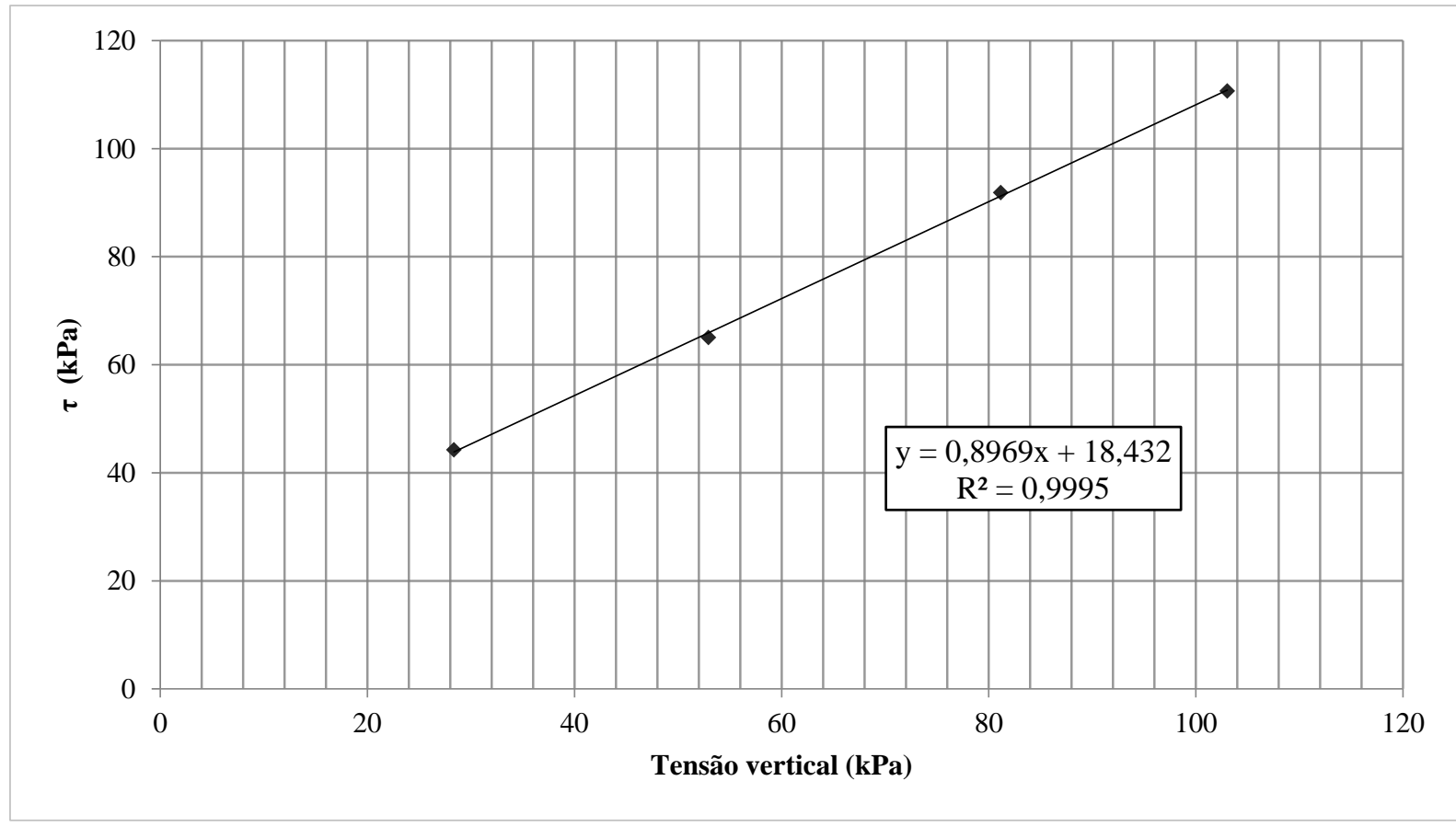

Figura B.24. Envoltória de Mohr-Coulomb da mistura M10. 


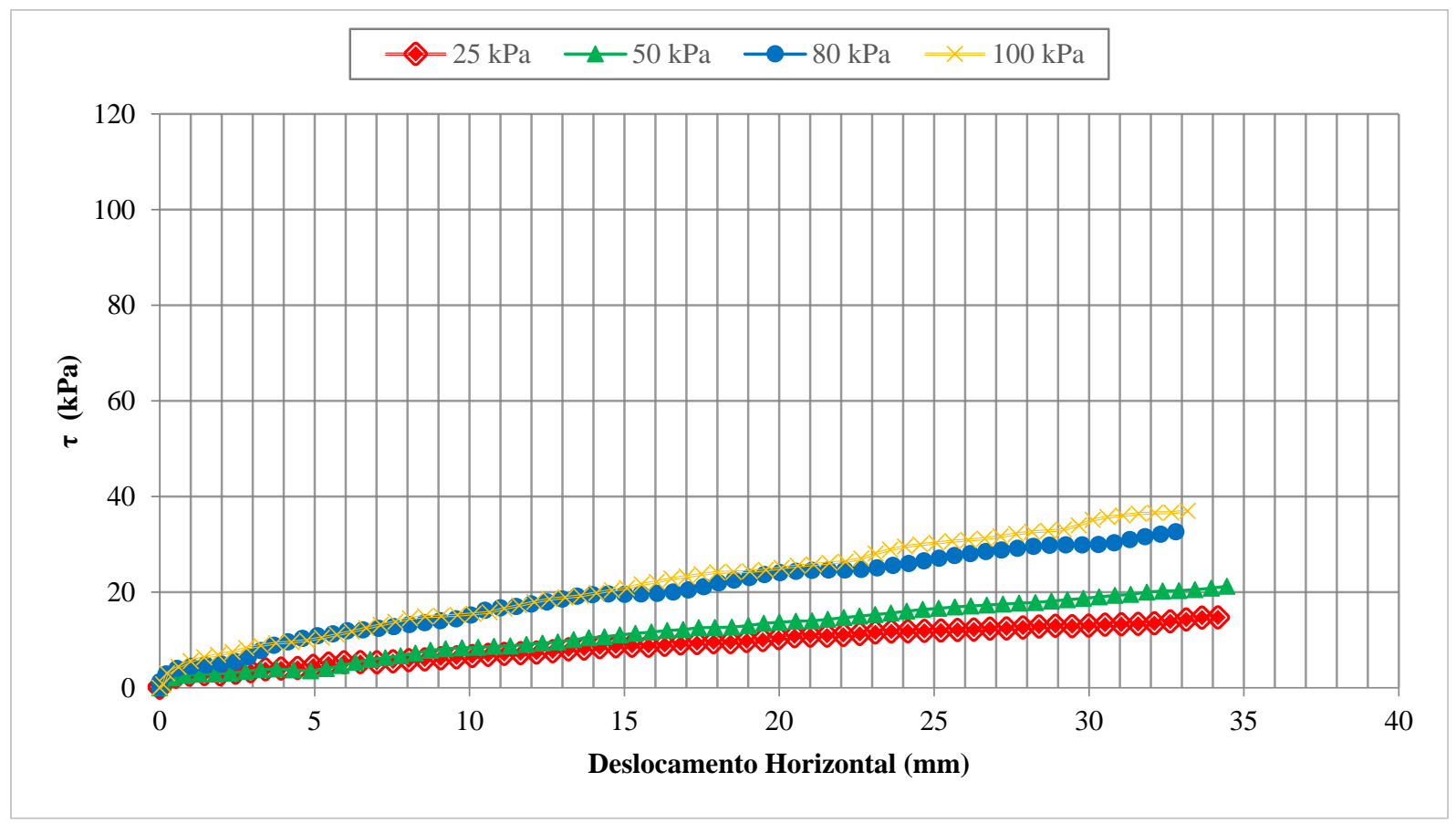

Figura B.25. Deslocamento vertical versus Deslocamento horizontal da mistura M100.

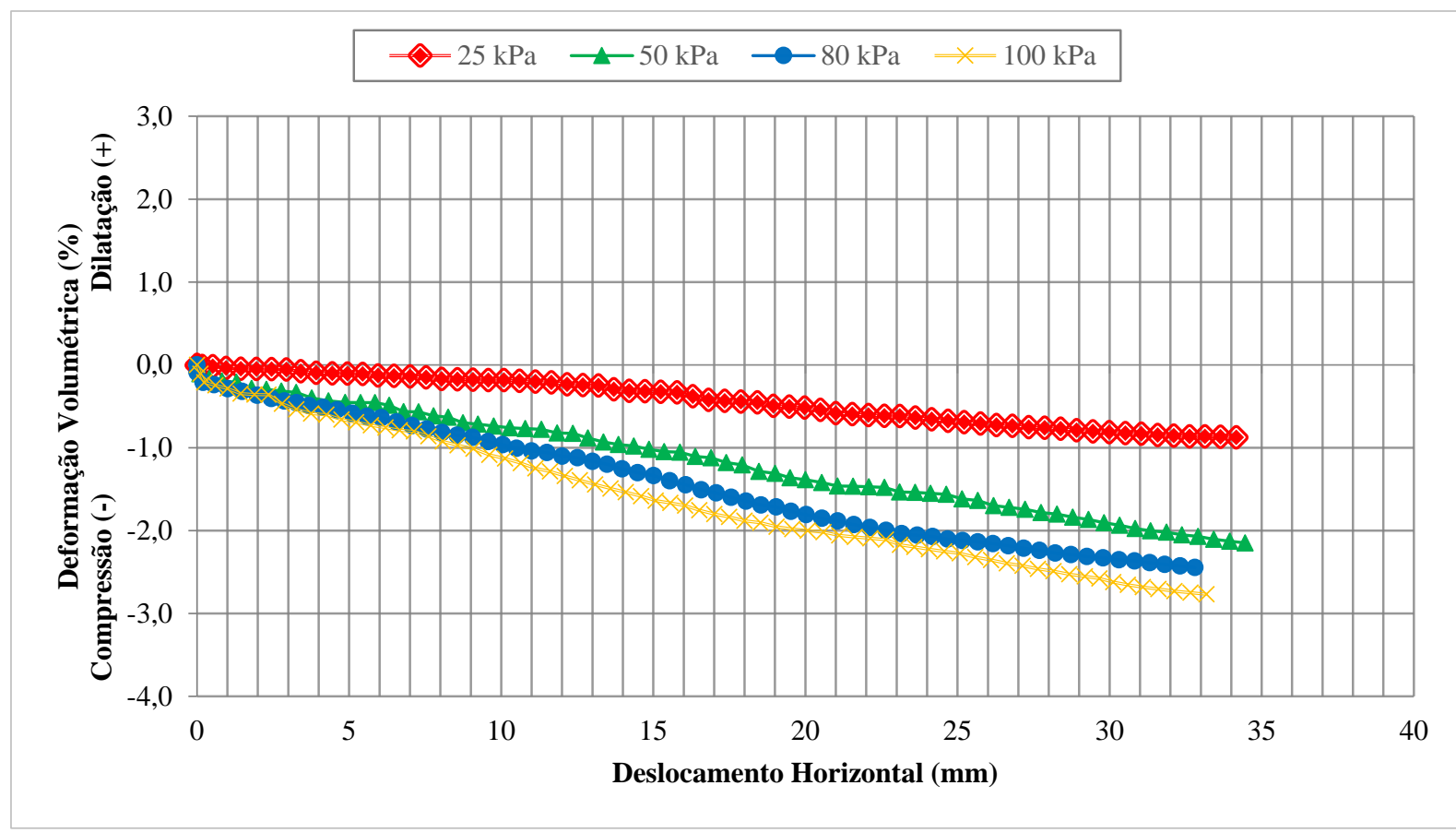

Figura B.26. Deformação volumétrica versus Deslocamento horizontal da mistura M100. 


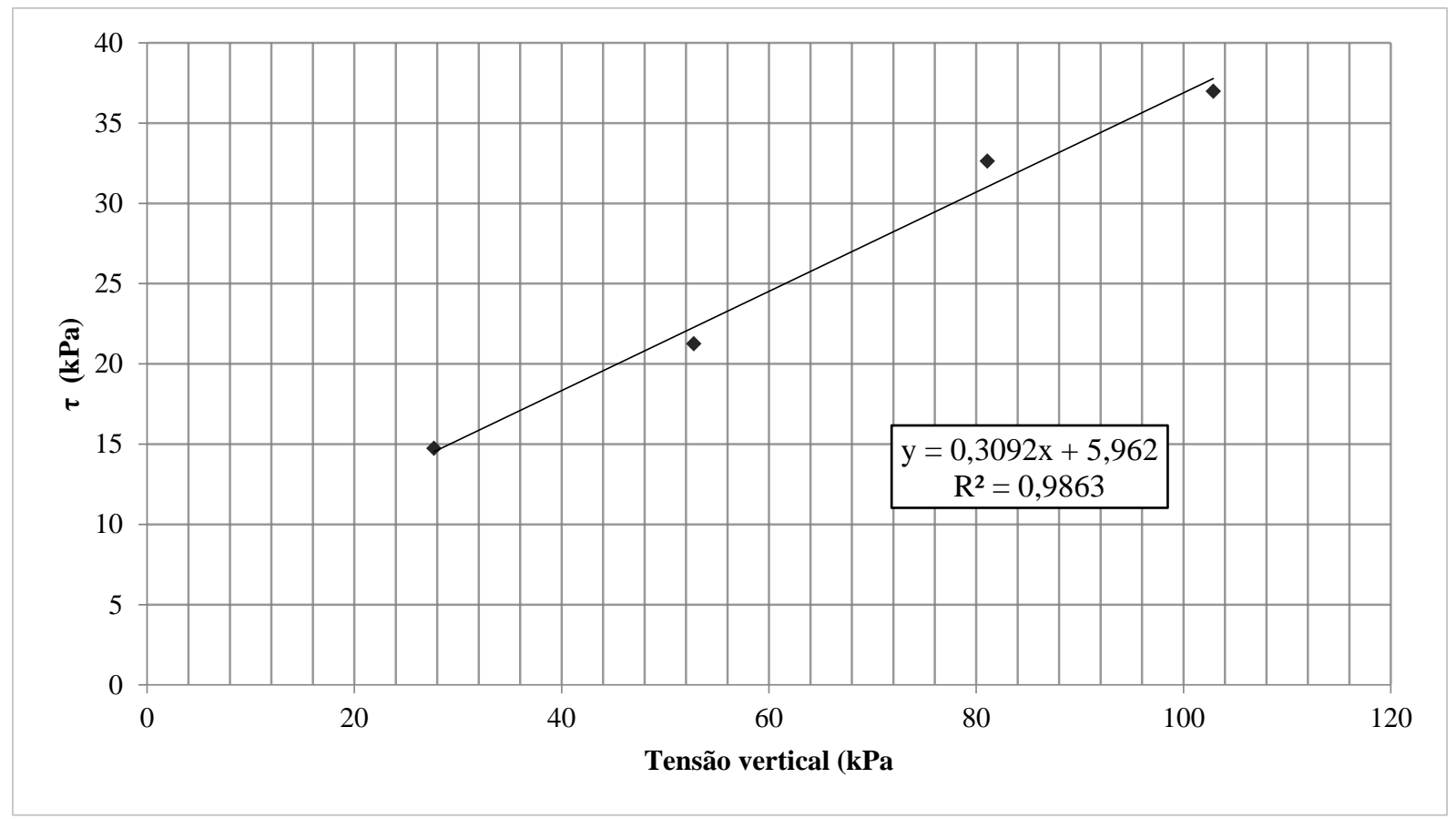

Figura B.27. Envoltória de Mohr-Coulomb da mistura M100. 